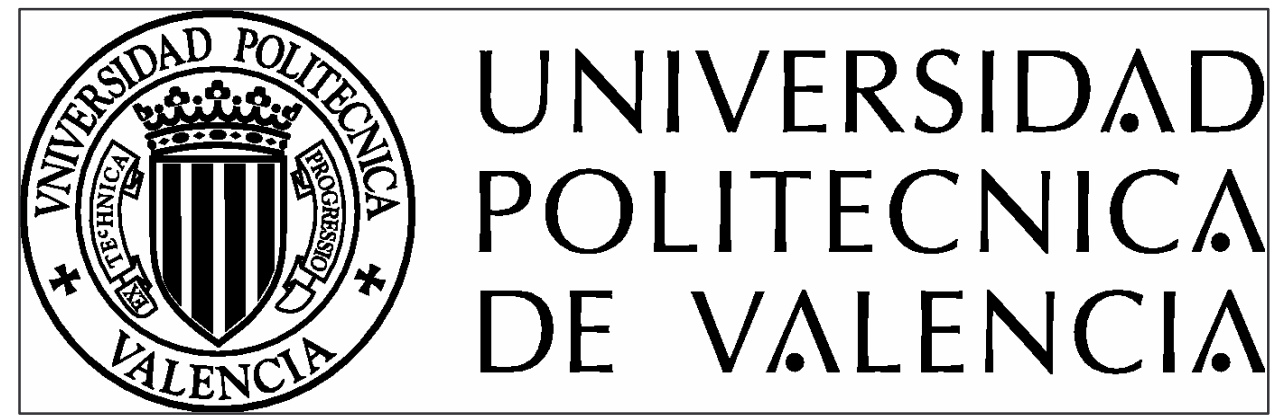

DEPARTAMENTO DE ORGANIZACIÓN DE EMPRESAS, ECONOMÍA FINANCIERA Y CONTABILIDAD

\title{
ESTUDIO DE LA GESTIÓN DEL CONOCIMIENTO SOBRE LOS RESULTADOS ORGANIZATIVOS: ANÁLISIS DEL EFECTO MEDIADOR DE LAS COMPETENCIAS DIRECTIVAS
}

\section{TESIS DOCTORAL:}

Doctorando:

FRANCISCO JAVIER LARA GARCÍA

Director:

DR. D. IGNACIO GIL PECHUAN

Codirector:

DR. D. DANIEL PALACIOS MARQUES

Valencia, 2005 


\section{AGRADECIMIENTOS}

Quisiera aprovechar esta líneas para mostrar mi más sincero agradecimiento a todos aquellos que me han estado apoyando durante estos años.

Sin duda, es ardua la tarea de nombrar a cada una de las personas que han estado a mi lado, animando y motivando los inicios de una misión investigadora para que llegara a buen puerto. Tan sólo espero no defraudarles y que la espera y las innumerables horas de lectura, trabajo de campo, análisis de resultados y conclusiones, resulten finalmente de interés tanto para ellos como para cualquier lector.

En concreto, he de agradecer especialmente a mi Director de Tesis, el Dr. D. Ignacio Gil Pechuán, sin cuyo continuo ánimo y constancia no hubiera sido posible esta primera piedra de mi edificio investigador. Ha sido un privilegio y un honor contar con su apoyo desde el principio. Este gran privilegio se ha visto incrementado con la Codirección del Dr. D. Daniel Palacios Marques, a quien le agradezco la gran generosidad que me ha mostrado en todo momento, haciéndome partícipe de su conocimiento en la materia que se ha abordado en este trabajo. También quisiera manifestar mi agradecimiento a los profesores Pablo Cardona, Manuel Guillem, Juan Sapena, Francisco Arteaga, German Martín, Martina Gonzalez-Gallarza, David Servera, Maria Gil, Isabel Mañez, Cristina Muñoz, Ana Martinez, Asun Gandía entre otros muchos que por limitación de espacio y tiempo no sería posible nombrar, pero sin cuyo asesoramiento, dirección y orientación, hubiera sido imposible la tarea realizada.

Soy consciente de que se quedan muchas personas por citar. Sirva este agradecimiento genérico para todas ellas. Cada una sabe que cuenta con mi cariño y estima.

Finalmente, permítaseme terminar agradeciendo en particular a mi familia -tesoro de gestión de conocimiento y ejemplo donde los haya de dirección por competencias- su paciencia, su cariño y su comprensión.

Muchas gracias. 
RESUMEN TESIS DOCTORAL:

Francisco J avier Lara García

\section{“ESTUDI O DE LA GESTI ÓN DEL CONOCI MI ENTO SOBRE LOS RESULTADOS ORGANI ZATI VOS: ANÁLI SIS DEL EFECTO MEDI ADOR DE LAS COMPETENCIAS DI RECTI VAS".}

En el futuro, la única ventaja competitiva sostenible será la creación de conocimiento organizativo y su buena gestión (Drucker, 1993; Grant, 1996; Teece, 1998). En la nueva economía, el conocimiento no es uno más de los factores de producción. Se ha convertido en el principal factor (Drucker, 1994). Esta visión se está traduciendo en el ámbito empresarial en un creciente interés por la medición de los activos intangibles como el capital intelectual. El propósito de la presente investigación ha sido estudiar la mediación de las Competencias Directivas, en la relación entre la Gestión del Conocimiento y los Resultados Organizativos, en orden a la generación y sostenibilidad de una serie de competencias distintivas, sobre las que mantener una ventaja competitiva diferencial.

En primer lugar hemos procedido a realizar una aproximación a los conceptos básicos de información, conocimiento, capacidades y característivas organizativas, así como a los de competencias, recursos y activos estratégicos.

En segundo lugar, una vez adentrados en el ámbito del conocimiento y del aprendizaje en las organizaciones, nos hemos centrado en las definiciones y modelos (teóricos y prácticos) existentes en la literatura científica y en la práctica profesional sobre la Gestión del Conocimiento. Modelos como los de Nonaka y Takeuchi (1995), Kaplan y Norton (1996), Edvinson (1996), Brooking (1996), Sveiby (1997), Drogonetti y Roos (1998), Bueno (1998) y Camison y Palacios (1999), ponen de manifiesto el interés que está suscitando en nuestro entorno, tanto internacional como nacional, la influencia de la Gestión del Conocimiento en las organizaciones económicas y no económicas.

Resulta cada día más evidente que la gestión de las organizaciones no puede realizarse como tradicionalmente venía teniendo lugar. Conceptos como la globalización y la generalización de las tecnologías de la información, hacen que sea necesario una adaptación rápida y flexible a las circunstancias del entorno. En el ámbito empresarial, vemos como la productividad a bajo coste se queda desbordada por economías intensivas en mano de obra barata. Pero a la vez, las organizaciones perciben que no pueden competir con las mismas estrategias. En este sentido, la opción por la gestión del conocimiento, el desarrollo y la innovación, aparecen como una alternativa necesaria a considerar. 
Sin embargo, en la dirección de las empresas, tanto a nivel nacional como a nivel local, se percibe una falta de concienciación de la evolución de los mercados internacionales, en la medida en que no están del todo convencidos que la Gestión del Conocimiento influya positivamente en los propios Resultados Organizativos, tangibles e intangibles.

En tercer lugar, en aras a demostrar esta relación, nuestra investigación quiere poner un grano de arena, sobre la hipótesis de que dicha relación está intermediada por las Competencias Directivas, es decir, por los comportamientos observables y habituales que contribuyen al éxito en una tarea o función (Chinchilla y Cardona, 1999).

El trabajo de investigación realizado propone un modelo de mediación de las Competencias Directivas entre la implantación de un sistema de Gestión de Conocimiento y los Resultados Organizativos, sobre la base de un estudio en profundidad de la literatura científica y la aplicación práctica de dichos sistemas, y con un estudio empírico en el ámbito de la Comunidad Valenciana. 
DOCTORAL THESIS

Francisco J avier Lara García

\section{STUDY OF THE KNOWLEDGE MANAGEMENT ON THE ORGANI ZATI ONAL RESULTS:ANALYSIS OF THE MEDI ATI NG EFFECT OF THE DI RECTI VE COMPETITIONS.}

In the future, the only sustainable competitive advantage will be the creation of organizational knowledge and its good management (Drucker, 1993; Grant, 1996;Teece, 1998).In the new economy, the knowledge is not one more of the production factors. One has become the main factor (Drucker, 1994).This vision is being translated in the enterprise scope in an increasing interest by the measurement of the intangible assets like the intellectual capital. The intention of the present investigation would be to study the mediation of the Directive Competitions, in the relation between the Knowledge Management and the Organizational Results, in order to the generation and sustainability of a series of distinguishing competitions, on which to maintain an advantage competitive differential.

In the first place we have come to make a conceptual approach to the basic concepts of information, knowledge, organizatational capacities and caracteristics, as well as to those of strategic competitions, resources and assets.

Secondly, once entered in the scope of the knowledge and the learning in the organizations, we have been centered in the definitions and models (theoretical and practical) existing in scientific literature and actually professional on the Knowledge Management. Models like those of Nonaka and Takeuchi (1995), Kaplan and Norton (1996), Edvinson (1996), Brooking (1996), Sveiby (1997), Drogonetti and Roos (1998), Good (1998) and Camisón and Palacios (1999), show the interest that are provoking in our surroundings, international as much national, the influence of the Knowledge Management in the economic and non economic organizations.

Is every day more evident that the management of the organizations cannot be made as traditionally come taking place. Concepts like the globalization and the generalization of the technologies of the information cause that it is necessary a fast and flexible adaptation to the circumstances of the surroundings. In the enterprises, we see as the productivity to low cost remains overflowed by intensive economies in cheap manual labour force. But simultaneously, organizations perceive that they cannot compete with same strategies. In this sense, the option by the Knowledge Management, the Development and the Innovation, appears like an alternative necessary to consider. 
Nevertheless, in the direction of the companies, as much at national level as at local level, a lack of awareness of the evolution of the international markets is perceived, in the measurement in which absolutely they are not convinced that the Knowledge Management influences positively in the own Organizational Results, tangible and intangible.

In altars to demonstrate this relation, our investigation wants to put a sand grain, on the hypothesis that this relation is intermediate of the Directive Competitions, that is to say, by the observable and habitual behaviours that contribute to the success in a task or function (Chinchilla and Cardona, 1999).

The made work of investigation tries to raise a model of mediation of the Directive Competitions between the Organizational implantation of a system of Knowledge Management and Results, on the base of a study in depth of scientific literature and the practical application of these systems, and with an empirical study in the scope of the Valencian Community. 


\title{
RESUM TESI DOCTORAL:
}

\author{
Francisco Javier Lara García
}

\section{"ESTUDI DE LA GESTIÓ DEL CONEIXEMENT SOBRE ELS RESULTATS ORGANITZATIUS: ANÀLISIS DE L'EFECTE MEDIADOR DE LES COMPETÈNCIES DIRECTIVES".}

En el futur, l'únic avantatge competitiu sostenible serà la creació de coneixement organitzatiu i la seva bona gestió (Drucker, 1993; Grant, 1996; Teece, 1998). En la nova economia, el coneixement no és un més dels factors de producció. S'ha convertit en el principal factor (Drucker, 1994). Aquesta visió s'està traduint en l'àmbit empresarial en un creixent interès pel mesurament dels actius intangibles com el capital intel.lectual. El propòsit de la present investigació ha estat estudiar la mediació de les Competències Directives, en la relació entre la Gestió del Coneixement i els Resultats Organitzatius, amb vista a la generació i sostenibilitat d'una sèrie de competències distintives, sobre les quals mantenir un avantatge competitiu diferencial.

En primer lloc hem procedit a realitzar una aproximació als conceptes bàsics d'informació, coneixement, capacitats i característics organitzatives, així com als de competències, recursos i actius estratègics.

En segon lloc, una vegada endinsats en l'àmbit del coneixement i de l'aprenentatge en les organitzacions, ens hem centrat en les definicions i models (teòrics i pràctics) existents en la literatura científica i en la pràctica professional sobre la Gestió del Coneixement. Models com els de Nonaka i Takeuchi (1995), Kaplan i Norton (1996), Edvinson (1996), Brooking (1996), Sveiby (1997), Drogonetti i Roos (1998), Bueno (1998) i Camison i Palacios (1999), posen de manifest l'interès que està suscitant en el nostre entorn, tant internacional com nacional, la influència de la Gestió del Coneixement en les organitzacions econòmiques i no econòmiques.

Resulta cada dia més evident que la gestió de les organitzacions no pot realitzarse com tradicionalment venia tenint lloc. Conceptes com la globalització i la generalització de les tecnologies de la informació, fan que siga necessària una adaptació ràpida i flexible a les circumstàncies de l'entorn. En l'àmbit empresarial, veiem com la productivitat a baix cost es queda desbordada per economies intensives en mà d'obra barata. Però alhora, les organitzacions perceben que no poden competir amb les mateixes estratègies. En aquest sentit, l'opció per la gestió del coneixement, el desenvolupament i la innovació, apareixen com una alternativa necessària a considerar. 
No obstant això, en la direcció de les empreses, tant a nivell nacional com a nivell local, es percep una falta de conscienciació de l'evolució dels mercats internacionals, en la mesura que no estan del tot convençuts que la Gestió del Coneixement influesca positivament en els propis Resultats Organitzatius, tangibles i intangibles.

En tercer lloc, per tal de demostrar aquesta relació, la nostra investigació vol prestar atemció a la hipòtesi que aquesta relació està mitjançada per les Competències Directives, és a dir, pels comportaments observables i habituals que contribueixen a l'èxit en una tasca o funció (Chinchilla i Cardona, 1999).

El treball d'investigació realitzat proposa un model de mediació de les Competències Directives entre la implantació d'un sistema de Gestió de Coneixement i els Resultats Organitzatius, sobre la base d'un estudi en profunditat de la literatura científica i l'aplicació pràctica d'aquests sistemes, i amb un estudi empíric en l'àmbit de la Comunitat Valenciana. 


\section{INDICE GENERAL}

O0. INTRODUCCIÓN

001. INTERÉS DE LA INVESTIGACIÓN 2

002. OBJETO DE LA INVESTIGACIÓN

003. POSICIONAMIENTO TEÓRICO 6

004. ETAPAS Y METODOLOGÍA

01. APROXIMACIÓN CONCEPTUAL 9

011. OBJETIVOS Y CONTENIDOS $\quad 10$

012. VENTAJA COMPETITIVA SOSTENIBLE (VCS) 11

013. ENFOQUE BASADO EN COMPETENCIAS (EBC) 13

014. RECURSOS, CAPACIDADES Y COMPETENCIAS 21

015. ACTIVOS ESTRATÉGICOS 32

02. DELIMITACIÓN DE LA GESTIÓN DEL CONOCIMIENTO (GC) 48

021. OBJETIVOS Y CONTENIDOS DEL CAPÍTULO 49

022. INTRODUCCIÓN AL CONCEPTO DE GC 50

023. MODELOS DE GESTIÓN DE CONOCIMIENTO

0231. MODELOS TEÓRICOS DE MEDICIÓN

0232. MODELOS PRÁCTICOS DE GESTIÓN 87

024. UN MODELO EN BASE A PRINCIPIOS Y PRÁCTICAS 93

025. GC, CAPITAL INTELECTUAL Y APRENDIZAJE ORGANIZATIVO 97

03. DELIMITACIÓN DE LAS COMPETENCIAS DIRECTIVAS (CD) 101

031. INTRODUCCIÓN A LA GESTIÓN POR COMPETENCIAS 104

032. INTRODUCCIÓN AL CONCEPTO DE COMPETENCIAS DIRECTIVAS 115

0321. DEFINICIÓN DE CD 115

0322. IDENTIFICACIÓN DE COMPETENCIAS RELEVANTES 117

0323. NIVELES DE COMPETENCIAS DIRECTIVAS 119

033. COMPETENCIAS DIRECTIVAS: DIMENSIONES Y GLOSARIO 125

0331. DIMENSIÓN DE NEGOCIO: ESTRATÉGICAS 126

0332. DIMENSIÓN INTERPERSONAL: INTRATÉGICAS 132

0333. DIMENSIÓN PERSONAL: PERSONALES 138

04. MODELO RELACIONAL DE LA GC, LAS CD Y LOS RO 151

041. OBJETIVOS Y CONTENIDOS DEL CAPÍTULO 152

042. GESTIÓN DEL CONOCIMIENTO Y DESEMPEÑO ORGANIZATIVO 152

043. LAS CD: VARIABLE DE INTERMEDIACIÓN 160

0431. EFECTO DE LA INTRODUCCIÓN DE LA GC SOBRE LAS CD 160

0432. MODELO TEÓRICO E HIPÓTESIS DE INVESTIGACIÓN 164 
05. INVESTIGACIÓN EMPÍRICA

051. OBJETIVOS Y CONTENIDOS 174

052. UNIDADES DE OBSERVACIÓN 176

053. AMBITO DE ESTUDIO 177

054. DISEÑO DE INSTRUMENTOS DE MEDICIÓN 179

055. DISEÑO DE LA ENCUESTA 183

056. CARACTERÍSTICAS DE LA MUESTRA Y TRABAJO DE CAMPO 195

06. ANÁLISIS ESTADÍSTICO DE LOS RESULTADOS 197

061. OBJETIVOS Y CONTENIDOS DEL CAPITULO 198

062. ANÁLISIS ESTADÍSTICO DE RESULTADOS 199

063. CONTRASTES DE HIPÓTESIS 229

$\begin{array}{ll}\text { 07. CONCLUSIONES } & 241\end{array}$

071. VALORACIÓN PERSONAL $\quad 242$

072. FUTURAS LÍNEAS DE INVESTIGACIÓN 254

08. REFERENCIAS BIBLIOGRÁFICAS 255

ANEXOS

Anexo 1. Cuestionario I, enviado para la investigación empírica.

Anexo 2. Cuestionario II, enviado para la investigación empírica.

Anexo 3. Cuestionario III, enviado para la investigación empírica. 


\section{INDICE FIGURAS}

Figura 1. Dimensión de las capacidades (Elaboración propia)

Figura 2. Modelo de competencias de Lado, Boyd y Wright (1992: 82)

Figura 3: Modelo de competencias distintivas de Camisón (2002)

Figura 4: Modelo de gestión de conocimiento de Tissen, Andriessen y Deprez (1998)

Figura 5: Modelo de espiral de conocimiento de Nonaka y Takeuchi (1995)

Figura 6: Modelo del Balanced Business Scorecard (Kaplan y Norton, 1996)

Figura 7: Modelo del Navigator Skandia (Edvinsson, 1996)

Figura 8: Enfoques e Indicadores del Navigator Skandia (Edvinsson, 1996)

Figura 9: Modelo Technology Broker (Brooking, 1996)

Figura 10: Modelo Intellectual Assets Motinor (Sveiby, 1997)

Figura 11: Indicadores del Modelo Intellectual Assets Motinor (Sveiby, 1997)

Figura 12: Arbol de Configuración de Valor (Roos et al, 1997)

Figura 13: Modelo Intellect (Euroforum, 1998)

Figura 14: Elementos de Capital Humano (Euroforum, 1998)

Figura 15: Elementos de Capital Estructural (Euroforum, 1998)

Figura 16: Elementos de Capital Relacional (Euroforum, 1998)

Figura 17: Modelo de Medición del Capital Intelectual (Euroforum, 1998)

Figura 18: Estructura y Función del Capital Intangible (Bueno, 1998)

Figura 19: Modelo de Gestión del Conocimiento de Arthur Andersen (1999)

Figura 20. Conceptuación del capital intelectual (Bontis, 1998)

Figura 21: Sistema de Gestión (Cardona, 2001)

Figura 22: Organización Jerárquica (Cardona, 2001)

Figura 23: Organización Profesional (Cardona, 2001)

Figura 24: Organización Competente (Cardona, 2001)

Figura 25: Efectos de la implantación de un modelo de GC

(elaboración propia a partir del modelo de Firestone, 2001)

Figura 26: Actividades en la GC (Davenport, 1999)

Figura 27: Efectos de la implantación de la GC (Wigg, 1999)

Figura 28: Stocks y Flujos de Conocimiento (Decarolis y Deeds, 1999)

Figura 29: Modelo de Capital Intelectual y Desempeño (Bontis, 2000)

Figura 30: Modelo de Gestión de Conocimiento (Palacios, 2002)

Figura 31: Modelo simplificado de Gestión de Conocimiento (Palacios, 2002)

Figura 32: Modelo inicial

Figura 33: Modelo simplificado

Figura 34: Modelo final

Figura 35: Modelo operativo de la GC 


\section{INDICE TABLAS}

Tabla 1. Requisitos de las competencias distintivas: Grant (1991), Amit (1993), Barney (1986), Peteraf (1993)

Tabla 2: Modelo de competencias distintivas dinámicas. Elaboración propia a partir de Camisón (2002)

Tabla 3: Los comportamientos negativos (Otto Walter, 2003)

Tabla 4: Las competencias directivas más buscadas (Cardona y Chinchilla, 2001)

Tabla 5: Contrato implícito (Cardona, 2004)

Tabla 6: Listado universal de competencias (Thornton y Byham, 1989)

Tabla 7: Niveles de competencias directivas (Cardona y Lombardia, 2004)

Tabla 8: Características de los cuestionarios de aprendizaje organizativo (Moilanen, 2001)

Tabla 9: Cuestionario de Goh y Richards (1997)

Tabla 10: Cuestionario de Tannenbaum (1997)

Tabla 11: Instrumento de Brown y Eisenhardt (1998)

Tabla 12: Cuestionario de Yeung (1999)

Tabla 13: Características Externas Organizativas (Lara, 2005)

Tabla 14: Capacidades Internas Organizativas (Lara, 2005)

Tabla 15: Competencias Directivas (elaboración propia a partir de Cardona y

Lombardía, 2005)

Tabla 16: Resultados Organizativos (elaboración propia)

Tabla 17: Ficha técnica del estudio empírico (elaboración propia)

Tabla 18. Fiabilidad de las escalas (elaboración propia)

Tabla 19: Resumen de los resultados obtenidos del análisis factorial (elaboración propia)

Tabla 20: Correlación entre los factores de la GC (elaboración propia)

Tabla 21: Correlación entre los factores de las CD (elaboración propia)

Tabla 22: Correlación entre los factores de los RO (elaboración propia)

Tabla 23: Correlación entre todos los factores del modelo (elaboración propia)

Tabla 24: Resumen de regresiones para las características externas (elaboración propia)

Tabla 25: Resumen de regresiones para las capacidades internas (elaboración propia)

Tabla 26: Resumen de regresiones para la gestión del conocimiento

(elaboración propia)

Tabla 27: Resumen de regresiones para las competencias estratégicas

(elaboración propia)

Tabla 28: Resumen de regresiones para las competencias intratégicas

(elaboración propia)

Tabla 29: Resumen de regresiones para las competencias personales

(elaboración propia)

Tabla 30: Resumen de regresiones para las competencias directivas

(elaboración propia)

Tabla 31: Matriz de correlaciones (elaboración propia)

Tabla 32: Resumen de regresiones para la gestión del conocimiento y las competencias directivas conjuntamente (elaboración propia) 


\section{CAPÍTULO O:}

\section{INTRODUCCIÓN}

0.1. INTERÉS DE LA INVESTIGACIÓN

0.2. OBJETIVOS DE LA INVESTIGACIÓN

0.3. POSICIONAMIENTO TEÓRICO

0.4. ETAPAS Y METODOLOGÍA 


\subsection{INTERÉS DE LA INVESTIGACIÓN}

Entrados en el siglo XXI, son muchos las investigaciones que defienden una idea: en el futuro, la única ventaja competitiva sostenible será la creación de conocimiento organizativo y su buena gestión (Drucker, 1993; Grant, 1996; Teece, 1998). "En la nueva economía, el conocimiento no es uno más de los factores de producción. Se ha convertido en el principal factor de producción" (Drucker, 1994). Los factores de producción tradicionales (trabajo y capital) están siendo sustituidos por un nuevo concepto más inmaterial, más intangible: el conocimiento.

Esta visión se está traduciendo en el ámbito empresarial por un creciente interés por la medición de los activos intangibles como el capital intelectual. ¿Podemos confiar en los actuales métodos contables?, ¿cómo podemos capitalizar el conocimiento de nuestras organizaciones?

Como resultado de estas experiencias están apareciendo en nuestro entorno multitud de iniciativas, tanto públicas como privadas, para poner pies y cabeza a estas ideas. Organizaciones como el Proyecto Ingenio UPV, el Club Intelect, y el mismo Plan moderniza de la Generalitat Valenciana se encuentran en esta misma línea y ya están dando sus primeros resultados.

A nivel nacional hay que destacar la labor que se viene realizando desde el Cluster de Conocimiento del País Vasco, el Proyecto Meritum, la Universidad Corporativa de Unión FENOSA, o bien, el Euroforum ESCORIAL.

En las escuelas de directivos más importantes de nuestro territorio nacional, como son el Instituto de Enseñanza Superior de Empresa (IESE) y el Instituto de Empresa (IE), cada vez son más frecuentes las jornadas, seminarios, cursos y programas sobre esta materia, muestra evidente del interés del entorno empresarial y profesional para aplicar estos proyectos a sus organizaciones. 
En un reciente estudio, los profesores Andreu y Almansa (2003) del IESE, sostienen que en las empresas españolas la gestión del conocimiento sigue dos enfoques principalmente: la percepción tecnológica y la percepción humana. Mientras que para la primera, la gestión del conocimiento se lleva a cabo en la medida en que la tecnología lo permite, la percepción humana considera que sólo las personas desarrollan, incorporan y usan conocimiento en el sentido más amplio del concepto. Como vemos, por tanto, sigue siendo este un tema de candente actualidad y cuya investigación sigue siendo objeto de discusión, debate e interés, tanto para el mundo académico, como para el mundo empresarial, a cuya aplicación va dirigida esta investigación.

Su relevancia en el mundo académico y de la investigación, tanto a nivel nacional como internacional, se viene notando desde mucho antes, pero ha cobrado especial fuerza desde la década de los noventa, aumentando de forma exponencial el número de artículos, trabajos y revistas especializadas en estos temas (Journal of Knowledge Management, Journal of Intellectual Capital, Strategic Management Journal, Harvard-Deusto Business Review, etc.).

No obstante, consideramos que existe espacio suficiente para contribuciones relevantes que argumenten y validen las distintas relaciones que pueden darse entre la Gestión del Conocimiento (GC en adelante) y las Gestión de Competencias Directivas (GCD, en adelante), así como la relación de estos dos sistemas con los Resultados Organizativos (RO, en adelante) de las empresas.

Además, hay ciertos indicios para creer que se emplean índices ciertamente poco rigurosos para la medición de constructos básicos como el conocimiento, el capital intelectual o las competencias y que falta rigor metodológico en algunos estudios promovidos por empresas consultoras con claros intereses en los resultados obtenidos.

Por todo ello, nos mueve desarrollar esta investigación, realizada desde el mundo académico, el ánimo y la ilusión de aportar una visión más independiente 
de esta nueva realidad a la que nos estamos acercando y que viene a conocerse como "sociedad de la información", "sociedad del conocimiento" o también "sociedad competente". Y a la vez, nos gustaría aportar unos resultados para el ámbito empresarial, que demuestren los beneficios de una adecuada Gestión del Talento, y en especial, del Talento Directivo en las organizaciones. 


\subsection{OBJETIVOS DE LA INVESTIGACIÓN}

El propósito de la presente investigación es el estudio de la función mediadora de las CD (Competencias Directivas) entre la GC (Gestión del Conocimiento) y los RO (Resultados Organizativos), en el marco de la Gestión del Talento. Para ello, trataríamos de analizar la medida en que la introducción de sistemas de GC en las organizaciones permite generar y sostener una serie de competencias distintivas, sobre las que mantener una ventaja competitiva sostenible y diferencial.

Para la consecución de estos objetivos se requiere, en una primera instancia, de un análisis riguroso del marco teórico existente hasta la fecha, para precisar las características y los procesos mediante los cuales se producen competencias distintivas $\mathrm{y}$, como consecuencia, rentas económicas. Todo ello sobre la base de un enfoque antropológico de la empresa, donde además de dichas rentas se persigue igualmente el desarrollo y compromiso de los empleados, y una relación eficaz de la personas consigo mismo y con el entorno.

En segundo lugar, procederemos a delimitar conceptualmente la Gestión de Competencias Directivas, como punto de partida para poder diseñar una serie de indicadores de medición con los que realizar nuestra investigación empírica y determinar el grado de introducción. Para ello, contaremos con el apoyo de los primeros estudios que se han realizado en España para comprobar el grado de integración del concepto y de los proyectos de GC en las empresas españolas.

Por último, será fundamental valorar en qué medida la GCD es capaz de ayudar en la consecución de las metas y objetivos estratégicos marcados por la organización, y en especial por la Dirección. 


\subsection{POSICIONAMIENTO TEÓRICO}

De los objetivos que se persiguen se deduce que nuestro posicionamiento teórico no pueda ser único, ya que se verían deterioradas, por unívocas, las consecuencias resultantes de nuestra investigación.

Por ello, y en aras a una mayor interdisciplinariedad de nuestra investigación, trataremos de abarcar el amplio cuerpo doctrinal que abarca la GC. Sin embargo, dada su corta vida trataremos de ceñirnos a la doctrina que ostenta en la actualidad una mayor difusión por su seriedad, rigor académico y aplicación práctica. 


\subsection{ETAPAS Y METODOLOGÍA}

La estructura de nuestra investigación se dividirá en dos partes. En la primera parte, de carácter teórico, se han revisado las principales aportaciones al estudio, tanto de carácter conceptual como de naturaleza operativa.

En el primer capítulo, se desarrolla una aproximación conceptual a los conceptos de ventaja competitiva sostenible, recursos, capacidades y competencias, y a los activos estratégicos, tanto desde una perspectiva estática como dinámica, básicos todos ellos para entender con mayor profundidad los constructos que nos permitirán validar el modelo propuesto.

En el segundo capítulo, se delimita el concepto de gestión del conocimiento, analizando los principales modelos de medición y gestión del conocimiento, centrando nuestra atención en especial el un modelo basado en la distinción entre principios y prácticas, y que ya ha sido previamente validado empíricamente (Palacios, 2002). Terminamos este capítulo con una sucinta referencia a las relaciones entre la GC, el Aprendizaje Organizativo y el Capital Intelectual.

En el tercer capítulo se delimita conceptualmente el concepto de competencias directivas, siguiendo fundamentalmente a los profesores Cardona, Chinchilla y García-Lombardía (2005), en su desarrollo de las competencias para el liderazgo.

En el cuarto capítulo, se detalla el modelo teórico explicativo de las relaciones entre gestión del conocimiento y competencias directivas. Previamente, se hace una revisión teórica sobre los principales modelos que relacionan estos constructos. Como consecuencia de las relaciones teóricas presentes en el modelo, se extrae un conjunto de hipótesis a contrastar. 
La segunda parte, de carácter empírico, pretende aplicar los conceptos desarrollados en los capítulos teóricos, con el fin de desarrollar un instrumento de medida que nos permita contrastar las hipótesis que se desprenden del modelo teórico planteado en el capítulo cuarto.

La investigación empírica consta de dos capítulos. En el capítulo quinto se describe el diseño de la investigación empírica, destacando los aspectos metodológicos utilizados. Comprende la descripción del objeto y la selección de las técnicas de observación y tratamiento de los datos.

En el capítulo sexto procedemos al análisis estadístico de los resultados, dedicando especial interés a la determinación de las propiedades sociométricas exigibles a las diferentes escalas de medidas utilizadas.

Por último, dedicamos el capítulo séptimo para exponer de forma resumida las conclusiones obtenidas y las limitaciones presentes en la investigación, identificando además posibles investigaciones que a partir del trabajo realizado consideramos de interés desarrollar en el futuro no muy lejano. 


\section{CAPÍTULO 1:}

\section{APROXIMACIÓN CONCEPTUAL}

1.1. OBJETIVOS Y CONTENIDO

1.2. LA VENTAJA COMPETITIVA SOSTENIBLE

1.3. EL ENFOQUE BASADO EN COMPETENCIAS

1.4. RECURSOS, CAPACIDADES Y COMPETENCIAS

1.5. ACTIVOS ESTRATÉGICOS 


\subsection{OBJETIVOS Y CONTENIDO}

El objetivo principal de este capítulo es determinar los requisitos de los activos estratégicos para lograr ventajas competitivas sostenibles, tanto desde una perspectiva estática como dinámica. Una vez determinadas estas condiciones, podremos analizar el valor de los activos del conocimiento como origen de rentas económicas, desarrollo del compromiso de los empleados, y de relaciones eficaces de las personas consigo mismas y con su entorno.

Previamente consideraremos en el apartado 1.2 como el concepto de ventaja competitiva ha sido tratado por diferentes enfoques, y las implicaciones que tiene para su estudio. En el epígrafe 1.3 nos centraremos en el enfoque basado en competencias (en adelante $\mathrm{EBC}$ ), centrando nuestro interés en la triple perspectiva de las capacidades dinámicas, el enfoque basado en el conocimiento y el enfoque basado en el aprendizaje. Dentro del EBC, desarrollaremos en el apartado 1.4 los conceptos nucleares al mismo como son los recursos, las capacidades y las competencias. En el epígrafe 1.5 se establecerán los requisitos que deben cumplir los activos estratégicos para lograr ventajas competitivas sostenibles. Y una vez determinadas estas condiciones, en el apartado 1.6 estudiaremos el valor de los activos de conocimiento como origen de rentas económicas, desarrollo del compromiso de los empleados, y de relaciones eficaces de las personas consigo mismas y con su entorno. 


\subsection{LA VENTAJA COMPETITIVA SOSTENIBLE}

Los motivos que conducen a ciertas empresas a disfrutar de posiciones de ventaja competitiva sostenible constituyen la principal preocupación de la literatura estratégica (Rumelt, Schendel y Teece, 1991).

Superado el enfoque estructuralista, en la economía industrial se adopta una postura menos determinista, e incorpora la teoría de juegos como instrumento para analizar los procesos de interacción competitiva entre las empresas rivales de una industria (Tirole, 1990).

El enfoque de recursos (Lippman y Rumelt, 1982; Wernerfelt, 1984; Teece, 1990; Barney, 1991; Grant, 1991) es heredero de las aportaciones pioneras de Selznick (1957), Penrose (1959) y Andrews (1971).

Penrose (1959) concibe la empresa como un conjunto de recursos productivos, cuyo valor para el crecimiento no descansa en sí mismos sino en los servicios que producen esos recursos o la forma en que son utilizados. Penrose señala que estos servicios configuran la competencia empresarial y la competencia directiva.

A partir del enfoque basado en los recursos, emerge el enfoque basado en el conocimiento, que lo considera como un recurso clave o estratégico para las empresas. En este sentido, Grant (1996) señala que este enfoque pone énfasis en dos elementos: el conocimiento como el recurso que aporta mayor proporción de valor añadido en una empresa; y además, las barreras para transferir y duplicar el conocimiento que dotan a éste de una importancia estratégica que no poseen otros recursos.

En este sentido, los procesos de generación y adquisición de conocimiento se convierten en un elemento esencial de análisis para comprender el desarrollo de estrategias de cambio en las empresas. Esta creación de conocimiento depende en gran medida del conocimiento tácito de los individuos, desarrollado a través del aprendizaje y comunicación dentro de 
la organización, que a su vez permite su transformación en conocimiento explícito (Nonaka, 1994).

Sin embargo, hasta el momento hemos presentado un enfoque básicamente estático. Mahoney y Pandian (1992) señalan que el enfoque de recursos y capacidades se basa en la confluencia del enfoque de recursos y el de las capacidades dinámicas, que analizan un mismo problema desde dos perspectivas complementarias: estática la primera y dinámica la segunda, la naturaleza de las competencias básicas y su valor como fuente de ventajas competitivas.

Como denominador común de una serie de paradigmas que destacan el papel de los recursos, capacidades y competencias como los elementos esenciales para explicar la posición competitiva alcanzada por una empresa, surge el enfoque basado en las competencias. 


\subsection{EL ENFOQUE BASADO EN COMPETENCIAS}

El enfoque basado en competencias (EBC) recoge todas aquellas perspectivas que tienen como denominador común la importancia de los activos intangibles como fuente de ventajas competitivas sostenibles.

Foss (1996) concede a este enfoque un papel destacado en la medida en que implica una conceptualización consistente de las empresas en términos de competencias.

Sanchez, Heene y Thomas (1996) señalan que el enfoque basado en las competencias supone que las empresas compiten proactivamente a través de un aprendizaje basado en la experiencia, en orden a desarrollar competencias que se utilizan en las diferentes actividades del negocio y que hacen posible el desarrollo de un conjunto de productos individuales.

Sin embargo, este enfoque también ha recibido críticas por su planteamiento esencialmente estático y por el excesivo énfasis en los recursos individuales (Knudesen, 1996; Foss, 1997).

A continuación haremos referencia a las líneas de pensamiento del EBC que consideramos más relevantes para tener en cuenta en esta investigación:

- Teoría de la estrategia: Selznick (1957), Penrose (1959) o Andrews (1971). La empresa se define como una colección de recursos heterogéneos, que pueden explicar la diferencia de posición competitiva entre las empresas. Las competencias se conciben como fortalezas que permiten aprovechar las oportunidades en los mercados.

- Enfoque basado en recursos: Wernerfelt (1984), Barney (1991), Peteraf (1993) y Grant $(1991,1995)$. La empresa tiene su mirada hacia el interior, hacia sus recursos internos, y en su relación con la estrategia. 
- Enfoque evolutivo: Nelson y Winter (1982), Nelson (1991, 1995) y Winter (1995). La empresa se interpreta como un conjunto de normas y procedimientos organizativos, que se intentan transformar para buscar un ajuste satisfactorio con el entorno.

- Enfoque basado en las capacidades dinámicas: Mahoney y Pandian (1992), Teece, Pisano y Shuen (1990, 1997), Eisenhardt y Martin (2000) y Zollo y Winter (2002). Centra su atención en el conjunto de conocimientos y habilidades que crean las competencias esenciales de la empresa. La competitividad de las empresas se basa en las capacidades y habilidades que éstas poseen.

- Enfoque de la competitividad basada en las competencias: Prahalad y Hamel $(1990,1994)$, Hamel y Prahalad (1993) y Sánchez, Heene y Thomas (1996). Se centran en el estudio de los procesos de generación, potenciación y desarrollo de las competencias. La empresa se define como un conjunto de competencias aplicables a distintos campos de actividad vinculadas por un tronco tecnológico común.

- Enfoque basado en el conocimiento: Kogut y Zander (1992), Hedlund (1994), Nonaka y Takeuchi (1995), Grant (1996), Spender (1996) y Nonaka y Cono (1998). Este enfoque parte de la premisa que el conocimiento es el activo clave que explica la competitividad empresarial. Las competencias se consideran como una colección de formas de conocimiento con distintos grados de complejidad, especificidad y codificabilidad.

- Enfoque basado en el aprendizaje: Brown y Duguid (1991), Lave y Wenger (1991), Blacker (1993), Cook y Yanow (1996) y Sánchez y Heene (1997). Centrados en la forma en que las personas interpretan o dan sentido a sus experiencias en el trabajo. Los individuos son seres sociales que construyen juntos la comprensión de lo que les rodea y aprenden de la interacción social dentro de sistemas como son las organizaciones. 
Nuestro posicionamiento teórico se va a centrar en tres perspectivas dentro del EBC como son el enfoque de las capacidades dinámicas, el enfoque basado en el conocimiento y el enfoque del aprendizaje. Por tanto, nos centramos en la vertiente dinámica del EBC.

\subsubsection{EL ENFOQUE DE LAS CAPACIDADES DINÁMICAS}

El enfoque basado en los recursos tiene un carácter estático, derivado de un proceso competitivo de equilibrio estático. Este enfoque no explica adecuadamente la forma y el motivo por el cual ciertas empresas logran alcanzar una ventaja competitiva en mercados dinámicos o en situaciones de cambio (Black y Boal, 1994; Knudsen, 1996; Foss, 1997)

De hecho al asumir la insustituibilidad de los recursos valiosos como condición para el mantenimiento de la ventaja competitiva, se niega de forma implícita la posibilidad de competencia schumpeteriana. El enfoque dinámico se basa en introducir el concepto de competencia schumpeteriana (Schumpeter, 1934).

Como resultado del estudio de los enfoques que acabamos de plantear, se ha producido un proceso de reflexión que ha culminado en el desarrollo de una visión más dinámica del enfoque de recursos.

De esta forma, el enfoque basado en las capacidades dinámicas centra su atención en el conjunto de conocimientos y habilidades que crean las competencias esenciales de la empresa. Las capacidades enfatizan el papel clave de la dirección estratégica en adaptar, integrar y reconfigurar apropiadamente las habilidades organizativas, recursos y competencias funcionales internas y externas (Teece, Pisano y Schuen, 1997: 515). Según estos autores, las capacidades dinámicas hacen referencia a la habilidad de la empresa para integrar, construir y reconfigurar competencias internas $y$ externas para tratar con ambientes en constante evolución.

Similar a la definición anterior, Eisenhardt y Martin (2000: 1107) definen las capacidades dinámicas como las rutinas organizativas y estratégicas 
mediante las cuales las empresas obtienen nuevas configuraciones de recursos cuando los mercados emergen, colisionan, se dividen, evolucionan y mueren.

\section{Dimensiones de las capacidades}

Hasta el momento nos hemos referido a las dimensiones estática y dinámica de las capacidades. A continuación consideramos interesante profundizar en su carácter individual y colectivo.

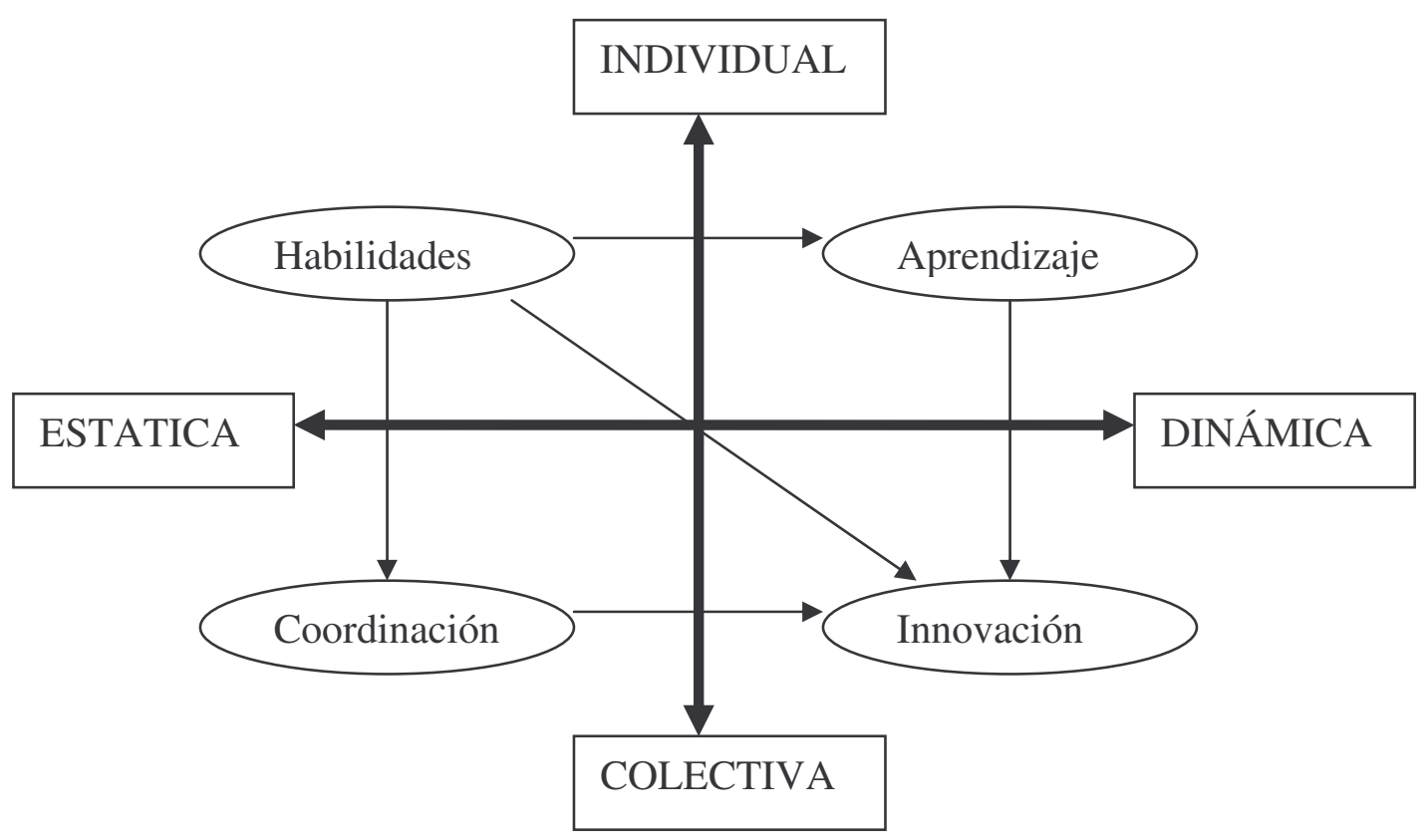

Figura 1: Dimensión de las capacidades (Elaboración propia)

Las capacidades individuales y estáticas se podrían asimilar al concepto de capital humano, ya que es bastante sencillo asignar rentas por el desarrollo de una determinada habilidad. Sin embargo, a medida que el conocimiento se hace más dinámico y colectivo, más complejo se hace el proceso de acumulación y división de las rentas creadas. Por el contrario, las capacidades estáticas colectivas son las habilidades o destrezas de interacción colectiva, como la coordinación.

Las capacidades dinámicas individuales hacen referencia a la habilidad de aprender en el trabajo o learning by doing. $\mathrm{Y}$ por último, las capacidades dinámicas colectivas describen el proceso interactivo de aprendizaje e innovación. Este tipo de capacidad es específica de la empresa, difícil de 
replicar y transferir, por lo que se considera como fuente para la creación de ventaja competitiva (Palacios, 2002)

La acumulación de capacidades dinámicas se ve influenciada por la mejora en determinadas habilidades o destrezas y capacidades transferibles, que también las puede obtener la empresa invirtiendo. En particular, las habilidades técnicas permiten obtener conocimiento externo mientras que las destrezas en comunicación facilitan la interacción y la difusión de conocimiento en la empresa (Zollo y Winter, 2002)

Cohen y Levinthal (1990) argumentan que el conocimiento previo es útil a la hora de asimilar nuevo conocimiento. De forma similar, la experiencia previa en aprender y solucionar problemas durante la fase de formación, mejora la forma de aprender en la empresa. La etapa de formación proporciona a los empleados las habilidades técnicas, sociales y de comunicación que necesitan, así como sus habilidades de aprendizaje y adaptación.

Por lo tanto, el papel que juega la educación en la acumulación de capacidades dinámicas es el de ofrecer un conjunto de herramientas y una base sólida para que el posterior aprendizaje continua sea exitoso (Ranft y Lord, 2002).

Teece y Pisano (1998) afirman que las capacidades dinámicas de una empresa se determinan por tres clases de factores:

- $\quad$ Procesos: rutinas organizativas y de gestión. Los procesos clave que generan capacidades dinámicas incluyen la integración de las fuentes de conocimiento en la empresa y el aprendizaje.

- Posicionamiento: inversiones en tecnología, bases de clientes y proveedores. De acuerdo con el marco de las capacidades dinámicas, el posicionamiento relativo de los competidores con respecto a los activos estratégicos determina la cuota de mercado y la rentabilidad de la empresa. 
- Trayectoria: el camino seguido por la empresa determina las alternativas estratégicas a seguir. El aprendizaje habitualmente se caracteriza como un proceso incremental de prueba y error que se va acumulando.

\subsubsection{EL ENFOQUE BASADO EN EL CONOCIMIENTO}

Grant (1996), McEvily y Chakravarthy (2002) afirman que las empresas se deben considerar como generadoras, depositarias e integradoras de conocimiento. La habilidad para crear valor no se basa en sus recursos físicos o financieros, sino en un conjunto de recursos intangibles basados en el conocimiento (Itami y Roehl, 1987). De este modo, las empresas compiten para crear y utilizar conocimiento eficaz y eficientemente (Nonaka, 1994).

Desde esta perspectiva el conocimiento se considera como un activo clave o estratégico para la empresa, por lo que se erige como elemento básico de análisis. En este sentido, resultan especialmente transcendentes los procesos de generación, desarrollo y aplicación del conocimiento (Nonaka, 1994; Grant, 1996). El resultado de esta corriente de investigación ha sido el modelo de creación de conocimiento a través del proceso en espiral.

Desde una perspectiva más pragmática se integra en esta perspectiva el enfoque del capital intelectual (Hudson, 1993; Brooking, 1996; Edvisson y Malone, 1997; Stewart, 1997; Roos et al., 1997; Bontis, 1998, 2000) Según Edvisson y Malone (1997), la diferencia entre el valor contable de las acciones y el de mercado puede estar justificada por la presencia de un concepto nuevo, como es el de capital intelectual, que hace referencia al valor resultante del conjunto de activos intangibles creados por la empresa.

Para estos autores, el capital intelectual es algo más que capital humano, es más que objetos intangibles... Tal vez podría considerarse como un flujo de dinámicas de valor, un flujo de generación de capacidades ocultas, caso de los sistemas organizativos, marcas, bases de datos, patentes, relaciones con los clientes, etc. Este ratio entre este valor y el de mercado podría ser una 
aproximación a la " $q$ " de Tobin (1969). Las empresas intensivas en conocimiento tienen unos valores de " $q$ " superiores a aquellas en las que el conocimiento no se considera un recurso clave o estratégico.

\subsubsection{EL ENFOQUE BASADO EN EL APRENDIZAJE}

La evolución de la Dirección Estratégica hacia una visión más dinámica se ha apoyado en la creciente integración entre esta disciplina y la Teoría de la Organización, representada por el Enfoque del Aprendizaje Organizativo (Argyris, 1976, 1994, 1996; Argyris y Schon, 1978; Senge, 1990; Huber, 1991; Miner y Mezias, 1996; Crossan, Lane y White, 1999).

Este enfoque ha adquirido especial relevancia en los últimos 30 años, sin embargo Crossan, Lane y White (1999) argumentan que el término aprendizaje organizativo es esquivo, alegando para ello tres razones: en primer lugar, no hay referentes precisos sobre el concepto de organización; en segundo lugar, el verbo aprender está siendo mal interpretado; y finalmente, que existe un conflicto candente para discernir si el aprendizaje es un fenómeno individual u organizativo.

Nos encontramos en nuestra investigación con tres visiones en cierto grado contrapuestas entre sí:

- March y Olsen (1975): analizan el efecto de las limitaciones cognitivas de los directivos sobre el aprendizaje. Estos autores describen el ciclo de aprendizaje como un sistema en el que las acciones de las personas, basadas en sus creencias individuales, llevan a las organizaciones a actuar, lo que a su vez despierta respuestas en el entorno. El ciclo se completa cuando la respuesta del entorno tiene incidencia sobre las creencias individuales.

- $\quad$ Nonaka y Takeuchi (1995): centran su interés en la generación y puesta en valor de conocimientos para la innovación de productos. 
- Huber (1991: 89): sostiene que una organización aprende si mediante su proceso de información se modifican sus comportamientos potenciales. Diferencia cuatro procesos en el aprendizaje organizativo: la adquisición de conocimiento, la distribución de la información, su interpretación y la memoria organizativa.

Al repecto, Camisón (2002) señala que la deseable convergencia entre el enfoque basado en el conocimiento y el aprendizaje organizativo no acaba de progresar, manteniéndose como corrientes de pensamiento paralelas, el primero con una inspiración más económica y el segundo con un carácter más sociológico. El nivel de solapamiento es elevado, trabajando ambos enfoques en los mismos cuatro niveles (individual, grupal, organizativo e interorganizativo) y estudiando el proceso de renovación de las competencias distintivas de la organización en etapas concordantes. 


\subsection{RECURSOS, CAPACIDADES Y COMPETENCIAS}

\subsubsection{Recursos}

Camisón (2002), distingue los recursos en sentido amplio y en sentido estricto. Recurso en sentido amplio se entiende como aquel medio que sirve para alcanzar un objetivo marcado de antemano. En este sentido, el concepto de recurso englobaría a todos aquellos factores de producción sobre los cuales la empresa puede ejercer un control efectivo, independientemente de que tenga sobre ellos derechos de propiedad. De lo anterior se deduce que este concepto de recurso va más allá de la concepción de factor productivo, propia de la teoría económica.

Esta conceptualización de recurso incluye también al de capacidad, en la medida en que las capacidades de una empresa son también recursos con los que ésta cuenta. Wernerfelt (1984:172) considera en la definición de recursos a "todos los activos tangibles e intangibles, incluyendo el personal cualificado, el conocimiento tecnológico propio, las marcas, los contactos comerciales o los procedimientos organizativos".

Barney $(1991: 101 ; 1997: 142)$ también adopta una visión amplia de los recursos, incluyendo "todos los activos, capacidades, procesos organizativos, atributos de la empresa, información, conocimiento, etc., controlados por una empresa que la hacen capaz de concebir e implantar estrategias que mejoren su eficacia y eficiencia".

Por otro lado, el concepto de recurso en sentido estricto asume un uso diferenciado al de capacidad. Grant (1991:118) concibe los recursos como inputs para el proceso productivo: entre ellos podemos señalar las patentes, marcas, capital financiero, etc.

De manera similar, Amit y Schoemaker (1993:35) se refieren a los recursos como stocks de factores disponibles que son poseídos 0 controlados por la empresa y que son convertidos en productos finales 
utilizando un amplio rango de otros activos de la empresa y de mecanismos de enlace como la tecnología, los sistemas de información directiva, los sistemas de incentivos, la confianza entre dirección y el personal, etc.

El debate sigue abierto. Palacios (2002) se decanta por diferenciar entre recurso y capacidad, por lo que utiliza una acepción en sentido estricto. Así denomina como recursos tanto a los activos tangibles como a los intangibles susceptibles de protección legal, que pueden funcionar de manera independiente a las personas. Las capacidades serían entonces los activos intangibles vinculados a las personas que los sustentan (empleados, directivos, clientes, proveedores) o a la empresa como organización, cuya protección legal es imposible o muy difícil.

El propio Palacios (2002) elabora una tabla de categorías de activos para los recursos y las capacidades siguiendo a Ansoff (1965:112-119), Grant (1991:119) y Barney (1991:101):

- Ansoff: diferencia entre Investigación y Desarrollo (I+D), Operaciones, Comercialización, Dirección general y financiación.

- Grant: distingue entre Recursos financieros, físicos, humanos, tecnológicos, organizativos y Reputación.

- Barney: hace referencia a los Recursos de capital físico, de capital humano y de capital organizativo.

A partir de este desarrollo incluimos dentro de los recursos:

- Activos tangibles: los más fáciles de identificar y evaluar debido a que tienen un soporte físico y se concretan en algo material, generalmente a través de la información que proporcionan los estados contables tradicionales. El objetivo de su gestión es la optimización en su utilización. El principal problema que presentan es que la valoración contable puede no ser significativa a efectos estratégicos (Grant, 1996) 
- Recursos físicos (capital físico): incluyen el equipamiento productivo, almacenes, inventario, centros de aprovisionamiento, equipamento informático, etc.

- Recursos financieros (capital financiero): hacen referencia a la estructura de financiación de la empresa, que le permite acometer inversiones en los demás factores. Se restringe a la tesorería, al capital circulante y a las inversiones financieras en la empresa.

- Activos intangibles: susceptibles de protección legal, que pueden funcionar de manera independiente a las personas. Comprenden los recursos humanos, organizativos, comerciales y tecnológicos.

- Recursos humanos: el capital humano es el recurso intangible por excelencia. Por capital humano nos referimos básicamente a los conocimientos adquiridos por una persona que incrementan su productividad y el valor de su contribución a la empresa. Incluye los contactos y relaciones personales, además de otras cualidades individuales como la reputación, lealtad, polivalencia y flexibilidad.

- Recursos organizativos: el capital organizativo de una empresa incluye los acuerdos de cooperación que tiene con proveedores, distribuidores y socios tecnológicos, además de su entramado de rutinas organizativas y su cultura empresarial. Estos elementos pueden considerarse como mecanismos de vinculación y movilización de los distintos factores productivos empleados, que facilitan la conversión de los inputs en bienes y servicios, creando valor al tiempo que determinan la eficiencia y la propia capacidad de innovación de la empresa. 
- Recursos comerciales: aquellos activos comerciales susceptibles de ser objeto de protección legal y cuya propiedad incumbe a la empresa. Normalmente, se derivan de contratos de distribución o de abastecimiento privilegiado o en exclusiva.

- Recursos tecnológicos: el stock de capital tecnológico incluye conocimientos relacionados con el acceso, utilización y mejora de las técnicas de producción y las tecnologías de producto. Se amplía y perfecciona a través de las actividades de I+D y de la adopción y asimilación de las tecnologías desarrolladas por otras empresas, a las que se accede mediante licencias o por la compra de tecnología incorporada a máquinas y equipos de producción.

\subsubsection{Capacidad}

Tomando la concepción estricta de recurso, se pueden extraer dos características clave que distinguen a una capacidad de un recurso. Una capacidad es específica de la empresa, ya que se encuentra incrustada en la organización y en sus procesos, lo que no ocurre con un recurso ordinario. Debido a su arraigo en la organización, la propiedad de una capacidad no puede ser transferida fácilmente de una organización a otra sin transferir propiamente la propiedad de la organización, o alguna subunidad de la organización. De la misma forma, Teece, Pisano y Shuen (1997:518) argumentan que aquello que es distintivo no puede ser comprado o vendido a menos que se venda la propia organización, o algunas de sus subunidades.

Dado que las capacidades están incrustadas en las empresas, si una empresa desapareciera, sus capacidades se disiparían, pero sus recursos sobrevivirían en manos de los nuevos propietarios. Un ejemplo lo podemos encontrar en la empresa Intel Corporation, una de las mayores fabricantes a nivel mundial de microprocesadores. Si esta empresa desaparece, sus patentes en microprocesadores (recursos) continuarían en manos del nuevo propietario, 
pero su habilidad en el diseño de nuevas generaciones de procesadores (capacidad) se perdería. Intel puede transferir fácilmente la propiedad de sus patentes en microprocesadores, pero difícilmente puede ceder su habilidad para diseñar nuevas generaciones de microprocesadores, al menos sin perder una parte importante de ella misma.

La segunda característica que distingue a una capacidad de cualquier recurso es que el principal propósito de una capacidad es el de mejorar la productividad de los otros recursos que la empresa posee. Amit y Schoemaker (1993:35) establecen la analogía de los bienes intermedios, de forma que se puede pensar de forma abstracta en las capacidades como "bienes intermedios" que son generados por la empresa y que mejoran la productividad de sus recursos, así como la flexibilidad estratégica y la protección de su producto o servicio final. Esta distinción entre recurso y capacidad es análoga a la que realizan otros autores como Miller y Shamsie (1996) entre recursos sistemáticos y discretos, o Brumagin (1994) entre recursos elementales y de alto nivel.

Así, si las capacidades no pueden ser adquiridas con facilidad, y tal como señalan Teece, Pisano y Shuen (1997) las capacidades tienen que construirse, el cometido de un directivo debe estar encaminado a impulsar su desarrollo en la organización. En esta línea, Makadok (2001:387) señala dos mecanismos que permiten a los directivos crear rentas económicas en sus empresas: la elección de los mejores recursos y la creación o mejora de las capacidades ya existentes.

El concepto de capacidad ha estado ligado por algunos autores al de rutina organizativa. La mera posesión de un conjunto de recursos no genera ventajas si no se activa eficazmente. Las capacidades no sólo dependen de los recursos de la empresa sino de su habilidad para combinarlos, integrarlos y movilizarlos. Por tanto, las capacidades no se limitan a la organización coordinada de un conjunto de recursos, sino que, de acuerdo con Grant (1991:122), se requieren "patrones de coordinación complejos entre personas y entre personas y recursos". El concepto de rutina organizativa tiene especial 
trascendencia para hacer un uso apropiado de los recursos y habilidades de la empresa. Una capacidad es, en esencia, una rutina, o un conjunto de rutinas interactuando y la organización es en sí misma un conjunto de rutinas (Grant, 1991:122).

Nelson y Winter (1982:112) afirman que las rutinas cumplen un doble cometido: por una parte son garantía de estabilidad cuando actúan como memoria de la empresa, pero por otra incorporan elementos de mutación endógena, es decir, pautas que favorecen el cambio y el progreso, introduciendo así una visión dinámica. Ello nos conduce a distinguir entre rutinas estáticas y dinámicas, tal como proponen Dosi, Teece y Winter (1992:192).

Las rutinas estáticas representan la capacidad para replicar ciertas tareas previamente desarrolladas, aunque con el tiempo mejoran. En cambio, las rutinas dinámicas están relacionadas con el aprendizaje y el desarrollo de nuevos productos y procesos.

Configurado el dominio propio de los recursos, pasaremos a desarrollar el dominio de las capacidades, formado por los activos intangibles vinculados a las personas que las sustentan (directivos, empleados, clientes, proveedores, etc) o a la empresa como organización, cuya protección legal es muy difícil y en algunos casos imposible. Camisón (2002) incluye dentro del dominio de las capacidades:

- Capacidades humanas: conocimientos, habilidades, experiencia, formación y la capacidad de aprendizaje de los miembros de una organización. No están depositadas en la organización, por lo que ésta no puede ejercer ningún control sobre ellas.

- Capacidades organizativas: cultura de la organización, estructura organizativa, relaciones informales entre sus diferentes miembros y sus sistemas de planificación y control. 
- $\quad$ Capacidades comerciales: relaciones de la empresa con agentes externos (clientes, proveedores, distribuidores, etc.), grado de conocimiento del mercado, siempre que no esté codificado en la organización. La reputación empresarial también la considera como capacidad comercial, aunque Grant (1991:119) la concibe como un recurso. También se podrían incluir la capacidad para obtener información de los clientes, la habilidad para diseñar y lanzar nuevos productos al mercado, la eficacia del proceso de evaluación y control de las actividades de marketing, etc.

- Capacidades tecnológicas: inversión, utilización y mejora de las tecnologías que utiliza la empresa, con el fin de mejorar sus procesos y los productos / servicios que ofrece. También se incluye la capacidad para obtener información del estado de la ciencia y las tecnologías relevantes, la habilidad para generar tecnologías de proceso avanzadas, la conciencia por la empresa de sus competencias en innovación, especialmente respecto a las tecnologías clave.

- Capacidades financieras: capacidad de gestión del capital de la empresa. Capacidad para obtener información sobre los mercados financieros nacionales e internacionales, la habilidad para obtener información creadora de valor en tiempo real procedente del sistema contable, la capacidad para aprovechar la legislación con el fin de optimizar la gestión financiera, la eficacia para incrementar las reservas vía autofinanciación, la capacidad de acrecentar el capital vía ampliaciones, la habilidad para obtener financiación a un coste medio bajo, etc.

- $\quad$ Capacidades directivas: son las que se despliegan con el fin de coordinar y dar una identidad a todo el proceso de obtención de valor. Incluyen la capacidad de los líderes para articular una visón estratégica, así como la capacidad de interpretar efectivamente el entorno en relación a posibles oportunidades y amenazas. 
García, Ortiz y Vargas (2001) establecen cuatro grupos de capacidades en función de la composición y relación de los recursos y capacidades. El criterio que proponen los autores para realizar su clasificación es la complejidad. Los recursos y capacidades se identifican como partes de un conjunto jerárquico analizando su grado de tangibilidad, y consecuentemente, su valor estratégico. En el extremo inferior se sitúan los recursos tangibles, mientras que en el superior se hallan las capacidades más complejas.

Las capacidades resultan de la combinación de activos tangibles y/o intangibles. La esencia de la capacidad es su carácter intangible debido a que su principal componente es el conocimiento subyacente a la hora de desplegar y emplear conjuntamente diferentes activos empresariales para el desarrollo de las actividades organizativas. La diferente naturaleza del conocimiento según los elementos combinados $y$, por tanto, el desigual comportamiento en el criterio de complejidad hacen que sea necesario establecer una tipología atendiendo al valor estratégico de dicho conocimiento.

Para desarrollar una capacidad, se hace necesaria la combinación de recursos y/o capacidades jerárquicamente inferiores. Para delimitar la complejidad de las capacidades, utilizan la dimensión cuantitativa y la cualitativa, analizando para ello el número de activos y las interrelaciones que se establecen entre ellos.

- $\quad$ Capacidad $1^{\circ}$ nivel: hace referencia a la combinación de recursos tangibles que posee la empresa.

- $\quad$ Capacidad $2^{\circ}$ nivel: son las que se forman resultado de la combinación de recursos tangibles e intangibles.

- $\quad$ Capacidad $3^{\circ}$ nivel: las capacidades de tercer y cuarto nivel son más interesantes desde un punto de vista estratégico. Tienen lugar cuando nacen de la combinación de recursos intangibles. El nivel de complejidad es superior respecto a las de nivel inferior. 
- Capacidad $4^{\circ}$ nivel: provienen de la combinación de capacidades de cualquiera de los tipos anteriores. Son las que tienen mayor relevancia para el análisis estratégico, pero en cambio son el grupo de capacidades más difíciles de estudiar, ya que plantean mayores dificultades en su definición y delimitación.

\subsubsection{Competencias}

Procedemos a continuación a la distinción del constructo competencias. En general, se considera que los términos capacidad y competencia tienen el mismo significado y son utilizados indistintamente (Prahalad y Hamel, 1990), aunque existe literatura que los diferencia (Stalk, Evans y Shulman, 1992; Javidan, 1998; Camisón, 2002).

Teece (1994) entiende por competencia el "conjunto de habilidades tecnológicas diferenciadas, activos complementarios, rutinas organizativas y capacidades que posibilitan la base para la competitividad de la empresa."

Aaker (1989), Hall (1992) o Hamel (1994) definen las competencias como aquellas "operaciones que la empresa es capaz de realizar a través de la integración de un conjunto de activos, es decir, lo que la empresa hace, en contraposición a lo que tiene."

Javidan (1998) sostiene que para identificar y explotar las competencias de la empresa, es necesario que todos los niveles en la organización conozcan bien los conceptos de recursos, capacidades y competencias esenciales. En el tercer nivel, las competencias coordinan e integran las capacidades. Situadas en el último nivel, en el más alto, se encuentran las competencias esenciales, que están formadas por los conocimientos y habilidades compartidos por todas las unidades de negocio de la organización y son resultado de la integración y consonancia de las competencias de las distintas unidades. 
Las competencias esenciales o nucleares (core competencies) se obtienen por la explotación conjunta de diversos recursos en los que la organización es especialmente hábil y que le permiten obtener la ventaja competitiva (Prahalad y Hamel, 1990). A diferencia de los activos físicos, las competencias esenciales no disminuyen con el uso, todo lo contrario, mejoran cuando son utilizadas y compartidas.

Prahalad y Hamel (1990) sostienen que la cartera de competencias de una empresa conforma el origen de la ventaja competitiva. Distinguen tres características de las competencias nucleares: 1) permiten el acceso a una amplia variedad de mercados; 2) aumentan significativamente el valor del producto para el usuario final; y 3) permiten la armonización de tecnologías y habilidades de producción, las cuales serán difícilmente imitables.

En este sentido podemos afirmar que la competitividad de una empresa se basa en sus competencias esenciales y derivado de ellas, en sus productos esenciales. Estas competencias esenciales son el resultado del aprendizaje colectivo de la organización.

Camisón (2002) diferencia tres etapas en la conceptuación de las competencias distintivas de una organización. En la primera fase, el concepto se equipara al de "fortalezas de la empresa" propuesto por el análisis estratégico convencional. En la segunda fase se acota su dominio, y se desarrollan las características que deben poseer los recursos y capacidades para estimarse como activos estratégicos. En la tercera parte se hace un análisis más dinámico del concepto, estableciendo que una ventaja competitiva sostenible debe sostenerse sobre las capacidades dinámicas.

La concepción de las competencias distintivas como las fortalezas de la empresa en relación a los competidores se puede encontrar en los trabajos clásicos de estrategia. Así, Selznick (1957) entiende el concepto de competencia distintiva como lo que puede hacer bien la empresa. Ansoff (1965: 110-117) introduce el perfil de las competencias refiriéndose a los puntos fuertes y débiles relativos a áreas específicas de competencias y habilidades. 
En la segunda etapa, el concepto de competencias distintivas se amplia respecto a los puntos fuertes de la empresa. Las competencias distintivas se entienden como recursos y capacidades difícilmente imitables por los competidores. En el siguiente epígrafe vamos a establecer las características que deben cumplir los activos estratégicos para poder generar ventajas competitivas sostenibles. 


\subsection{ACTIVOS ESTRATÉGICOS}

Los recursos y capacidades determinantes de la ventaja competitiva sostenible de una organización se han venido denominando como recursos críticos (Wernerefelt, 1984), factores estratégicos (Barney, 1986; 1991), activos estratégicos (Amit y Schoemaker, 1993; Schoemaker y Amit, 1994) o stocks de activos estratégicos o críticos (Dierickx y Cool, 1989).

Las competencias distintivas deben cumplir los siguientes requisitos:

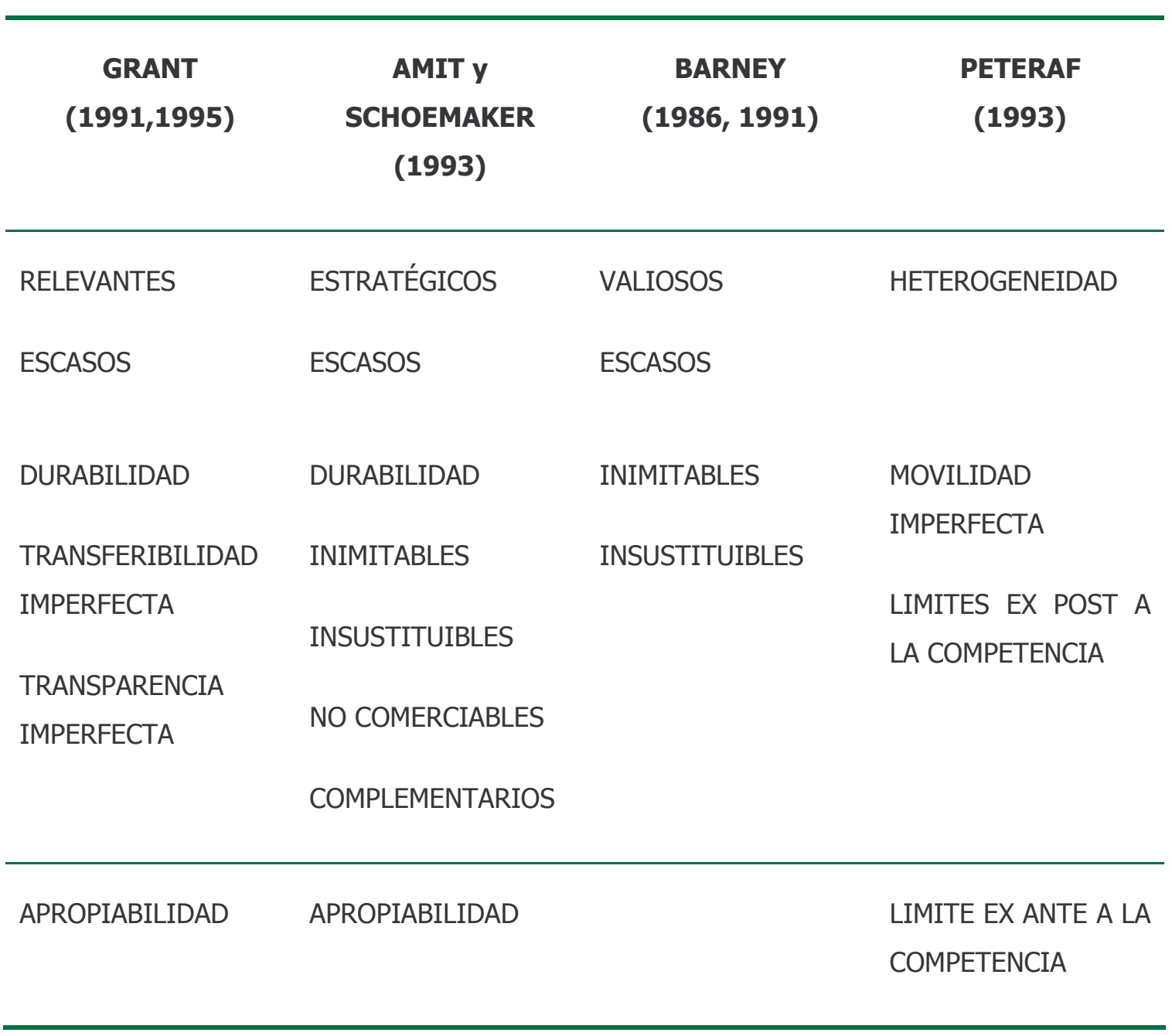

Tabla 1: Requisitos de las competencias distintivas: Grant (1991), Amit (1993), Barney (1986), Peteraf (1993)

Por tanto, podemos concluir analizando de forma transversal los requisitos que señalan estos autores que básicamente son tres: el logro de una ventaja competitiva, sostener la ventaja competitiva y la apropiación de rentas. 


\subsubsection{Condiciones para alcanzar la ventaja competitiva}

Peteraf (1993) desarrolla un modelo capaz de sintetizar las principales aportaciones efectuadas a la hora de explicar las condiciones que deben satisfacer los recursos y capacidades para que emerja una ventaja competitiva. Dichas condiciones son:

- Heterogeneidad: la distribución asimétrica de los recursos y capacidades determina los diferenciales de resultados en las empresas. Así, las empresas con recursos y capacidades superiores alcanzarán mayor nivel de desempeño.

- Límites ex-post a la competencia: si la ventaja competitiva que crea la empresa es imitada por los competidores, automáticamente queda inhabilitada por lo que es necesario introducir obstáculos a la imitación o límites ex-post a la competencia (Peteraf, 1993). Estos obstáculos dificultan que las empresas instaladas o nuevos competidores puedan duplicar los recursos y capacidades de las empresas con mejores resultados.

- Movilidad imperfecta: la movilidad imperfecta de los activos estratégicos de una empresa impide que su valor extraordinario se convierta en un coste de oportunidad y se vea anulado. Si un activo no tiene valor fuera de la empresa a la cual está asociado, será completamente intransferible o inamovible. Este es el caso de la reputación empresarial (Dierickx y Cool, 1989).

- Límites ex - ante a la competencia: evitan que las rentas no sean compensadas por los costes asociados al control de los factores productivos más valiosos. Para ello se requiere la existencia de imperfecciones en los mercados de factores.

De esta manera, la obtención de ventajas competitivas se debe por un lado, a la posesión de ciertos activos estratégicos, y por otro, a las competencias distintivas que permitan aprovechar de forma eficaz dichos activos. 


\subsubsection{La sostenibilidad de la ventaja competitiva}

Siguiendo el esquema de Grant (1991, 1995), la sostenibilidad de la ventaja competitiva depende de la imposibilidad de imitar las competencias distintivas que han permitido la consecución de la ventaja competitiva, y por otra parte, de su durabilidad.

\section{- Inimitabilidad}

Para que la competencia no sea capaz de imitar las competencias distintivas que nos han permitido la consecución de una ventaja competitiva, se requieren barreras a la imitación o límites ex post a la competencia. Estos límites son posibles gracias a la creación de mecanismos de aislamiento (Rumelt, 1984). Estos mecanismos permiten que el coste para los imitadores de alcanzar la ventaja competitiva sea lo suficientemente elevado como para anular las rentas potenciales que se obtendrían.

Grant $(1991,1995)$ plantea tres problemas que surgen en todo el proceso de imitación:

Primero, "la falta de conocimiento sobre las causas reales que posibilitan la consecución de la ventaja competitiva, debido a la ambigüedad causal o a la transparencia imperfecta".

El concepto de ambigüedad causal (Lippman y Rumelt, 1982; Dierickx y Cool, 1989; Grant, 1991; Peteraf, 1993) fue introducido por Lippman y Rumelt (1994) y hace referencia a la dificultad para conocer qué activos funcionan y la manera en que lo hacen.

El segundo problema deriva de "la dificultad existente para replicar, por parte de un potencial imitador, las competencias que le han llevado a una empresa a lograr la ventaja competitiva, ya que en muchos casos son imperfectamente móviles o imperfectamente transferibles". 
Sin embargo, a través de la inversión en competencias sustitutivas, los competidores pueden llegar a construir la ventaja competitiva, por lo que se hace necesario añadir la característica de imperfecta sustituibilidad (Dierickx y Cool, 1989; Barney, 1991; Collis, 1994).

El tercer y último problema es "la falta de convicción por parte de los potenciales imitadores de que esa estrategia les puede generar rendimientos superiores". Hill y Deeds (1996:435) destacan que la propia inercia de una organización puede condicionar su habilidad para la imitación.

\section{- Durabilidad}

La durabilidad está relacionada con la velocidad de erosión de un activo, e influye en la persistencia de la heterogeneidad (Dierickx y Cool, 1989; Grant, 1991; Amit y Schoemaker, 1993; Peteraf, 1993; Collis, 1994; Collis y Montgomery, 1995). De este modo, Grant (1991:124) respalda que para que las ventajas competitivas sean duraderas, las competencias deben depreciarse o hacerse obsoletas en la menor medida posible. Una renovación o inversión en estas competencias puede paliar su grado de depreciación.

La distinción hecha por Dierickx y Cool (1989: 1506) entre stocks y flujos es de especial relevancia a la hora de analizar la sostenibilidad de la ventaja competitiva. Para ello utilizan la metáfora de la bañera, según la cual, en un momento determinado de tiempo, el stock de agua de la bañera viene representado por el nivel de agua dentro de la bañera, mientras que los flujos, que varían el nivel de agua existente, vienen determinados por el grifo (flujo positivo) y por el agujero de la bañera (flujo negativo). Trasladando la metáfora al mundo empresarial, los stocks se consideran el montante de recursos existente en un momento de tiempo determinado, mientras que los flujos se refieren a las inversiones necesarias para mantener y aumentar dicho stock.

La ventaja competitiva no depende del flujo de inversiones, sino de los stocks que estén disponibles en un determinado momento. Cuando se realizan 
inversiones o cualquier flujo en la empresa, suele repercutir en los stocks después de un período temporal, es decir, la repercusión de los flujos no es inmediata en los stocks.

\subsubsection{La apropiabilidad de las rentas}

Grant (1991) señala dos factores que determinan la posibilidad de apropiación de las rentas: la ambigüedad de los derechos de propiedad y el poder de negociación.

\section{- La ambigüedad de los derechos de propiedad} (Dierickx y Cool, 1989; Grant, 1991) es una característica que condiciona significativamente el proceso de apropiación de las rentas. De hecho, Grant (1991: 129) asevera que una de las condiciones que deben cumplir las competencias es que la empresa posea sobre ellas propiedad y control. Cuando se generan rentas en una empresa, es difícil discernir la contribución de las competencias en la generación de valor añadido, ya que en muchos casos no son poseídas individualmente y su productividad no puede calcularse de forma aislada. Los recursos intangibles de la organización tales como marcas, patentes o derechos de propiedad intelectual aunque son propiedad de la empresa, también dejan una puerta abierta a la ambigüedad. Cuando la propiedad es ambigua, existe otro elemento que tiene un papel capital en la apropiación de las rentas: el poder de negociación.

- El poder de negociación es más efectivo cuando las competencias no se poseen individualmente, y cuando los recursos y capacidades asociados a las competencias sean específicos de la organización y de alguna manera disminuya su valor cuando se utilizan en un contexto diferente. 


\subsubsection{Las competencias distintivas}

Hemos diferenciado tres etapas para conceptuar las competencias distintivas. En una primera etapa se asociaba el concepto de competencia distintiva al de fortaleza de la empresa. En una segunda etapa se acota su dominio y se definen las características que deben poseer los recursos y capacidades para estimarse como activos estratégicos. En la tercera etapa vamos a realizar una interpretación más dinámica del concepto, estableciendo que una ventaja competitiva sostenible debe descansar sobre competencias dinámicas.

El enfoque dinámico se basa en introducir el concepto de competencia schumpeteriana, de forma que el interés no sólo se centra en las competencias desarrolladas en un momento dado, sino en el proceso de generación y desarrollo de estas competencias. De hecho, el proceso de desarrollo de las competencias realmente implica un proceso de aprendizaje (Andreu y Ciborra, 1996).

Las competencias distintivas se desarrollan en la organización a través de un proceso de transformación, por el cual recursos y capacidades disponibles en el mercado se utilizan de forma combinada dentro del contexto organizativo con el fin de producir competencias esenciales. De esta manera, el proceso de aprendizaje polariza el grado de especificidad e inimitabilidad de la competencia esencial.

En este sentido, Palaciós (2002) conceptua las competencias distintivas o esenciales como "los recursos y capacidades que poseen simultáneamente las condiciones de ser activos estratégicos, capacidades dinámicas y estar basados en activos intangibles."

Collis (1994:147) destaca que es prácticamente imposible identificar el conjunto de competencias distintivas de la organización, debido a su disociabilidad con la actividad desempeñada. Grant (1995: 166) sugiere una clasificación previa de las diversas actividades, sugiere que las capacidades 
más importantes son aquellas que nacen de la integración de capacidades funcionales individuales.

De hecho, existe un extenso cuerpo de literatura que aporta criterios válidos para distinguir las distintas categorías de competencias distintivas. Entre los principales autores podemos citar a Hall (1992, 1993), Lado, Boyd y Wright (1992), Lado y Wilson (1994), Hamel (1994), Turner y Crawford (1994), Miller y Shamsie (1996) y Durant (1997).

La clasificación propuesta por Ansoff $(1979,1985)$ distingue las competencias distintivas basadas en competencias funcionales de las competencias fruto de la integración de capacidades funcionales (denominadas genéricamente como competencias directivas). Los cuatro tipos de competencias funcionales que identifica este autor son: I+D, operaciones, marketing y finanzas. Por su parte, las competencias directivas hacen referencia a la responsabilidad estratégica de la dirección general, que deberá ser receptiva y sintonizar con el entorno, descubrir las implicaciones del cambio y determinar las acciones necesarias para su implementación.

Sin embargo, una adecuada clasificación de las competencias distintivas debería reflejar, además, la estructura jerárquica en la que están organizadas. Fernández y Suárez (1996: 75) proponen la siguiente jerarquización: 1) capacidades de primer nivel o estáticas, que están relacionadas con las actividades funcionales de la empresa; 2) las capacidades de segundo nivel o dinámicas, que facilitan la integración de las actividades funcionales e incluyen las competencias asociadas con el cambio y la innovación; 3) las capacidades de tercer nivel que incluyen las capacidades de aprender a aprender y de aprender más rápido que la competencia.

Lado, Boyd y Wright (1992: 82) desarrollan un modelo de competencias en el que existen diversas categorías, que se delimitan en función de las actividades que se desarrollan en el proceso de generación de 
valor. Se trata de identificar aquellas categorías de competencias que poseen las características necesarias para sostener la ventaja competitiva.

Figura 2: Modelo de competencias de Lado, Boyd y Wright (1992: 82)

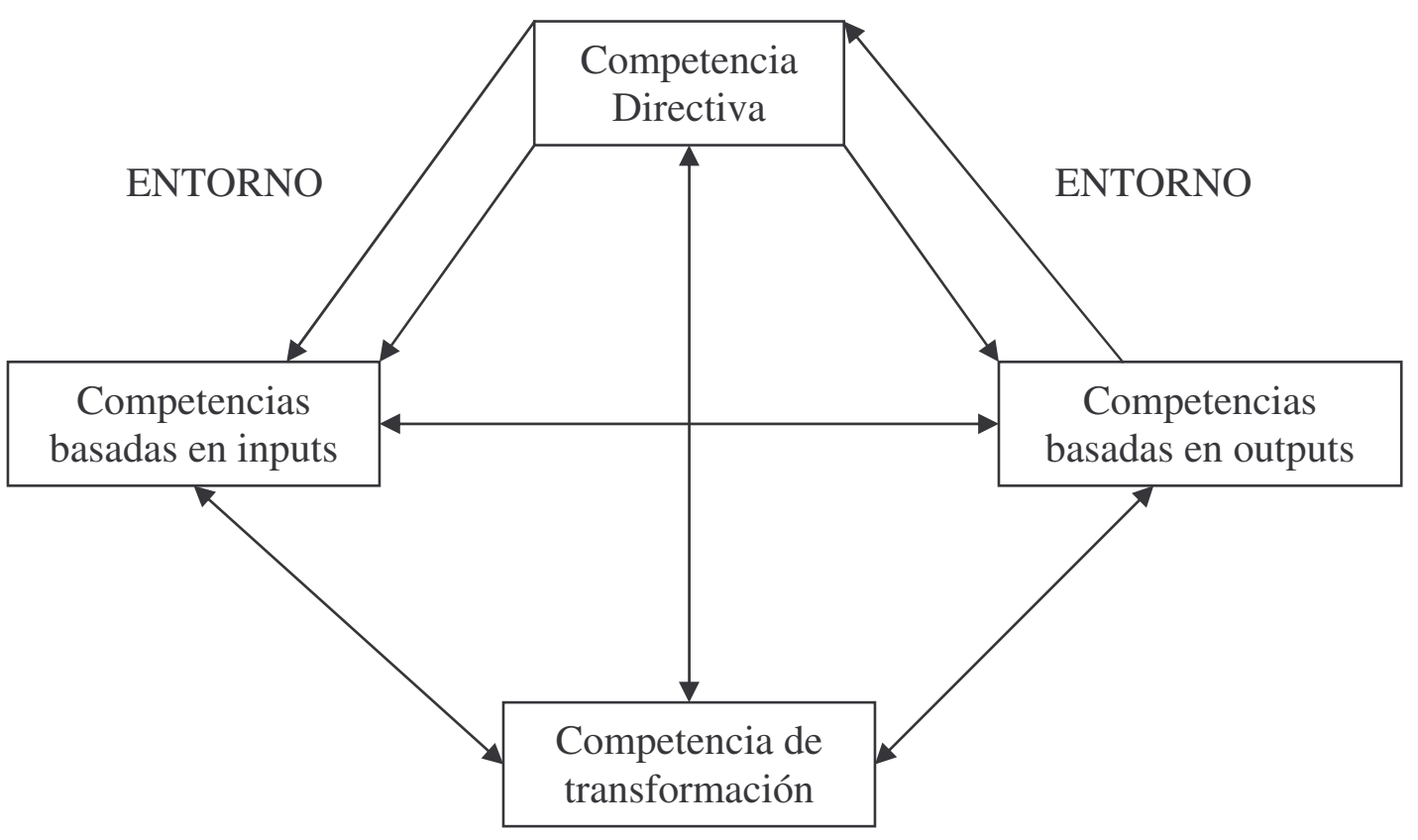

Las categorías que identifica el modelo son las siguientes:

- Competencias directivas: son las que determinan la visión estratégica de la organización, la forma de comunicarla a sus empleados y de delegarla para llevarla a cabo. Estas competencias actúan como resorte para el desarrollo del resto de competencias. De ahí la importancia que tienen para la generación de rentas y la sostenibilidad de la ventaja competitiva (Castañas y Helfat, 1991; Lado, Boyd y Wright, 1992). Las competencias directivas son las que se sitúan en un nivel jerárquico superior. El resto de competencias puede situarse en un mismo nivel ya que interaccionan entre ellas.

- Competencias basadas en los inputs o recursos: son las que se derivan de la acumulación de recursos, tanto tangibles como intangibles y que a través de los procesos de transformación sirven para crear nuevos productos y servicios que dan valor a los clientes (Lado, Boyd y Wright, 1992). Unas competencias en dirección 
eficaces son capaces de movilizar adecuadamente este tipo de competencias.

- Competencias de transformación: este tipo de competencias es equivalente a las "competencias de arquitectura" de Henderson y Cockburn (1994). Lado, Boyd y Wright (1992: 85) las definen como "aquéllas requeridas para convertir de forma ventajosa los inputs en outputs". Actúan combinando los recursos y habilidades que se han adquirido del exterior o se han generado en la propia organización, gracias a las competencias basadas en los inputs.

- Competencias basadas en los outputs: son las más visibles en el mercado, resultado de la utilización de las competencias que hemos desarrollado anteriormente. Lado, Boyd y Wright (1992: 87) las definen como activos estratégicos invisibles basados en el conocimiento.

Palacios (2002) ha clasificado las competencias combinando los criterios funcional y de cadena de valor, introduciendo una estructura jerárquica de competencias, tal como propone Grant (1996). De hecho, las capacidades son tanto más versátiles a medida que aumenta su nivel, por lo que una conceptuación de las competencias distintivas restringida a las capacidades funcionales seguramente excluiría los factores con mayor poder creador de ventajas competitivas sostenibles. 
Competencias distintivas dinámicas o de innovación

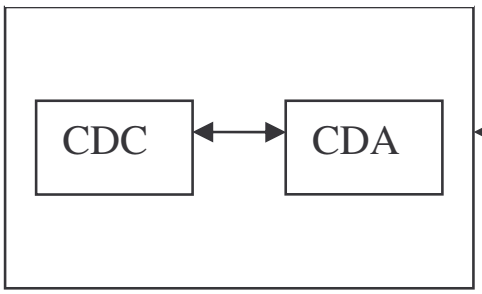

Donde:

CDC: Conocimiento

CDA: Aprendizaje

CDRH: Recursos humanos

CDD: Directivas

CDT: Tecnológicas

CDO: Organizativas

CDM: Marketing

CDP: Producción

CDF: Finanzas
Competencias distintivas de coordinación / cohesión

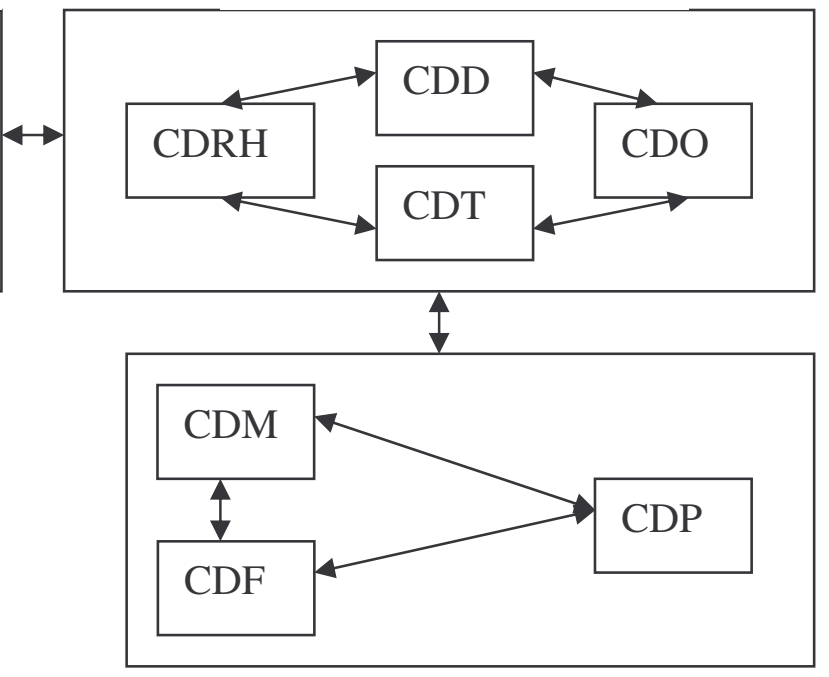

Competencias distintivas estáticas o de primer nivel

Figura 3: Modelo de competencias distintivas de Camisón (2002a)

Clasificación jerárquica de las competencias distintivas (Camisón 2002a):

- Competencias distintivas estáticas o de primer nivel: se asocian con las actividades funcionales de la empresa. Entre ellas podemos destacar las competencias distintivas en finanzas, producción y marketing.

- Competencias distintivas en finanzas: hacen referencia a la gestión del capital de la empresa. Incluyen el conocimiento valioso disponible sobre los mercados financieros, la capacidad para obtener información creadora de valor en tiempo real procedente del sistema contable, la capacidad de aprovechar la legislación para optimizar la gestión financiera, la habilidad para incrementar las reservas vía autofinanciación, la capacidad para encontrar oportunidades de inversión con una rentabilidad económica superior al coste de la deuda, la eficacia en la planificación y el control financiero, etc. 
- Competencias distintivas en producción: este tipo de competencias incluye el posible conocimiento valioso disponible de proveedores, suministradores o contratistas. También engloban la eficacia del proceso de respuesta a oscilaciones en el volumen de demanda, la habilidad para fabricar sobre pedido y ajustar el diseño del producto a las necesidades del cliente, la habilidad para seleccionar las mejores ubicaciones para las instalaciones productivas o la habilidad para mantener un bajo nivel de stocks sin deterioro del servicio.

- Competencias distintivas en marketing: estas competencias se asocian con el grado de eficacia de los esfuerzos de difusión de conocimiento por la empresa, con el fin de lograr en el mercado una reputación innovadora y creativa (tareas de educación de los clientes, actividades de comunicación y de reconocimiento a la empresa, presencia pública de la empresa en conferencias, publicaciones y ferias, etc.).

\section{- Competencias distintivas de coordinación y cohesión}

o de segundo nivel: facilitan la integración de ciertas actividades funcionales, explorando continuamente nuevas combinaciones de recursos y capacidades que se ajusten al mercado o que generen cambios (Teece et al., 1994; Teece, Pisano y Shuen, 1997; Eisenhardt y Martin, 2000). Este tipo de competencias incluyen los procesos dedicados al desarrollo de nuevos productos.

- Competencias distintivas directivas: hacen referencia a aquellos conocimientos o habilidades en las que la dirección está cualificada especialmente gracias a su formación, experiencia y responsabilidades asumidas. Son relevantes en la medida en que determinan el enfoque estratégico de la organización y marcan su manera de actuar. Condicionan al resto de competencias, ya que las competencias que posee la 
organización se generan por las decisiones y acciones que asume la dirección.

Incluye el conocimiento del negocio por parte de los directivos, su capacidad para analizar y seleccionar las mejores decisiones, así como la habilidad para lograr un compromiso a largo plazo coherente con las aspiraciones de la propiedad.

Del mismo modo, puede incluirse aquí la dimensión humana asociada a este tipo de competencias. A título de ejemplo podemos citar la capacidad de los directivos para regular su comportamiento y las relaciones humanas por un conjunto de reglas morales que le doten de mayor credibilidad.

Otra dimensión que forma parte de este tipo de competencias es la que se refiere al estilo de dirección o la habilidad de liderazgo. Esta dimensión abarca el estilo de gestión dominante, el principio de autoridad, la habilidad para desarrollar el consenso o la capacidad de actuar como modelo de los demás.

- Competencias distintivas tecnológicas: están relacionadas con las decisiones de inversión, utilización y mejora de las tecnologías de producto y proceso que maneja una determinada empresa. Podemos distinguir cuatro dimensiones en las que desglosar este tipo de competencias: mejoras incrementales del stock de conocimiento, conocimiento interno explícito protegido legalmente, conocimiento interno tácito e insertado y la gestión de la tecnología.

Dentro de la dimensión asociada con las mejoras incrementales del stock de conocimiento, podemos incluir la habilidad para la diferenciación tecnológica del producto o la conciencia de la empresa hacia sus competencias tecnológicas, especialmente respecto a las tecnologías clave. 
Respecto al conocimiento interno explícito protegido legalmente, se hace referencia a las capacidades tecnológicas plasmadas en patentes de producto y proceso y a la capacidad de extraer rendimiento a las patentes en procesos y productos internos y externos a la empresa (Liebowitzy Beckman, 1998).

En relación a la dimensión tecnológica relacionada con el conocimiento interno tácito e insertado, podemos identificar el grado de inimitabilidad y diferenciación de las tecnologías de producto o proceso empleadas, o el grado de explicitación y documentación de las rutinas y tecnologías de producción que permitan hacerlas compartibles y reutilizables.

Respecto a la gestión de la tecnología, incluye la capacidad de gestión de tecnologías de proceso avanzadas, la capacidad de asimilar las nuevas tecnologías e innovaciones útiles o de potencial probado, la habilidad para crear y gestionar una cartera de tecnologías interrelacionadas, así como la capacidad para dominar, generar o absorber las tecnologías básicas y claves del negocio.

\section{- Competencias distintivas organizativas:} abarcan todos los aspectos relacionados con la cultura organizativa, los sistemas de recompensa e incentivos, el diseño organizativo o las rutinas organizativas.

- Cultura organizativa: incluye la capacidad de la empresa para implantar un clima organizativo estimulante y agradable, que incentive el esfuerzo y rechace comportamientos apáticos; el grado de implantación de un clima organizativo de colaboración en vez de rivalidad; el compromiso con el bienestar de los empleados, los valores culturales de los miembros de la organización (satisfacción de los empleados con el trabajo para el logro de sus objetivos personales, el grado de 
participación de los empleados en el establecimiento de objetivos, planes y tareas, el grado de fidelidad de los empleados con la organización o el grado de ausencia o de absentismo laboral).

- Sistemas de recompensa e incentivos: comprenden el grado de aceptación por el personal de la política de retribución y de incentivos; la importancia otorgada en la organización a recompensas no monetarias y el grado de conocimiento y de aceptación de los criterios de evaluación, promoción y recompensa.

- Diseño organizativo: hace referencia a la definición de roles, estructuración de tareas, compromiso a largo plazo con el empleado y planes de carrera basados en la experiencia y dedicación a la empresa.

- Rutinas organizativas: la empresa puede lograr competencias distintivas organizativas a medida que sus rutinas de control, planificación, coordinación, procesos de trabajo, etc. sean inimitables y se diferencien de las utilizadas por sus competidores.

- Competencias distintivas en recursos

humanos: una adecuada gestión de recursos humanos (selección, formación, promoción, remuneración, etc.) se traduce positivamente en un incremento de sus habilidades, conocimientos, experiencia y capacidad de aprendizaje (Lado y Wilson, 1994).

Este tipo de competencias también abarca las cualidades sociales del personal de la organización, como la capacidad de los empleados de movilizar a otras empresas compartiendo una visión común, su capacidad de comunicación efectiva y de empatía, su habilidad para construir y liderar redes sociales, la 
capacidad y la predisposición para colaborar, su disposición a introducir y aceptar cambios en sus tareas y entornos laborales, etc.

- Competencias distintivas dinámicas o de innovación:

a este tipo de competencias se refiere el enfoque basado en competencias dinámicas. En esta línea, Teece, Pisano y Shuen (1997) sostienen que las competencias que realmente importan para la competitividad son las competencias dinámicas. Engloban las capacidades relacionadas con la capacidad de aprender (Collis, 1994), la habilidad para el uso y la transferencia de conocimiento, la habilidad para gestionar la I+D+I, etc.

Las competencias dinámicas son llamadas por Lado, Boyd y Wright (1992) "competencias basadas en la transformación" y por Henderson y Cockburn (1994) "competencias de arquitectura".

En nuestra investigación vamos a considerar que el aprendizaje y el conocimiento son dos dimensiones diferentes y complementarias de una competencia dinámica superior: la innovación. Igualmente, Helfat y Raubitschek (2000) adoptan un criterio similar, distinguiendo entre sistemas de conocimiento y sistemas de aprendizaje como categorías distintas pero íntimamente relacionadas de competencias dinámicas.

Camisón (2002) afirma que el concepto de competencias distintivas tiene dos peculiaridades, inspiradas ambas en el deseo de convergencia teórica y de clarificación conceptual: asimila competencias dinámicas y competencias en innovación; y considera componentes de las primeras tanto las competencias en conocimiento como en aprendizaje. 
A su vez, las competencias distintivas dinámicas o de innovación podemos agruparlas en dos tipos:

\section{COMPETENCIAS DISTINTIVAS DINÁMICAS}

\section{APRENDIZAJE}

\section{CONOCIMIENTO}

Compromiso del liderazgo con el Sistema de Gestión del Conocimiento cambio y el aprendizaje Adquisición interna de conocimiento

Cultura de innovación y aprendizaje

Desarrollo de competencias Transferencia y distribución del conocimiento

Diseño organizativo abierto al Aplicación del conocimiento aprendizaje

Memoria organizativa (stock de
conocimiento)




\section{CAPÍTULO 2:}

\section{DELIMITACIÓN DE LA GESTIÓN DEL CONOCIMIENTO}

2.1. OBJETIVOS Y CONTENIDO DEL CAPÍTULO

2.2. INTRODUCCIÓN AL CONCEPTO DE GESTIÓN DE CONOCIMIENTO

2.3. MODELOS TEÓRICOS Y PRÁCTICOS DE GESTIÓN DE CONOCIMIENTO

2.4. UN MODELO DE GC EN BASE A LA DISTINCIÓN ENTRE PRINCIPIOS Y PRÁCTICAS

2.5. GESTIÓN DE CONOCIMIENTO, APRENDIZAJE ORGANIZATIVO Y CAPITAL INTELECTUAL 


\subsection{OBJETIVOS Y CONTENIDO DEL CAPÍTULO}

Tanto a nivel académico como empresarial, sigue existiendo bastante confusión terminológica sobre lo que en el mundo anglosajón y japonés se entiende por know-how o saber hacer.

Junto con el concepto de Knowledge Management o Gestión del Conocimiento (KM o GC, en adelante) hemos de añadir otros como el término Learning Organization u Organización que Aprende (LO u OA, en adelante), más recientemente Aprendizaje Organizativo ( $\mathrm{AO}$, en adelante) (EasterbySmith, 1997; Shivarastava, 1983; Senge, 1990; Argyris y Schön, 1978 y otros), u otros vocablos como los de Intelectual Capital o Capital Intelectual (IC o CI, en adelante). Junto con ellos, pero en un capítulo distinto, haremos referencia a otros constructos como son las Coaching Competencies o Competencias Directivas (CC o CD, en adelante) (Cardona P., Chinchilla, N. y GarcíaLombardía, M., 2002).

El presente capítulo está dedicado al análisis de los fundamentos teóricos que dan sustento a la GC, partiendo del supuesto de que en este campo de estudio no existe un marco conceptual bien delimitado, ni una metodología a partir de la cual se pueda realizar una investigación sistemática. 


\subsection{INTRODUCCIÓN AL CONCEPTO DE GC}

A pesar de que la GC se ha convertido en un campo de investigación considerable en los últimos años, y materia de enseñanza en el ámbito académico y profesional, todavía resulta difícil encontrar una definición unívoca en los diferentes trabajos existentes sobre la materia.

Por lo que se refiere a las definiciones que aparecen en la literatura sobre la GC, la mayor parte de ellas incide en la aplicación del conocimiento de la empresa, ya sea a través de su capital humano, o en activos depositados en la empresa tales como patentes, rutinas, bases de datos, etc., con el fin de crear valor.

Garvin (1994), la define como aquella que "incluye no sólo los procesos de creación, adquisición y transferencia del conocimiento, sino el reflejo de ese nuevo conocimiento en el comportamiento de la organización."

Gopal y Gagnon (1995), dicen que comprende la "identificación de categorías de conocimiento necesarias para apoyar la estrategia empresarial global, la evaluación del estado actual del conocimiento de la empresa, y la transformación de la base de conocimiento actual en una nueva y poderosa base de conocimiento, rellenando las lagunas de conocimiento".

Según Petrash (1996), consiste en "conseguir el conocimiento preciso para la persona adecuada en el momento justo, con el fin de que pueda tomar la mejor decisión."

Macintosh (1996), incluye la "identificación, análisis del conocimiento requerido y disponible, y la subsiguiente planificación y control de las acciones para desarrollar los activos de conocimiento con el fin de cumplir los objetivos de la organización."

O'dell (1996) afirma que "aplica enfoques sistemáticos para buscar, entender y utilizar conocimiento para crear valor." 
Revilla (1996) señala que "significa gestionar los procesos de creación, desarrollo, difusión y explotación del conocimiento para ganar capacidad competitiva."

Lei, Hitt y Bettis (1996) la entienden como la "capacidad dinámica preeminente en la empresa así como el principal impulso del resto de competencias y capacidades."

Hibbard (1997) afirma que es "el proceso de captura de la experiencia colectiva de una empresa allá donde resida (en bases de datos, en papel o en las personas) y de su posterior distribución en aquel lugar donde pueda ayudar."

Beckman (1997) indica que comprende "el proceso de creación de nuevas capacidades, el estímulo a la innovación y la mejora del valor que se le da al cliente."

Para Tejedor y Aguirre (1998) es el "conjunto de procesos de creación de nuevas capacidades, el estímulo a la innovación y la mejora del valor que se le da al cliente."

Bueno (1998) define la misma como "una función que planifica, coordina y controla los flujos de conocimiento que se producen en la organización en relación con sus actividades y con su entorno, con el fin de crear ciertas competencias esenciales."

Schüppel, MüllerStewens y Gómez (1998) dicen que "comprende los siguientes aspectos: producción, reproducción, distribución, utilización y la multiplicación de conocimientos relevantes."

Entre ellas, las definiciones de Lei, Hitt y Bettis (1996) y la de Beckman (1997) son las que mejor se ajustan a la concepción de GC que buscamos con el fin de desarrollar los objetivos que nos hemos propuesto en la investigación, ya que relacionan la GC con la creación de competencias distintivas, y en concreto con las competencias directivas. A diferencia del resto de definiciones, 
en las que se considera la GC como un conjunto de etapas, es estas dos definiciones se busca un nexo de enlace con la obtención de una ventaja competitiva sostenible.

Siguiendo una perspectiva de proceso, Schüppel, Müller-Stewens y Gómez (1998) destacan que la GC puede ser implantada como un proceso, teniendo en cuenta las siguientes consideraciones:

1.- El proceso debe centrarse en los sujetos del conocimiento, introduciendo el conocimiento externo adquirido.

2.- Este conocimiento debe ser relevante en su entorno competitivo.

3.- El proceso debe incrementar la disponibilidad, comunicación y transferencia de conocimiento.

4.- Se debe determinar la riqueza y validez del conocimiento.

Desde una perspectiva de gestión, Tissen, Andriessen y Deprez (1998) diferencian entre gestión estratégica y gestión operativa del conocimiento. La gestión operativa utiliza las tecnologías de la información para organizar y distribuir la información hacia y procedente de los empleados. La gestión estratégica es un proceso que relaciona el conocimiento de la empresa con: el diseño de estructuras organizativas que fomentan el conocimiento, la estrategia empresarial y el desarrollo de profesionales del conocimiento. 


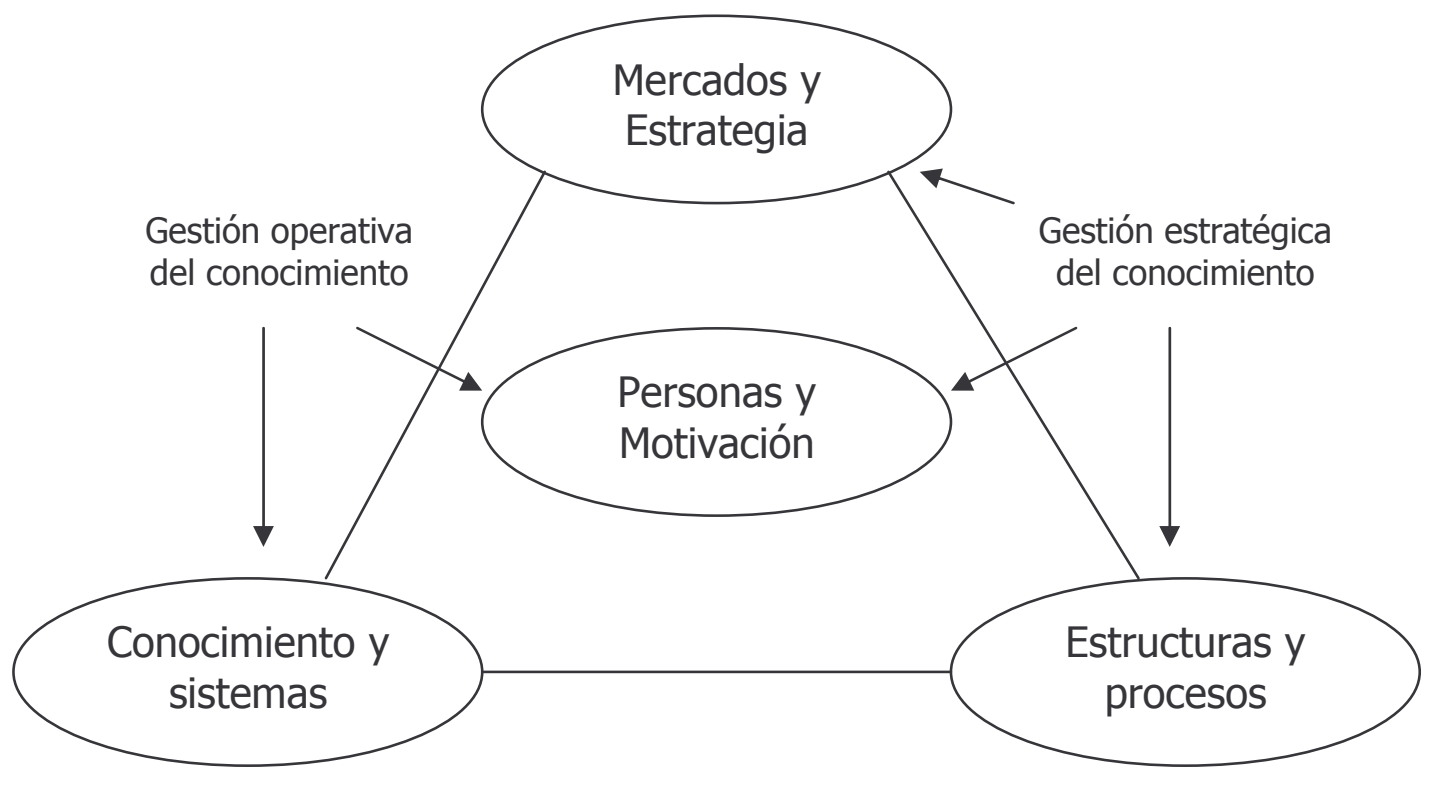

Figura 4: Modelo de gestión de conocimiento de Tissen, Andriessen y Deprez (1998) 


\subsection{MODELOS TEÓRICOS Y PRÁCTICOS DE GC}

Tabla de los modelos teóricos de GC (elaboración propia)

\begin{tabular}{|c|c|}
\hline Nonaka y Takeuchi (1995) & $\begin{array}{l}\text { Proceso de creación de conocimiento: } \\
\text { la espiral del conocimiento }\end{array}$ \\
\hline Kaplan y Norton (1996) & $\begin{array}{l}\text { Indicadores financieros } y \text { no } \\
\text { financieros para medir los resultados } \\
\text { organizativos }\end{array}$ \\
\hline Edvinsson (1996) & $\begin{array}{l}\text { Diferencia entre valor contable y valor } \\
\text { de mercado. }\end{array}$ \\
\hline Brooking (1996) & Auditoría del Capital Intelectual \\
\hline Sveiby (1997) & $\begin{array}{l}\text { Expectativas en la generación de } \\
\text { flujos de caja futuros }\end{array}$ \\
\hline Drogonetti y Roos (1998) & $\begin{array}{l}\text { Sistematización del Capital Intelectual: } \\
\text { flujos y stocks de conocimientos }\end{array}$ \\
\hline Euroforum (1998) & $\begin{array}{l}\text { Capital Intelectual: Humano, } \\
\text { Estructural y Relacional }\end{array}$ \\
\hline Bueno (1998) & $\begin{array}{lll}\text { Dirección } & \text { Estratégica } & \text { por } \\
\text { Competencias } & & \end{array}$ \\
\hline Camisón y Palacios (1999) & $\begin{array}{l}\text { Proceso dinámico del Capital } \\
\text { Intelectual. }\end{array}$ \\
\hline
\end{tabular}




\subsubsection{Modelos teóricos de medición del Capital Intelectual}

\section{A) LA ESPIRAL DEL CONOCIMIENTO (NONAKA, TAKEUCHI, 1995)}

El proceso de creación del conocimiento para Nonaka y Takeuchi (1995) es a través de un modelo de generación de conocimiento mediante dos espirales de contenido epistemológico y ontológico.

Es un proceso de interacción entre conocimiento tácito y explícito que tiene naturaleza dinámica y continua. Se constituye en una espiral permanente de transformación ontológica interna de conocimiento, desarrollada siguiendo 4 fases que podemos ver de forma gráfica en la siguiente figura:

Dimensión

Epistemológica

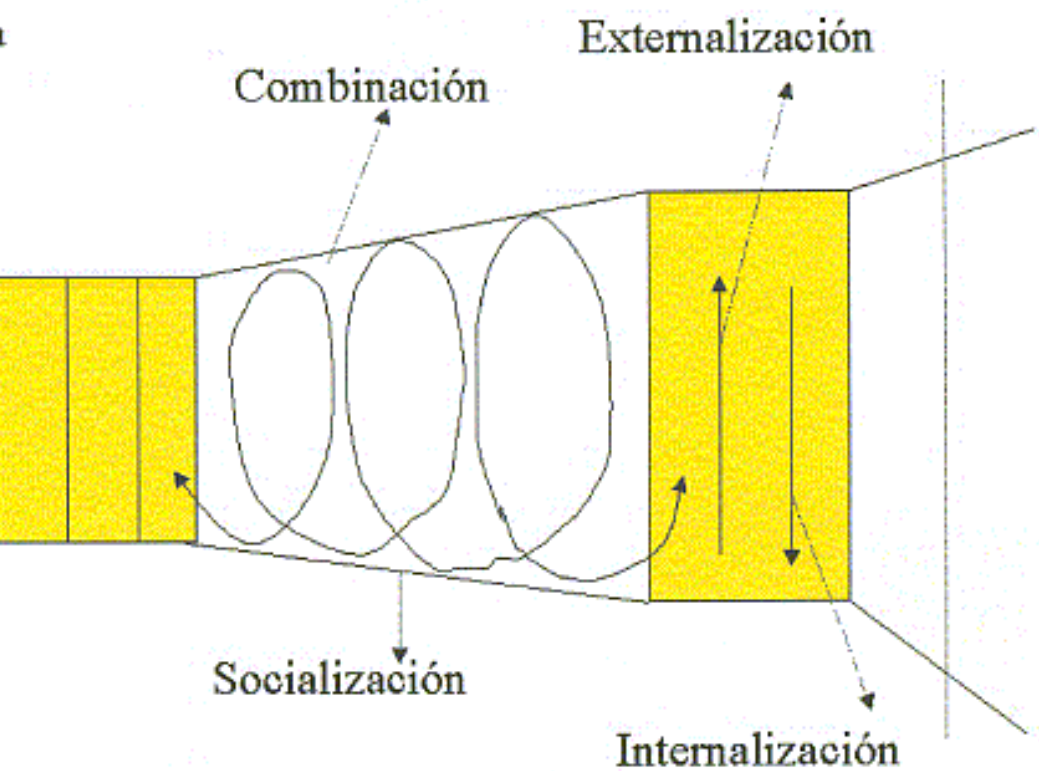

Conocimiento

Tácito

Dimensión Ontológica Individual Grupo Organización Interorganización

Nivel de conocimiento

Figura 5: Modelo de espiral de conocimiento de Nonaka y Takeuchi (1995)

La Socialización, es el proceso de adquirir conocimiento tácito a través de compartir experiencias por medio de exposiciones orales, documentos, 
manuales y tradiciones y que añade el conocimiento novedoso a la base colectiva que posee la organización;

La Exteriorización, es el proceso de convertir conocimiento tácito en conceptos explícitos que supone hacer tangible mediante el uso de metáforas conocimiento de por sí difícil de comunicar, integrándolo en la cultura de la organización; es la actividad esencial en la creación del conocimiento;

La Combinación, es el proceso de crear conocimiento explícito al reunir conocimiento explícito proveniente de cierto número de fuentes, mediante el intercambio de conversaciones telefónicas, reuniones, correos, etc., y se puede categorizar, confrontar y clasificar para formas bases de datos para producir conocimiento explícito.

La Interiorización, es un proceso de incorporación de conocimiento explícito en conocimiento tácito, que analiza las experiencias adquiridas en la puesta en práctica de los nuevos conocimientos y que se incorpora en las bases de conocimiento tácito de los miembros de la organización en la forma de modelos mentales compartidos o prácticas de trabajo

Para Nonaka y Takeuchi, lo expresado por Peter Drucker en el sentido de que, la esencia de la dirección es, cómo se puede aplicar de la mejor forma un conocimiento existente para poder crear otro conocimiento nuevo o reciclado, es justificado ya que sus estudios en compañías japonesas respaldan el proceso de creación del conocimiento que ambos Japoneses han sostenido. 


\section{B) BALANCED BUSINESS SCORECARD (KAPLAN Y NORTON, 1996)}

Este modelo consiste en un sistema de indicadores financieros y no financieros que tienen como objetivo medir los resultados obtenidos por la organización.

Kaplan y Norton comienzan su labor investigadora en 1.990, con la profunda convicción de que los modelos de gestión empresarial basados en indicadores financieros, se encuentran completamente obsoletos. Su labor se materializa en el libro "The Balanced Scorecard".

El modelo integra los indicadores financieros (de pasado) con los no financieros (de futuro), y los integra en un esquema que permite entender las interdependencias entre sus elementos, así como la coherencia con la estrategia y la visión de la empresa.

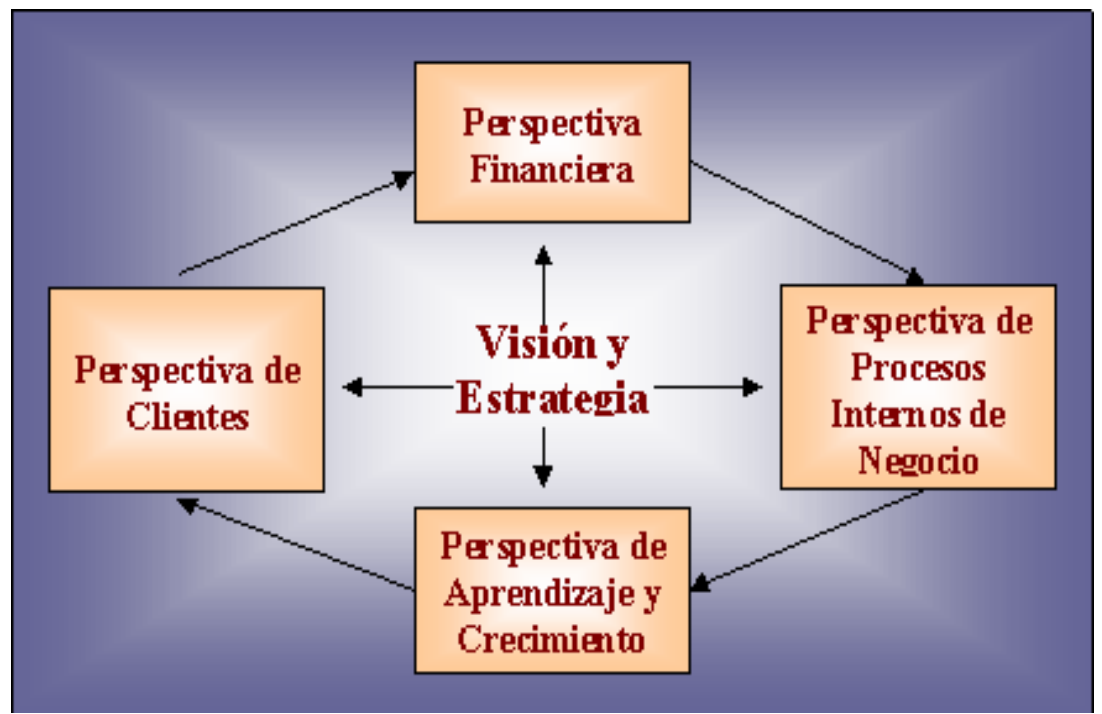

Figura 6: Modelo del Balanced Business Scorecard (Kaplan y Norton, 1996)

Dentro de cada bloque se distinguen dos tipos de indicadores: 1) Indicadores Driver (factores condicionantes de otros). 2) Indicadores Output (indicadores de resultado). 
El modelo presenta cuatro bloques:

\section{Perspectiva Financiera}

El modelo contempla los indicadores financieros como el objetivo final; considera que estos indicadores no deben ser sustituidos, sino complementados con otros que reflejan la realidad empresarial. Ejemplo de indicadores: rentabilidad sobre fondos propios, flujos de caja, análisis de rentabilidad de cliente y producto, gestión de riesgo,...

\section{Perspectiva de Cliente}

El objetivo de este bloque es identificar los valores relacionados con los clientes, que aumentan la capacidad competitiva de la empresa. Para ello, hay que definir previamente los segmento de mercado objetivo y realizar un análisis del valor y calidad de éstos. En este bloque los indicadores drivers son el conjunto de valores del producto / servicio que se ofrece a los clientes (indicadores de imagen y reputación de la empresa, de la calidad de la relación con el cliente, de los atributos de los servicios / productos.

Los indicadores output se refieren a las consecuencias derivadas del grado de adecuación de la oferta a las expectativas del cliente. Ejemplos: cuota de mercado, nivel de lealtad o satisfacción de los clientes,...

\section{Perspectiva de Procesos Internos de Negocio}

Analiza la adecuación de los procesos internos de la empresa de cara a la obtención de la satisfacción del cliente y conseguir altos niveles de rendimiento financiero. Para alcanzar este objetivo se propone un análisis de los procesos internos desde una perspectiva de negocio y una predeterminación de los procesos clave a través de la cadena de valor.

Se distinguen tres tipos de procesos: 
1.- Procesos de Innovación (difícil de medir). Ejemplo de indicadores: \% de productos nuevos, \% productos patentados, introducción de nuevos productos en relación a la competencia...

2.- Procesos de Operaciones. Desarrollados a través de los análisis de calidad y reingeniería. Los indicadores son los relativos a costes, calidad, tiempos o flexibilidad de los procesos.

3. - Procesos de servicio postventa. Indicadores: costes de reparaciones, tiempo de respuesta, ratio ofrecido,...

\section{Perspectiva del Aprendizaje y Mejora}

El modelo plantea los valores de este bloque como el conjunto de drivers del resto de las perspectivas. Estos inductores constituyen el conjunto de activos que dotan a la organización de la habilidad para mejorar y aprender. Se critica la visión de la contabilidad tradicional, que considera la formación como un gasto, no como una inversión.

La perspectiva del aprendizaje y mejora es la menos desarrollada, debido al escaso avance de las empresas en este punto. De cualquier forma, la aportación del modelo es relevante, ya que deja un camino perfectamente apuntado y estructura esta perspectiva. Clasifica los activos relativos al aprendizaje y mejora en:

- Capacidad y competencia de las personas (gestión de los empleados).

- Sistemas de información (sistemas que proveen información útil para el trabajo).

- Cultura-clima-motivación para el aprendizaje y la acción. 


\section{C) NAVIGATOR DE SKANDIA (EDVINSSON, 1996)}

La principal línea de argumentación de Leif Edvisson es la diferencia entre los valores de la empresa en libros y los de mercado. Esta diferencia se debe a un conjunto de activos intangibles, que no quedan reflejados en la contabilidad tradicional, pero que el mercado reconoce como futuros flujos de caja. Para poder gestionar estos valores, es necesario hacerlos visibles.

El enfoque de Skandia parte de que el valor de mercado de la empresa está integrado por: El Capital Financiero y El Capital Intelectual (que descompone en bloques):

Los elementos del Capital Intelectual son:

- Capital Humano. Conocimientos, habilidades, actitudes,... de las personas que componen la organización.

- Capital Estructural. Conocimientos explicitados por la organización. Integrado por tres elementos:

- Clientes. Activos relacionados con los clientes (fidelización, capacidad de conformar equipos mixtos,...$)$.

- Procesos. Forma en que la empresa añade valor a través de las diferentes actividades que desarrolla.

- Capacidad de Innovación. Posibilidad de mantener el éxito de la empresa a en el largo plazo a través del desarrollo de nuevos productos o servicios. 


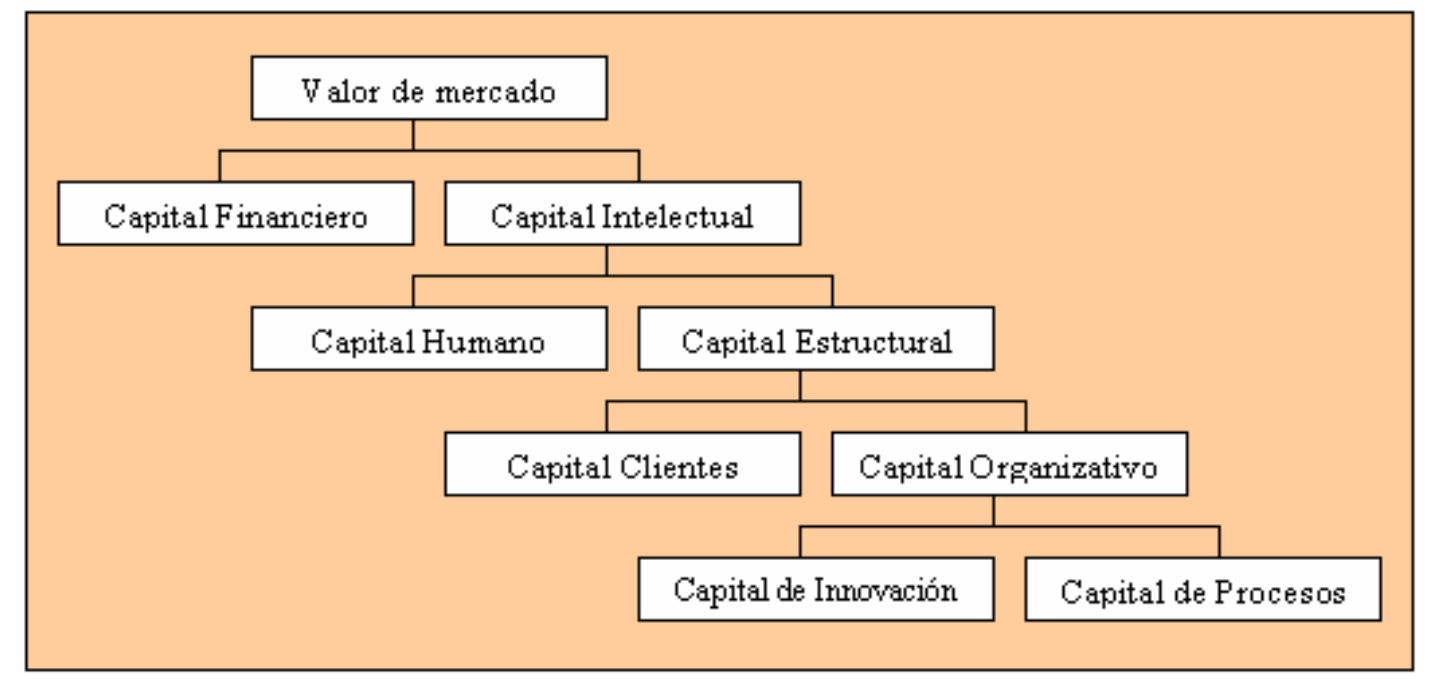

Figura 7: Modelo del Navigator Skandia (Edvinsson, 1996)

La síntesis del Capital Intelectual y la dimensión financiera y temporal quedan recogidos en el modelo denominado Navigator:

El triángulo superior es el Enfoque Financiero (Balance de Situación), el pasado de la empresa. A los indicadores tradicionales añade ratios que evalúan el rendimiento, rapidez y calidad.

El presente esta constituido por las relaciones con los clientes y los procesos de negocio. La base es la capacidad de innovación y adaptación, que garantiza el futuro. El centro del modelo y corazón de la empresa es el Enfoque Humano.

Los indicadores deben cumplir unos requisitos: relevancia, precisión, adimensionalidad y facilidad de medición. Se han realizado implantaciones reales de éste modelo. 


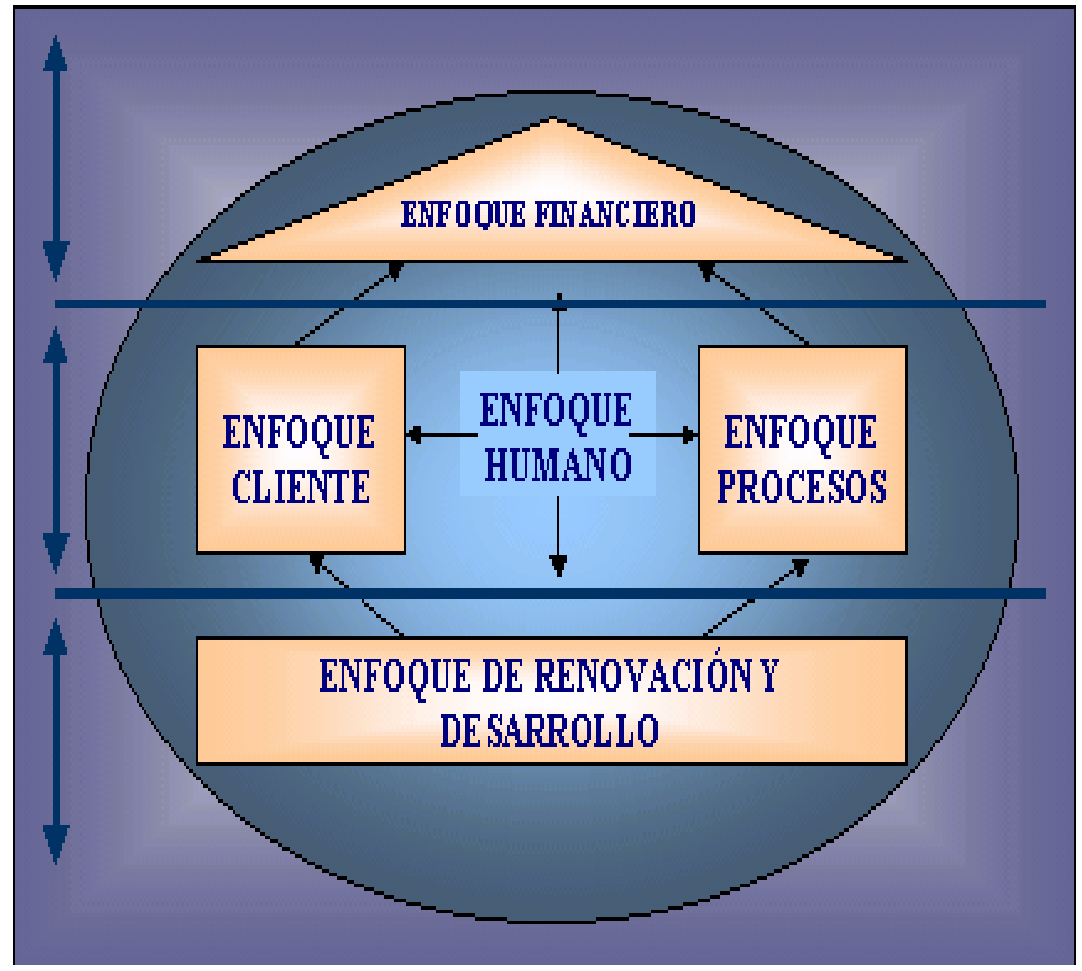

Figura 8: Enfoques e Indicadores del Navigator Skandia (Edvinsson, 1996) 


\section{D) TECHNOLOGY BROKER (BROOKING, 1996)}

Annie Brooking (1996) parte del mismo concepto que el modelo de Skandia: El valor de mercado de las empresas es la suma de los activos tangibles y el Capital Intelectual.

El modelo no llega a la definición de indicadores cuantitativos, sino que se basa en la revisión de un listado de cuestiones cualitativas. Brooking (1996) incide en la necesidad del desarrollo de una metodología para auditar la información relacionada con el Capital Intelectual.

Los activos intangibles se clasifican en cuatro categorías, que constituyen el Capital Intelectual:

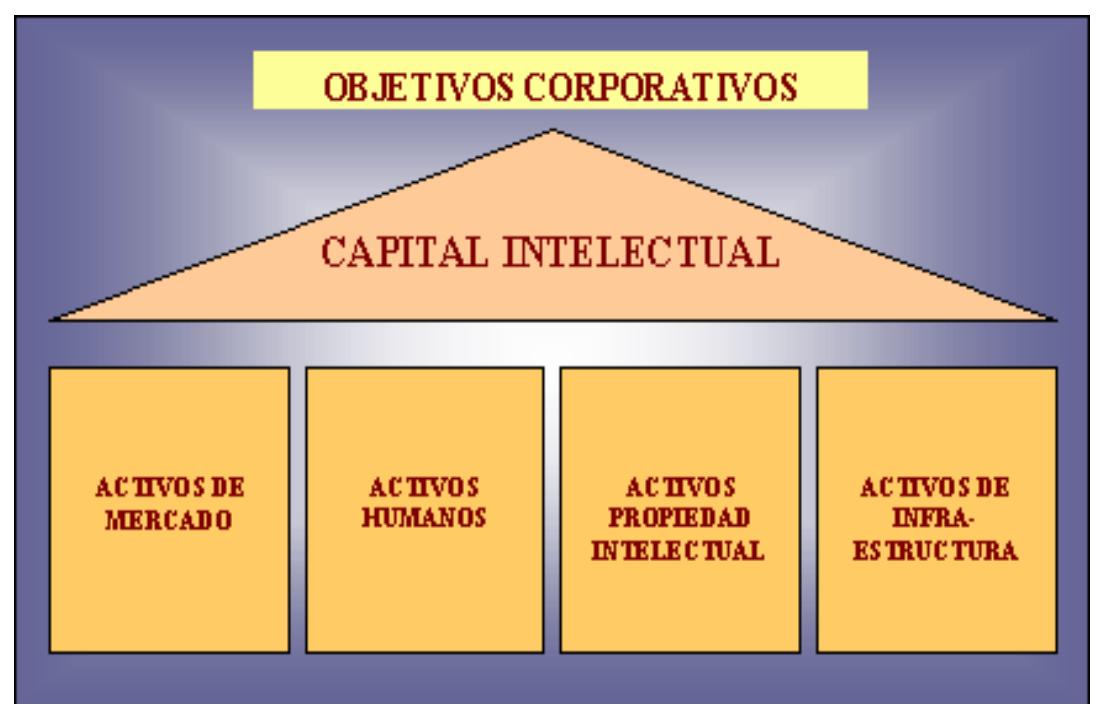

Figura 9: Modelo Technology Broker (Brooking, 1996)

\section{Activos de Mercado}

Proporcionan una ventaja competitiva en el mercado. Indicadores: marcas, clientes, nombre de la empresa, cartera de pedidos, distribución, capacidad de colaboración,... 


\section{Activos de Propiedad Intelectual}

Valor adicional que supone para la empresa la exclusividad de la explotación de un activo intangible. Indicadores: Patentes, copyrights, derechos de diseño, secretos comerciales,...

\section{Activos Humanos}

Se enfatiza la importancia que tienen las personas en las organizaciones por su capacidad de aprender y utilizar el conocimiento. Brooking (1996) afirma que el trabajador del tercer milenio será un trabajador del conocimiento, al que se le exigirá participación en el proyecto de empresa y una capacidad para aprender continuamente. Indicadores: aspectos genéricos, educación (base de conocimientos y habilidades generales), formación profesional (capacidades necesarias para el puesto de trabajo), conocimientos específicos del trabajo (experiencia), habilidades (liderazgo, trabajo en equipo, resolución de problemas, negociación, objetividad, estilo de pensamiento, factores motivacionales, comprensión, síntesis,...

\section{Activos de Infraestructuras}

Incluye las tecnologías, métodos y procesos que permiten que la organización funcione. El modelo incluye: filosofía de negocio, cultura de la organización (puede ser un activo o un pasivo en función del alineamiento con la filosofía del negocio), sistemas de información, las bases de datos existentes en la empresa (infraestructura de conocimiento extensible a toda la organización). 


\section{E) INTELLECTUAL ASSETS MONITOR (SVEIBY, 1997)}

Sveiby (1997) basa su argumentación sobre la importancia de los activos intangibles en la gran diferencia existente entre el valor de las acciones en el mercado y su valor en libros. Esta diferencia, según Sveiby, se debe a que los inversores desarrollan sus propias expectativas en la generación de los flujos de caja futuros debido a la existencia de los activos intangibles.

Antes de definir los activos intangibles, hay que determinar el objetivo de la medición y en función del usuario final, determinar los aspectos más relevantes. Según este autor, la medición de activos intangibles presenta una doble orientación:

- Hacia el exterior, para informar a clientes, accionistas y proveedores.

- Hacia el interior, dirigida al equipo directivo para conocer la marcha de la empresa.

Sveiby (1997) clasifica los activos intangibles en tres categorías, dando origen a un balance de activos intangibles. Identifica los siguientes:

Competencias de las Personas. Incluye las competencias de la organización como son planificar, producir, procesar o presentar productos o soluciones.

Estructura Interna. Es el conocimiento estructurado de la organización como las patentes, procesos, modelos, sistemas de información, cultura organizativa,... así como las personas que se encargan de mantener dicha estructura. 
Estructura Externa. Comprende las relaciones con clientes y proveedores, las marcas comerciales y la imagen de la empresa

Figura 10: Modelo Intellectual Assets Motinor (Sveiby, 1997)

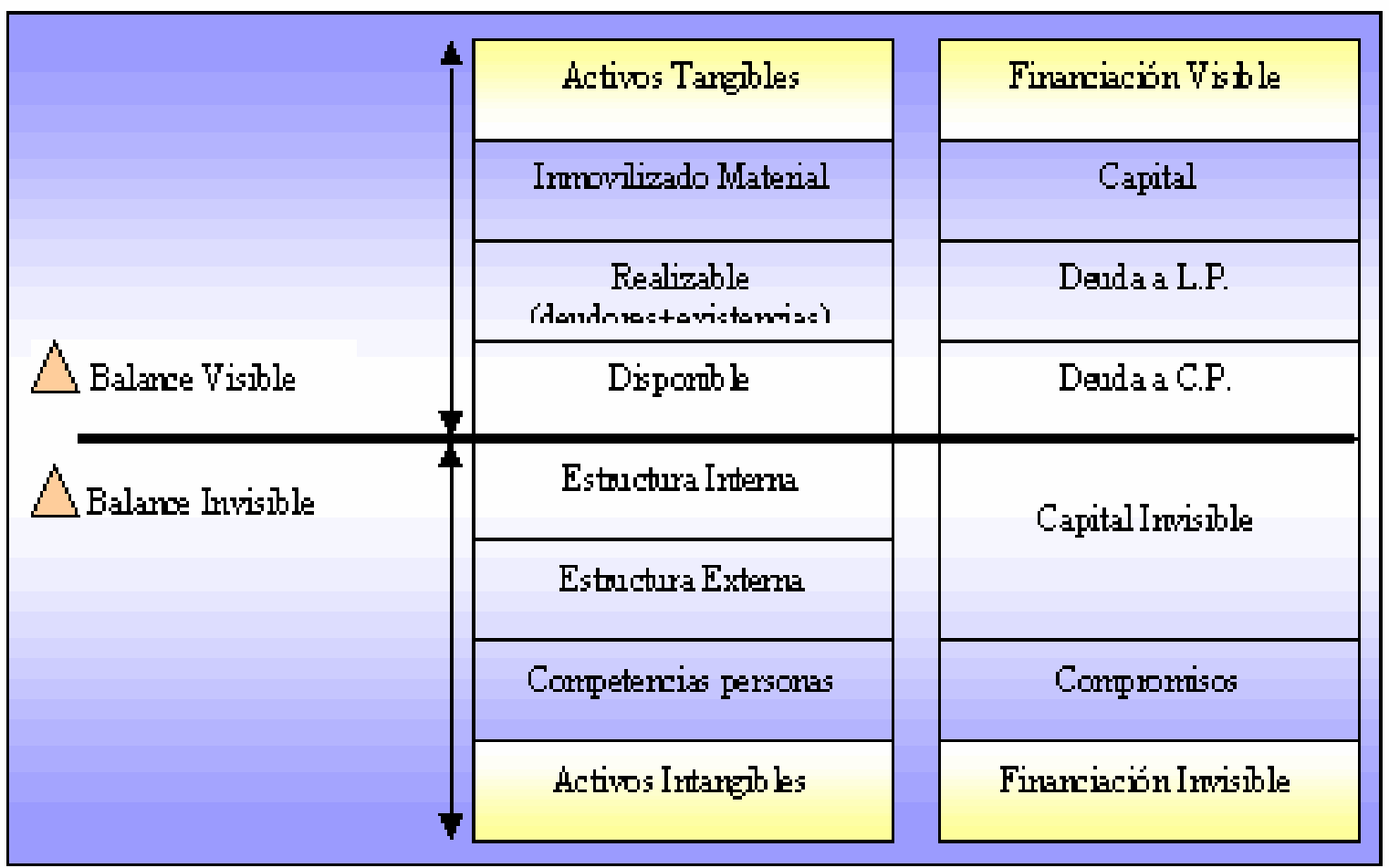

Según Sveiby (1997), las personas son el único agente verdadero en las organizaciones, y las encargadas de crear la estructura interna (organización) y externa (imagen). Ambas, tanto la interna como la externa, son estructuras de conocimiento y que permanecen en la empresa incluso tras la marcha de un alto número de trabajadores.

Sveiby (1997) propone tres tipos de indicadores dentro de cada uno de los tres bloques:

- Indicadores de crecimiento e innovación: recogen el potencial futuro de la empresa.

- Indicadores de eficiencia: nos informan hasta qué punto los intangibles son productivos (activos). 
- Indicadores de estabilidad: indican el grado de permanencia de estos activos en la empresa.

El Monitor de Activos Intangibles:

\begin{tabular}{|c|c|c|c|}
\hline & COMPETENCIAS & $\begin{array}{l}\text { ESTRUCTURA } \\
\text { INTERNA }\end{array}$ & $\begin{array}{l}\text { ESTRUCTURA } \\
\text { EXTERNA }\end{array}$ \\
\hline $\begin{array}{l}\text { Indicadores de } \\
\text { Crecimiento } \\
\text { In novación }\end{array}$ & $\begin{array}{l}\text { - Experiencia. } \\
\text { - Nivel de educación. } \\
\text { - Coste de } \\
\text { formación. } \\
\text { - Rotación. } \\
\text { - Clientes que } \\
\text { fomentan las } \\
\text { competencias. }\end{array}$ & $\begin{array}{l}\text { - Inversiones en } \\
\text { nuevos méto dos y } \\
\text { sistemas. } \\
\text { - Inversión en los } \\
\text { sistemas de } \\
\text { informa ción. } \\
\text { - Contribución de los } \\
\text { clientes a la estructura } \\
\text { interna. }\end{array}$ & $\begin{array}{l}\text { - Rentabilidad por } \\
\text { cliente. } \\
\text { - Crecimiento } \\
\text { orgánico. }\end{array}$ \\
\hline $\begin{array}{l}\text { Indicadores de } \\
\text { Eficiencia }\end{array}$ & $\begin{array}{l}\text { - Proporción de } \\
\text { profesionales. } \\
\text { - Valor añadido por } \\
\text { profesional. }\end{array}$ & $\begin{array}{l}\text { - Proporción del } \\
\text { personal de apoyo. } \\
\text { - Ventas por personal } \\
\text { de apoyo. } \\
\text { Medidas de valores y } \\
\text { actitud. }\end{array}$ & $\begin{array}{l}\text { - Indice de } \\
\text { satisfacción de los } \\
\text { clientes. } \\
\text { - Indice éxito } \\
\text { fracaso. } \\
\text { - Ventas por clientes. }\end{array}$ \\
\hline $\begin{array}{l}\text { Indicadores de } \\
\text { Estabilidad }\end{array}$ & $\begin{array}{l}\text { - Edad media. } \\
\text { - Antigüedad. } \\
\text { - Posición } \\
\text { remunerativa rel ativa. } \\
\text { - Rotación de } \\
\text { profesionales. }\end{array}$ & $\begin{array}{l}\text { - Edad de la } \\
\text { organización. } \\
\text { * Rotación del } \\
\text { personal de apoyo. } \\
\text { - El ratio rookie. }\end{array}$ & $\begin{array}{l}\text { - Proporción de } \\
\text { grandes clientes. } \\
\text { - Ratios de clientes } \\
\text { fieles. } \\
\text { Estructura de } \\
\text { antigüedad. } \\
\text { - Frecuencia de } \\
\text { repetición. }\end{array}$ \\
\hline
\end{tabular}

Figura 11: Indicadores del Modelo Intellectual Assets Motinor (Sveiby, 1997) 


\section{F) INTELECTUAL CAPITAL (DROGONETTI Y ROOS, 1998)}

Drogonetti y Ross (1998) estudian la aplicación del concepto de Capital Intelectual a un programa gubernamental, el Business Network Programme, implementado en Australia por AusIndustry.

Se hace alusión a la actual tendencia a buscar una teoría nueva que pueda adoptar la función de marco general y de lenguaje para todos los recursos intangibles. Algunos autores (Edvinsson \& Malone, 1997; Bontis, 1996; Roos \& Roos, 1997) han empezado a clasificar bajo el nombre de Capital Intelectual todos los recursos intangibles, y a analizar sus interconexiones. Pero el problema está en la definición de recursos intangibles. Así para Drogonetti y Ross (1998) recurso "es cualquier factor que contribuya a los procesos de generación de valor de la compañía, y que esté, de manera más o menos directa, bajo el control de la propia compañía".

Como vemos es una definición un tanto imprecisa, pero esto no es malo, ya que el Capital Intelectual es algo absolutamente singular en todas y cada una de las empresas. Por ello, aunque no se pueda definir el concepto de Capital Intelectual, se pueden clasificar en categorías y tipos siguiendo un criterio de gestión.

El valor de la compañía proviene de sus activos físicos y monetarios (Capital Financiero), y de sus recursos intangibles (Capital Intelectual). Dentro del Capital Intelectual hay dos categorías generales, Capital Humano y Capital Estructural, con tres subdivisiones cada una. Esta clasificación la vemos en la siguiente figura: 


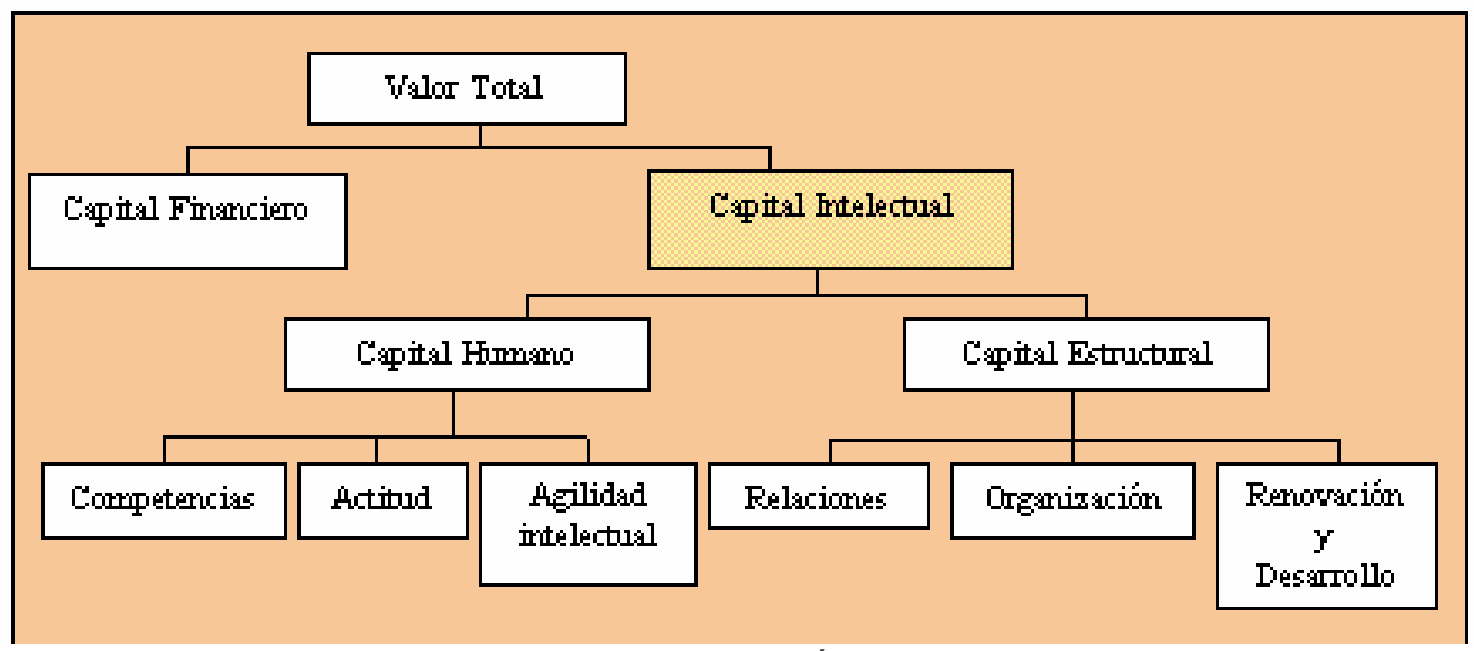

Figura 12: Arbol de Configuración de Valor (Roos et al, 1997)

Por otra parte la identificación de las clases de Capital Intelectual (stocks de recursos intangibles) no es suficiente para garantizar su correcta gestión, necesitamos también, los flujos de Capital Intelectual, esto es los cambios en los stocks de recursos intangibles (Roos et all, 1997).

Añadir la perspectiva de flujo a la de stock proporciona más información que cualquiera de ellas por separado. Además, la información sobre el flujo de capital intelectual presenta algunos desafíos adicionales en términos de complejidad. Los flujos del Capital Intelectual no son necesariamente un juego de suma cero. La investigación nos ha demostrado que el conocimiento y la información producen rendimientos crecientes, al contrario de los decrecientes de los recursos tradicionales (tierra, trabajo y capital). Por ello los flujos añaden una perspectiva de incalculable valor al estudio del Capital Intelectual, pero también tienen problemas de medición.

Drogonetti y Ross (1998) plantean un índice de Capital Intelectual que integre a los diferentes indicadores del Capital Intelectual en una única medida. Lo que se hace es ver la importancia relativa de los diferentes indicadores, y se transforman en números sin dimensión (normalmente porcentajes). Este índice proporciona a los gestores una nueva línea de partida que se centra en el rendimiento financiero del Capital Intelectual, cuando la tradicional se centraba en el financiero. 
Entre las conclusiones del estudio se dice que: "un sistema de Capital Intelectual es, en sí mismo, un recurso intangible de la organización". Así, un sistema de Capital Intelectual pasa a formar parte del Capital Intelectual de la compañía y cuanto mejor lo utilice, más Capital Intelectual se creará. Crear un sistema de Capital Intelectual llega a ser una actividad semi-circular. 


\section{G) INTELECT (EUROFORUM, 1998)}

El modelo responde a un proceso de identificación, selección, estructuración y medición de activos hasta ahora no evaluados de forma estructurada por las empresas.

Pretende ofrecer a los gestores información relevante para la toma de decisiones y facilitar información a terceros sobre el valor de la empresa. El modelo pretende acercar el valor explicitado de la empresa a su valor de mercado, así como informar sobre la capacidad de la organización de generar resultados sostenibles, mejoras constantes y crecimiento a largo plazo.

\section{Características del Modelo}

1. Enlaza el Capital Intelectual con la Estrategia de la Empresa.

2. Es un modelo que cada empresa debe personalizar.

3. Es abierto y flexible.

4. Mide los resultados y los procesos que los generan.

5. Aplicable.

6. Visión Sistémica.

7. Combina distintas unidades de medida.

\section{Estructura del Modelo Intelect:}

Bloques.- Es la agrupación de Activos Intangibles en función de su naturaleza (Capital Humano, Capital Estructural y Capital Relacional).

Elementos.- Son los activos intangibles que se consideran dentro de cada bloque. Cada empresa en función de su estrategia y de sus factores críticos de éxito, elegirá unos elementos concretos 
Indicadores.- Es la forma de medir o evaluar los elementos. La definición de indicadores debe hacerse en cada caso particular.

El siguiente gráfico presenta los tres grandes bloques en los que se estructura el modelo, cada uno de los cuales debe ser medido y gestionado con una dimensión temporal que integre el futuro.

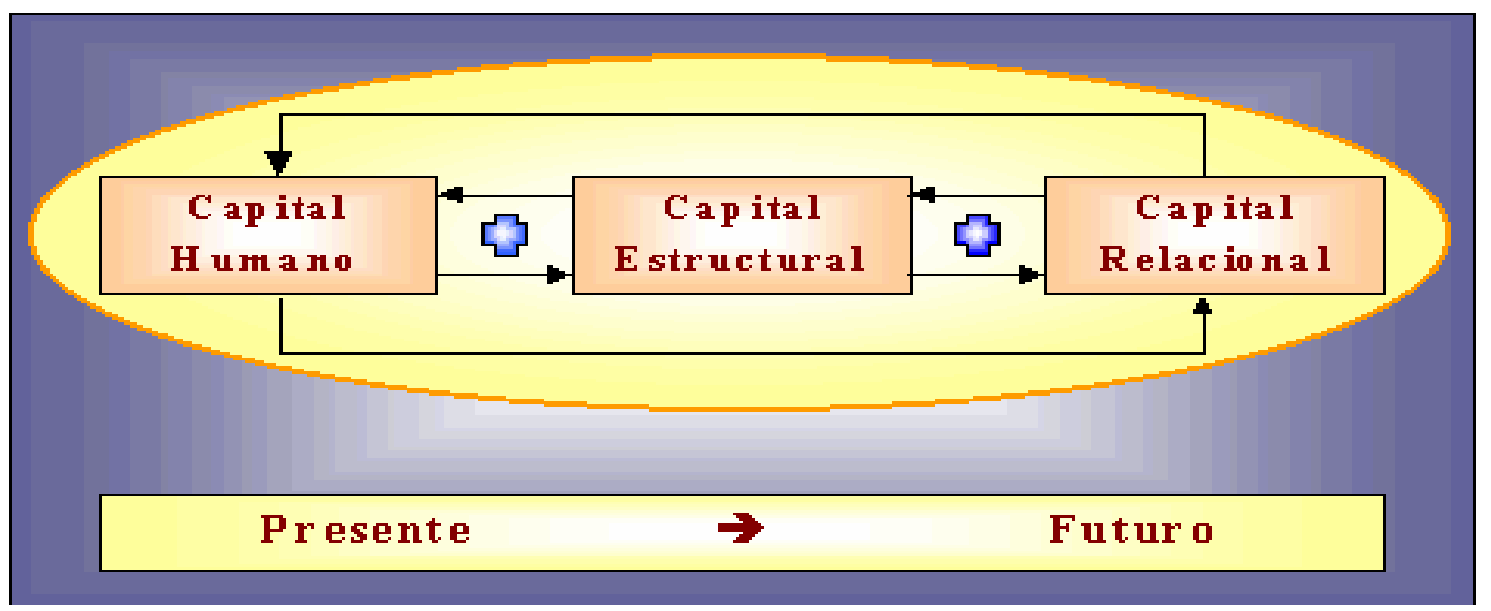

Figura 13: Modelo Intellect (Euroforum, 1998)

\section{Capital Humano}

Se refiere al conocimiento (explícito o tácito) útil para la empresa que poseen las personas y equipos de la misma, así como su capacidad para regenerarlo; es decir, su capacidad de aprender. El Capital Humano es la base de la generación de los otros dos tipos de Capital Intelectual. Una forma sencilla de distinguir el Capital Humano es que la empresa no lo posee, no lo puede comprar, sólo alquilarlo durante un periodo de tiempo. 


\begin{tabular}{|l|l|}
\hline \multicolumn{1}{|c|}{ PRESENTE } & \multicolumn{1}{|c|}{ FUTURO } \\
\hline Satisfacción del Personal. & Mejora de las Competencias. \\
Tipología del Personal. & Capacidad de innovación de las personas y \\
Competencias de las personas. & equipos. \\
Liderazgo. & \\
Trabajo en Equipo. & \\
Estabilidad: riesgo de pérdida. & \\
\hline
\end{tabular}

Figura 14:"Elementoš de Capital Hünano (Ëuroforum, 1998)

\section{Capital Estructural}

Es el conocimiento que la organización consigue explicitar, sistematizar e internalizar y que en un principio puede estar latente en las personas y equipos de la empresa. Quedan incluidos todos aquellos conocimientos estructurados de los que depende la eficacia y eficiencia interna de la empresa: los sistemas de información y comunicación, la tecnología disponible, los procesos de trabajo, las patentes, los sistemas de gestión,... El Capital Estructural es propiedad de la empresa, queda en la organización cuando sus personas la abandonan. Un sólido Capital Estructural facilita una mejora en el flujo de conocimiento e implica una mejora en la eficacia de la organización.

\begin{tabular}{|l|l|}
\hline \multicolumn{1}{|c|}{ PRESENTE } & \multicolumn{1}{|c|}{ FUTURO } \\
\hline Cultura Orgarizacional. & Procesos de Innovación. \\
Filosofia de Negocio. & \\
Procesos de Refle xión Estratégica. & \\
Estructura de la Organización. & \\
Propiedad Intelectual. & \\
Tecrología de Proceso. & \\
Tecrología de Producto. & \\
Procesos de Apoyo. & \\
Procesos de Captación de Conocimiento. & \\
Mecanismos de Transmisión y & \\
Comunicación. & \\
Tecrología de la Información. & \\
\hline
\end{tabular}

Figura 15: Elementos de Capital Estructural (Euroforum, 1998) 


\section{Capital Relacional}

Se refiere al valor que tiene para una empresa el conjunto de relaciones que mantiene con el exterior. La calidad y sostenibilidad de la base de clientes de una empresa y su potencialidad para generar nuevos clientes en el futuro, son cuestiones claves para su éxito, como también lo es el conocimiento que puede obtenerse de la relación con otros agentes del entorno (alianzas, proveedores,...$)$.

\begin{tabular}{|l|l|}
\hline \multicolumn{1}{|c|}{ PRESENTE } & \multicolumn{1}{|c|}{ FUTURO } \\
\hline Base de Clientes Relevantes. & Capacidad de Mejora / Recreación de la \\
Lealtad de Clientes. & Base de Clientes. \\
Intersidad de la Relación con Clientes. & \\
Satisfacción de Clientes. & \\
Procesos de Servicio y A poyo al Cliente. & \\
Cercanía al Mercado. & \\
Notoriedad de Marcas. & \\
Reputación / Nornbre de la empresa. & \\
Alianzas Estratégicas. & \\
Interrelación con Proveedores. & \\
Interrelación con otros Agentes. & \\
\hline
\end{tabular}

Figura 16: Elementos de Capital Relacional (Euroforum, 1998)

\section{Dimensiones incorporadas:}

Presente/Futuro: estructuración y medición de los activos intangibles en el momento actual y sobre todo, revelar el futuro previsible de la empresa, en función a la potencialidad de su Capital Intelectual y a los esfuerzos que se realizan en su desarrollo.

Interno/Externo: debemos identificar intangibles que generan valor desde la consideración de la organización como un sistema abierto. Se consideran los activos internos (creatividad personas, sistemas de gestión de la información,...) y externos (imagen de marca, alianzas, lealtad,...) 
Flujo/Stock: el modelo tiene un carácter dinámico, ya que no sólo pretende contemplar el stock de capital intelectual en un momento concreto del tiempo, sino también aproximarse a los procesos la conversión entre los diferentes bloques de Capital Intelectual

Explícito/Tácito: no sólo se consideran los conocimientos explicitos (transmisibles), sino también los más personales, subjetivos y difíciles de compartir. El adecuado y constante transvase entre conocimientos tácitos y explícitos es vital para la innovación y el desarrollo de la empresa.

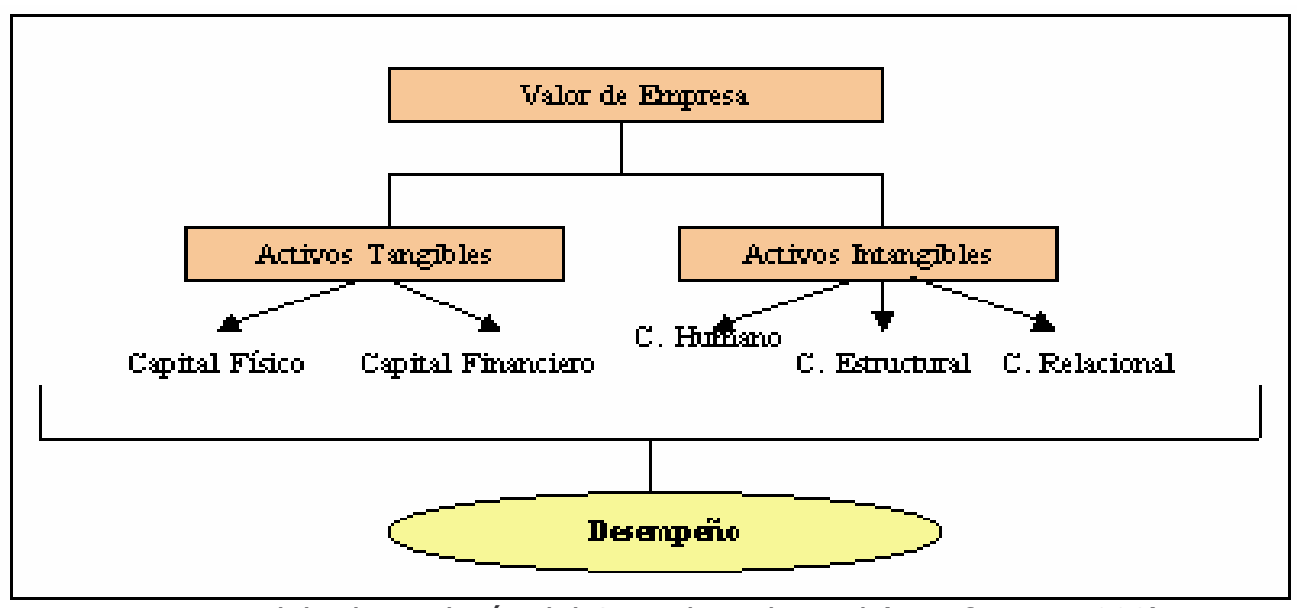

Figura 17: Modelo de Medición del Capital Intelectual (Euroforum, 1998) 


\section{H) MODELO DE DIRECCIÓN ESTRATÉGICA POR COMPETENCIAS: EL CAPITAL INTANGIBLE (BUENO, 1998)}

Bueno (1998) profundiza en el concepto de Capital Intelectual, mediante la creación del modelo de dirección estratégica por competencias. Como ya hemos visto, en estos últimos años, los intangibles cobran cada vez más importancia en la realidad económico empresarial. Esta evidencia ha justificado el interés que a lo largo de la década actual diferentes investigadores, expertos, entidades e instituciones están mostrando para conocer cómo se crean, cómo se miden, con qué indicadores, y cómo se deben gestionar los citados activos intangibles, tanto en cuanto a su consideración dinámica, como "flujos de conocimientos" (Roos y otros, 1997 y Steward, 1997), como en su aceptación estática o valor intangible en un momento concreto del tiempo.

Estos grupos de interés vienen acordando que el valor posible del capital intangible o intelectual de la empresa puede estar recogido y evaluado por la diferencia entre el valor de mercado de la compañía (V) y el valor contable de sus activos productivos (Ac). En consecuencia, el capital intangible representa "la valoración de los activos intangibles creados por los flujos de conocimientos de la empresa".

Concepto que queda reflejado en la ecuación:

\section{$\mathrm{Cl}=\mathrm{W}-\mathrm{AC}$}

Donde:

$\mathrm{CI}=$ Capital Intangible $\mathrm{o}$ intelectual

$\mathrm{V}=$ Valor de mercado de la empresa.

Ac $=$ Activos productivos netos de la empresa según valor contable. 
Esta conceptualización hace que cobre interés la propuesta de capital intangible como clave estratégica de la competencia actual y que está representada en la figura siguiente. Como ya sabemos, el Capital Intangible es el "conjunto de competencias básicas distintivas de carácter intangible que permiten crear y sostener la ventaja competitiva".

Todo esto ha llevado formular la Dirección Estratégica por Competencias, paradigma que viene emergiendo en la década actual para orientar mejor la eficiencia y eficacia de la empresa en la sociedad del conocimiento.

Para Bueno y Morcillo (1997) "la competencia esencial" está compuesta por tres elementos o componentes básicas distintivas: unas de origen tecnológico (en sentido amplio: saber y experiencia acumulados por la empresa); otras de origen organizativo ("procesos de acción" de la organización); y otras de carácter personal (actitudes, aptitudes y habilidades de los miembros de la organización). De la combinación de estas competencias básicas distintivas se obtiene la "competencia esencial".

El objeto de la Dirección Estratégica por Competencias es buscar la "competencia esencial" como combinación de las "competencias básicas distintivas", ya que, ella es la encargada de analizar la creación y sostenimiento de la ventaja competitiva. Siendo ésta la resultante de dichas "competencias distintivas", es decir, de lo que quiere ser, lo que hace o sabe, y lo que es capaz de ser y de hacer la empresa, en otras palabras, la expresión de sus actitudes o valores, de sus conocimientos (básicamente explícitos) y de sus capacidades (conocimientos tácitos, habilidades y experiencia).

Una vez vistos estos conceptos fundamentales, y partiendo de las ideas del proyecto Intelect, se puede definir analíticamente el Capital Intelectual. Así podemos ver que este está formado por: 
Donde:

$\mathrm{CH}=$ Capital Humano o conjunto de competencias personales.

$\mathrm{CO}=$ Capital Organizativo o conjunto de competencias organizativas.

$\mathrm{CT}=$ Capital Tecnológico o conjunto de competencias tecnológicas.

$\mathrm{CR}=$ Capital relacional o conjunto de competencias relacionales o con el entorno.

Nota. El Capital Estructural está formado por el CO y el CT.

Si observamos la figura siguiente vemos la estructura y función del Capital Intangible. Esta estructura delinea tres argumentos básicos de la Dirección Estratégica por Competencias:

Las actitudes o valores (personales, organizativas, tecnológicas y relacionales): lo que quiere ser la empresa.

Los conocimientos (explícitos e incorporados en los activos de la empresa, tanto en una como en otra "competencia básica distintiva"): Lo que saber hacer o lo que hace la empresa.

Las capacidades (conocimientos tácitos, habilidades y experiencia): lo que es capaz de ser y de hacer es decir, su saber hacer bien o mejor que los competidores. 
Figura 18: Estructura y Función del Capital Intangible (Bueno, 1998)

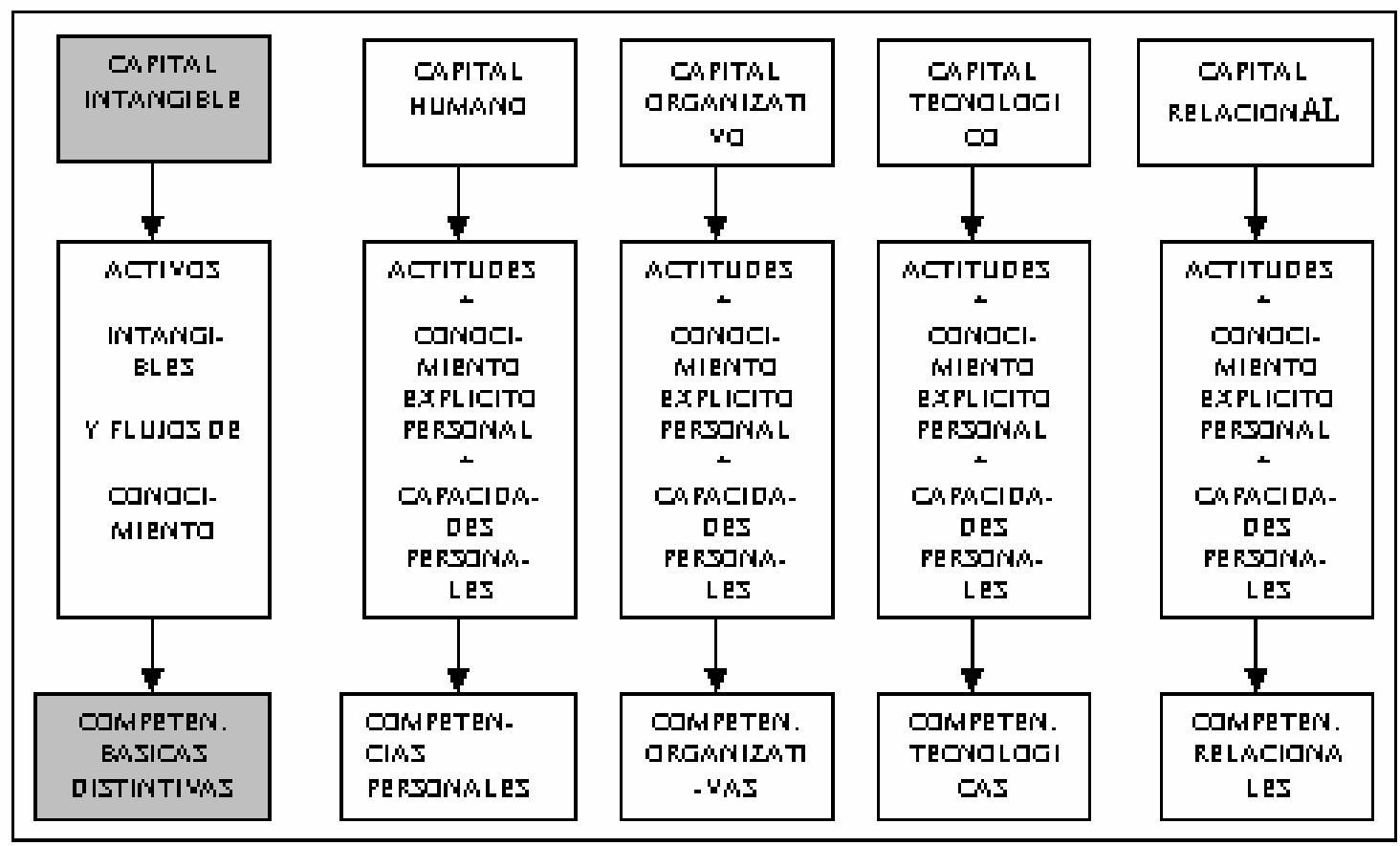

Para Bueno (1998) este modelo permitirá orientar estratégicamente la gestión del conocimiento de la empresa, como forma dinámica de crear nuevos conocimientos que posibiliten mejorar la posición competitiva de la empresa. El modelo ofrece las pautas o guías de actuación siguientes:

- Cómo crear, cómo innovar, y cómo difundir el conocimiento.

- Cómo identificar el papel estratégico de cada "competencia básica distintiva" y de cada uno de sus componentes.

- Cómo conocer o cuales son los valores que las personas incorporan a la organización.

- Cómo saber o cómo crear conocimiento a partir de los conocimientos explícitos y tácitos existentes en la empresa.

- Cómo saber hacer o cómo lograr el desarrollo de capacidades que facilitan la sostenibilidad de la ventaja competitiva.

- Cómo trabajar y compartir experiencias en el seno de la organización. 
- Cómo comunicar e integrar ideas, valores y resultados.

- Cómo comprender colectivamente y cómo liberar los flujos de conocimientos por la estructura organizativa o como proceso que lleve a la empresa a la consideración de "organización inteligente". 


\section{I) NOVA (Camisón y Palacios,1999)}

El objetivo del modelo que proponen es el de medir y gestionar el capital intelectual en las organizaciones. Este modelo va a ser útil para cualquier empresa, independientemente de su tamaño.

Siguiendo la conceptualización seguida por (Bueno, 1998), consideran que el capital intelectual está formado por el conjunto de activos intangibles que generan o generarán valor en un futuro. La gestión del conocimiento hace referencia al conjunto de procesos que permiten que el capital intelectual de la empresa crezca.

Dividen el capital intelectual en cuatro bloques:

Capital humano: Incluye los activos de conocimientos (tácitos o explícitos) depositados en las personas.

Capital organizativo: Abarca los activos de conocimientos sistematizados, explicitados o internalizados por la organización, ya lo sean en:

- Ideas explicitadas objeto de propiedad intelectual (patentes, marcas).

- Conocimientos materializables en activos de infraestructura susceptibles de ser transmitidos y compartidos por varias personas (descripción de invenciones y de fórmulas, sistema de información y comunicación, tecnologías disponibles, documentación de procesos de trabajo, sistemas de gestión, estándares de calidad).

- Conocimientos internalizados compartidos en el seno de la organización de modo informal (formas de hacer de la organización: rutinas, cultura, etc.).

Capital social: Incluye los activos de conocimiento acumulados por la empresa gracias a sus relaciones con agentes de su entorno. 
Capital de innovación y de aprendizaje: Incluye los activos de conocimientos capaces de ampliar o mejorar la cartera de activos de conocimientos de los otros tipos, o sea, el potencial o capacidad innovador de la empresa.

El modelo tiene un carácter dinámico, en la medida en que también persigue reflejar los procesos de transformación entre los diferentes bloques de Capital Intelectual. La consideración conjunta de los stocks y los flujos de Capital Intelectual, añade una gran riqueza al estudio. En otros modelos como el de (Roos et al., 1997), se separa la estática de la dinámica, es decir, no se integran en el mismo modelo.

Una característica diferencial del modelo respecto a los modelos estudiados, es que permite calcular, además de la variación de capital intelectual que se produce entre dos períodos de tiempo, el efecto que tiene cada bloque en los restantes (Capital humano, organizativo, social y de innovación y de aprendizaje).

Por tanto, nos interesa saber entre dos períodos determinados de tiempo:

- La variación de capital intelectual.

- El aumento o disminución de capital entre cada uno de los bloques.

- La contribución de un bloque al incremento/disminución de otro bloque

Para obtener los indicadores necesarios para medir el capital humano, organizativo, social y de innovación y de aprendizaje se han dividido estos bloques en diferentes grupos según la naturaleza de los activos intangibles.

Así los grupos que hemos definido para cada bloque son los siguientes: 


\section{CAPITAL HUMANO}

1. Conocimientos técnicos.

2. Experiencia.

3. Habilidades de liderazgo.

4. Habilidades de trabajo en equipo

5. Estabilidad del personal

6. Habilidad directiva para la prospectiva y el anticipo de retos

\section{CAPITAL ORGANIZATIVO}

1. Conocimientos relativos a cuestiones internas protegidos legalmente (tecnologías, productos, procesos).

2. Conocimientos relativos a cuestiones externas protegidos legalmente (nombre de marca, logotipos).

3. Idoneidad del conocimiento (o grado de disponibilidad de conocimiento diferencial y de valor) empleado en los procesos básicos del negocio (procesos críticos sobre los cuáles se sostienen las ventajas competitivas de la empresa), así como su nivel de explicitación y documentación que permita hacer ese conocimiento compartible y reutilizable, avanzando así hacia una explotación eficiente de los mismos. Es pues el saber hacer organizativo empleado conjuntamente con los activos tangibles. Se puede medir por indicadores de los resultados (eficiencia) del proceso o mediante indicadores de los elementos que inciden en dichos resultados (grado de documentación y rutina del proceso -alcanzado con manuales o estándares de calidad, por ejemplo-, adecuación de la tecnología empleada -grado de obsolescencia de los medios físicos y de los 
conocimientos tecnológicos empleados-,grado de inimitabilidad y diferenciación de las tecnologías de proceso empleadas).

4. Idoneidad del conocimiento (o grado de disponibilidad de conocimiento diferencial y de valor) de producto, así como su nivel de explicitación y documentación que permita hacer ese conocimiento compartible y reutilizable, avanzando así hacia el logro de productos de mayor calidad, con menor tasa de errores, etc. Se puede medir por indicadores de los resultados (grado de diversificación de la cartera de producto de la empresa, eficacia del producto) o mediante indicadores de los elementos que inciden en dichos resultados (grado de documentación y rutina de la tecnología del producto, grado de inimitabilidad y diferenciación de las tecnologías de producto empleadas).

5. Acumulación de conocimiento basado en la curva de experiencia.

6. Disponibilidad de mecanismos o programas de gestión del conocimiento.

7. Grado de uso efectivo del conocimiento existente (número de consultas, tiempo medio de consulta de bases de datos, etc.).

8. Disponibilidad de mecanismos sociales de transmisión y comunicación de conocimiento (distribución de informes escritos, reuniones de presentación, procedimientos de benchmarking interno como compartición de las mejores prácticas entre departamentos, creación de grupos interdisciplinares, rotación interdepartamental, etc.).

9. Grado de uso efectivo de los mecanismos de transmisión y comunicación de conocimiento (por ejemplo, con indicadores como el número de foros electrónicos internos establecidos), principalmente mediante la implantación de tecnologías de la información (número de PC por empleado, inversión en TI por empleado, gastos de formación en TI/inversión en TI) y de su uso efectivo (beneficios derivados, como reducción de gastos administrativos). 
10. Disponibilidad y eficacia de los sistemas de captación de información relevante y actualizada sobre nuevas necesidades de los clientes, cambios en el entorno competitivo que pueden generar nuevos mercados/clientes, etc. (sistemas de inteligencia de marketing, bases de datos del entorno o de los competidores, participación en foros sectoriales, etc.).

11. Cultura organizativa compartida y asumida por el personal de la organización.

12. Valores culturales, actitudes y comportamientos que estimulan la creatividad y la innovación (confianza, apertura al diálogo, asunción de riesgos, experimentación, delegación y autorresponsabilización, reflexión -no separación entre pensar y hacer-, y aceptación de los errores).

13. Conocimiento de las variables clave para satisfacer a los empleados de la empresa.

14. Definición clara de la misión de la empresa.

15. Conocimiento de las competencias distintivas origen de las ventajas competitivas de la empresa.

16. Grado de conocimiento y alineación del personal con la estrategia.

17. Desarrollo de las competencias mediante la formación.

18. Desarrollo de las competencias mediante el aprendizaje en el trabajo (asignación de tareas retadoras, trabajo en equipo e interdisciplinar, polivalencia).

19. Desarrollo de las competencias mediante la comunicación y el debate (por ejemplo, con foros de debate electrónicos). 


\section{CAPITAL SOCIAL}

1. Conocimiento de los clientes relevantes (conocimiento de su perfil, identificación de las mejores clientes por rentabilidad y tamaño).

2. Conocimiento de las variables clave para fidelizar a los clientes.

3. Conocimiento de las variables clave para satisfacer a los clientes (conocimiento de sus necesidades y de cómo valoran los distintos atributos de los productos competidores).

4. Intensidad de la relación con el cliente para crear conocimiento (número de proyectos conjuntos, reuniones de trabajo o colaboraciones en I+D con clientes, \% personal trabajando en casa del cliente o viceversa).

5. Intensidad de la relación con el proveedor para crear conocimiento (número de proyectos conjuntos, reuniones de trabajo o colaboraciones en I+D con proveedores, \% personal trabajando en casa del proveedor o viceversa).

6. Recursos de conocimiento compartidos merced a la localización de la empresa en distritos industriales.

7. Intensidad y estructuración de las alianzas estratégicas establecidas por la empresa con competidores, clientes, proveedores, centros tecnológicos, universidades u otras organizaciones para crear conocimiento.

8. Intensidad y estructuración de los mecanismos para captar información sobre los competidores (por ejemplo, actividades de benchmarking).

9. Capacidad de captación de conocimiento mediante la interacción con otros agentes (administración pública, entorno medioambiental, asociaciones de consumidores, etc.). 


\section{CAPITAL DE INNOVACIÓN Y DE APRENDIZAJE}

1. Creatividad y capacidad de innovación

2. Grado de sistematización de la innovación y la creatividad (por ejemplo, mediante la definición de estrategias de I+D).

3. Conocimiento de los procesos de $I+D+I$ para el lanzamiento de nuevos productos/procesos

4. Esfuerzos dedicados a la actividad innovadora frente a la actividad ordinaria (gastos de I+D sobre gastos de producción).

5. Eficacia de los esfuerzos de difusión de conocimientos por la empresa para ampliar su base de clientes (tareas de educación de los clientes, actividades de comunicación y de reconocimiento a la empresa, presencia pública de la empresa en conferencias, publicaciones, ferias, etc.).

Con el fin de realizar una validación del modelo y de aplicar en el mundo empresarial aquellos conceptos que han desarrollado en el modelo, se ha creado el Club de Gestión del Conocimiento y la Innovación de la Comunidad Valenciana. Está formado por más de 30 empresas entre las que destacan (Bancaja, Caja de Ahorros del Mediterráneo, Economía3, Famosa, J'Hayber, Kelme, Lladró, Panamá Jack, Reebok España, Runner Transportes, Hoteles Sidi, Tau Cerámica, etc.).

El club nace para alimentar el debate intelectual sobre las ideas de gestión y, sobre todo, cómo convertirlas en práctica empresarial. Sus objetivos fundamentales son la promoción, el apoyo y la mejora continua del conocimiento en gestión a través de la cooperación y la comunicación permanentes entre los agentes públicos y privados implicados. 


\subsubsection{Modelos prácticos de Gestión del Conocimiento}

\section{A) KPMG CONSULTING (TEJEDOR Y AGUIRRE, 1998)}

El modelo parte de la siguiente pregunta: ¿qué factores condicionan el aprendizaje de una organización y qué resultados produce dicho aprendizaje? Para responder a esta pregunta KPMG realiza un esfuerzo que produce un modelo cuya finalidad es la exposición clara y práctica de los factores que condicionan la capacidad de aprendizaje de una organización, así como los resultados esperados del aprendizaje.

Una de las características esenciales del modelo es la interacción de todos sus elementos, que se presentan como un sistema complejo en el que las influencias se producen en todos los sentidos.

La estructura organizativa, la cultura, el liderazgo, los mecanismos de aprendizaje, las actitudes de las personas, la capacidad de trabajo en equipo, etc., no son independientes, sino que están conectados entre sí.

\section{Los factores condicionantes del aprendizaje.}

Los factores que configuran la capacidad de aprender de una empresa han sido estructurados en los tres bloques siguientes, atendiendo a su naturaleza:

1.- Compromiso firme y consciente de toda la empresa, en especial de sus líderes, con el aprendizaje generativo, continuo, consciente y a todos los niveles.

El primer requisito para el éxito de una iniciativa de gestión del conocimiento es reconocer explícitamente que el aprendizaje es un proceso que debe ser gestionado y comprometerse con todo tipo de recursos. 
Capítulo 2: Delimitación de la GC

2.- Comportamientos y mecanismos de aprendizaje a todos los niveles. La organización como ente no humano sólo puede aprender en la medida en que las personas y equipos que la conforman sean capaces de aprender y deseen hacerlo.

Disponer de personas y equipos preparados es condición necesaria pero no suficiente para tener una organización capaz de generar y utilizar el conocimiento mejor que las demás. Para lograr que la organización aprenda es necesario desarrollar mecanismos de creación, captación, almacenamiento, transmisión e interpretación del conocimiento, permitiendo el aprovechamiento y utilización del aprendizaje que se da en el nivel de las personas y equipos. Los comportamientos, actitudes, habilidades, herramientas, mecanismos y sistemas de aprendizaje que el modelo considera son:

- La responsabilidad personal sobre el futuro (proactividad).

- La habilidad de cuestionar los supuestos (modelos mentales).

La visión sistémica (ser capaz de analizar las interrelaciones existentes dentro del sistema, entender los problemas de forma no lineal y ver las relaciones causa-efecto a lo largo del tiempo).

- La capacidad de trabajo en equipo.

- Los procesos de elaboración de visiones compartidas.

- La capacidad de aprender de la experiencia.

- El desarrollo de la creatividad.

- La generación de una memoria organizacional.

- Desarrollo de mecanismos de aprendizaje de los errores.

- Mecanismos de captación de conocimiento exterior.

○ Desarrollo de mecanismos de transmisión y difusión del conocimiento. 
Si se consigue que las personas aprendan, pero no convierten ese conocimiento en activo útil para la organización, no se puede hablar de aprendizaje organizacional. La empresa inteligente practica la comunicación a través de diversos mecanismos, tales como reuniones, informes, programas de formación internos, visitas, programas de rotación de puestos, creación de equipos multidisciplinares, $\ldots$.

3.- Desarrollo de las infraestructuras que condicionan el funcionamiento de la empresa y el comportamiento de las personas y grupos que la integran, para favorecer el aprendizaje y el cambio permanente.

Pero no debemos olvidar que las condiciones organizativas pueden actuar como obstáculos al aprendizaje organizacional, bloqueando las posibilidades de desarrollo personal, de comunicación, de relación con el entorno, de creación, etc.

Las características de las organizaciones tradicionales que dificultan el aprendizaje:

- Estructuras burocráticas.

- Liderazgo autoritario y/o paternalista.

- Aislamiento del entorno.

- Autocomplacencia.

- Cultura de ocultación de errores.

○ Búsqueda de homogeneidad.

- Orientación a corto plazo.

- Planificación rígida y continuista.

○ Individualismo. 
En definitiva, la forma de ser de la organización no es neutra y requiere cumplir una serie de condiciones para que las actitudes, comportamiento y procesos de aprendizaje descritos puedan desarrollarse.

\section{Los resultados del aprendizaje.}

Una vez analizados los factores que condicionan el aprendizaje, el modelo refleja los resultados que debería producir ese aprendizaje. La capacidad de la empresa para aprender se debe traducir en:

○ La posibilidad de evolucionar permanentemente (flexibilidad).

- Una mejora en la calidad de sus resultados.

- La empresa se hace más consciente de su integración en sistemas más amplios y produce una implicación mayor con su entorno y desarrollo.

- El desarrollo de las personas que participan en el futuro de la empresa. 


\section{B) MODELO ANDERSEN (ARTHUR ANDERSEN, 1999)}

Andersen (1999) reconoce la necesidad de acelerar el flujo de la información que tiene valor, desde los individuos a la organización y de vuelta a los individuos, de modo que ellos puedan usarla para crear valor para los clientes.

\section{¿Qué hay de nuevo en este modelo?:}

Desde la perspectiva individual, la responsabilidad personal de compartir y hacer explícito el conocimiento para la organización.

Desde la perspectiva organizacional, la responsabilidad de crear la infraestructura de soporte para que la perspectiva individual sea efectiva, creando los procesos, la cultura, la tecnología y los sistemas que permitan capturar, analizar, sintetizar, aplicar, valorar y distribuir el conocimiento.

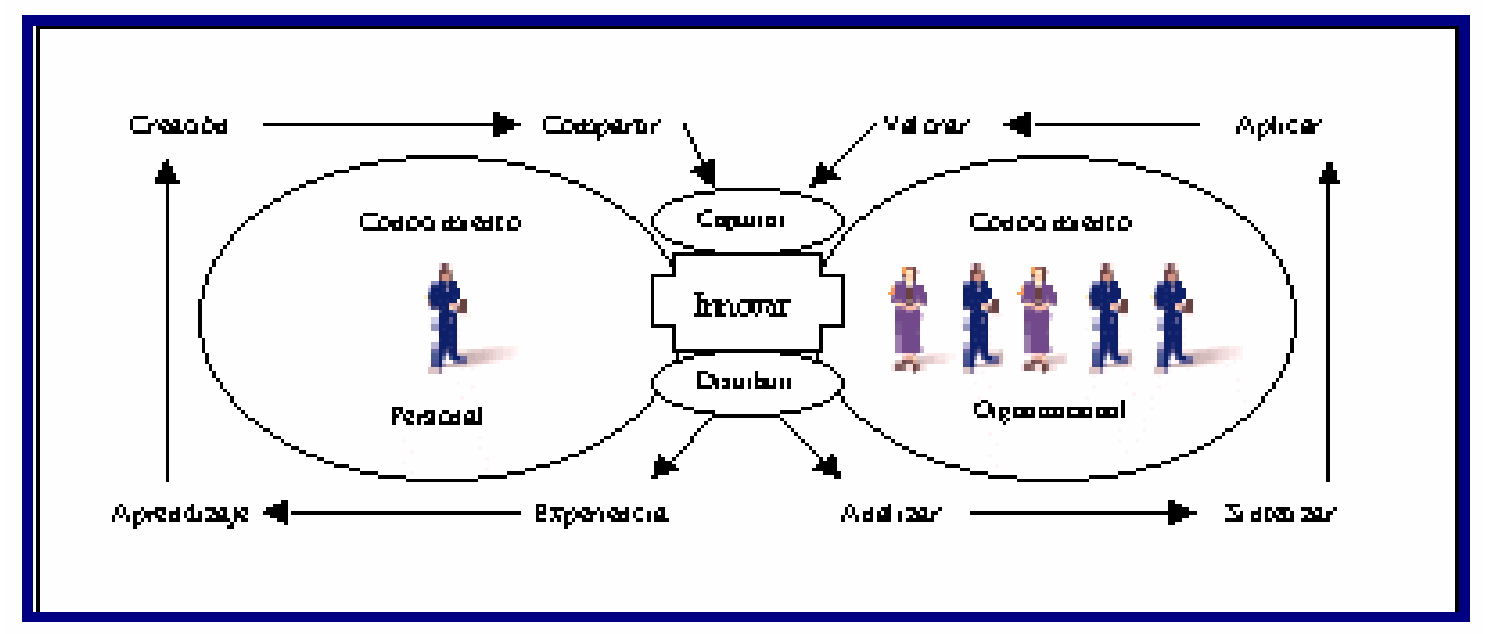

Figura 19: Modelo de Gestión del Conocimiento de Arthur Andersen (1999)

Se han identificado dos tipos de sistemas necesarios para el propósito fijado:

\section{1.- Sharing Networks}

Acceso a personas con un propósito común a una comunidad de práctica. Estas comunidades son foros virtuales sobre los temas de mayor interés de un determinado servicio o industria. Existen más de 80 comunidades de prácticas. 
- Ambiente de aprendizaje compartido

- Virtuales: AA on line, bases de discusiones, etc.

o Reales: Workshops, proyectos, etc.

\section{2.- Conocimiento "empaquetado"}

La espina dorsal de esa infraestructura se denomina "Arthur Andersen Knowledge Space", que contiene:

- Global best practices.

- Metodologías y herramientas.

- Biblioteca de propuestas, informes... 


\subsection{UN MODELO DE GC: PRINCIPIOS Y PRÁCTICAS}

Para determinar nuestro modelo de GC, seguimos la opinión de Palacios (2003), que concibe la GC como la de un sistema directivo que captura aspectos establecidos de organización y los amplía para proporcionar una metodología práctica. Define el contenido del constructo GC a partir de dos dimensiones: principios y prácticas.

Los principios hacen referencia a los objetivos deseados por la organización. Se corresponder con un nivel de investigación más abstracto o relacionado con las ideas. La existencia de unos principios básicos guía la acción organizativa.Los principios se implementan a través de un conjunto de prácticas y técnicas, que representan todas las actividades y los métodos utilizados para implantar la GC.

Las prácticas se corresponden con un nivel de investigación más práctico y perceptible. Desde esta dimensión, se entiende la GC como una innovación organizativa que comporta cambios importantes en la implantación de la estrategia y en las prácticas de dirección tradicionales. Los trabajos que centran su atención en el proceso de implantación de la GC se han concentrado en las áreas críticas o prácticas más relevantes para que el sistema sea aplicado eficazmente.

Así, Palacios (2003) parte del siguiente concepto de GC: "La GC es una herramienta de gestión que se caracteriza por un conjunto de principios junto con una serie de prácticas y técnicas a través de las que se introducen los principios, cuyo objetivo es el de crear, convertir, difundir y aprovechar el conocimiento".

Esta concepción del constructo, a partir de principios y prácticas, permite comprobar si el sistema de dirección se afronta en base a las creencias y valores que recogen los principios de la GC, y más importante todavía, si esos principios se materializan en un conjunto de prácticas y técnicas en su comportamiento habitual. 
Existen muy pocos trabajos en la literatura en los que se señalen de forma explícita los principios de la GC. La literatura se refiere a facilitadotes 0 impulsores de la generación de conocimiento e, indistintamente, a características de la organización que aprende.

Martinez et al. (2001:7) distinguen entre principios específicos y genéricos. Los principios específicos de la GC son aquellos que orientan específicamente la GC con el objeto de potenciar la generación de conocimiento en la organización y la cristalización del conocimiento en forma de rutinas organizativas. Por el contrario, los principios genéricos hacen referencia al planteamiento global existente en la dirección de la empresa, sin referirse de forma específica a la GC, que facilitan sustancialmente su aplicación de forma sistemática.

En este sentido, podemos destacar como principios específicos.

1. Liderazgo y compromiso de la dirección con la GC.

2. Participación y compromiso de los empleados en la generación de conocimiento y en el deseo de aprender y mejorar.

3. Cultura propicia al aprendizaje y al cambio.

4. Atención, vigilancia y seguimiento estrecho y continuado de las variables significativas de su entorno general y específico.

5. Cooperación con clientes y proveedores.

6. Cooperación en el ámbito interno de la empresa.

7. Trabajo en equipo.

8. Fomento de transferencia de información y conocimiento relevante.

9. Análisis exhaustivo del diseño de procesos y productos.

10. Mejora continua de los conocimientos, procesos, productos y servicios. 
Por otro lado, desde el punto de vista de los principios genéricos, Martinez (2001) destaca:

1. Planteamiento estratégico.

2. Propósito estratégico compartido.

3. Generación de un clima organizativo propicio al aprendizaje.

4. Compensaciones adecuadas a los stakeholders.

5. Asignación de los medios necesarios.

6. Diseño de la organización que facilite la eficacia y eficiencia de la empresa.

Davenport (1996) desarrolla un conjunto de principios sobre GC, que más que un conjunto de valores y creencias a seguir por la organización, son como una serie de recomendaciones o consejos prácticos a seguir:

1. La gestión efectiva del conocimiento requiere de soluciones híbridas que involucren tanto a las personas como a la tecnología.

2. La GC tiene una dimensión altamente política.

3. La GC requiere de gestores de conocimiento.

4. La GC se beneficia más de los mapas y mercados, que de los modelos y jerarquías.

5. Compartir y utilizar conocimiento son habitualmente actos poco naturales.

6. La GC significa mejorar los procesos de trabajo de conocimiento.

7. El acceso al conocimiento es sólo el principio. La GC nunca finaliza.

8. La GC requiere de un contrato que incluya temas relacionados con la propiedad intelectual. 
Palacios (2002) desarrolla una concepción de la GC en una serie de principios y prácticas, que podemos sintetizar en los siguientes:

1. Orientación hacia el desarrollo, la transferencia y la protección del conocimiento.

2. Aprendizaje continuo de la organización

3. Entender la organización como un sistema global

4. Desarrollo de una cultura innovadora que impulse proyectos de $I+D+I$

5. Enfoque en las personas

6. Gestión por competencias y desarrollo de nuevas competencias. 


\subsection{GC, AO Y CAPITAL INTELECTUAL}

Camisón (2002) señala que el enfoque basado en el aprendizaje organizativo (AO) y la GC son dos corrientes de pensamiento paralelas, cuya convergencia no acaba de progresar. La primera presenta una inspiración más sociológica y la segunda adquiere un carácter más económico.

Sin embargo, existe un vínculo muy amplio entre el $A O$ y la $\mathrm{GC}$, en la medida en que el conocimiento se genera a través de procesos de aprendizaje, siendo éste un mecanismo individualizado que depende de la capacidad de cada individuo y de sus experiencias de aprendizaje pasadas (Revilla, 1996). Ambas perspectivas trabajan sobre los mismos cuatro niveles (individual, grupal, organizativo e interorganizativo).

Por lo que respecta a la perspectiva del capital intelectual, la podemos considerar como una orientación pragmática al enfoque basado en el conocimiento. De hecho, uno de los principales objetivos de la GC es mejorar y explotar el capital intelectual de una organización.

Desde este punto de vista, no es tan necesario desarrollar potentes sistemas de medida que nos determinen la magnitud del capital intelectual de una organización, sino determinar aquellos bloques (humano, organizativo, relacional, ...) que lo forman, y analizar en qué medida pueden ser mejorados a través de una introducción efectiva de la GC.

Roos et al. (1997) sostienen que el capital intelectual engloba a todos los recursos intangibles de la organización. Bueno (1998) afirma que este término se emplea para designar el conjunto de activos de una sociedad que, pese a no estar reflejados en los estados contables tradicionales, generan o generarán valor para la empresa del futuro.

El capital intelectual se considera como un constructo multidimensional de segundo orden. Sus subdominios o bloques suelen incluir al capital humano, organizativo y relacional. 
- Capital Humano: Incluye los activos de conocimiento (tácitos o explícitos) depositados en las personas. No únicamente son importantes los conocimientos y destrezas adquiridas por un empleado, sino que también es muy importante su relación con el resto de empleados con el fin de crear grupos de trabajo dentro de la empresa (Lado y Wilson, 1994). La magnitud de este capital viene condicionada por el grado de compromiso de cada empleado, factores como su motivación, el grado de adecuación de los objetivos individuales con los objetivos de grupo, etc.

De forma similar, Hudson (1993) define el capital humano como una combinación de herencia genética, educación, experiencia, actitudes sobre la vida y los negocios. Bontis (1998) describe el capital humano como la capacidad colectiva de la empresa para extraer las mejores soluciones a partir del conocimiento de sus individuos.

- Capital Organizativo: Abarca los activos de conocimiento sistematizados, explicitados o internalizados por la organización, ya sean en ideas explicitadas objeto de propiedad intelectual (patentes, marcas), conocimientos materializables en activos de infraestructura susceptibles de ser transmitidos y compartidos por varias personas (invenciones y formulas, sistemas de información y comunicación, tecnologías, documentación de procesos de trabajo, sistemas de gestión, estándares de calidad), o conocimientos internalizados, compartidos en el seno de la organización de manera informal (rutinas, cultura, etc.)

Roos et al. (1997: 42) describen el capital organizativo como "/o que queda en la empresa cuando los empleados se van a casa por la noche". Las empresas con un capital organizativo especialmente desarrollado, están dotadas de una cultura que permite a sus empleados intentar cosas nuevas, aprender, fallar, etc. 
- Capital Relacional: Incluye los activos de conocimiento acumulados por la empresa gracias a sus relaciones con agentes de su entorno. En un principio se utilizó el término Capital Cliente, pero posteriormente se amplió para tener en cuenta el conocimiento que subyace en todas las relaciones que una organización desarrolla con competidores, proveedores, asociaciones, gobierno, y en definitiva, con todos los agentes que interactuan en su entorno.

El cliente ocupa un papel estelar en este bloque, por lo que todos aquellos aspectos relacionados con su satisfacción y fidelidad deben ser conocidos por la empresa, con el fin de proporcionarle un mejor servicio (Sullivan, 1998; Rastogi, 2000; Bontis, 2000).

El capital humano, a diferencia del organizativo y del relacional no es propiedad de la empresa. Un empleado puede cambiar de empresa con lo que los conocimientos que están depositados en ese individuo se van con él. De hecho, uno de los principales objetivos de la GC es solucionar este problema, es decir, se han de habilitar mecanismos en la empresa para transformar el conocimiento de los empleados en activos de propiedad intelectual protegidos por la ley, tales como patentes, copyright, marcas de venta, secretos de venta, tecnología registrada y know-how. A su vez, puede disponer de datos objetivos sobre el conocimiento útil que aporta cada empleado o cada grupo a la empresa. 
A continuación se muestra la conceptuación de Bontis (1998) de capital intelectual, distinguiendo cada uno de los bloques y con un breve resumen de las características de cada uno.

$$
\begin{gathered}
\text { CAPITAL } \\
\text { INTELECTUAL }
\end{gathered}
$$

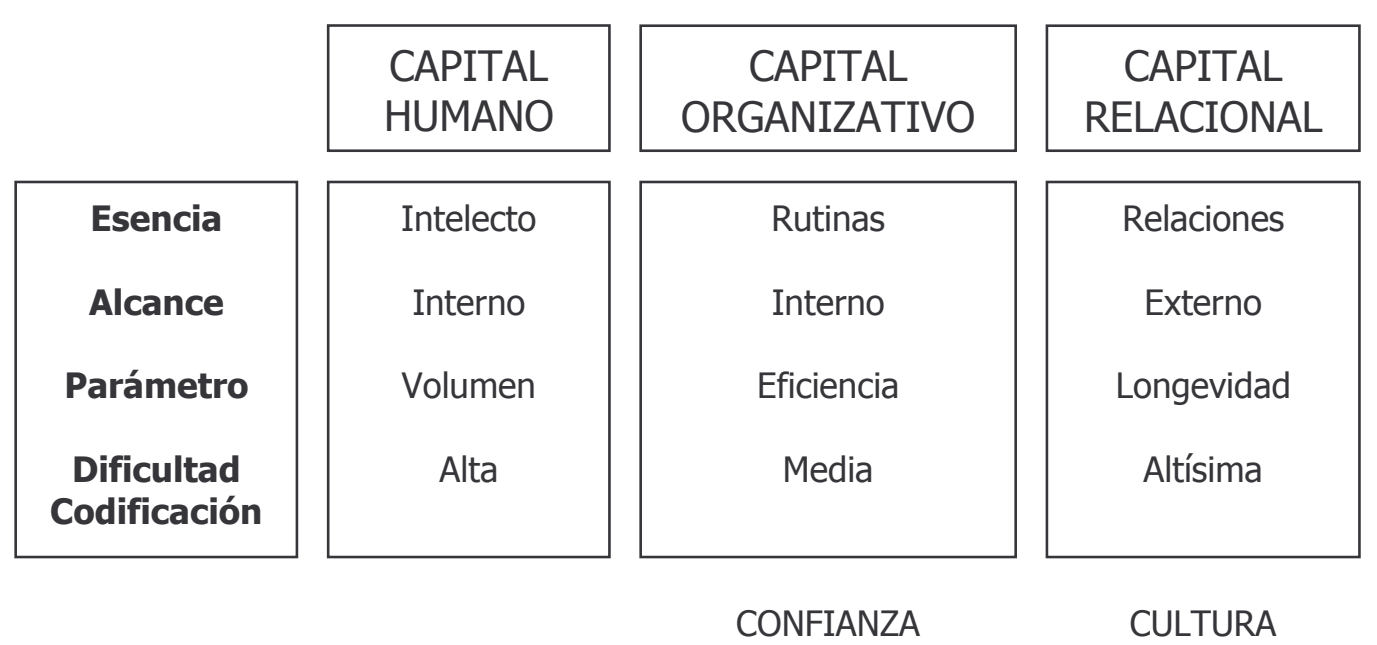

Figura 20. Conceptuación del capital intelectual (Bontis, 1998) 


\section{CAPÍTULO 3:}

\section{DELIMITACIÓN CONCEPTUAL DE LAS COMPETENCIAS DIRECTIVAS}

3.0. OBJETIVOS Y CONTENIDOS DEL CAPÍTULO

3.1. INTRODUCCIÓN A LA GESTIÓN POR COMPETENCIAS:

MODELOS DE DIRECCIÓN

3.2. INTRODUCCIÓN AL CONCEPTO DE COMPETENCIAS DIRECTIVAS

3.3. COMPETENCIAS DIRECTIVAS: DEFINICIONES Y GLOSARIO 


\subsection{OBJETIVOS Y CONTENIDOS DEL CAPÍTULO}

Nuestro mundo es complejo, cambiante y global. Es en este entorno donde las empresas, en tanto que organizaciones humanas, han de desarrollar su actividad. Por esta razón, es esencial comprender cómo construir, gestionar e integrar las fuerzas que cooperan para lograr la supervivencia a largo plazo de la empresa en cumplimiento de su misión. $Y$ entre esas fuerzas, las más importantes y complejas son, precisamente, las personas.

Una empresa es una organización de personas, es decir, un conjunto de personas que trabajan de forma coordinada para conseguir unos objetivos que a todos interesan, aunque sea por motivos diferentes (Perez Lopez, J.A., 1991). En cualquier persona que trabaja en una organización, se dan unos procesos básicos que se pueden representar con el siguiente esquema (Cardona, P., 2001)

Figura 21: Sistema de Gestión del Talento (Cardona, 2001)

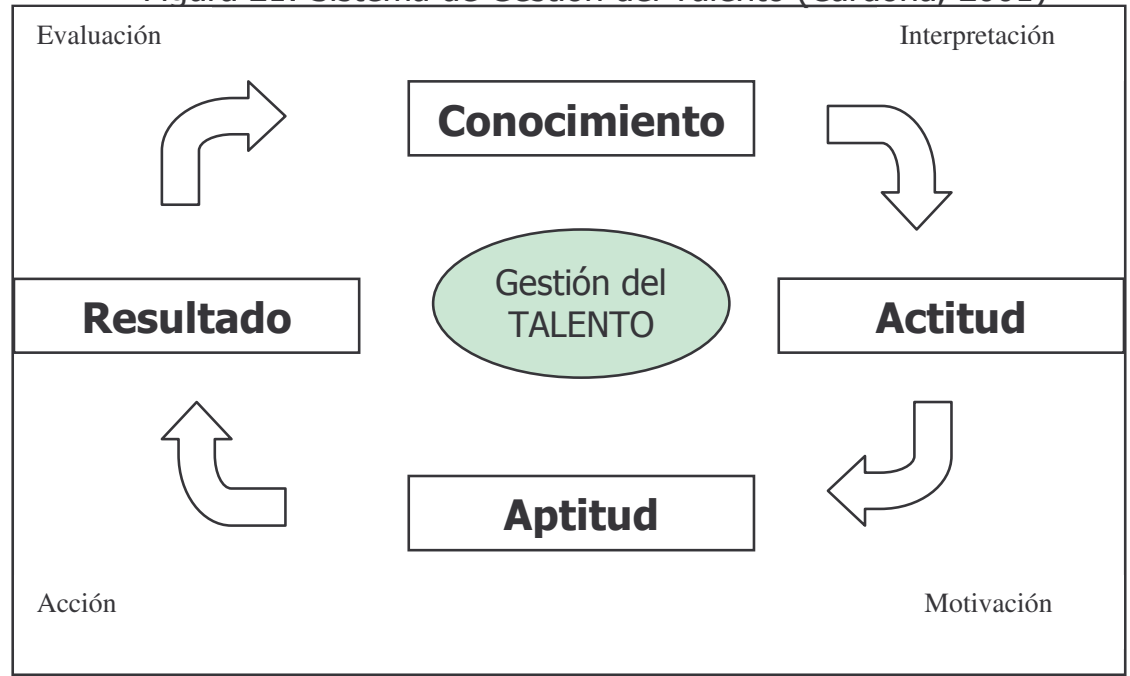

Cada una de las personas que integran la organización debe poseer un cierto tipo de conocimiento sobre la empresa para realizar su trabajo. Este input produce una concepción concreta sobre el rol del empleado dentro de la organización: quién soy en este lugar. Esta concepción, a su vez, da lugar en el empleado a una cierta actitud más o menos proactiva y participativa, que es como el pozo del que surgen las motivaciones concretas. El tipo de motivación que se produce en él como resultado de esta actitud llevará al desarrollo de 
diferentes tipos de aptitudes o talentos que, a través de las acciones cotidianas, producirán unos resultados específicos. Finalmente, estos resultados serán evaluados, y esta valoración, a su vez, es un nuevo conocimiento que refuerza o no la identidad del empleado en esa organización.

El comportamiento de las personas en la empresa y, en general, en el entorno profesional, no depende exclusivamente de sus conocimientos técnicos y aptitudes. El sistema de gestión y el estilo de dirección de la empresa van a provocar la adopción de actitudes y el desarrollo de motivaciones de diferente tipo: ambos elementos tienen tanta o más influencia sobre el resultado final como aptitudes y conocimientos del empleado.

La evolución de las estructuras organizativas puede analizarse a la luz de este esquema básico. Estaríamos ante tres grandes modelos de organización, cada uno de los cuales presenta un estilo concreto de dirección: la organización jerárquica (Dirección por Tareas), la organización profesional (Dirección por Objetivos), y la organización competente (Dirección por Objetivos y Competencias). 


\subsection{INTRODUCCIÓN A LA GESTIÓN POR COMPETENCIAS: MODELOS DE DIRECCIÓN}

\subsubsection{La organización jerárquica y la Dirección por Tareas}

En estrecha relación con la organización científica del trabajo de Fayol y Taylor. Su aspecto central es la tarea, es decir, el qué hay que hacer. Tradicionalmente, el vínculo que une el trabajo de las personas que integran la empresa con los objetivos de la misma es el puesto de trabajo, entendido como el conjunto de tareas que un empleado debe realizar para que la empresa pueda lograr sus objetivos.

La Dirección por Tareas genera una posición del subordinado puramente reactiva: recibe un conjunto de órdenes, a través de las que se transmiten las tareas a realizar, y se espera de él únicamente que las realice. La motivación del empleado es puramente extrínseca: la razón por la que realiza estas tareas es para recibir alguna recompensa a cambio. Su papel consiste en comprender las órdenes recibidas y ejecutarlas. Por ello, el talento que desarrolla será alto en calidad pero bajo en iniciativa: el talento dependiente. Este empleado será evaluado en función de los errores cometidos. Los aspectos básicos de esta forma de organización aparecen en el siguiente gráfico

Figura 22: Organización Jerárquica (Cardona, 2001)

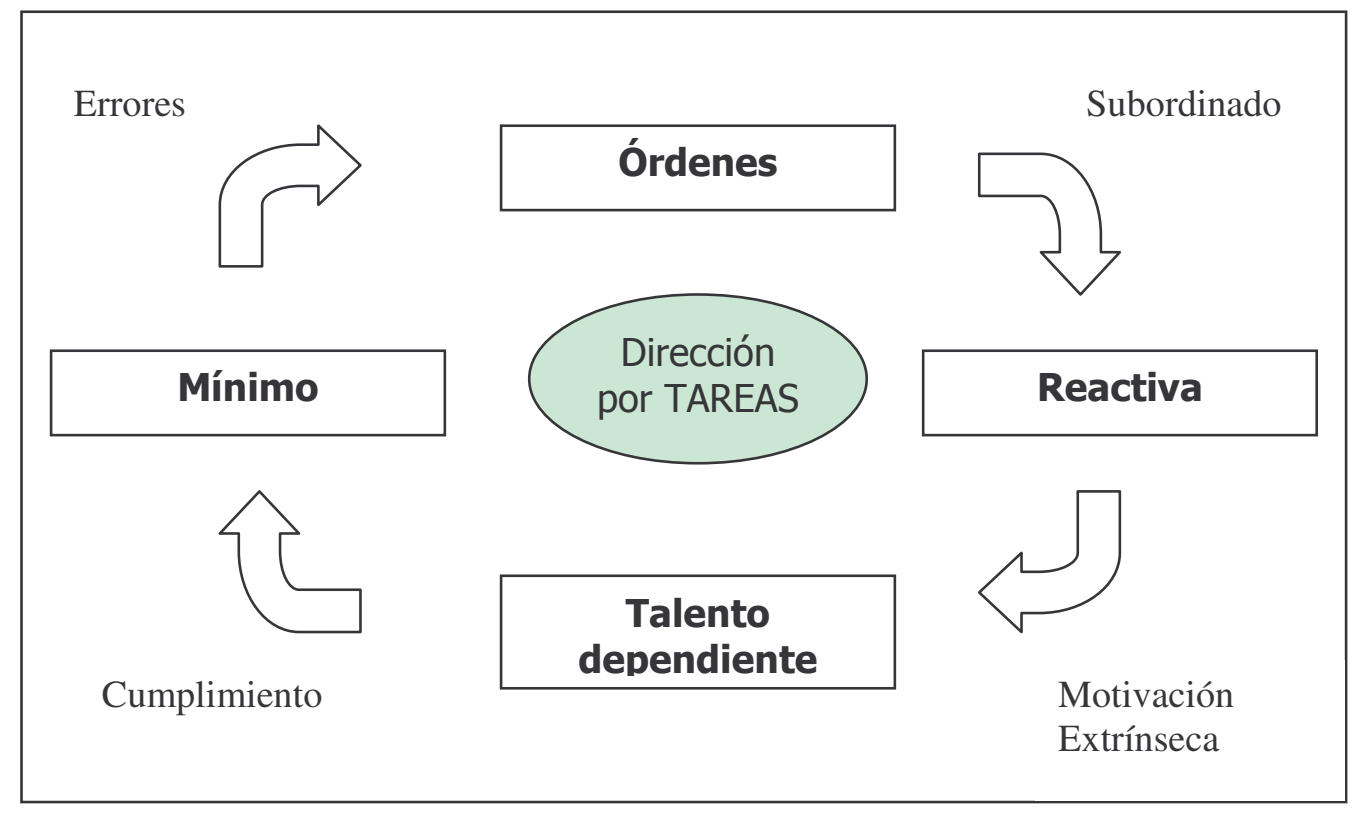


Todo ello se produce por un estilo burocrático de dirección caracterizado por el "ordeno y mando"- que está demostrando no ser el más eficiente a la hora de liderar entornos cambiantes. Además de la incapacidad para el cambio, el desempeño de un talento dependiente se ajusta a mínimos, es decir, hará sólo aquello que por contrato deba hacer, puesto que la única fuente de motivación es la extrínseca.

El enfoque tradicional basado en la definición de puestos de trabajo implica un proceso de asignación de personas a puestos. En la selección, esto se traduce en la búsqueda de perfiles que se ajusten a las características y requerimientos del puesto, determinadas a partir de la definición exhaustiva de las tareas a realizar. Parece lógico que, desde esta perspectiva, se busquen criterios objetivos, cuantificables, aptitudes y conocimientos cuya posesión en cierto grado se pueda demostrar a través de tests o diferentes sistemas de medida.

Esta forma de organización requiere, por lo general, estructuras rígidas y jerarquizadas, con estrictos sistemas de control. En definitiva, se trata de un tipo de organización que no se adapta fácilmente al cambio ni al entorno actual. "El desarrollo económico y la correspondiente búsqueda de la eficiencia de costes y la flexibilidad están llevando no sólo a la destrucción del puesto a través de la racionalización y el outsourcing, sino también al cambio radical dentro de la empresa en cuanto a la organización del trabajo: por ejemplo, las estructuras piramidales reducen sus niveles, se pone el énfasis en los procesos de creación de valor, ganan importancia los resultados frente a las tareas, y las fronteras entre los departamentos se diluyen."(Nybo, G., 2004)

\subsubsection{La organización profesional y la Dirección por Objetivos}

La reducción de niveles organizativos y la simplificación de los procedimientos permiten a las empresas tener una mayor flexibilidad a la hora de adaptarse y adelantarse a las necesidades de un entrono en el que los cambios se han acelerado de manera extraordinaria. Para conseguir esta descarga de la estructura, el foco de atención se desplaza de las tareas a los 
objetivos. Es estilo de dirección que aparece en esta nueva forma de organización profesional se basa en la delegación (empowerment). El empleado ya no recibe una orden sin más: conoce los objetivos de la empresa y concibe su trabajo como aportación al logro de los mismos. Por eso, no se ve a sí mismo como un simple subordinado, sino como un profesional ante un reto. La actitud que produce esta nueva identidad ya no es reactiva, sino proactiva, con iniciativa y aportación de valor a sus tareas.

La motivación que acompaña a este modo de dirección es más compleja. No se trata sólo de conseguir un sueldo o unos incentivos económicos: el empleado tiene también expectativas respecto a su propio desarrollo profesional. Esta fuente de motivación es la que se conoce como motivación intrínseca, e impulsa al subordinado a probar cosas nuevas, a arriesgar y a superar las posibles dificultades que conlleva todo proceso de aprendizaje. De ahí que con el tiempo desarrolle un tipo de talento diferente del que obtiene el subordinado en el modelo de Dirección por Tareas. El talento del profesional es más independiente tanto en su origen - porque no requiere las continuas órdenes del jefe - como por su fin: porque va en busca de sus propios objetivos.

Figura 23: Organización Profesional (Cardona, 2001)

Comparación

(competitiva)
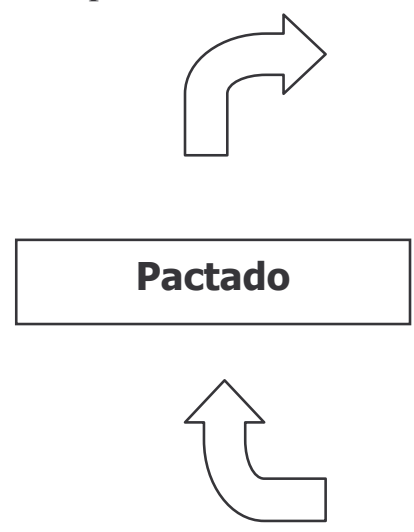

Éxito (personal)

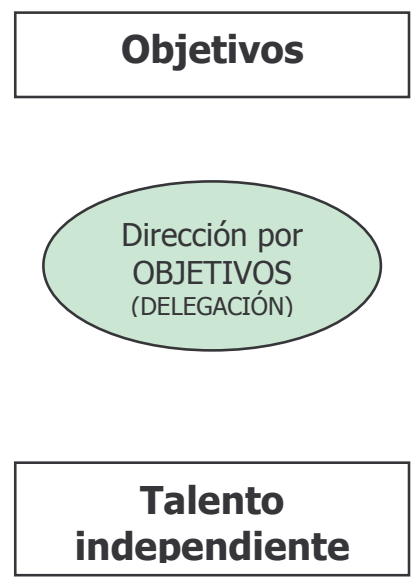

independiente

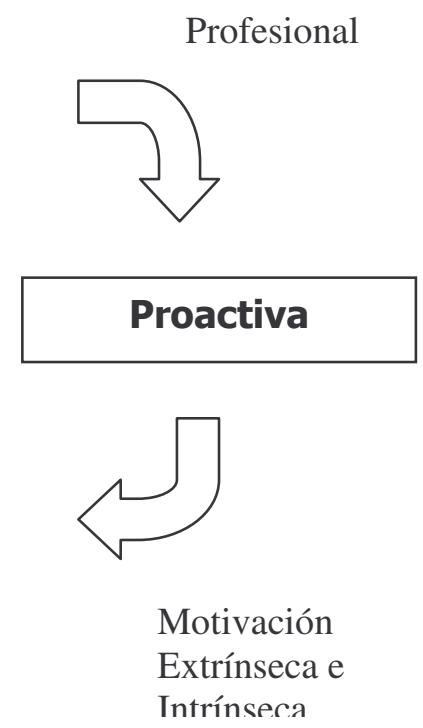


La Dirección por Objetivos supone un importante avance respecto a la Dirección por Tareas. El empleado es considerado como algo más que un mero subordinado, sin capacidad de decisión. El profesional dispone de una mayor autonomía a la hora de diseñar y realizar las tareas que le conducirán al logro de los objetivos. Los objetivos definen qué hacer, pero no cómo hay que hacerlo. Este grado de libertad produce un talento de mayor calidad que el de la organización jerárquica, pero a la vez abre la posibilidad de que se consigan los objetivos individuales de modos no óptimos, e incluso de forma dañina para la empresa a medio o largo plazo. Además, el enfoque de objetivos produce unas relaciones competitivas entre empresa y empleado $y$, en muchas ocasiones, entre los mismos empleados.

\subsubsection{La organización competente y la Dirección por}

\section{Competencias}

La pérdida de relevancia del puesto de trabajo como definición de tareas a realizar y las limitaciones de la Dirección por Objetivos son paralelas al cada vez mayor interés por las capacidades, conocimientos y actitudes de la persona que desempeña ese conjunto de tareas: esta es la base del enfoque basado en competencias. Lawler E.E., (1994) propone este enfoque considerando que, ante un entorno global, competitivo y cambiante, el conocimiento, análisis y gestión de las competencias de los integrantes de la empresa es más adecuado porque ofrece una imagen más real del verdadero capital humano de la empresa. Al hablar de la definición de puestos en el modelo de Dirección por Tareas se comentaba que, en dicho paradigma, las personas se adaptan a las tareas a través de la definición de los puestos. La Dirección por Competencias permite establecer un tipo de marco organizativo en el que son las tareas las que se adaptan a las personas, en función del perfil competencial de cada una de las personas que trabajan en la organización.

El centro de esta nueva forma de organización de la empresa es la definición de su misión: alrededor de este concepto giran y se articulan los procesos más importantes de la estructura formal, como la promoción, la 
selección o la formación de las personas que la integran. La misión de una empresa es aquel compromiso que caracteriza su identidad, aquello que la empresa pretende ser a través de las acciones coordinadas de sus miembros y de todos los que colaboran con ella. Para que, efectivamente, la estrategia y los objetivos conduzcan al logro de la misión es necesario que ésta sea conocida y compartida, y que cada una de las personas que trabajan en la empresa sepa cómo su trabajo contribuye a dicho logro.

El empleado, en una organización competente, no se siente subordinado, como ocurría en la organización jerárquica. Conoce los objetivos y entiende el para qué final de su trabajo. El empleado de esta nueva forma de organización se siente miembro de un equipo con una misión a cumplir y su actitud, por tanto, es cooperativa. Esta actitud es más que la simple actitud proactiva: pone toda su energía e iniciativa al servicio de la misión, en cooperación con las necesidades del conjunto.

Figura 24: Organización Competente (Cardona, 2001)

Contribución y

Desarrollo
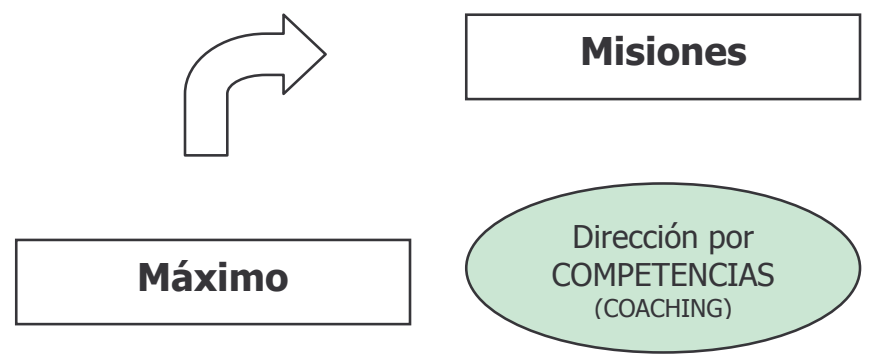

\section{Cooperativa}

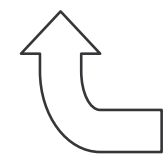

Mejora de la

Talento interdependiente organización

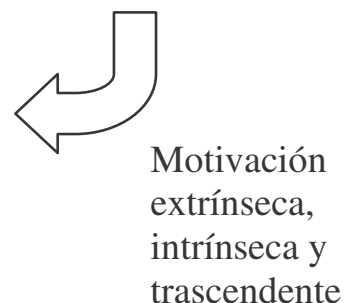

La motivación es triple: por una parte, se mantiene la motivación extrínseca (básicamente el salario) y la intrínseca (el propio desarrollo profesional) pero, además, aparece un tercer tipo de motivación: la 
trascendente (la satisfacción que el empleado siente por el hecho de contribuir con su desempeño al logro de la misión y los objetivos de la empresa).

Al sentirse miembro de un equipo, el empleado de este tipo de empresas hace suyo el objetivo de mejorar la organización a través de su propio desempeño. Por ello, este desempeño no va dirigido exclusivamente hacia los objetivos particulares, sino hacia las distintas necesidades que la organización requiere en cada momento. A estas necesidades mutuas entre distintas partes de la organización se les llama interdependencias. De ahí que el talento que se desarrolla sea un talento interdependiente: aquél que está pendiente de las necesidades del conjunto y es capaz de tomar decisiones teniendo en cuenta esas necesidades. Obviamente, es un talento más complejo y más efectivo que el puramente independiente, y requiere un cierto grado de motivación trascendente.

Las competencias deben a su vez reflejar los valores culturales y la misión misma de la empresa. En caso contrario, corren el peligro de aparecer como unos condicionantes arbitrarios, sin sentido ni interés real para la empresa. Cuando las competencias y los objetivos forman un sistema coherente con la misión es más sencillo reavivar la identificación de las personas con la empresa y fomentar en ellas una actitud cooperativa.

El estilo de dirección propio de este nuevo sistema de gestión está caracterizado por el apoyo del jefe en el proceso de desarrollo y la contribución del subordinado. El denominado coaching: el directivo, además de preocuparse por los resultados de su gente, debe preocuparse también por su desarrollo profesional. El sistema de competencias es una herramienta que facilita enormemente esta función: define cuáles son las competencias necesarias en cada caso, las describe de modo preciso, las evalúa para cada empleado, y enfoca los esfuerzos de la formación. Pero el directivo debe ser capaz de utilizar el sistema como máximo responsable de la formación de su gente. 


\subsubsection{De la Teoría a la Práctica: empresas, directivos y estilos de dirección en el siglo XXI}

Los resultados de un estudio empírico realizado por Otto Walter en 2003 arrojan unos resultados un tanto sorprendentes. Se pretendía conocer algo más acerca de las expectativas de los jefes respecto a los empleados y las quejas más frecuentes de los últimos respecto al comportamiento de los primeros.

Tabla 3: Los comportamientos negativos (Otto Walter, 2003)

\begin{tabular}{lcll}
\hline Comportamientos & $\%$ & & $\%$ \\
Falta de respeto & 49.33 & Incumplimiento de compromisos & 21.56 \\
Prepotencia & 37.47 & No comunicar bien & 21.29 \\
No escuchar & 30.32 & Injusticia & 19.54 \\
Incompetenciadirectiva & 28.98 & Falsedad & 18.46 \\
Falta de apoyo al equipo & 28.17 & Robo de medallas & 17.79 \\
Falta de trato humano & 25.61 & Falta de confianza & 17.12 \\
No implicación & 24.66 & Falta de valor & 14.69 \\
No controlar bien & 24.66 & Poca claridad de objetivos & 10.11 \\
\hline Autoritarismo & 24.26 & No respeto a los horarios & \\
\hline
\end{tabular}

Los empleados parecen quejarse de comportamientos y actitudes que dibujan un estilo de dirección autoritario y, más aún, una cierta falta de escrúpulos y de consideración por parte de los jefes. Desde la perspectiva de la Dirección por Objetivos, si estos mismos jefes estuvieran logrando buenos resultados económicos este tipo de datos quedarían subsumidos bajo la estela de una brillante evaluación del desempeño. Nos estaríamos fijando en el qué pero no en el cómo. 
Incorporando la perspectiva de la Dirección por Competencias, sin embargo, sí tendríamos elementos suficientes para considerar cuáles son las áreas de mejora o carencias de los directivos cuyos empleados se manifiestan de esta forma. Por ejemplo, podríamos hablar de carencias en las competencias de Dirección de personas, Trabajo en equipo, Integridad o Toma de decisiones. Esto permitiría emprender acciones y planes de formación más adecuados para minimizar sus efectos negativos.

En el año 2001, el IESE realizó un estudio dirigido a conocer cuáles eran las competencias directivas más valoradas por las empresas a la hora de contratar directivos. La idea subyacente a esta investigación es que, además de los requerimientos técnicos específicos para el desempeño de cada puesto concreto, las empresas buscan un conjunto de actitudes o habilidades soft en sus futuros directivos. Para este estudio se utilizó un listado amplio de competencias, elaborado por los profesores Cardona y Chinchilla ${ }^{1}$ tras varios años de investigación.

Tabla 4: Las competencias directivas más buscadas (Cardona y Chinchilla, 2001)

\begin{tabular}{lllll}
1 & Orientación al cliente & 6 & Comunicación \\
\hline 2 & Liderazgo & 7 & Visión de negocio \\
\hline 3 & Integridad & 8 & Aprendizaje \\
\hline 4 & Iniciativa & 9 & Toma de decisiones \\
\hline 5 & Trabajo en equipo & & \\
\hline
\end{tabular}

\footnotetext{
${ }^{1}$ El Cuestionario de Competencias Directivas (CCD) base del Test TELÉMACO (Anexo)
} 
Como se puede observar, estas diez competencias dibujan un perfil de directivo equilibrado, capaz de dirigir personas, comprender y dominar el negocio y, además, capaz de aprender. Estas competencias tienen un impacto importante sobre los resultados, pero difícilmente pueden ser medidas directamente a través de una evaluación del desempeño. La evaluación de resultados se centra en el pasado: se trata de valorar lo que se ha hecho o lo que no se ha hecho, en comparación con unos objetivos predefinidos. Es decir, se busca medir el qué, dejando de lado el cómo se logran esos resultados. Esta forma de organizar el trabajo en la empresa puede llegar a resultar peligroso: en el caso extremo, se pueden llegar a fomentar modos de hacer que son inconsistentes con las competencias y valores que la empresa trata de desarrollar en sus empleados (Pfeffer J., 1998)

Para lograr perfiles directivos adecuados, las empresas deben introducir algún tipo de sistema de gestión por competencias en los procesos de selección, promoción y formación.

\section{Un nuevo contrato implícito}

Una de las cuestiones que surge a la hora de tratar el tema de las competencias, y aún más si estamos hablando del desarrollo interno de las mismas a través del sistema de gestión y del coaching por parte de los directivos, es que existe el riesgo de tirar el esfuerzo (y el dinero) si la gente formada se va luego a otra organización. Pero ese no es el mayor riesgo. Lo peor sería que la empresa no formara a su gente y que, debido a ello, la gente no pudiera irse a ninguna otra empresa. A pesar de todo, es lógico que preocupe el alto nivel de rotación en algunas empresas.

Si tenemos en cuenta las consecuencias negativas de una elevada rotación (costes, falta de integración con la cultura de la empresa, escasa relevancia del sistema informal, etc.) y consideramos la pertenencia no sólo como un "estar aquí mientras me paguen lo que yo quiero", sino como la consecuencia de un compromiso real del empleado con la misión de la organización, quedará aún más claro que el éxito de cualquier empresa a medio 
y largo plazo exige la generación de vínculos más allá de cuestiones relacionadas sólo con la remuneración.

Dicho vínculo tiene una expresión formal, el contrato físico o explícito, que recoge las condiciones de trabajo, la remuneración, los posibles beneficios sociales, los compromisos que adquiere el empleado, etc. Pero este vínculo formal no puede recoger otro tipo de cuestiones que, en los últimos tiempos, han aparecido como tanto o más importantes que las relativas a la remuneración o el horario. Estamos ante lo que se suele llamar el contrato implícito.

En toda interacción entre dos partes, cada una de ellas busca algo, en concreto, la satisfacción de unas necesidades concretas. Estas necesidades no han de interpretarse como aspectos puramente materiales, sino que también el ser humano tiene necesidad de sentirse parte de un equipo, sentirse apreciado, desarrollarse personal y profesionalmente, etc. La satisfacción de estas necesidades es precisamente lo que mueve a cualquier individuo a actuar: ¿qué tipo de necesidades satisface una persona al trabajar?

La primera respuesta es evidente: obtener unos recursos necesarios para la subsistencia, pero desde luego, existen otro tipo de necesidades cuyo deseo de satisfacción impulsa al individuo a trabajar, y a hacerlo dentro de una organización determinada. "El ser humano necesita, dentro de determinados límites, una cierta tensión entre lo que es y lo que debería ser pero aún no se ha alcanzado. Sólo esta tensión plenifica la vida, promueve la acción y proporciona un criterio de decisión".(Katzenberg, J.R., 2003)

El individuo busca en la realización de un trabajo algo más que la obtención de recursos necesarios para la subsistencia: busca el desarrollo de ciertas capacidades o un cierto reconocimiento social. De hecho, en más empresas de las que pueda parecer a simple vista los altos directivos o los propios dueños no aceptan que su misión sea únicamente maximizar los beneficios económicos. Para obtener esos resultados económicos a largo plazo, deben buscar y favorecer el pleno desarrollo profesional de quienes en ella 
trabajan. De otro modo, los altos niveles de rotación, la desmotivación de los empleados y la sujeción estricta al cumplimiento de lo establecido en un contrato formal conduce a la utilización de sistemas de control y de incentivos cada vez más costosos, que dificultan enormemente la competitividad.

Tanto en las personas como en la empresa, por consiguiente, y siguiendo al profesor Cardona, existen contratos implícitos: expectativas que van más allá del contrato formal. Estas expectativas no son estables, sino que han ido variando en el tiempo.

Tabla 5: Contrato implícito (Cardona, 2004)

\section{ANTES AHORA}

¿Qué busca el trabajador? Seguridad Desarrollo profesional

¿Qué busca la empresa? $\quad$ Resultados Capacidades

Las empresas no pueden ni pretenden ofrecer trabajos "de por vida", y por tanto, no sería realista que el trabajador basara su contrato implícito en la seguridad del empleo. Por ello, las expectativas han ido derivando hacia lo que se conoce como "empleabilidad". Lo que el trabajador espera es que la empresa mantenga en todo momento su nivel de empleabilidad en el mercado de trabajo. Esto se consigue sobre todo mediante el desarrollo profesional que la empresa puede favorecer en su propio contexto de trabajo o mediante la participación en programas de formación. Por otro lado, la empresa está cada vez más concienciada de que, además de resultados, necesita desarrollar continuamente el talento. $\mathrm{Y}$ esto es así porque aunque hoy se consigan los resultados, es crítico que la empresa haya mejorado a la vez sus capacidades, si quiere conseguir los resultados mañana. 


\subsection{INTRODUCCIÓN AL CONCEPTO DE COMPETENCIAS DIRECTIVAS}

\subsubsection{Definición de competencias directivas}

El concepto de competencias comenzó a utilizarse a principios de la década de 1970, a partir de los estudios de McClelland sobre el éxito profesional. Según el autor, ni los test de inteligencia y aptitudes ni los resultados académicos resultaban suficientes para establecer previsiones fiables sobre el éxito profesional. El concepto de competencia aparece entonces para aglutinar todos aquellos factores que sí permiten establecer predicciones fiables al respecto.

En los años de 1980 y 1990, sin embargo, se realizan estudios que demuestran cómo los tests de aptitudes y de inteligencia son válidos a la hora de predecir parte del desempeño profesional. Las últimas tendencias en lo relativo a evaluación y medición del desempeño profesional muestran la conveniencia de considerar estos conceptos como factores complementarios al buscar predicciones válidas y fiables. Aptitudes, inteligencia y competencias son todos elementos necesarios para lograr el éxito en el desempeño de una determinada función o tarea.

El segundo impulso al tema de las competencias directivas lo constituye la obra de Boyatzis "The Competent Manager" (Boyatzis, R., 1983), en la que el autor habla específicamente de competencias de dirección. Se trata de un estudio empírico, cuyo objetivo es analizar cuáles son las competencias "umbral" que todos los mandos deberían poseer, y cuáles son las competencias "superiores", las que sólo poseen el $10 \%$ de los mejores mandos. La identificación de estas competencias se lleva a cabo con la ayuda de las definiciones de puestos. Sin embargo, el concepto mismo de competencia no queda definido de forma clara e inequívoca, sino que abarca un vasto conjunto de factores psicológicos y de conocimiento. 
En los 90, Woodrufe, C., (1993) define las competencias como aquellos comportamientos observables que contribuyen al éxito en una tarea o función. Definir "competencias" en términos de "comportamientos observables" significa que es posible llegar a su medición. Supone, así, un notable impulso hacia el diseño de métodos de evaluación e identificación de competencias.

Siguiendo ésta definición, Cardona y Chinchilla (1999) precisan aún más el ámbito de las competencias y las definen como comportamientos observables $\boldsymbol{y}$ habituales. Esta nueva delimitación del concepto implica que un comportamiento exitoso pero esporádico no puede ser considerado una competencia, porque no representa el dominio real de una tarea. Por ejemplo, tener una idea innovadora en un momento determinado no significa poseer en alto grado la competencia de Creatividad, por más oportuna que haya resultado esa idea innovadora. En cambio, tener ideas relevantes y distintas de forma habitual sí se considera poseer dicha competencia.

Las competencias así definidas se orientan claramente a la acción, lo que no ocurre en el caso de los conocimientos o de los rasgos de personalidad. En este marco, las competencias directivas son un subgrupo de competencias que hacen referencia a un tipo específico de función: la función directiva. Por tanto, como fase previa al diseño de un Directorio de Competencias Directivas, tenemos que las competencias:

Son comportamientos: es decir, no se trata de rasgos de personalidad o del temperamento, ni tampoco son conocimientos. Esta definición aboca el estudio de las competencias directivas y su desarrollo directamente a la acción.

Son comportamientos observables: se puede medir no sólo su grado de desarrollo en un momento dado, sino también el progreso y el aprendizaje.

Son comportamientos habituales: incorporados a la acción cotidiana de la persona. En este sentido, el desarrollo de cualquier competencia significa la adquisición de nuevos hábitos de comportamiento, lo que, si bien en ocasiones puede resultar un proceso lento, implica la posibilidad misma del aprendizaje. 


\subsubsection{Identificación de las competencias relevantes}

En primer lugar, son muy abundantes los ejemplos de listados o directorios de competencias que han sido diseñados partiendo de modelos prácticos de éxito en el trabajo. Esto ha ocurrido así en gran parte por el hecho de que, en el caso de las competencias, la práctica ha ido un paso por delante respecto a la investigación teórica.

Algunos autores han establecido listados universales de competencias, como por ejemplo, el de Thornton, C. y Byham, C. (1989):

Tabla 6: Listado universal de competencias (Thornton y Byham, 1989)

\begin{tabular}{ll} 
Presentación oral & Negociación \\
\hline Comunicación oral & Conocimientos técnicos \\
Comunicación escrita & Decisión \\
Análisis de los problemas de la empresa & Aceptación de riesgos \\
Atención a los problemas de las empresa & Creatividad \\
Análisis de los problemas externos a la empresa & Sensatez \\
Atención a los problemas externos a la empresa & Espíritu de análisis \\
Planificación y organización & Energía \\
Delegación & Amplitud de intereses \\
Desarrollo de subordinados & Iniciativa \\
Sensibilidad & Tolerancia al estrés \\
Autoridad sobre un individuo & Adaptabilidad \\
Autoridad sobre un grupo & Independencia \\
\hline Tenacidad & Motivación \\
\hline
\end{tabular}


El problema de este listado es que no se mantiene ninguna jerarquía o agrupación coherente de las diferentes competencias. Además, en este tipo de listados se suelen producir solapamientos y ciertos malentendidos: las competencias directivas suelen denominarse con palabras de gran carga conceptual en la vida cotidiana (comunicación, motivación, etc.): si no se definen de manera más estricta y concisa, no será posible asegurar el sentido unívoco de cada una de ellas.

Por eso, un modelo de competencias directivas coherente y completo requiere un paradigma teórico que lo sustente, basado en ciertas hipótesis acerca de la función directiva y de la acción humana. Dichas hipótesis habrían de ser contrastadas mediante estudios empíricos y herramientas estadísticas, pero el modelo teórico de base es esencial.

Puesto que estamos tratando de competencias directivas, vamos a analizar en primer lugar en qué consiste la función directiva y cuáles son las claves del éxito en su desempeño. A partir de ahí, diseñar el listado de competencias consistirá en encontrar aquellos comportamientos clave para alcanzar los objetivos de dicha función. 


\subsubsection{Niveles de competencias directivas}

La función directiva es un tema profusamente tratado en el ámbito de las teorías sobre Dirección. Desde la escuela de la dirección científica de Taylor y los principios de la escuela clásica de dirección de Fayol, a principios del siglo XX, hasta las modernas teorías de autores como Drucker o Kottler, los más influyentes autores han tratado de determinar cuál es la esencia del trabajo directivo. De forma muy general podemos considerar que el estudio de la dirección y de las funciones directivas se ha ido enriqueciendo, pasando por enfoques de tipo administrativo y de control a modelos de liderazgo que recogen temas como la motivación de los empleados.

Para nuestro trabajo nos apoyamos en el modelo de la función directiva de Pérez López J. A. (1991). Este autor, partiendo de un modelo antropológico de empresa, considera que los parámetros que determinan la calidad de una organización -y toda empresa lo es- son tres:

Eficacia: capacidad de la organización para lograr los objetivos que se propone. Sin un nivel mínimo de eficacia, la empresa simplemente no sobrevive.

Atractividad: grado de satisfacción que experimentan los miembros de una organización por el trabajo que realizan y por el desarrollo que alcanzan en ese trabajo.

Unidad: grado de confianza e identificación de las personas con la misión de la organización. En cada nivel, la unidad requiere el desarrollo de la confianza entre directivo y subordinado.

En concreto la función directiva consiste en diseñar estrategias que produzcan valor económico, desarrollando las capacidades de los colaboradores y creando un mayor nivel de confianza en la organización. De esta definición derivan tres dimensiones o talentos propios del directivo: 
Talento estratégico: es la capacidad de desarrollar e implementar estrategias que conduzcan al logro de buenos resultados económicos.

Talento ejecutivo: es la capacidad para desarrollar a los colaboradores, adaptando en cada momento las tareas a las aptitudes reales de cada uno.

Talento de liderazgo personal: es la capacidad de crear confianza e identificación de los colaboradores con la misión de la organización.

Para desempeñar con éxito cada una de estas dimensiones de la función directiva podemos definir tres grandes grupos de competencias directivas:

Competencias de negocio: son aquellas que se dirigen al logro de un mayor valor económico para la empresa. Estas competencias se refieren al conocimiento del sector y de la organización, a la gestión y negociación de los recursos, al trato con clientes y todo lo que tenga una repercusión directa en los beneficios económicos.

Competencias interpersonales: son aquellas que permiten el desarrollo de las capacidades de los empleados y su correcta funcionalidad en el trabajo. Estas competencias se refieren sobre todo al trato efectivo de las relaciones interpersonales como la comunicación, el trabajo en equipo o la delegación, además de todo lo relacionado con la actitud y la aptitud de los colaboradores.

Competencias personales: son aquellas que desarrollan la confianza y la identificación de los colaboradores. Estas competencias se refieren a aquellos aspectos del autoliderazgo que promueven la profesionalidad y la ejemplaridad del directivo. A su vez, este grupo se divide en competencias personales externas e internas. Las externas recogen aspectos relacionados con la respuesta personal a estímulos externos, como la iniciativa o la gestión del estrés. Mientras que las internas se centran en aquellos aspectos más íntimos de la persona, como su capacidad de aprendizaje o su integridad. 
La relación entre los parámetros de calidad de una empresa, los talentos directivo y las competencias necesarias para lograr el éxito en estas dimensiones es la siguiente:

Tabla 7: Niveles de competencias directivas (Cardona y Lombardia, 2004)

\begin{tabular}{|l|l|l|}
\hline Parámetros de calidad & Talentos del directivo & Competencias directivas \\
\hline Eficacia & Estratégico & De negocio \\
\hline Atractividad & Ejecutivo & Interpersonales \\
\hline Unidad & Liderazgo personal & Personales \\
\hline
\end{tabular}

Entre las funciones de un directivo está la de generar e implantar estrategias dirigidas a obtener buenos resultados económicos para la empresa: el fracaso en esta dimensión directiva conlleva, por lo general, la desaparición misma de la empresa. En el desempeño de esta dimensión de la función gerencial, el directivo pone en juego todo un grupo de competencias directivas, a las que hemos denominado competencias de negocio. El grado de desarrollo de estas competencias determinará la medida de su talento estratégico.

El talento estratégico actúa como condición necesaria pero no suficiente para alcanzar el éxito en la función directiva. Si nuestro directivo toma sus decisiones utilizando como único criterio el de eficacia, estará dejando de ver una gran parte de la realidad y, por tanto, sus decisiones no serán correctas a medio y largo plazo. En estas empresas los directivos son evaluados sólo en términos de resultados, lo que provoca que sólo tengan en cuenta la eficacia a la hora de decidir. Una de las primeras y más graves consecuencias de esta situación es que las personas que integran la empresa, en todos los niveles, se sienten cada vez menos motivadas a contribuir $\mathrm{o}$, dicho de otro modo, obtienen 
cada vez menos satisfacción del hecho de trabajar en esa empresa. Este déficit de motivación y/o satisfacción sólo se compensa con un incremento de las retribuciones u otros incentivos extrínsecos. En otras palabras, cada vez resulta más caro mantener a la gente unida a la empresa, pues la remuneración es el único incentivo que les mantiene en esa organización.

Gran parte de esta situación queda paliada cuando el directivo, además de buscar la eficacia, toma decisiones utilizando el criterio de la atractividad. Esto significa que, con su actividad diaria, el directivo puede hacer que quienes trabajan en la empresa obtengan cada vez mayor satisfacción de esta pertenencia. ¿Cómo se puede lograr este objetivo? La respuesta está en la puesta en funcionamiento de un conjunto de competencias -a las que llamamos interpersonales- que desarrollan la motivación intrínseca de los colaboradores.

Numerosos estudios muestran que, en el entorno profesional, una de las mayores fuentes de satisfacción es el aprendizaje y el desarrollo profesional. El directivo, a través de un estilo de dirección concreto, puede nutrir esta motivación. En el ejercicio de esta segunda dimensión el directivo desarrolla su talento ejecutivo: su capacidad de motivar y desarrollar personas.

Pero aún queda una tercera dimensión, la más profunda, la que se dirige al logro de la unidad en la empresa, entendida como el grado de confianza e integración de las personas con la misión de la misma. La unidad no se logra a base de repartir documentos en todos los niveles de la empresa en los que se exponga, con expresiones más o menos poéticas, la misión de la empresa. La unidad se consigue, sobre todo, demostrando coherencia personal en cada una de las decisiones directivas.

La ejemplaridad personal del directivo es indispensable para desarrollar la confianza de los colaboradores, que es la base de la unidad. Si se rompe esta confianza es muy difícil -por no decir imposible- pedir a los colaboradores que se muevan por motivación trascendente, esto es, por sentido de misión. 
Estas tres dimensiones de la función directiva presentan una visión amplia y completa del trabajo de un directivo. No se trata de escoger entre una u otra dimensión: todas ellas son necesarias y vitales para la empresa, sobre todo en el medio y largo plazo.

El éxito en cada una de ellas requiere el desarrollo de un tipo concreto de competencias. La excelencia en estas tres dimensiones, da lugar al liderazgo. De ahí que nos refiramos al listado general de competencias directivas como competencias del liderazgo.

A partir de este esquema hemos elaborado un listado de las competencias básicas que componen cada una de estas dimensiones. Este listado permite no sólo medir las competencias individuales sino que, además, ofrece información sobre los diferentes perfiles y estilos de dirección que se derivan del mayor o menor desarrollo de diferentes grupos de competencias.

Nuestro Directorio de Competencias de Liderazgo reúne las siguientes características:

Manejable: en total son 25 competencias, número que permite realizar evaluaciones sin recurrir a pesados cuestionarios.

Preciso: las competencias directivas han sido definidas de tal forma que no se producen solapamientos entre ellas.

Completo: las competencias definidas recogen los aspectos más relevantes de la función directiva.

Conciso: cada una de las competencias directivas está definida de forma clara y unívoca, lo que aumenta la validez y fiabilidad de los resultados. 
Como se ha mostrado, estos grupos o dimensiones directivas representan distintos niveles de profundidad, lo que tiene repercusiones en el desarrollo de las propias competencias. En general, las competencias más internas representarán hábitos más íntimos y estables de la persona, mientras que las competencias estratégicas responden a comportamientos cuya erradicación o incorporación resultará, en principio, más rápida. La metodología misma de este desarrollo, como se verá más adelante, tendrá diferentes matices en cada uno de los casos, siendo más importante la formación y el entrenamiento que la mera información cuanto más profundas sean las competencias. 


\subsection{COMPETENCIAS DIRECTIVAS: DIMENSIONES Y GLOSARIO}

Para la definición de las distintas dimensiones y el glosario de las CD, hemos seguido básicamente la obra de Cardona y García-Lombardía (2005), dado que consideramos que es la más apropiada para el interés de nuestra investigación. Así hemos distinguido entre la dimensión de negocio, interpersonal y personal; todas ellas íntimamente ligadas con la distinción que realizan los mismos autores entre competencias estratégicas, intratégicas y personales. A continuación de su definición, acompañamos una serie de comportamientos característicos de la misma a modo de ejemplo.

\subsubsection{Dimensión de negocio:}
a. Visión de negocio
b. Visión de la organización
c. Orientación al cliente
d. Gestión de recursos
e. Negociación
f. Networking

\subsubsection{Dimensión interpersonal:}
a. Comunicación
b. Gestión de conflictos
C. Carisma
d. Delegación
e. Coaching
f. Trabajo en equipo

\subsubsection{Dimensión personal:}

\section{a. Externa}

i. Proactividad

ii. Gestión personal

b. Interna

i. Mejora personal

ii. Autogobierno 


\section{VISIÓN DE NEGOCIO:}

"Es la capacidad de reconocer las amenazas y aprovechar las oportunidades que repercuten en la competitividad y efectividad del negocio"

\section{COMPORTAMIENTOS CARACTERÍSTICOS:}

$\checkmark$ Sabe cuáles son los objetivos de su organización y los prioriza.

$\checkmark$ Conoce las tendencias y prácticas del mercado relevantes para su negocio.

$\checkmark$ Conoce el posicionamiento de su empresa en el sector.

$\checkmark$ Conoce los puntos fuertes de su empresa y de la competencia.

$\checkmark$ Analiza el entorno para aprovechar las oportunidades y detectar las amenazas que afectan a su negocio.

$\checkmark$ Se anticipa a la evolución de los acontecimientos en un horizonte de tres a cinco años. 


\section{VISIÓN DE LA ORGANIZACIÓN}

"Es la capacidad de valorar la empresa más allá de los límites de la propia función, comprender la interrelación entre las distintas unidades y desarrollar la cooperación interfuncional."

\section{COMPORTAMIENTOS CARACTERÍSTICOS}

$\checkmark$ Establece y mantiene contactos con personas de otros departamentos.

$\checkmark$ Conoce los resultados de otras áreas y entiende cómo y en qué contribuye cada una a la cadena de valor de la empresa.

$\checkmark$ Colabora con otros departamentos cuando es necesario.

$\checkmark$ Podría trabajar con eficacia en otros departamentos de la empresa.

$\checkmark$ Es consciente de cómo sus decisiones pueden afectar a otras áreas.

$\checkmark$ Sabe a quién acudir dentro de la empresa ante cada necesidad. 


\section{ORIENTACIÓN AL CLIENTE}

"Es la capacidad de satisfacer las necesidades del cliente, ofreciendo una oferta de valor, cuidando todos los detalles de la relación, y dando respuesta a sus peticiones y sugerencias,"

\section{COMPORTAMIENTOS CARACTERÍSTICOS}

$\checkmark$ Emprende acciones para aumentar su base de clientes.

$\checkmark$ Responde con prontitud a las demandas y sugerencias de sus clientes.

$\checkmark$ Pone en práctica las medidas necesarias para descubrir las necesidades y expectativas de sus clientes.

$\checkmark$ Crea ofertas para sus clientes que generan valor añadido.

$\checkmark$ Actúa pensando en las necesidades reales de sus clientes.

$\checkmark$ Establece y mantiene relaciones efectivas con sus clientes y sabe ganarse su respeto y confianza. 


\section{GESTIÓN DE RECURSOS}

"Es la capacidad de utilizar los recursos materiales y económicos del modo más idóneo, rápido, económico y eficaz para obtener los resultados deseados."

\section{COMPORTAMIENTOS CARACTERÍSTICOS}

$\checkmark$ Conoce los objetivos y analiza cuál es el modo más eficiente de alcanzarlos.

$\checkmark$ Evalúa el impacto de sus acciones en los resultados económicos de la empresa.

$\checkmark$ Tiene en cuenta el coste de oportunidad de los recursos que compromete.

$\checkmark$ Toma decisiones y compromete recursos teniendo en cuenta su rentabilidad.

$\checkmark$ Realiza un seguimiento de la productividad real de los recursos empleados y controla las desviaciones.

$\checkmark$ Aprovecha y valora todo tipo de recursos: económicos, materiales, de tiempo, etc. 


\section{NEGOCIACIÓN}

"Es la capacidad de alcanzar acuerdos satisfactorios para las partes implicadas descubriendo o creando elementos que produzcan valor añadido a la relación."

\section{COMPORTAMIENTOS CARACTERÍSTICOS}

$\checkmark$ En las negociaciones, logra concesiones sin ceder en los puntos que no son negociables y sin dañar la relación.

$\checkmark$ Planifica bien el tiempo de la negociación, estableciendo plazos concretos.

$\checkmark$ Sabe ser enérgico y directo al tiempo que diplomático.

$\checkmark$ Encuentra nuevos puntos de negociación que hacen más fructífera la relación.

$\checkmark$ En las negociaciones, se ciñe a los hechos sin entrar en el plano personal.

$\checkmark$ Se gana rápidamente la confianza de las partes implicadas en la negociación. 


\section{NETWORKING}

"Es la capacidad de desarrollar, mantener y utilizar una amplia red de relaciones con personas clave dentro de la empresa y del sector."

\section{COMPORTAMIENTOS CARACTERÍSTICOS}

$\checkmark$ Mantiene contacto con diversas instituciones para ampliar su esfera de influencia.

$\checkmark$ Tiene un círculo de amigos influyentes con quienes comparte informaciones y contactos.

$\checkmark$ Sabe cómo obtener apoyos entre sus contactos.

$\checkmark$ Busca relacionarse de manera informal con personas clave de su entorno profesional.

$\checkmark$ Comprende las relaciones clave y los ámbitos sociales relevantes tanto dentro como fuera de la empresa.

$\checkmark$ Comprende las fuerzas que influyen en quienes toman decisiones y las sabe utilizar. 


\section{COMUNICACIÓN}

"Es la capacidad de escuchar y transmitir ideas de manera efectiva, empleando el canal adecuado en el momento oportuno, $y$ proporcionando datos concretos para respaldar sus observaciones $y$ conclusiones."

\section{COMPORTAMIENTOS CARACTERÍSTICOS}

$\checkmark$ Sus mensajes son concretos y tienen contenido.

$\checkmark$ Busca los momentos oportunos para decir las cosas, sin dejar conversaciones pendientes.

$\checkmark$ Escoge el medio idóneo para dar a conocer la información y se asegura de que su interlocutor la ha comprendido.

$\checkmark$ Adapta el lenguaje y el estilo a la persona o personas que tiene delante.

$\checkmark$ Afronta las conversaciones de manera clara, sincera y efectiva.

$\checkmark$ Escucha y anima a la gente a que dé sus opiniones y puntos de vista. 


\section{GESTIÓN DE CONFLICTOS}

"Es la capacidad de diagnósticar, afrontar y resolver conflictos interpersonales con prontitud $y$ profundidad, sin dañar la relación personal."

\section{COMPORTAMIENTOS CARACTERÍSTICOS}

$\checkmark$ Está abierto a las discrepancias en los enfoques y puntos de vista.

$\checkmark$ Busca puntos de unión entre las distintas posturas de modo dialogante y constructivo.

$\checkmark$ Afronta los conflictos con prontitud, en lugar de evitarlos o camuflarlos.

$\checkmark$ Cuida la parte emocional de los conflictos, para no dañar la relación personal.

$\checkmark$ Sabe recomponer las afrentas personales, pidiendo o aceptando el perdón cuando es preciso.

$\checkmark$ Intuye posibles causas de conflicto y se anticipa a ponerles remedio antes de que sea demasiado tarde. 


\section{CARISMA}

"Es la capacidad de lograr el compromiso de los colaboradores, inspirando su confianza, dando sentido a su trabajo y motivándoles a conseguir sus objetivos."

\section{COMPORTAMIENTOS CARACTERISTICOS}

$\checkmark$ Anima e ilusiona a su gente, destacando los aspectos positivos y motivantes de los problemas.

$\checkmark$ Fomenta el sentido de responsabilidad y profesionalidad en el trabajo.

$\checkmark$ Va por delante a la hora de poner esfuerzos por sacar adelante la misión encomendada.

$\checkmark$ Basa la relación con sus colaboradores en la confianza.

$\checkmark$ Exige cuidar los detalles con autoridad basada en su prestigio y ejemplaridad.

$\checkmark$ Ayuda a sus colaboradores a comprender el valor y el sentido de su trabajo. 


\section{DELEGACIÓN}

"Es la capacidad de conseguir que los colaboradores del equipo dispongan de la información y los recursos necesarios para tomar decisiones y lograr sus objetivos."

\section{COMPORTAMIENTOS CARACTERÍSTICOS}

$\checkmark$ Supervisa las tareas y los proyectos de su gente sin entrometerse en los detalles.

$\checkmark$ Busca ampliar el campo de responsabilidad de sus colaboradores.

$\checkmark$ Permite a sus colaboradores terminar su trabajo, proporcionando ayuda cuando lo solicitan.

$\checkmark$ Pide opinión a sus colaboradores a la hora de enfocar los problemas.

$\checkmark$ Implica a sus colaboradores en la generación y análisis de alternativas.

$\checkmark$ Sabe qué decisiones delegar a cada persona, según las capacidades y circunstancias de cada uno. 


\section{COACHING}

"Es la capacidad de ayudar a desarrollar el potencial de cada persona."

\section{COMPORTAMIENTOS CARACTERÍSTICOS}

$\checkmark$ Dedica tiempo y atención a sus colaboradores.

$\checkmark$ Se interesa por las circunstancias, necesidades e intereses de sus colaboradores.

$\checkmark$ Manifiesta una gran confianza en sus colaboradores, sin establecer juicios prematuros.

$\checkmark$ Sabe dar feedback en el momento oportuno y basado en hechos concretos.

$\checkmark$ Diseña con sus colaboradores un plan personal de desarrollo, ayudándoles a fijar objetivos de mejora.

$\checkmark$ Corrige constructivamente, aportando posibles soluciones. 


\section{TEAMWORKING}

"Es la capacidad de fomentar un ambiente de colaboración, comunicación y confianza entre los miembros del equipo."

\section{COMPORTAMIENTOS CARACTERÍSTICOS}

$\checkmark$ Cumple con esmero y responsabilidad las normas y acuerdos del equipo.

$\checkmark$ Evita las alusiones personales en los momentos de discrepancia.

$\checkmark$ Se involucra con los objetivos del equipo y los hace suyos.

$\checkmark$ Infunde moral y ánimo a los miembros del equipo en que colabora.

$\checkmark$ Promueve el diálogo constructivo entre los miembros del equipo.

$\checkmark$ Respeta y da prioridad a las reuniones del equipo. 


\section{PROACTIVIDAD}

\section{INICIATIVA}

"Es la capacidad de mostrar un comportamiento emprendedor, iniciando e impulsando los cambios necesarios con energía $y$ responsabilidad personal."

\section{COMPORTAMIENTOS CARACTERÍSTICOS}

$\checkmark$ Promueve mejoras en su departamento.

$\checkmark$ Participa activamente en la generación de nuevas ideas en su trabajo.

$\checkmark$ Analiza los problemas desde nuevos puntos de vista.

$\checkmark$ Supera las resistencias al cambio de los demás con energía y sin desalentarse.

$\checkmark$ Actúa con independencia dentro de su campo de actuación, sin necesidad de consultar cada paso.

$\checkmark$ Es capaz de asumir nuevos retos. 


\section{OPTIMISMO}

"Es la capacidad de ver el lado positivo de la realidad, tener fe en las propias posibilidades y afrontar las dificultades con entusiasmo."

\section{COMPORTAMIENTO CARACTERÍSTICO}

$\checkmark$ Está convencido de que las cosas saldrán adelante si se ponen los medios adecuados.

$\checkmark$ Imprime entusiasmo en todo lo que hace.

$\checkmark$ Se recupera con ánimo deportivo de los reveses profesionales y personales.

$\checkmark$ No se desanima ante las dificultades.

$\checkmark$ Destaca el aspecto positivo de cada situación.

$\checkmark$ Anima a los demás en los momentos de dificultad. 


\section{AMBICIÓN}

"Es la capacidad de establecer metas elevadas para sí y para los demás, y de perseguirlas con determinación."

\section{COMPORTAMIENTOS CARACTERÍSTICOS}

$\checkmark$ Es inconformista con la mediocridad y el continuismo.

$\checkmark$ Se compromete con objetivos difíciles cuando es necesario.

$\checkmark$ Persigue sus objetivos con tesón, sin desfallecer hasta alcanzarlos.

$\checkmark$ Acomete las tareas con decisión.

$\checkmark$ Defiende sus puntos de vista con determinación.

$\checkmark$ Busca la excelencia en todo lo que hace. 


\section{GESTIÓN PERSONAL}

\section{GESTIÓN DEL TIEMPO}

"Es la capacidad de priorizar los objetivos, programar las actividades de manera adecuada y ejecutarlas en el plazo previsto."

\section{COMPORTAMIENTOS CARACTERÍSTICOS}

$\checkmark$ Asigna el tiempo adecuado a cada tarea.

$\checkmark$ Evita interrupciones innecesarias.

$\checkmark$ Utiliza la agenda para programar sus actividades.

$\checkmark$ Es ordenado: sabe dónde tiene cada cosa y puede localizarla fácilmente cuando la necesita.

$\checkmark$ Sabe decir que no a tareas que le impedirían realizar sus objetivos.

$\checkmark$ Tiene unas prioridades claras y las sigue con coherencia a la hora de distribuir su tiempo. 


\section{GESTIÓN DE LA INFORMACIÓN}

"Es la capacidad de identificar y tratar de manera efectiva la información relevante para su trabajo."

\section{COMPORTAMIENTOS CARACTERÍSTICOS}

$\checkmark$ Utiliza fuentes fiables de información en su trabajo.

$\checkmark$ Mantiene activos los canales de información necesarios para su trabajo (e-mail, prensa, entrevistas, etc.)

$\checkmark$ Sabe extraer lo esencial de la información que recibe.

$\checkmark$ Guarda exclusivamente la información relevante para su trabajo.

$\checkmark$ Discrimina adecuadamente entre la información urgente y la que puede esperar.

$\checkmark$ Distribuye adecuadamente la información a quien corresponda. 


\section{GESTIÓN DEL ESTRÉS}

"Es la capacidad de mantener el equilibrio personal ante situaciones de especial tensión."

\section{COMPORTAMIENTOS CARACTERÍSTICOS}

$\checkmark$ Sabe detectar los síntomas del estrés y toma medidas para paliarlo.

$\checkmark$ Dedica el tiempo adecuado al descanso.

$\checkmark$ Mantiene hábitos de vida equilibrados.

$\checkmark$ Encuentra momentos de relajación y ruptura con el trabajo.

$\checkmark$ Es capaz de cortar con el trabajo cuando está con la familia o los amigos.

$\checkmark$ Mantiene un equilibrio entre su vida personal y la profesional. 


\section{MEJORA PERSONAL}

\section{AUTOCRÍTICA}

"Es la capacidad de aceptar y asumir las limitaciones $y$ errores personales."

\section{COMPORTAMIENTOS CARACTERÍSTICOS}

$\checkmark$ Reconoce sus limitaciones sin excusarse a sí mismo.

$\checkmark$ Afronta el feedback con actitud abierta y afán de superación.

$\checkmark$ Agradece los consejos de los demás

$\checkmark$ Adopta una actitud constructiva ante los errores y trata de aprender de ellos.

$\checkmark$ Acepta su responsabilidad ante los fallos y pide disculpas.

$\checkmark$ Se deja ayudar en aquellos aspectos en los que necesita mejorar. 


\section{AUTOCONOCIMIENTO}

"Es la capacidad de entender cómo es y cómo reacciona uno mismo ante distintas circunstancias, tanto en lo personal como en lo profesional."

\section{COMPORTAMIENTOS CARACTERÍSTICOS}

$\checkmark$ Examina con frecuencia su propio comportamiento.

$\checkmark$ Pide feedback a sus colaboradores para mejorar su comportamiento.

$\checkmark$ Pide feedback a sus superiores con intención de aprender.

$\checkmark$ Conoce sus carencias y sus puntos fuertes.

$\checkmark$ Reflexiona sobre sus experiencias para conocerse mejor a sí mismo.

$\checkmark$ Analiza sus sentimientos y cómo afectan a su rendimiento y a sus relaciones con los demás. 


\section{APRENDIZAJE}

"Es la capacidad de adquirir nuevos conocimientos, modificar hábitos y estar abierto al cambio."

\section{COMPORTAMIENTOS CARACTERÍSTICOS}

$\checkmark$ Dedica tiempo a su formación personal y profesional.

$\checkmark$ Se compromete a mejorar sus comportamientos fijando objetivos específicos para conseguirlo.

$\checkmark$ Busca situaciones y relaciones que le enriquezcan y le faciliten el desarrollo personal y profesional.

$\checkmark$ No se desanima ante las dificultades que conlleva el proceso de aprendizaje.

$\checkmark$ Tiene paciencia cuando no consigue mejorar con la rapidez esperada. 


\section{AUTOGOBIERNO}

\section{TOMA DE DECISIONES}

"Es la capacidad de tomar decisiones de modo adecuado y en el momento oportuno."

\section{COMPORTAMIENTOS CARACTERÍSTICOS}

$\checkmark$ Ante un problema, sabe seleccionar la información relevante para su resolución.

$\checkmark$ Analiza en profundidad las causas del problema, sin quedarse en lo evidente.

$\checkmark$ Explora sistemáticamente varias alternativas, analizando sus posibles consecuencias.

$\checkmark$ Define y pondera los criterios a tener en cuenta a la hora de elegir una alternativa.

$\checkmark$ Toma las decisiones que le competen en el momento adecuado.

$\checkmark$ Contrasta sus decisiones antes de ponerlas en práctica. 


\section{AUTOCONTROL}

"Es la capacidad de acometer acciones costosas."

\section{COMPORTAMIENTOS CARACTERÍSTICOS}

$\checkmark$ Tiene resistencia al cansancio.

$\checkmark$ Es constante y ordenado en el trabajo.

$\checkmark$ Termina las tareas que empieza, aunque surjan dificultades.

$\checkmark$ Hace lo que considera necesario en cada momento, sin dejarse llevar por lo fácil o apetecible.

$\checkmark$ Es capaz de realizar sacrificios para lograr sus objetivos.

$\checkmark$ Se concentra a fondo en los temas, sin saltar superficialmente de uno a otro. 


\section{EQUILIBRIO EMOCIONAL}

"Es la capacidad de reaccionar con las emociones y los estados de ánimo apropiados a cada situación."

\section{COMPORTAMIENTOS CARACTERÍSTICOS}

$\checkmark$ Reacciona equilibradamente ante situaciones conflictivas.

$\checkmark$ Es paciente con las propias limitaciones y con las de los demás.

$\checkmark$ Utiliza un tono respetuoso al corregir los fallos de los demás.

$\checkmark$ Mantiene un ánimo estable sin variaciones bruscas ante el menor cambio de circunstancias.

$\checkmark$ Es sensible ante las alegrías y las penas de los demás, demostrándolo con naturalidad y sin excentricidades.

$\checkmark$ Apacigua los ánimos en momentos de especial tensión. 


\section{INTEGRIDAD}

"Es la capacidad de comportarse de manera recta y honrada ante cualquier situación."

\section{COMPORTAMIENTOS CARACTERÍSTICOS}

$\checkmark$ Opina y actúa según lo que piensa: es sincero y transparente.

$\checkmark$ Presenta la verdad sin tapujos, en el momento adecuado y de forma amable.

$\checkmark$ Asume los compromisos adquiridos.

$\checkmark$ Usa con propiedad la información confidencial sin utilizarla indiscretamente en detrimento de otras personas.

$\checkmark$ Su comportamiento es coherente con sus principios.

$\checkmark$ Actúa con justicia a la hora de reconocer, defender y exigir aquello que le corresponde a cada persona. 


\section{CAPÍTULO 4:}

\section{MODELO TEÓRICO DE RELACIONES ENTRE LA GESTIÓN DEL CONOCIMIENTO, LAS COMPETENCIAS DIRECTIVAS Y LOS RESULTADOS ORGANIZATIVOS}

4.1. OBJETIVOS Y CONTENIDOS DEL CAPÍTULO

4.2. GESTIÓN DEL CONOCIMIENTO Y DESEMPEÑO ORGANIZATIVO

4.3. LAS COMPETENCIAS DIRECTIVAS (CD): VARIABLE MEDIADORA EN LA RELACIÓN GESTIÓN DEL CONOCIMIENTO (GC) Y RESULTADOS ORGANIZATIVOS (RO) 


\subsection{OBJETIVOS Y CONTENIDOS DEL CAPÍTULO}

El objetivo de este capítulo es establecer qué efecto tiene la introducción de la GC en las organizaciones, su relación con los resultados y las variables que intermedian entre ambas, con especial atención a las competencias directivas (CD). Para ello, nos basaremos en el enfoque basado en las capacidades dinámicas, en el aprendizaje y en el conocimiento. (Teece y Pisano, 1998).

\subsection{GESTIÓN DEL CONOCIMIENTO Y DESEMPEÑO ORGANIZATIVO}

La inversión en conocimiento es costosa, y teniendo en cuenta que la creación de conocimiento nuevo es un proceso implícitamente incierto, el conocimiento que aporta valor será improbable que se distribuya de forma uniforme entre los miembros de una organización, con lo que los individuos que lo desarrollen pueden potencialmente obtener rentas ricardianas $y$ monopolísticas (Winter, 1987).

Las rentas ricardianas se obtienen cuando una empresa posee factores de producción que son más productivos que los que disponen otras empresas que desarrollan la misma actividad. En su tratado original sobre las rentas, Ricardo introduce en ejemplo de la "buena tierra", en la que los costes de producción unitarios son inferiores a otra hectárea de tierra, siendo ésta última no tan buena.

Sin embargo, en la sociedad actual, los factores de producción no son tan básicos como la tierra, sino que nos encontramos con máquinas, empleados cualificados y sistemas organizativos del trabajo. Por lo tanto, un nivel de conocimiento superior permite a la organización construir mejores piezas o diseñar sistemas de producción más efectivos y eficientes (Penrose, 1959; Spender, 1994). 
El conocimiento organizativo es capaz de generar rentas ricardianas, dependiendo del valor asociado a éste. De forma similar, una empresa que desarrolle conocimiento a través de un sistema de diseño de producto más efectivo que la competencia, puede crear un producto único que le reporte rentas monopolísticas.

La diferencia entre el estado actual y el estado objetivo marcado por los diferentes objetivos estratégicos de la empresa, nos ayuda a entender en qué medida la introducción de un programa de GC ejerce un efecto sobre los resultados de la empresa.

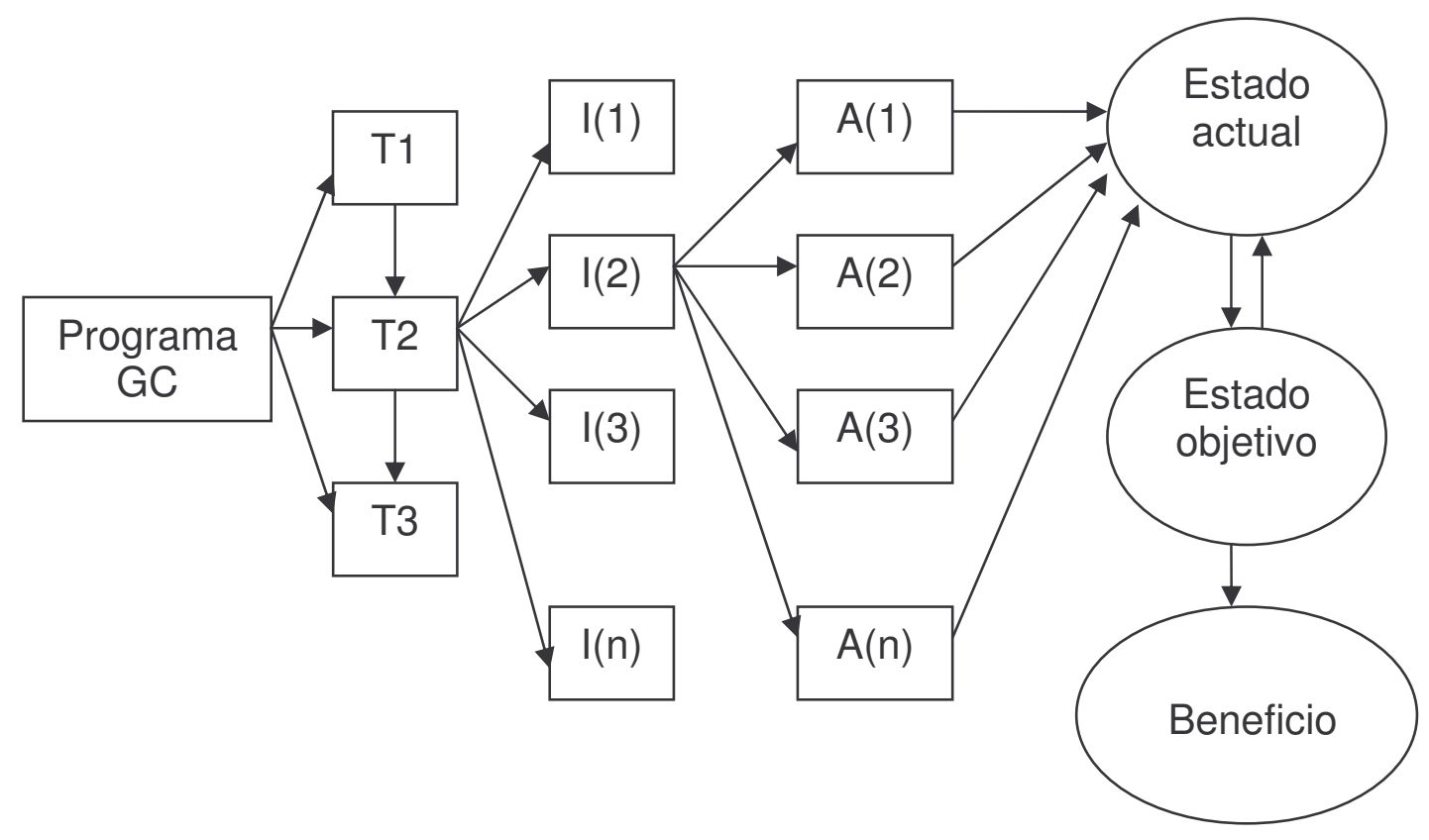

Figura 25: Efectos de la implantación de un modelo de GC (elaboración propia a partir del modelo de Firestone, 2001)

En la figura anterior, se representan los efectos de la implantación de un programa de GC en el beneficio, elaboración propia a partir del modelo de Firestone (2001). Donde "T" son las tareas, "I" el impacto en un determinado proceso de negocio, y "A" los atributos.

Uno de los principales problemas de este modelo es la simplificación de los efectos que se derivan de la implantación de un programa de GC. Las tareas que componen el programa de GC tienen un impacto en los procesos de negocio y ello repercute, positivamente, en los resultados empresariales. El 
modelo, se olvida de otras variables relacionadas con el capital humano, como la mejora en habilidades y destrezas que este modelo no recoge.

En este sentido, Davenport (1999) considera que es necesaria la introducción de medidas intermedias, medidas financieras. Estas medidas intermedias reflejan de forma ideal un aspecto de la organización, que si se mejora, será capaz de conducirnos a mejoras financieras en la empresa. Davenport (1999) relaciona la forma en la que las actividades de GC son capaces de influir en una serie de actividades intermedias, que sí tienen una incidencia directa sobre los resultados financieros.

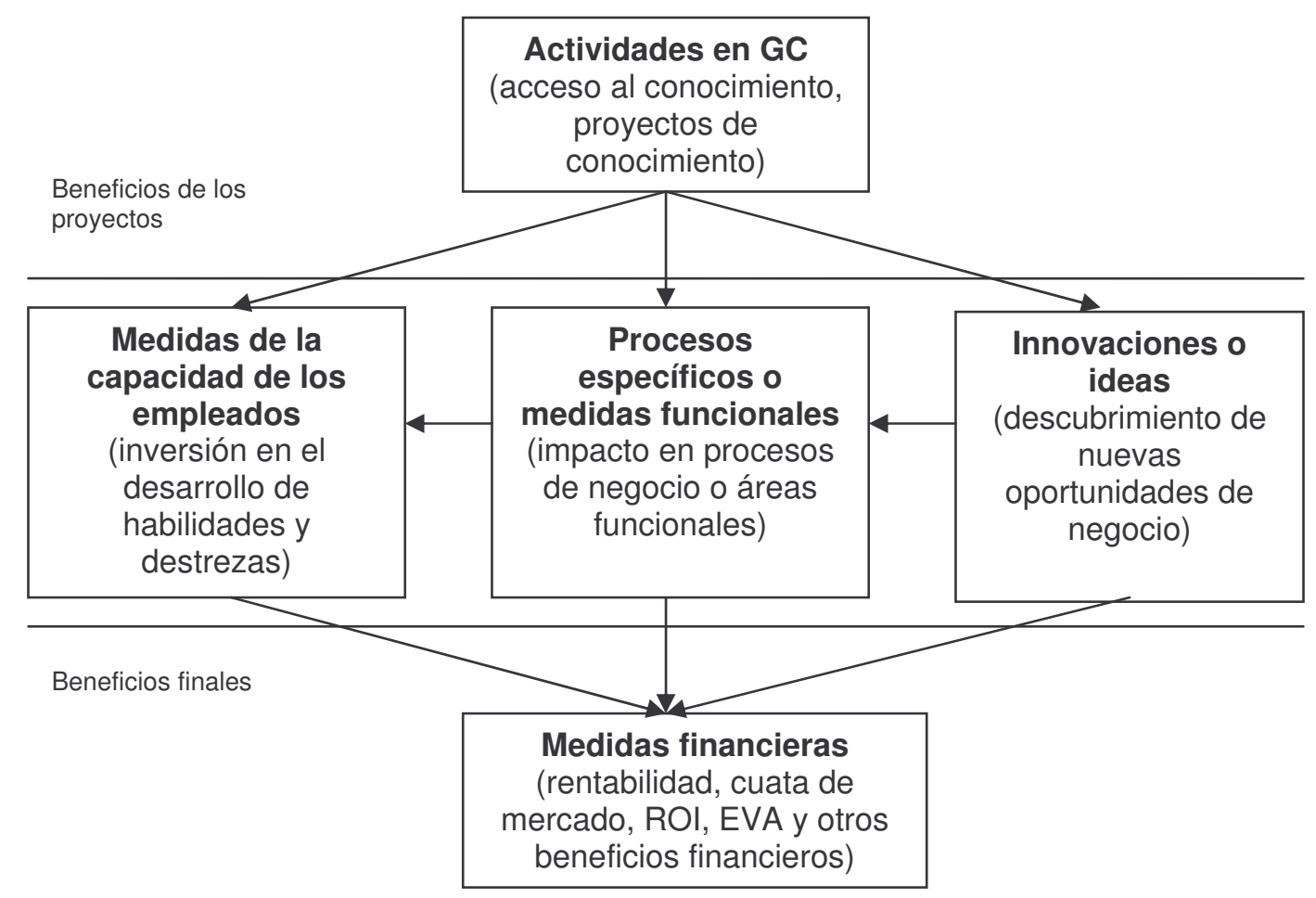

Figura 26: Actividades en la GC (Davenport, 1999)

En la figura anterior, Davenport (1999) relaciona la GC con las medidas financieras. Respecto a las medidas que se utilizan para evaluar las actividades de GC, podemos destacar el número de usuarios del sistema, el número de accesos al repositorio de conocimiento o los niveles de satisfacción de los empleados con las iniciativas de GC. 
Las medidas utilizadas para evaluar los proyectos de GC dependen del tipo de empresa de que se trate. Por ejemplo, en empresas relacionadas con la $\mathrm{I}+\mathrm{D}+\mathrm{i}$, podríamos utilizar como medida el tiempo que tarde una determinada idea en llegar al mercado o el porcentaje de ventas asociado a nuevos productos. En el caso de empresas dedicadas a la producción se podría hacer uso de medidas como el tiempo de inactividad por un incidente o la velocidad de transferencia de las tecnologías productivas.

Por eso decimos que un progreso en las actividades de GC no se traduce inmediatamente en una mejora del desempeño. Cuando las actividades relacionadas con iniciativas de GC mejoran, ello incide directamente en variables intermedias como las medidas de desempeño de proyectos, indicadores sobre las capacidades de los empleados que realizan las tareas relacionadas con conocimiento, y por último, la generación de ideas e innovaciones.

En este sentido, la generación de nuevas ideas e innovaciones en la empresa, puede derivar en una mejora de los procesos. De la misma manera, mejoras en los procesos también pueden ser consecuencia de un perfeccionamiento en las capacidades de los empleados.

La componente humana de la GC se recoge en el bloque asociado a la mediada de las capacidades de los empleados. Aquí se recogen aspectos tan relevantes como la retención de los empleados más valiosos, la formación, la experiencia, la satisfacción con los programas de GC, etc.

En este sentido, podemos afirmar que el modelo propuesto por Davenport (1999) es uno de los pocos que relaciona coherentemente la implantación de actividades de GC con la generación de resultados en la empresa, con la introducción de variables intermedias.

Siguiendo esta misma idea de introducir beneficios intermedios, Wigg (1999) representa un diagrama causa-efecto en el que se recogen los diferentes efectos derivados de la introducción de un programa de incentivos en 
GC. El valor añadido del modelo radica en introducir todos aquellos efectos que se derivan de un programa que incentive a crear y compartir conocimiento.

Actividad GC

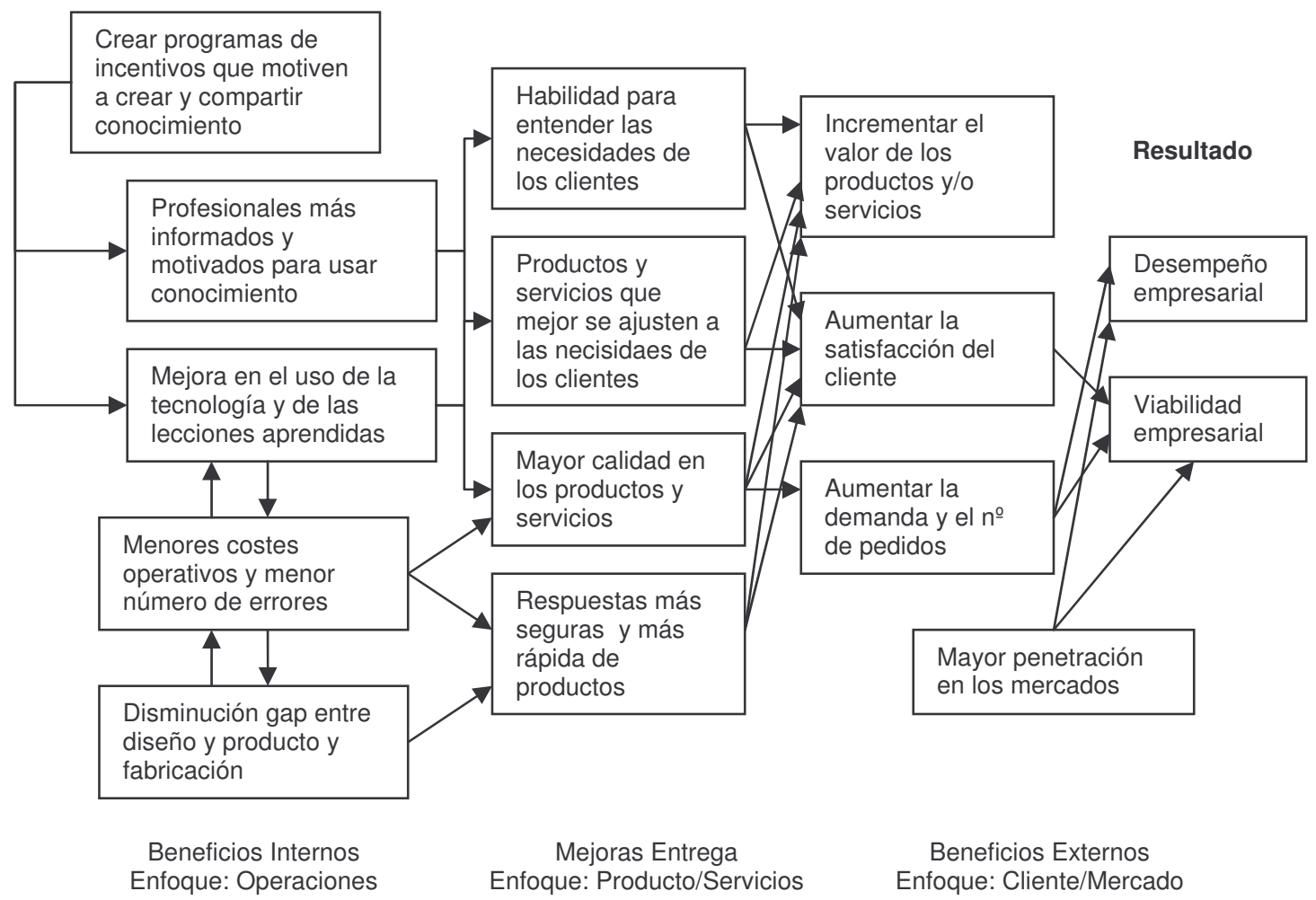

Figura 27: Efectos de la implantación de la GC (Wigg, 1999)

Otro estudio interesante que relaciona el conocimiento organizativo y el desempeño, es el que realizan Decarolis y Deeds (1999), relacionando los stocks y flujos de conocimientos de la organización. 


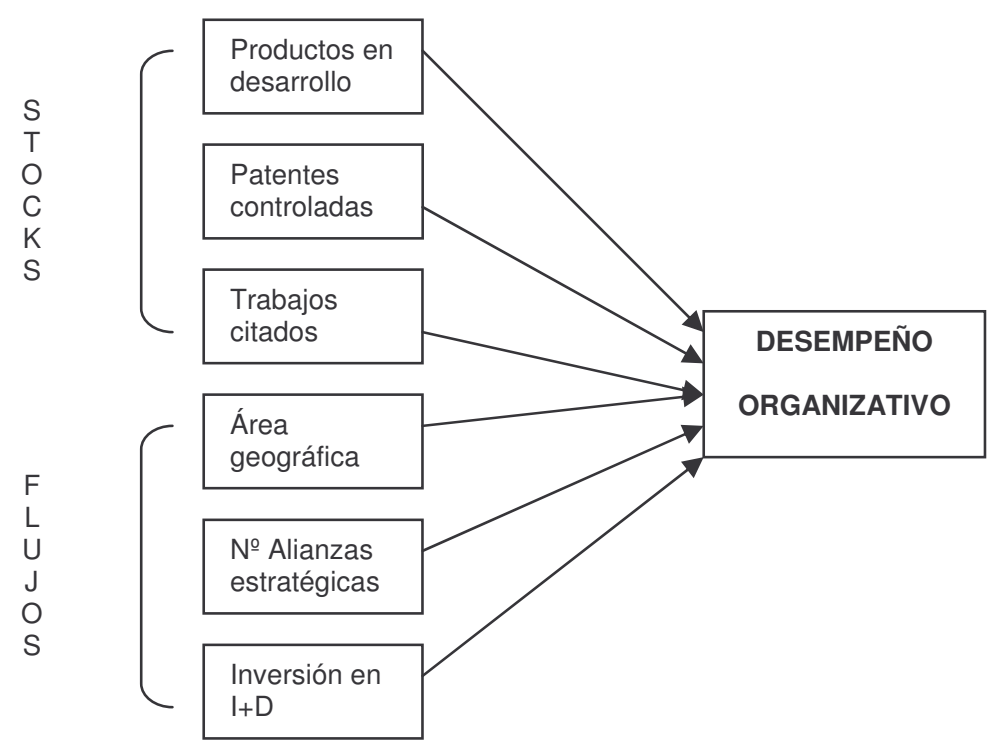

Figura 28: Stocks y Flujos de Conocimiento (Decarolis y Deeds, 1999)

Tras el estudio empírico, Decarolis y Deeds (1999) llegan a las siguientes conclusiones:

1. De las tres variables utilizadas para operativizar los flujos de conocimiento organizativo, únicamente es significativa el área geográfica en la que se desarrolla la empresa. Esta variable pone de manifiesto que la localización geográfica de la empresa incide de forma significativa en su capacidad para capturar conocimiento.

2. En relación a las tres variables empleadas para medir los stocks de conocimiento, la única que no es significativa es el número de patentes. Una razón que explica esta falta de significatividad puede atribuirse a que el número de patentes no refleja la calidad de las mismas. Otro motivo aduce a que el coste asociado a determinadas patentes podría ser prohibitivo para algunas empresas.

3. Los stocks de conocimiento organizativo tienen mayor impacto sobre los resultados que los flujos de conocimiento. 
Por tanto, para el caso de empresas intensivas en conocimiento, los resultados de este trabajo indican que dos variables que miden los stocks de conocimiento organizativo (productos en desarrollo y trabajos citados) y una asociada a los flujos (área geográfica en la que se ubica la empresa), tienen relación positiva con el desempeño empresarial.

Otro modelo que relaciona conocimiento y resultados es el que presenta Bontis (2000). Se trata de un modelo que nos permite determinar la relación existente entre el capital intelectual y el desempeño, pero que también nos aporta luz sobre la relación existente entre los diferentes bloques que componen el capital intelectual: humano, organizativo y relacional.

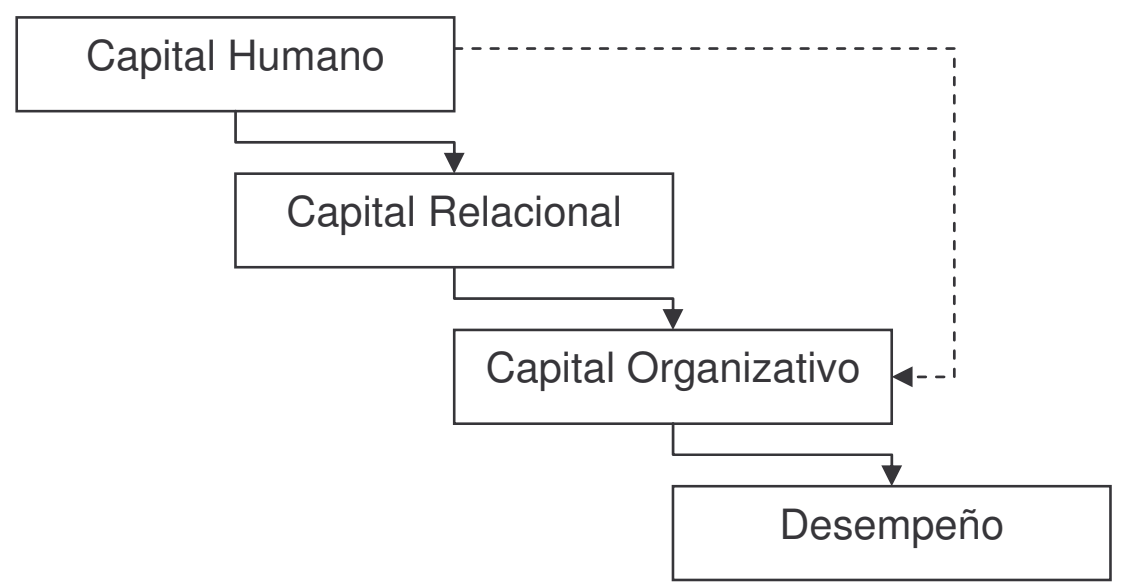

Figura 29: Modelo de Capital Intelectual y Desempeño (Bontis, 2000)

En la figura podemos comprobar que, la relación entre capital humano y capital organizativo es la que más llama la atención, ya que difiere considerablemente según se considere un determinado tipo de empresa.

Así, en las empresas de servicios, aparece una relación positiva entre ambas pero no significativa. Por el contrario, en las empresas no consideradas como de servicios, la relación entre el capital humano y el capital organizativo además de ser positiva resulta ser significativa. 
La interpretación empresarial que se le puede dar a este resultado en las empresas no consideradas como de servicios, es que la mayoría del capital intelectual se absorbe en elevados desembolsos de capital (maquinaria y equipamento), tal como ocurre en las empresas orientadas a la producción.

El hecho de que la relación entre el capital humano y el organizativo no aparezca estadísticamente como significativa, implica que todavía existe un gran desafío en las empresas que se consideran intensivas en conocimiento para codificar parte del conocimiento tácito que se encuentra en sus empleados. 


\subsection{LAS COMPETENCIAS DIRECTIVAS (CD): VARIABLE MEDIADORA EN LA RELACIÓN GESTIÓN DE CONOCIMIENTO (GC) Y RESULTADOS ORGANIZATIVOS (RO)}

De los modelos expuestos, estamos en la línea de Davenport (1999) de introducir variables intermedias que medien la relación entre la GC y los resultados. Las tres variables intermedias que propone Davenport (1999) son: la mejora de las habilidades y destrezas de los empleados de la organización (capital humano), la mejora en los procesos de negocio o áreas funcionales y la generación de ideas e innovaciones que generen nuevas oportunidades de negocio.

Consideramos que son las competencias directivas las que se convierten en las variables mediadoras en la relación entre la GC y el desempeño organizativo.

\subsubsection{Efectos de la introducción de la GC sobre las Competencias Directivas (CD)}

El estudio de cómo se generan o regeneran las competencias directivas está adquiriendo mayor relevancia, aunque todavía están poco estructuradas las acciones, decisiones directivas y organizativas que permiten renovar la cartera de activos estratégicos (Ranft y Lord, 2002; Zollo y Winter, 2002).

Camisón (2002a) identifica tres modelos directivos particularmente relevantes para el estudio de la generación de competencias directivas dinámicas, dado su creciente grado de implantación en la práctica empresarial y por la literatura académica desarrollada: la dirección de calidad, la GC y los acuerdos de cooperación o integración de la empresa en alianzas estratégicas.

Cardona y García-Lombardía (2005) identifican a su vez, tres modelos distintos de gestión del talento, sobre la distinción entre la dirección por tareas, la dirección por objetivos, y finalmente, la dirección por competencias. 
La GC se considera el principal impulsor del conjunto de competencias de una organización (Lei, Hitt y Bettis, 1996). Estos autores sostienen que el potencial de aprendizaje es uno de los principales factores de diversidad entre las empresas, y la ventaja competitiva radica principalmente en la manera en la que el conocimiento enriquece los procesos de aprendizaje.

Zollo y Winter (2002: 341) argumentan que una manera de crear competencias distintivas en aprendizaje es mediante el proceso que articula el conocimiento implícito a través de discusiones colectivas, dando cuenta de los procesos de evaluación. Compartir experiencias individuales y compararlas con las de los compañeros puede mejorar el nivel de comprensión de los mecanismos causales que intervienen en la relación de determinadas tareas (Liebowitz y Beckman, 1998).

En aquellas organizaciones en las que se fomenta la reflexión, la crítica y el cambio con el fin de mejorar continuamente, las nuevas ideas son muy valoradas independientemente del nivel jerárquico del capital humano que las formule (Cook y Yanow, 1996).

Si además, la organización alienta el aprendizaje continuo y la adquisición de nuevas habilidades y conocimientos mediante la rotación de puestos o la ampliación de tareas en el puesto, o introduce planes de carrera que incentivan el aprendizaje continuo, se fomenta la habilidad para desarrollar una cultura de innovación y aprendizaje, impulsando el trabajo en equipo y la resolución de problemas en grupo (Crossan, Lane y White, 1999).

Entender la GC desde un punto de vista holístico mejora la competencia en aprendizaje. Senge (1990) dota a este principio de especial trascendencia, ya que considera al pensamiento sistémico como la quinta disciplina para el aprendizaje organizativo. La visión compartida supone aptitudes para configurar visiones del futuro compartidas que propicien un compromiso (Beckman, 1997). El trabajo en equipo implica el dominio de la discusión y del diálogo, que es la capacidad de los miembros de un grupo de apartar sus presunciones y entrar 
en un auténtico pensamiento conjunto, lo cual favorece el aprendizaje (Senge, 1990).

Las normas y valores de una organización influyen en la capacidad de aprendizaje individual y colectivo. Esta capacidad se ve favorecida por una cultura que favorezca el diálogo, la comunicación, la apertura al cambio y a las múltiples perspectivas, la transparencia, la confianza, el riesgo, etc. (Argyris y Schon, 1978).

Un enfoque centrado en las personas también tiene repercusión sobre las capacidades de aprendizaje. Así, Yeung et al.(1999) consideran que establecer acciones encaminadas a identificar las necesidades de recursos y de información de todo el capital humano de la organización, así como la instauración de procedimientos para conocer su opinión y satisfacción mejora sus capacidades en aprendizaje.

Ranft y Lord (2002: 420) sostienen que la transferencia de conocimiento tiene lugar cuando se adquieren y se utilizan activos basados en el conocimiento. Así, una organización orientada al desarrollo y transferencia del conocimiento permite a su capital humano acceder con mayor rapidez y sin trabas al conocimiento que necesita (Szulanski, 1996). Esta transferencia puede llevarse a cabo mediante técnicas variadas como el diálogo y el debate. Los procedimientos de benchmarking interno, también pueden ser útiles para compartir las mejores prácticas entre departamentos y empleados.

La literatura también ha enfatizado que la codificación facilita la difusión del conocimiento existente (Winter, 1987; Nonaka, 1994). Zollo y Winter (2002) señalan que el desarrollo de una herramienta que recoja la ejecución de una tarea compleja, ya supone para los individuos relacionados con ella un esfuerzo para crear un modelo mental en el que se señalen las actividades a realizar bajo determinadas condiciones. Además, la codificación permite un mecanismo de soporte para el proceso de evolución de conocimiento, ya que fomenta la generación de nuevas propuestas que cambien las rutinas actuales. 
El aprendizaje continuo en la organización tiene un efecto positivo sobre la capacidad de crecimiento del stock de conocimiento (Yeung et al. 1999). Estos autores destacan que en aquellas organizaciones en las que se fomenta el compromiso con el aprendizaje y la innovación, se obtienen programas más eficaces orientados al desarrollo interno de competencias.

La gestión por competencias permite establecer programas orientados al desarrollo interno de competencias, tomando conciencia la empresa de sus competencias en innovación, especialmente respecto a las tecnologías clave. El desarrollo de competencias puede favorecerse introduciendo en la empresa programas de formación, equipos de trabajo multidisciplinares o fomentando la diversidad en las líneas de investigación (Dosi, Nelson y Winter, 2000).

Con todo ello, la introducción de los principios y prácticas de GC tiene una incidencia en la dimensión de conocimiento de las competencias dinámicas, incrementando el stock de conocimiento disponible, la eficacia del sistema de GC y la habilidad de la empresa en la gestión de proyectos de $\mathrm{I}+\mathrm{D}+\mathrm{i}$. 


\subsubsection{Modelo teórico e hipótesis de la investigación}

Las relaciones causa-efecto entre las variables independientes, intermedias y dependientes se resumen en el siguiente gráfico, a partir de Palacios (2002).

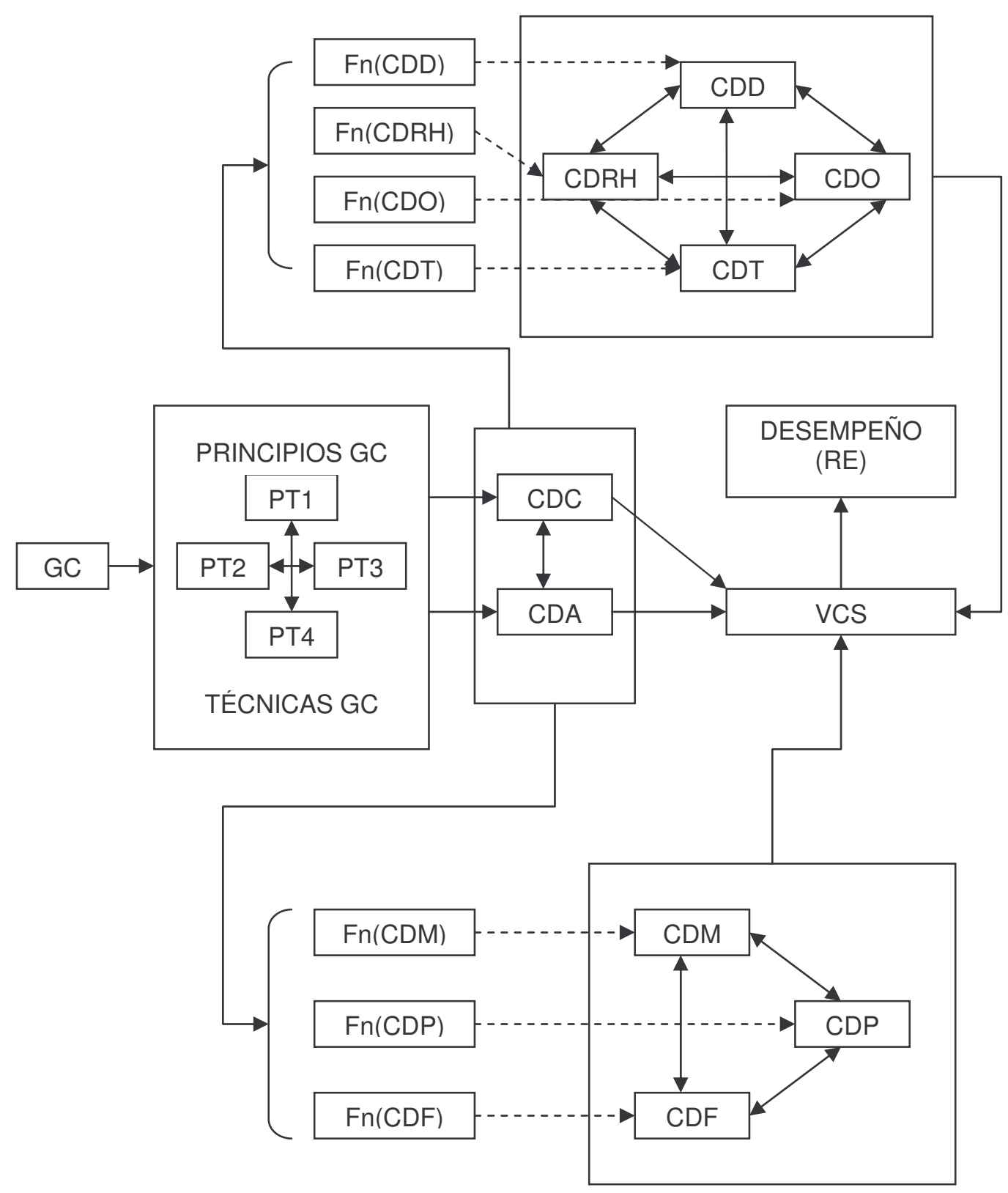

Figura 30: Modelo de Gestión de Conocimiento (Palacios, 2002) 
Donde,

GC: Gestión de Conocimiento

PT: Principios y Técnicas

CDC: Competencias Distintivas en Conocimiento

CDA: Competencias Distintivas en Aprendizaje

CDD: Competencias Distintivas en Dirección

CDRH: Competencias Distintivas en Recursos Humanos

CDO: Competencias Distintivas en Organización

CDT: Competencias Distintivas en Tecnología

CDM: Competencias Distintivas en Marketing

CDP: Competencias Distintivas en Producción

CDF: Competencias Distintivas en Finanzas

VCS: Ventajas Competitivas Sostenibles

RE: Rentas Económicas

Este modelo presenta un cierto grado de complejidad. Incluye tres tipos de competencias distintivas: funcionales, coordinación y dinámicas. Las funcionales se refieren a las áreas de marketing, producción y finanzas. Las de coordinación hacen referencias las áreas de dirección, recursos humanos, organización y tecnología. Y las dinámicas (o de innovación), a las de conocimiento y aprendizaje. Dado el enfoque teórico del trabajo nos vamos a centrar en las competencias dinámicas o de innovación, que tal como sostienen Teece, Pisano y Shuen (1997), son las que tienen incidencia en la competitividad empresarial. 
Respecto a la relación entre las competencias distintivas dinámicas y el proceso de generación y mantenimiento de las ventajas competitivas, cabe señalar que el enfoque basado en competencias considera que este tipo de competencias son claves para el desarrollo en la empresa de nuevas competencias (Revilla, 1996; Teece, Pisano y Shuen, 1997; DeCarolis y Deeds, 1999; McEvily y Chakravarthy, 2002). Además, la competencia en aprendizaje reúne las condiciones de activo estratégico, ya que es un activo escaso, tácito, idiosincrásico de la organización, y por tanto, difícilmente imitable e imperfectamente móvil (Zollo y Winter, 2002). Autores como Miles et al. (1998) y Teece (1998) defienden la idea de que en el futuro la creación de conocimiento organizativo y su buena gestión serán la única ventaja competitiva sostenible. En definitiva, tal como afirma Teece, Pisano y Shuen (1997) son las que tienen influencia en la competitividad empresarial.

En la siguiente figura se presenta el modelo definitivo que Palacios (2002) ha tenido en cuenta en la investigación para el análisis competitivo de la GC. El modelo incluye la GC conceptuada a partir de técnicas y principios, las CD como variable mediadora en la influencia de la GC sobre el desempeño, y el desempeño propiamente.

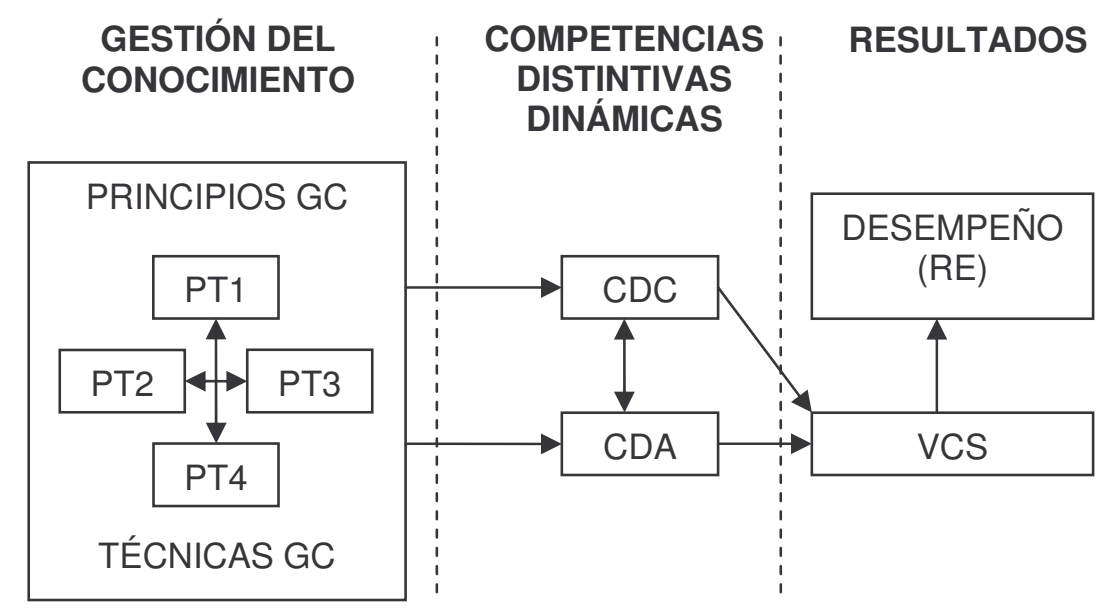

Figura 31: Modelo simplificado de Gestión de Conocimiento (Palacios, 2002) 
A partir de este modelo teórico desarrollado por Palacios (2002) y del modelo presentado en el capítulo anterior de Cardona y García-Lombardía (2005), hemos elaborado un modelo propio más específico, en el que nos centramos en el análisis de las Competencias Directivas a tres niveles: Estratégico, Intratégico y Personal. Las Competencias Directivas, aparecen en el modelo como una variable intermedia entre la GC (desde la perspectiva de Características y Capacidades Organizativas) y los RE, (tanto tangibles como intangibles).

Proponemos a continuación un modelo que integre los modelos existentes, y respecto a la GC, nos basamos en una distinción entre capacidades y características organizativas. Capacidades organizativas (internas) que integran flujos y stocks de conomicmiento. Los flujos de conocimiento son fundamentalmente de dos tipos: exploradores y explotadores. Los stocks de conocimiento los diferenciamos a nivel organizativo, de grupos de trabajo y de los individuos. Por otro lado, las Características organizativas (externas) hacen referencia a indicadores de la Vigilancia del Entorno Externo (VEE), Tecnologías de la Información (TI), Procesos de Planificación Estratégica (PPE) y Sistemas de Medición de la Gestión (SMG).

Tras la revisión bibliográfica, hemos optado por una clasificación de las $C D$ en tres niveles: estratégico, intratégico y personal. Dentro del nivel estratégico, consideramos de especial relevancia indicadores como la Visión de Negocio (VDN), la Gestión de Recursos (GDR), la Orientación al Cliente (OAC), el Networking (NET) y la Negociación (NEG); a nivel intratégico, hemos seleccionado indicadores como la Comunicación (COM), la Gestión de Conflictos (GDC), la Delegación (DEL), el Coaching (COA), el Trabajo en Equipo (TEE) y el Carisma (CAR); y en la esfera personal, la Proactividad (PRO), la Gestión Personal (GP), la Mejora Personal (MP), el Autogobierno (AUT) y la Integridad (INT).

Finalmente, hemos relacionado ambos constructor con la dimensión RO no económicos y económicos. Tomamos como referencia de los no económicos: 
la Satifacción de los Clientes (SDC), el Incremento de Clientes (IDC), la Satisfacción de los Empleados (SDE), el Nivel de Calidad (NDC) y la Reputación (REP); mientras que como indicadores económicos utilizamos la Rentabilidad sobre Fondos Propios (RFP), las Ventas (VTA), Beneficios (BEN), la Productividad laboral (PRO) y los Costes de Producción (CDP)

Figura 32: Modelo inicial

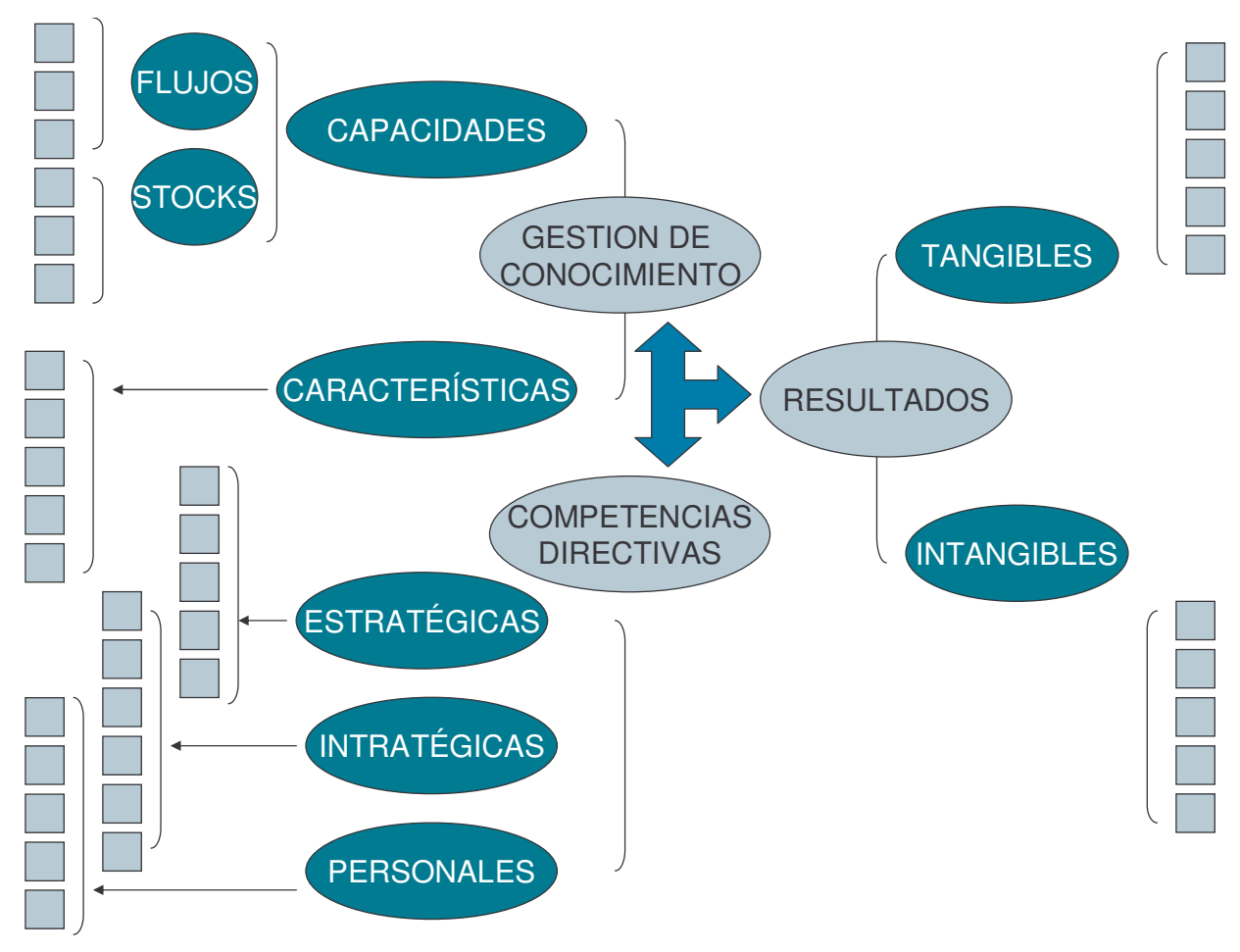

Este primer modelo, podemos presentarlo en una segunda versión más simplificada, que nos permite hacernos idea de las relaciones causales que pueden existir entre las variables intermedias.

Figura 33: Modelo simplificado

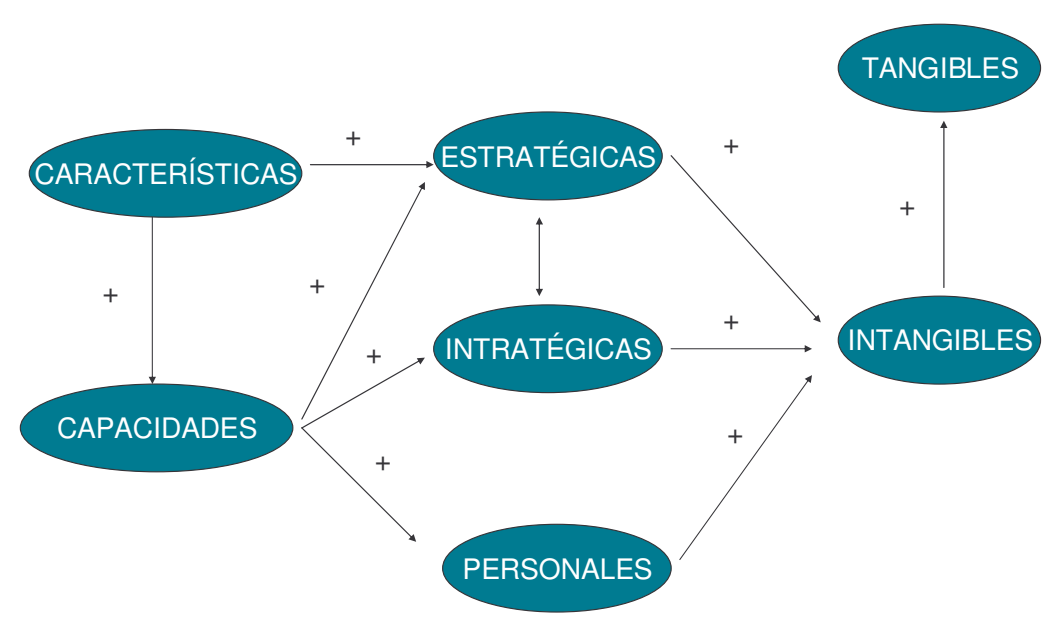


En este modelo simplificado, hemos tratado de representar las relaciones de causalidad que como se puede observar comienzan por las características externas organizativas y que influyen tanto en las capacidades organizativas externas como en las competencias directivas estratégicas, ya que hacen referencia más propiamente a los aspectos externos de la dirección. Por otro lado, las capacidades organizativas internas están relacionadas con las tres dimensiones de las competencias directivas. Las competencias directivas estratégicas a simple vista presentarían una correlación con las intratégicas y una relación de causalidad con los resultados organizativos intangibles, mientras que las competencias directivas intratégicas y personales las relacionamos como causa de los resultados organizativos intangibles. Finalmente, los resultados organizativos intangibles, estarían relacionados causalmente con los tangibles.

Por último, presentamos una versión holística del modelo que vamos a tratar de contrastar empíricamente, con una serie de relaciones intermedias que sigue la línea de Decarolis y Deeds (1999):

Figura 34: Modelo final (Lara, 2005)

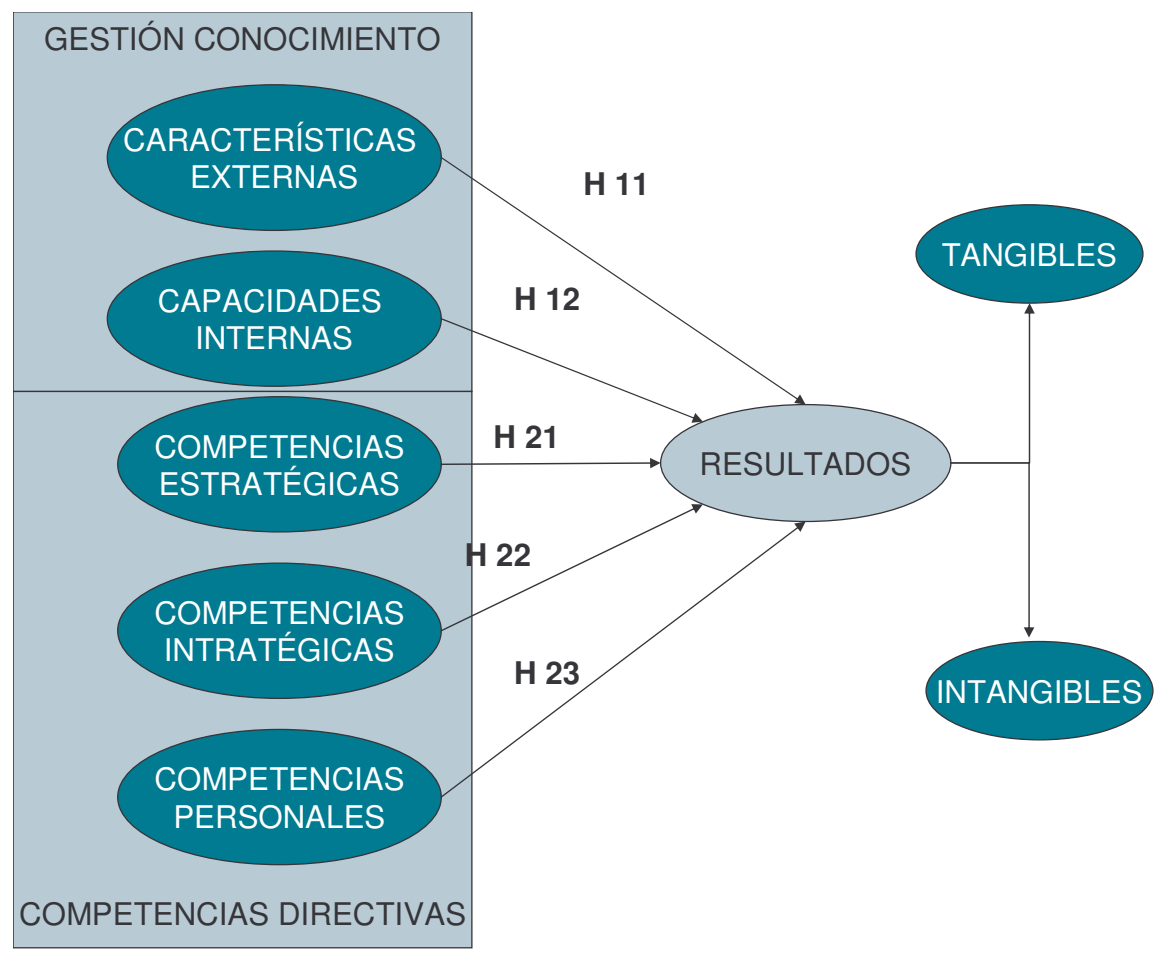


A continuación resumimos las principales hipótesis que pretendemos contrastar en este trabajo. Para ello, ordenamos la exposición según el mismo orden que hemos seguido para construcción del modelo.

Vamos a enunciar cuatro conjuntos de hipótesis.

H1: "El grado en que una organización está concienciada con la implantación de un sistema de Gestión del Conocimiento (GC), está positivamente relacionado con los Resultados Organizativos (RO)."

Existen ocasiones en las que las actitudes y percepciones que tiene la dirección cuando implanta un programa de GC, no se corresponden con los Resultados Organizativos, es decir, la dirección afirma estar comprometida con la GC, pero sin embargo estas palabras no se trasladan en un liderazgo comprometido y una actuación acorde, que se refleje en los propios RO.

Nuestro interés radica en conocer si aquellas empresas que dicen estar concienciadas con la GC, ven directamente correlacionada su implicación con los RO tanto tangibles como intangibles.

Para desarrollar esta primera hipótesis, se hace necesario plantearnos otras dos subhipótesis:

- H11: "El grado de desarrollo de las Características Externas (CE), técnico estructurales, está positivamente relacionado con la obtención de los Resultados Organizativos (RO)"

- H12: "El grado de desarrollo de las Capacidades Internas (CI), de Aprendizaje, está positivamente relacionado con la obtención de los Resultados Organizativos (RO)" 
En segundo lugar, trataremos de probar si existe o no una relación positiva de los $\mathrm{RO}$, en función del desarrollo de las $\mathrm{CD}$ tanto a nivel estratégico, intratégico, como personal.

H2: "El grado en que una organización tiene desarrolladas la Competencias Directivas (CD), está positivamente relacionado con los Resu/tados Organizativos (RO)."

En este sentido, podríamos desglosar esta segunda hipótesis en tres subapartados, en función de la relación de cada nivel de Competencias Directivas, con los Resultados Organizativos.

- H21: "El grado en que una organización tiene desarrolladas las Competencias Directivas Estratégicas (CDE), está positivamente relacionado con los Resultados Organizativos (RO)."

- H22: "El grado en que una organización tiene desarrolladas las Competencias Directivas Intratégicas (CDI), está positivamente relacionado con los Resultados Organizativos (RO)".

- H23: "El grado en que una organización tiene desarrolladas las Competencias Directivas Personales (CDP), está positivamente relacionado con los Resultados Organizativos (RO)".

En tercer lugar, se nos plantea una tercera hipótesis intermedia, que trataría de relacionar entre sí el desarrollo de la Gestión del Conocimiento con el desarrollo de las Competencias Directivas, que podríamos enunciar de la siguiente manera:

H3: "El grado en que una organización está concienciada con la implantación de un sistema de Gestión del Conocimiento (GC), está positivamente relacionado con el desarrollo de las Competencias Directivas (CD) de la misma." 
A su vez, esta interrelación, permite adentrarnos en una múltiple variedad de combinaciones posibles entre los componentes principales de ambos constructor: las características y las capacidades organizativas (GC); y los tres niveles estratégico, intratégico y personal (CD). Sin embargo, nos limitaremos a contrastar este hipótesis general.

Por último, en cuarto lugar, planteamos una última hipótesis resumen de las anteriores, en la que pretendemos sintetizar la expresión de nuestro modelo, relacionando ambas variables intermedias con los Resultados Organizativos. De esta forma, queda planteada de la siguiente manera:

H4: "Los Resultados Organizativos (RO) se pueden explicar en función de la intermediación de la Gestión del Conocimento (GC) y las Competencias Directivas (CD)."

Expresado matemáticamente, podríamos plantear el siguiente modelo de función lineal:

\section{$\mathbf{R O}=\mathbf{G C}+\mathbf{C D}$}

Donde:

$$
\begin{aligned}
& \mathrm{RO}=\mathrm{RT}+\mathrm{RI} \\
& \mathrm{GC}=\mathrm{CARO}+\mathrm{CAPO} \\
& \mathrm{CD}=\mathrm{CDE}+\mathrm{CDI}+\mathrm{CDP}
\end{aligned}
$$

En consecuencia:

$$
\begin{aligned}
& R O=R T+R I=(C A R O+C A P O)+(C D E+C D I+C D P) \\
& =R T+R I=(O(C A R+C A P))+(C D(E+I+P))
\end{aligned}
$$

$$
R I=[(0(C A R+C A P))+(C D(E+I+P))]-R T
$$




\section{CAPÍTULO 5:}

\section{DISEÑO DE LA INVESTIGACIÓN EMPÍRICA}

5.1. OBJETIVOS Y CONTENIDOS

5.2. UNIDADES DE OBSERVACIÓN

5.3. AMBITO DE ESTUDIO

5.4. DISEÑO DE INSTRUMENTOS DE MEDICIÓN

5.5. DISEÑO DE LA ENCUESTA

5.6. CARACTERISTICAS DE LA MUESTRA Y TRABAJO DE CAMPO 


\subsection{OBJETIVOS Y CONTENIDOS}

El objetivo básico de este capítulo es el de abordar las cuestiones relacionadas con el diseño de la investigación empírica, necesarias para contrastar las hipótesis que acabamos de plantear en el capítulo anterior, y cuyos resultados serán expuestos en el capítulo siguiente.

Kinnear y Taylor (1993:127) señalan que el diseño de la investigación puede catalogarse como un plan básico que guía las etapas de recolección de datos y el análisis del proyecto. Se debe especificar el tipo de información que se requiere, las fuentes de datos y los procedimientos utilizados para su recolección. Igualmente, el diseño de la investigación empírica debe ser acorde con los objetivos planteados y, con el modelo conceptual.

De acuerdo con estos objetivos básicos, la investigación empírica está estructurada en dos etapas sucesivas aunque interrelacionadas. La primera de ellas tiene como objetivo desarrollar un instrumento de medida del modelo. La segunda, pretende aplicar la información obtenida de dicho instrumento de medida para evaluar los efectos del modelo sobre los resultados.

Dos cuestiones básicas a abordar en el diseño de la investigación empírica son la delimitación de las unidades de observación y del ámbito de estudio. La determinación del ámbito de estudio debe estar en consonancia con los objetivos propuestos. Por tanto, su elección está condicionada por la necesidad de seleccionar un conjunto de empresas, a partir de las cuales obtener información relevante para proceder al contraste con el modelo teórico.

A continuación se llevará a cabo un análisis general sobre el diseño de instrumentos de medida necesarios para recabar información, para pasar a continuación al diseño particular de los instrumentos de medida para la GC, las CD y el RO. 
Seguidamente, se procederá a desarrollar el diseño de la encuesta, que es el modelo de observación utilizado con el fin de obtener la información necesaria para el contraste de las hipótesis. Se definirán las características de la muestra y se explicará el trabajo de campo.

Finalmente, justificaremos la metodología analítica empleada para el contraste de las hipótesis, que a su vez viene determinada por los objetivos y la naturaleza de los datos. Así, argumentaremos como los modelos de ecuaciones estructurales se convierten en una metodología válida para analizar los efectos del modelo. 


\subsection{UNIDADES DE OBSERVACIÓN}

La realidad a observar en nuestro estudio es el grado en que una empresa está concienciada con los principios de la GC, lo que a su vez se materializa en un conjunto de características y capacidades organizativas, la creación de CD estratégicas, intratégicas y personales; y la mejora del resultado.

La unidad de análisis que vamos a considerar será, por tanto, la empresa, que como unidad es la que se involucra en una iniciativa de GC. 


\subsection{AMBITO DE ESTUDIO:}

\section{Empresas de la Comunidad Valenciana: empresas intensivas en conocimiento}

Durante los últimos años, las empresas intensivas en conocimiento están adquiriendo cada vez mayor relevancia. Básicamente son empresas donde la mayoría del trabajo tiene un carácter intelectual, y en la que sus empleados, la mayoría de ellos cualificados, conforman la principal fuerza de trabajo (McEvily y Chakravarthy, 2002; Ranft y Lord, 2002). Estas empresas ofrecen productos/servicios cualificados utilizando como principal recurso el conocimiento de sus empleados. Este es también el caso de la Comunidad Valenciana, que en los últimos años está experimentando un importantísimo auge en la aparición de empresas intensivas en conocimiento, como lo pone también de manifiesto el aumento de actividad económica orientada al sector servicios. En este sentido, cobra aún mayor valor los resultados que podamos extraer de nuestra investigación.

El concepto de empresas intensivas en conocimiento, sin embargo, es un poco vago, ya que no existe un criterio objetivo para determinar el grado en que una empresa es intensiva en conocimiento. No existe una clase de equivalencia que determine de forma nítida las fronteras de este tipo de empresas (Alvesson, 2000).

Las funciones de selección, retención y desarrollo de personal competente son capitales en las empresas intensivas de conocimiento. Uno de los principales problemas de este tipo de empresas es retener al personal clave, manteniendo su compromiso y lealtad con la empresa. Aunque también es un problema para cualquier empresa, en este caso es más acuciante debido a dos circunstancias:

1.- Los empleados son el recurso más importante de la empresa. Algunas veces es el único significativo. El capital y el mobiliario adquieren en este caso menos importancia. 
2.- En muchos casos, un grupo de empleados de la empresa crea una nueva empresa propia y se lleva consigo a clientes de la primera. En este caso, el problema es doble ya que la empresa pierde capital humano y capital relacional, en definitiva, se minora substancialmente su capital intelectual.

Alvesson (2000) destaca la significatividad que tiene la identidad social a la hora de entender la lealtad de los empleados. La identidad social se refiere a la categoría con la que el individuo se identifica (división, ocupación, nacionalidad, étnica, etc.). Así, una identidad social específica con un determinado grupo incrementa la probabilidad de que ciertas ideas, valores y normas asociadas con el grupo se incorporen y asimilen más fácilmente.

Respecto a las características propias de los empleados de este tipo de empresas, hay que destacar un elevado grado de motivación y conformidad. En muchos casos, la libertad en la realización de tareas se valora más que una gratificación salarial (Alvesson, 2000). 


\subsection{DISEÑO DE INSTRUMENTOS DE MEDICIÓN}

La escala de medición debe ser útil para recoger información sobre el constructo a evaluar, y dicha información debe ser obtenida por el procedimiento más exacto y fiel posible. Además, debe cumplir con una serie de propiedades sociométricas para su valoración.

Desarrollamos a continuación el procedimiento genérico que vamos a seguir para elaborar un instrumento de medición sobre un constructo determinado, y que además, cumpla las propiedades sociométricas exigibles a las escalas de medición en las ciencias sociales.

Siguiendo para ello a Churchill (1979) y De Vellis (1991), distinguimos:

FASE 1: Conceptuación del constructo (Revisión de la literatura)

FASE 2: Identificar las dimensiones que forman el dominio del constructo (Revisión de la literatura)

FASE 3: Generar las variables o ítems a medir

FASE 4: Purificar y reducir la escala (Panel de expertos, pruebas piloto)

FASE 5: Elaboración del cuestionario definitivo

FASE 6: Diseño de la muestra y obtención de datos sobre la muestra elegida.

FASE 7: Segunda validación de la escala (Cumplimiento de las propiedades sociométricas). 


\subsubsection{Diseño del instrumento de medida}

La literatura sobre la GC, en lo que se refiere al desarrollo de instrumentos de medida, se ha polarizado hacia la medición del capital intelectual (Bueno, 1998; Bontis, 2000) y en algún caso al del conocimiento organizativo (DeCarolis y Deeds, 1999). En nuestra investigación entendemos que la GC no es un concepto directamente medible, sino que se trata de un constructo que se deriva de un conjunto de variables observables que pueden valorarse a través de una encuesta.

Para diseñar el instrumento de medida de la GC, seguiremos el esquema propuesto anteriormente.

\section{FASE 1: Conceptuación y dimensionalidad del constructo GC}

El primer paso consiste en conceptuar el constructo a medir. En este sentido, hemos conceptuado la GC como una "sistema de gestión que se compone por un conjunto de características técnico estructurales $y$ capacidades organizativas de aprendizaje, cuyo objetivo es el de crear, convertir, difundir $y$ aprovechar el conocimiento generado en las personas a través del desarrollo de sus aptitudes y habilidades."

A partir de esta conceptuación de la GC, distinguimos la dimensión de las características de las capacidades. Así, las características organizativas se componen a su vez de cuatro apartados: vigilancia del entorno externo, tecnologías de la información, procesos de planificación estratégica y sistemas de medición. Todas ellas configuran las características técnico estructurales de que goza una organización. Cada apartado ha sido valorado con 5 items, lo que supone que esta primera dimensión de la GC contenga 20 items.

En segundo lugar, y dentro del constructo GC, aparece una segunda dimensión, denominada capacidades organizativas que se compone a su vez de dos bloques: stocks y flujos de conocimiento. En primer lugar, el bloque de los stocks o inventarios de conocimientos está medido con 9 items, tratando de medir el conjunto de capacidades que ostentan las personas, grupos y 
organizaciones. En segundo lugar, los flujos de conocimiento o relaciones de influencia entre las personas y las organizaciones, se miden con un conjunto de 6 ítems, diferenciando las relaciones de carácter explorador, de las relaciones de carácter explotador. De esta manera, la primera dimensión de GC queda medida por un total de 35 items.

\section{FASE 2: Identificación de los atributos y construcción de la escala de medición.}

Centrándonos más en el modelo de medida, entendemos la GC como un constructo multidivisional que se manifiesta a través de diferentes características y capacidades organizativas. Así, podemos considerar la GC como un modelo latente en el que las dimensiones representan al constructo, mientras que los indicadores representan a cada dimensión, siendo las dimensiones no observables. Recordemos que en el caso de los modelos latentes, el constructo es una abstracción de orden superior a partir de las dimensiones. Las dimensiones son en sí mismas constructos que se rigen como manifestaciones de un constructo más general. Así, el constructo se puede representar como la comunalidad de las dimensiones. El modelo de operativización de la GC lo resumimos en la siguiente figura.

Figura 35: Modelo operativo de la GC

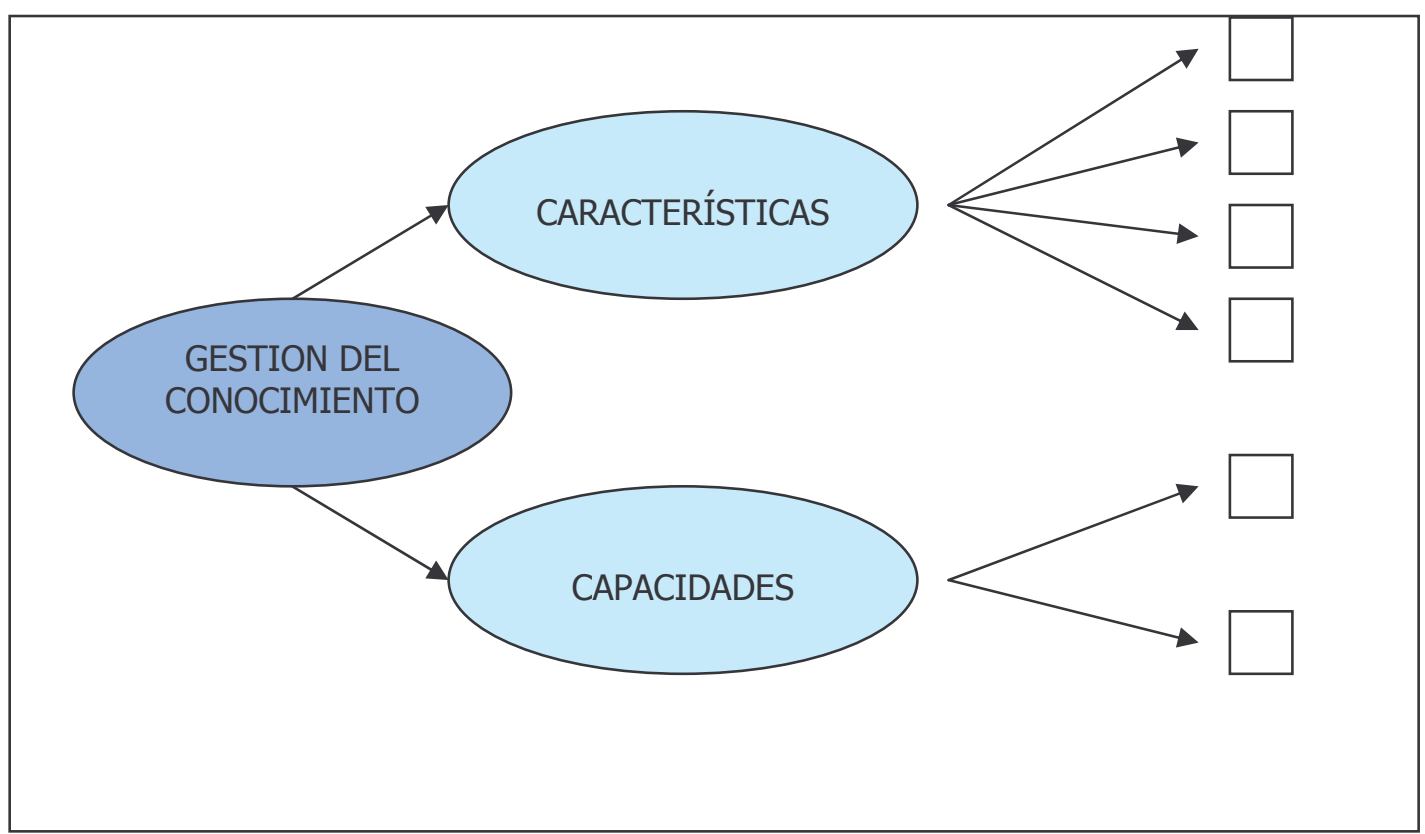


Una vez tenemos el modelo operativo desarrollado, procederemos a la generación y selección de ítems. El procedimiento que se ha seguido para obtener los indicadores ha sido mediante una revisión extensa de la literatura.

El principal problema para generar ítems surge por la inexistencia de trabajos empíricos anteriores, salvando el de Palacios (2002). Aún así, hemos seguido junto con el señalado anteriormente, los trabajos de Davenport y Prusak (1998), Dibella y Nevis (1998) y Rastogi (2000), en los que se hace referencia a los factores críticos de éxito en la implantación de un programa de GC. Y por otro lado, los referentes a escalas de medición procedentes del aprendizaje organizativo.

Moilanem (2001:10) realiza una revisión de los principales instrumentos utilizados para evaluar la capacidad de aprendizaje organizativo. Este autor analiza los instrumentos de medida en base a cuatro características: arquetipo, holístico, entendible y testado. En la siguiente tabla mostramos algunos instrumentos de medición de la capacidad de aprendizaje organizativo junto con las cuatro características comentadas anteriormente.

Características sobre los cuestionarios de aprenidizaje organizativo (Moilanen, 2001)

\begin{tabular}{|c|c|c|c|c|}
\hline Intrumento & Arc & Ho & Ent & Testado \\
\hline $\begin{array}{l}\text { The Learning Company Questionnaire } \\
\text { (Pedler, Burgoyne y Boydell, 1997) }\end{array}$ & No & $\mathrm{Si}$ & $\mathrm{Si}$ & No \\
\hline $\begin{array}{l}\text { The Complete Learning Organization } \\
\text { Benchmark (Mayo y Lank, 1994) }\end{array}$ & No & Si & $\mathrm{Si}$ & No \\
\hline $\begin{array}{l}\text { Learning Enviroment Survey } \\
\text { (Tannenbaum, 1997) }\end{array}$ & No & No & $\mathrm{Si}$ & Si \\
\hline $\begin{array}{l}\text { The Learning Audit } \\
\text { (Pearn, Roderick y Mulrooney, 1995) }\end{array}$ & No & No & No & No \\
\hline $\begin{array}{l}\text { Learning Organization Capability } \\
\text { Assessment (Redding y Catalanello, 1994) }\end{array}$ & Si & $\mathrm{Si}$ & No & No \\
\hline $\begin{array}{l}\text { Dimensions of the Learning Organization } \\
\text { Questionnaire (Yang, Watkins y Marsick, 1998) }\end{array}$ & No & $\mathrm{Si}$ & $\mathrm{Si}$ & $\mathrm{Si}$ \\
\hline
\end{tabular}

Tabla 8: Características de los cuestionarios de aprendizaje organizativo (Moilanen, 2001)

De los instrumentos dedicados a la medición de la capacidad de aprendizaje organizativo nos vamos a centrar en cuatro: el cuestionario de Goh y Richards (1997), el cuestionario de Tannenbaum (1997), el instrumento de Brown y Eisenhardt (1998) y el cuestionario de Yeung et al. (1999). 
1. Cuestionario de Goh y Richards (1997): La encuesta sobre aprendizaje organizativo que desarrollan estos autores tiene como objeto identificar y medir las características organizativas esenciales que favorecen el aprendizaje organizativo.

2. Cuestionario de Tannenbaum (1997): Este instrumento está encaminado a determinar el entorno en el que se produce el proceso de aprendizaje. Así, se estudian los aspectos relacionados con el entorno laboral que tienen incidencia sobre el aprendizaje organizativo. El lenguaje un tanto informal con el que están redactados los ítems facilita su respuesta.

3. Instrumento de Brown y Eisenhardt (1998): El objetivo de este instrumento es determinar si una empresa se encuentra situada "al filo del caos".

4. Cuestionario de Yeung et al. (1999): Este cuestionario se utiliza para medir las capacidades de aprendizaje en la organización. El cuestionario es bastante amplio, ya que además de recoger cuestiones propias del aprendizaje organizativo, también incluye otros aspectos de la empresa. Para ello se estructura en siete secciones: la estrategia, la cultura, los tipos de aprendizaje de las organizaciones, las capacidades para aprender, la capacidad para cambiar, los procedimientos de recursos humanos y el contexto de negocio. El negocio se entiende como unidad primaria de la organización en la que trabaja la persona que responde al cuestionario.

A partir de la revisión teórica realizada, obtuvimos un primer conjunto de indicadores que era bastante extenso, teniendo en cuanta las posteriores limitaciones prácticas del cuestionario, por lo que se redujo la escala utilizando un panel de expertos, de forma que los indicadores reflejasen las características esenciales del constructo y el cuestionario no fuera demasiado extenso.

El proceso de reducción de la escala tuvo lugar en dos etapas: en una primera etapa utilizando la metodología Delphi, y en una segunda fase mediante una muestra piloto. El método Delphi nos resulta útil para reducir la 
escala a partir de las opiniones expuestas por el grupo de expertos que componen el panel. Respecto a la muestra piloto, nos permite comprobar aspectos referidos a la adecuación de la escala, obsevando el grado de dificultad a la hora de responder el cuestionario, su extensión o la manera de redactar las cuestiones.

El método Delphi elimina la influencia que puedan tener determinado individuos en la interacción personal. Además, está libre de los posibles sesgos y desventajas asociados a la puesta en práctica de reuniones grupales. De esta forma evita la pérdida de tiempo que se produce como consecuencia de discusiones que tienden a caer en la rutina, cuando miembros del grupo se centran en razonamientos muy concretos durante mucho tiempo. Al reducir la conformidad o presión del grupo, asegura todas las opiniones en la respuesta final.

Una cuestión a definir a la hora de realizar el método Delphi, es determinar el número de expertos que van a participar. El número de expertos que participan en un panel suele oscilar entre 10 y 30 . Un número elevado de participantes hace más fiables los resultados, pero si son homogéneos no tiene sentido incrementar el número, ya que pocas ideas nuevas pueden aportar y más complejo se hace el posterior análisis de los resultados.

Una vez hemos comentado el número de expertos que deben componer el panel, hemos de definir una serie de criterios que deben reunir éstos para formar parte del panel. Destacamos dos requisitos para formar parte en la base de expertos:

1. Conocimiento o experiencia en materias relacionadas con la GC.

2. Conocimiento de las empresas integrantes de la muestra, preferiblemente en temas relacionados con la GC. 
Siguiendo estos criterios, el panel quedó definitivamente constituido por 11 personas, con la siguiente procedencia: 6 académicos (Catedráticos de Universidad y Profesores de reconocidas Escuelas de Negocios, nacionales e internacionales), 5 expertos profesionales de reconocido prestigio, correspondientes a directivos de empresa y especialistas en el sector procedentes de asociaciones empresariales o instituciones ligadas al entorno empresarial e institucional de la Comunidad Valenciana (Feria de Valencia, Puerto de Valencia, Camara de Comercio, Ivex y Consultoria).

Una vez determinado el grupo de expertos, se confeccionó el primer cuestionario, formado por 80 ítems. El cuestionario se organizó en tres partes, por una parte los ítems relativos a las características y capacidades organizativas de GC (1-41), por otra parte los relativos a las CD (41-70), y por último, los relativos a los RO (71-80).

La mayor parte de las cuestiones empleadas para recoger las observaciones de los expertos son preguntas llamadas de escala, en las que el experto debe asignar una puntuación a cada una de las posibles opciones según su grado de verosimilitud. Estas preguntas tienen un tratamiento cuantitativo y son de fácil respuesta. Además, esta configuración permite el posterior tratamiento informático de las respuestas.

Para cada una de las cuestiones, los expertos debían responder con el grado de acuerdo / desacuerdo en la utilización de los ítems, con el fin de evaluar los objetivos propuestos. Para ello se utilizó una escala entre " 1 " y "5", valorando con una puntuación de "1" si está "Muy en desacuerdo" y "5" si está "Totalmente de acuerdo".

En el anexo del cuestionario se les ofreció a los expertos la posibilidad de efectuar comentarios, que en muchas ocasiones resultan clarificadores de determinadas respuestas u observaciones, lo que enriquece el contenido de la investigación. Debe señalarse que en el proceso también se suministró información relativa al grado de acuerdo o consenso de sus respuestas en la ronda anterior, solicitándoles que argumentasen el motivo de sus opiniones, y 
transmitiéndoles al mismo tiempo las razones aducidas por otros colaboradores para avalar sus respuestas.

Una vez recibidos los cuestionarios, se procedió a la eliminación de los ítems que presentaban un menor grado de acuerdo. También se atendía a las sugerencias y modificaciones que se planteaban.

Los resultados obtenidos muestran que la mayoría de los ítems que habíamos desarrollado son de gran importancia para los objetivos propuestos. Estas puntuaciones tan elevadas dificultaron el proceso de eliminación de ítems, por lo que se siguieron los siguientes criterios:

1. Eliminar los ítems de menor puntuación

2. Reformular o eliminar los ítems con una mayor variabilidad o dispersión en las respuestas. Estos ítems no han alcanzado un alto grado de consenso entre los expertos.

3. Si un ítem que está considerado como una característica, los expertos disienten y lo entienden como una capacidad, se realizan las modificaciones oportunas. Lo mismo en caso contrario y respecto a las competencias.

4. Incluir las sugerencias de los expertos. De este modo se pueden agrupar ítems que se consideran parecidos.

Otra cuestión a determinar cuando se desarrolla el método Delphi es el número de rondas necesarias para detener el proceso. Una de las características de este método es su flexibilidad en la práctica. El criterio de finalización de sucesivos envíos vino determinado por los resultados obtenidos tras las dos rondas efectuadas, al haberse cumplido el grado de consenso deseado. Además, la literatura señala que a medida que aumenta el número de rondas, el número de expertos se reduce, con lo que el grado de consenso disminuye. 
Una vez finalizado el método Delphi, obtuvimos 61 ítems a incluir en la escala de medición. Los ítems relativos a las características y capacidades organizativas de GC (1-35), por otra parte los relativos a las CD (36-51), y por último, los relativos a los RO (52-61). La siguiente fase llevada a cabo con el fin de testar y reducir la escala fue la realización de una prueba piloto pretest con el fin de evaluar su funcionamiento.

Se consideró adecuado realizar una prueba piloto en una muestra de empresas perteneciente a diversos sectores de la Comunidad Valenciana. El objetivo de la prueba era determinar cuestiones relativas al grado de dificultad del cuestionario, la utilización de un lenguaje comprensible por los directivos, la extensión apropiada del cuestionario, el grado de conocimiento previo sobre la materia, el índice de respuestas obtenidas, etc.

El instrumento de medida previo fue testado dos veces. La primera vez fue testado en 10 empresas, requiriendo la colaboración de los Directivos de Personal (Recursos Humanos). Todas las dudas, dificultades de interpretación y sugerencias de mejora se tuvieron en cuenta, y cuando se consideraron adecuadas se incorporaron al cuestionario. Antes de dar formato final, se llevó a cabo un segundo testeo, llevado a cabo dos semanas antes del envío definitivo. 


\subsection{DISEÑO DE LA ENCUESTA}

La identificación de las empresas ha sido posible gracias a la base de datos del IMPIVA (Instituto de la Mediana y Pequeña Industria Valenciana) de 2002, donde hemos podido obtener toda la información relativa a número de empleados, facturación, rentabilidad, capital social, etc.

La primera parte tiene como objeto determinar la concienciación de la empresa con las características y capacidades organizativas de GC. Para ello se le proporciona al encuestado una definición precisa de las características y capacidades organizativas, con el fin de que puedan discernir nítidamente cada una de las cuestiones.

A continuación, se muestra el número de ítems utilizados en el cuestionario definitivo para cada característica y para capacidad organizativa.

\begin{tabular}{|l|c|}
\hline \multicolumn{1}{|c|}{ Características Externas Organizativas } & (No ítems) \\
\hline Vigilancia del Entorno Externo & 5 \\
\hline Tecnologías de la Información & 5 \\
\hline Procesos de planificación Estratégica & 5 \\
\hline Sistemas de medición de gestión & 5 \\
\hline TOTAL & 20 \\
\hline
\end{tabular}

Tabla 13: Características Externas Organizativas (Lara, 2005) 


\begin{tabular}{|l|c|}
\hline \multicolumn{1}{|c|}{ Capacidades Internas Organizativas } & (No ítems) \\
\hline $\begin{array}{l}\text { Stocks de conocimientos: capacidades de la } \\
\text { organización, de los grupos y de los individuos }\end{array}$ & 9 \\
\hline $\begin{array}{l}\text { Flujos de conocimientos: relaciones de influencia entre } \\
\text { la organización y los individuos }\end{array}$ & 6 \\
\hline TOTAL & 15 \\
\hline
\end{tabular}

Tabla 14: Capacidades Internas Organizativas (Lara, 2005)

En la escala de medida de la GC se utilizó una escala de 1 a 5, en la que el encuestado señala un 5 si está totalmente de acuerdo con la afirmación, un 1 si está totalmente en desacuerdo y un número intermedio si su opinión no esta totalmente definida.

El segundo bloque de preguntas se utiliza para evaluar las competencias directivas de la organización (CD), tanto en la dimensión estratégica, como intratégica y personal.

Para medir las CD utilizamos de nuevo una escala likert de 5 puntos. Así, una puntuación de 5 quiere decir que la empresa está mucho mejor que la competencia en ese ítem, mientras que una puntuación de 1 indica que la empresa está mucho peor que la competencia, siendo 3 el promedio de la competencia.

A continuación mostramos el número de ítems utilizados en cada dimensión, tanto para las competencias directivas estratégicas, intratégicas como personales. 


\begin{tabular}{|l|c|}
\hline \multicolumn{1}{|c|}{ Competencias Directivas } & No ítems \\
\hline $\begin{array}{l}\text { Estratégicas: visión de negocio, gestión de recursos, } \\
\text { orientación al cliente, networking y negociación. }\end{array}$ & 6 \\
\hline $\begin{array}{l}\text { Intratégicas: comunicación, gestión de conflictos, } \\
\text { delegación, coaching, teamworking y carisma. }\end{array}$ & 5 \\
\hline $\begin{array}{l}\text { Personales: proactividad, gestión personal, mejora } \\
\text { personal, autogobierno e integridad. }\end{array}$ & 16 \\
\hline \begin{tabular}{l} 
TOTAL \\
\hline
\end{tabular}
\end{tabular}

Tabla 15: Competencias Directivas (elaboración propia a partir de Cardona y Lombardía, 2005)

La última parte del cuestionario está dedicada a la medición de los Resultados de la Organización (RO). Para ello el encuestado debe valorar subjetivamente su desempeño en relación a los competidores, siendo 1 (muy malo, estamos por debajo de la competencia), 2 (malo, por debajo de la competencia), 3 (normal, en el promedio de la competencia) 4 (notable, por encima de la competencia), 5 (sobresaliente, mucho mejor que la competencia). En este sentido, hemos dividido este último apartado en dos subdimensiones, como son la intangible y la tangible.

Tabla 16: Resultados Organizativos (Lara, 2005)

\begin{tabular}{|l|c|}
\hline \multicolumn{1}{|c|}{ Resultados de la Organización } & No ítems \\
\hline $\begin{array}{l}\text { Intangibles: satisfacción de los clientes, incremento de } \\
\text { clientes, satisfacción de empleados, nivel de calidad y } \\
\text { reputación de la organización. }\end{array}$ & 5 \\
\hline $\begin{array}{l}\text { Tangibles: rentabilidad sobre fondos propios, crecimiento } \\
\text { de las ventas, crecimiento del beneficio, productividad } \\
\text { laboral y mejora en costes de producción. }\end{array}$ & 5 \\
\hline TOTAL & 10 \\
\hline
\end{tabular}


EL CUESTIONARIO SIGUIENTE TRATA DE RELACIONAR LA GESTION DEL CONOCIMIENTO, LAS COMPETENCIAS DIRECTIVAS Y LOS RESULTADOS DE LAS ORGANIZACIONES, PARA VER SI EXISTES RELACIONES DE CIERTA RELEVANCIA SIGNIFICATIVA A NIVEL EMPIRICO. TODA LA INFORMACION SERA TRATADA CONFIDENCIALIMENTE Y A PETICION DE LOS INTERESADOS SE LES HARA LLEGAR UN RESUMEN DE LOS RESULTADOS.

\section{CARACTERISTICAS DE LA ORGANZACION}

Evalue en una 6ecala de 1 (muy poco importante) a 5 (muy Importante) la Importancla que

tienan para la organlzacion los sigulentes mecanismos devilallancha dalentomaexterng

1 El seguimiento de los competidores

(Benchmarking, las mejores practicas)

2 Recogida de Informacion del contacto directo con sus clentes

(estudos de mercado especificos, sondeos y encuestas...)

3 La elaboracion de posibles escenarios de futuro

(simulaciones de escenarios, roleplay)

4 Contactos con Instuciones externas (universidades, centros

tecnologicos, asodaciones protesionales, consultoras, revistas,...)

5 Contactos con proveedores

(Asistencla a Ferlas, reuniones con proveedores)

\begin{tabular}{|llllllllll}
$\bigcirc$ & 1 & $\bigcirc$ & 2 & $\bigcirc$ & 3 & $\bigcirc$ & 4 & $\bigcirc$ & 5 \\
\hline & 1 & $\bigcirc$ & 2 & $\bigcirc$ & 3 & $\bigcirc$ & 4 & $\bigcirc$ & 5 \\
\hline & 1 & $\bigcirc$ & 2 & 0 & 3 & $\bigcirc$ & 4 & $\bigcirc$ & 5 \\
$\square$ & 1 & $\bigcirc$ & 2 & $\bigcirc$ & 3 & $\bigcirc$ & 4 & $\bigcirc$ & 5 \\
$\square$ & 1 & $\bigcirc$ & 2 & $\bigcirc$ & 3 & $\bigcirc$ & 4 & $\bigcirc$ & 5 \\
\hline
\end{tabular}

Evalue en una eecala de 1 (muy poco importante) a 5 (muy Importante) la Importancla que

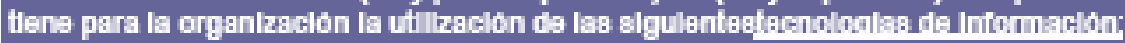

6 Tecnologlas Intranet (e-mal, redes de servicios internos, e:c.)

7 Otras tecnologlas de colaboracion (groupware, videoconterenclas,

foros vir:uales, workfow, etc.)

8 Herramlentas tecnoioglcas de gestion (ORACLE, MP5, ERP, CRM) o

de soporte a la declision (data mining, data modelling,...)

9 Sistemas de gestion documental (bases de datos, repostorios, efc.)

10 Herramlen'as tecnologlcas de bósqueda (Internet, buscadores, exc.)

\begin{tabular}{|l|llllllllll|} 
& 0 & 1 & 0 & 2 & 0 & 3 & 0 & 4 & 0 & 5 \\
& 0 & 1 & 0 & 2 & 0 & 3 & 0 & 4 & 0 & 5 \\
\hline & 0 & 1 & 0 & 2 & 0 & 3 & 0 & 4 & 0 & 5 \\
\hline & 0 & 1 & 0 & 2 & 0 & 3 & 0 & 4 & 0 & 5 \\
\hline & 0 & 1 & 0 & 2 & 0 & 3 & 0 & 4 & 0 & 5 \\
\hline
\end{tabular}

Senale su grado de acuerdo o desecuerdo (1= Muy en desecuerdo; $5=$ Muy de acuerdo)

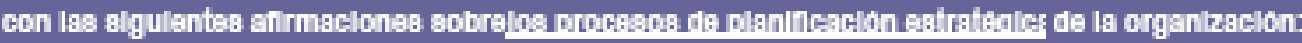

11 En la organlzacion se promueve la definicion de una mision contun

conforme a la que establecer un sentido general de dreccion

12 En la organizacion se desarrollan procesos de reflexion estrateglcos

dirigidos a plasmar la mision general en unos objetwos concretos

13 En la organizacion se promueve la coherencla estrateglca medlante la integracion y coordinacion de los diterentes objetivos y poilicicas

14 Los objetwos y politicas son comunicados a los empleados de la organizacion

15 En la crganizacion se promueve y se estimula el compromiso de los

empleados con los aspectos de entasis estrateglco

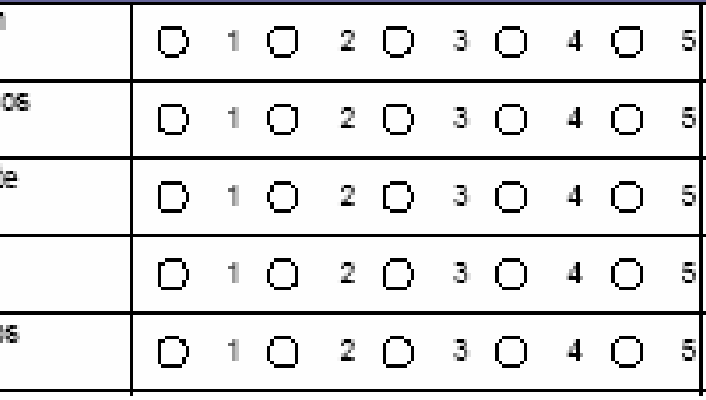

4. Evalue en una eecala de 1 (Muy poco Importante) a 5 (Muy Importante) la Importancla que

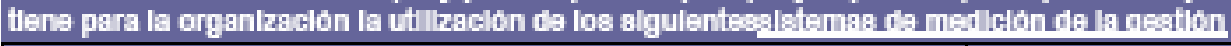

16 Slstemas de informacion contable y de conirol presupuestario

17 Sistemas de evaluacion del desempefio de los trabajadores

18 Parametros tecnicos y sistemas de evaluacion de la calload

19 Sistemas de medicion de la satisfaccion de los clentes

20 Otros aspectos no es:rictemente financleros de los resultados

(medoamblente, capltal intelectual, seguridad, etc.) 
I. CAPACIDAD DE APREMDIZAJE DE LA ORGAMIZACION

Valore entre las posiciones 1 (respuesta de la izqulerda) y 5 (respuesta de la derecha) las

sigulentes aflrmaciones relativas a:

\section{STOCKS DE CONOCIMIENTO: conjunto de eapacidades de la organlzacion, de los grupos y de los Indlwiduos}

La organizacion dlapone de estrateglas claras de posicionamlento para el futuro

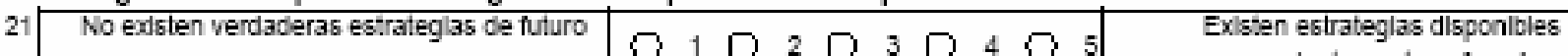

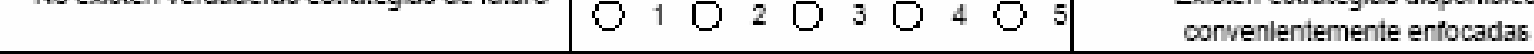

La organlzaclon dlapone de una estructura organizativa que permite trabajar eficlentemente

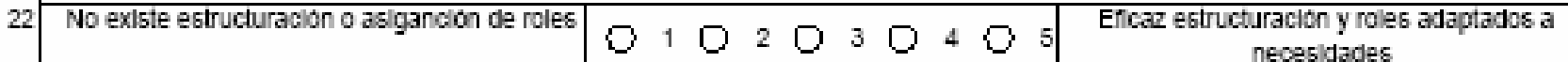

La cultura organizativa representa unos valores signiricativos para la organ|zacion

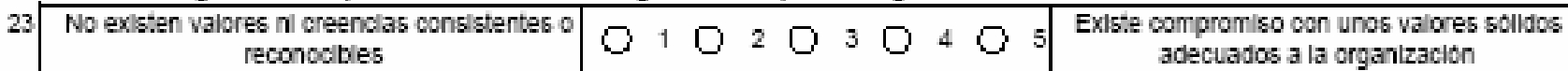

Los grupos de trabajo estan plenamente capacitados para tomar las decleiones relativas a su actividad

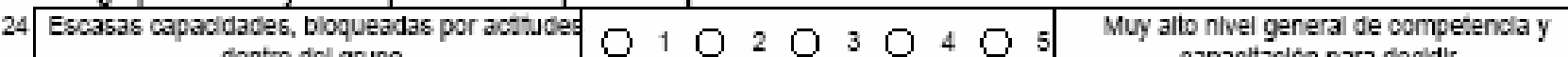

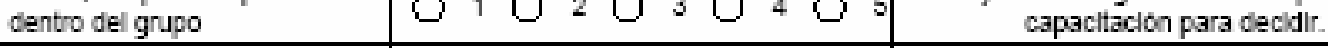

Los grupos de trabajo demuestran estar capacitados para resolver con eficacla sus conflictos

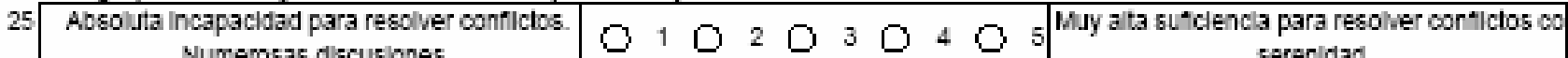
Numerosas dlscuslones

Los Integrantes de los grupos comparten internamente los logros y los fracasos de su trabajo en común

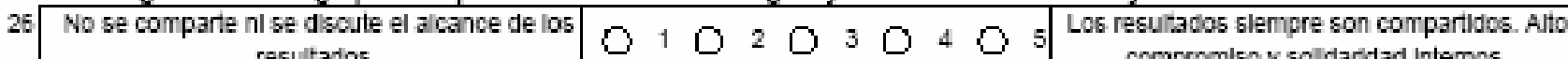
resultados compromiso y soldaridad intemos.

Los empleados de la organizacion poseen la cuallficacion y conocimlentos necesarios

\begin{tabular}{l|lllllllllll|}
\hline Cualincacion y conocimientos minimos & 0 & 1 & 0 & 2 & 0 & 3 & 0 & 4 & $\bigcirc$ & 5
\end{tabular}

Los empleados de la organizacion reallzan con competencla las tareas proplas de su trabajo

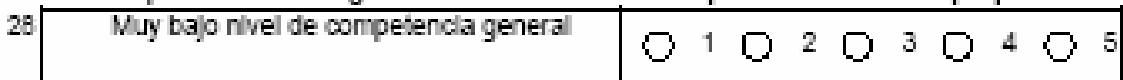

Los empleados manifieatan en au trabajo un alto sentido del rigor y de la responsabilidad

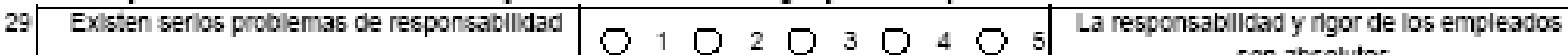
Cualificacion y conocimientos excelentes Muy alto nivel de competencla genera

\section{FLUJOS DE CONOCIMIENTO: relaciones de Infiuencla entre la organizaclon y los Individuos y viceversa.}

La formacion es utllizada para mejorar los conocimlentos y habllidades de los Indlviduos o de los grupos

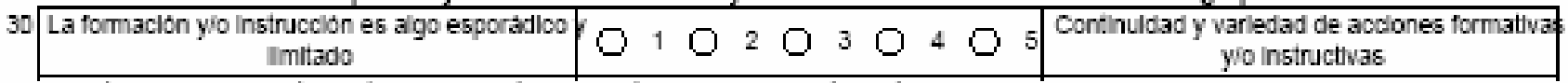

Practicas como el outdoor trainning (entrenamiento fuera del puesto de trabajo) o asignaciones

especlales a otros departamentos son utllizadas para desarrollar una fuerza de trabajo mas flexible.

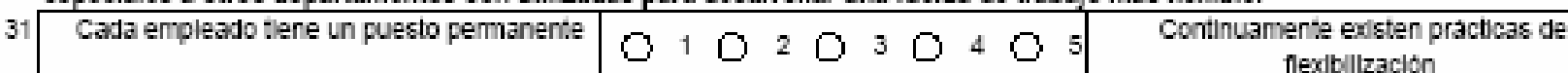

La organizacion tlene tecnologias y herramientas que permiten y facilltan el Intercamblo de conocimlento

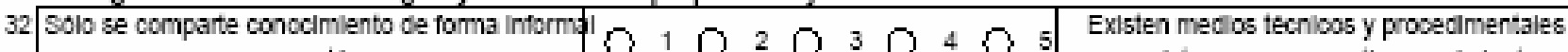
o espontànea previstos para compartir conocimlento

Los Integrantes de los grupos de trabajo de la organizacion comparten entre sl sus experienclas y aus conocimlentos indlviduales

\begin{tabular}{|c|cccccccccc|c|}
\hline $\begin{array}{c}\text { Los indlviduos se limitan a realizar su tarea sin } \\
\text { compartir experienclas }\end{array}$ & $\begin{array}{llllllll}\text { Cooperar y compartir experlenclas es } \\
\text { fundamental para el gupo }\end{array}$ \\
\hline
\end{tabular} Los empleados de la organizaclon tlenen oportunidad de particlpar en declilones de la mlsma

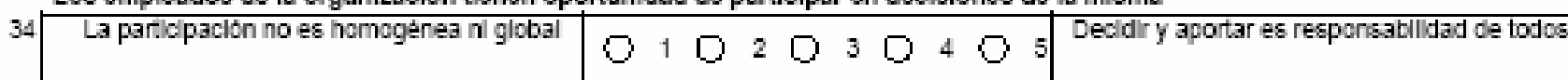

Existe un alstema de retribucion que fomenta compartir el conocimlento a toda la organizacion

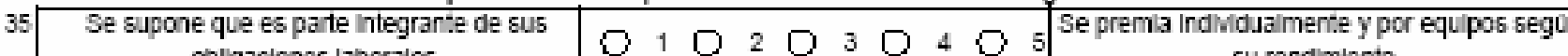
ooligaciones laborales

su rendimlento 


\section{COMPEIENCIAS DIRECTIVAS}

\section{ESTRATEGICAS}

36 Visión de Negocios capacidad de reconocer los peligros y aprovechar las oportunidades que repercutenen la efectividad del negoclo.

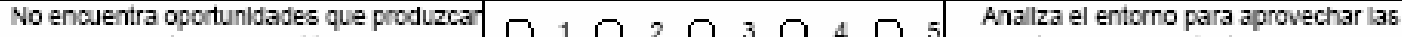
ventajas compertivas oportunidades y detectar los pellgros.

37 Gestión de los recursos: utiliza los recuinsos del modo mis iddoneo, rápido, económico y eficaz

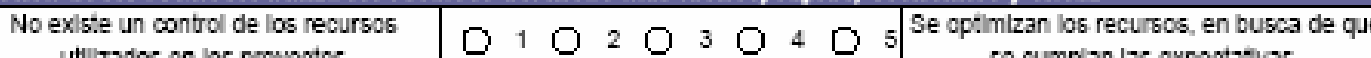
se cumplan las expectatvas.

38 Orientación al cliente: capacidad de satisfacer las necesidades del cliente, ofreciendo uns oferta de valor, cuidando todos los detalles de la relación, y dando respuesta a sus peticiones y sugerencias.

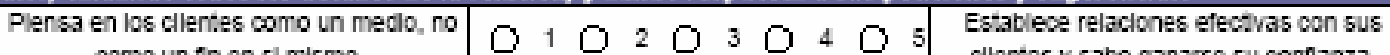
O 4 cllentes y sabe ganarse su connanza.

39 Networking: capacidad de desarrollar, mantener y utilizar una amplia red de relaciones con personas clave dentro de la empresa y del sector. \begin{tabular}{|c|ccccccccc|c|c|}
\hline $\begin{array}{c}\text { No le gusta establecer relaclones Informale } \\
\text { con personas de su trabalo }\end{array}$ & 0 & 1 & 0 & 2 & 0 & 3 & 0 & 4 & 0 & 5 & $\begin{array}{c}\text { Sabe como obtener apoyos entre sus } \\
\text { contactos. Tlene don de gentes. }\end{array}$ \\
\hline
\end{tabular}

40 Negociación: capacidad de alcanzar acuerdos satisfactorios para las partes implicadas, descubriendo o creando elementos qua produrzean valor anidido a la relacion.

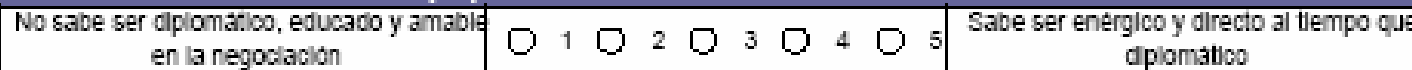

\section{INTRATEGICAS}

\section{Comunicación: capacidad de escuchar y transmitir ideas de manera efectiva, empleando el canal} adecuado en el momento oportuno, y proporcionando datos concretos para respaldar sus conclusiones.

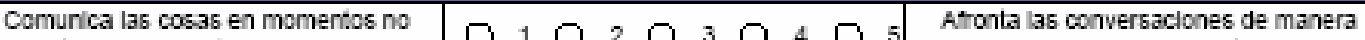
oportunos o en un tono inadecuado.

42 Gestib́n de conflictos: capacidad de diagnosticar, afrontar y resolver conflictos interpersonales con prontitud y profundidad, sin danar la relacion personal.
Prefere encubrir los confilctos a
confrontarlos con claridad.

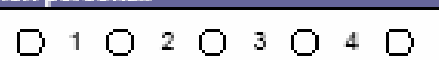
Atronta los confilctos con prontitud, en luga de evitarios o canumiarios.

43 Delegación: capacidad de conseguir que los colaboradores del equipo dispongan de la información

y los recurses necesarios para tomar decisiones y lograr sus objetivos.

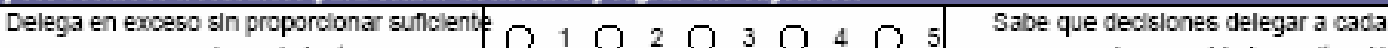

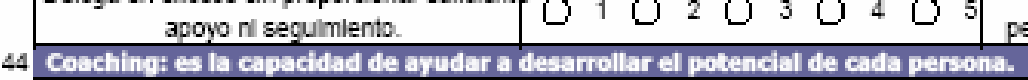

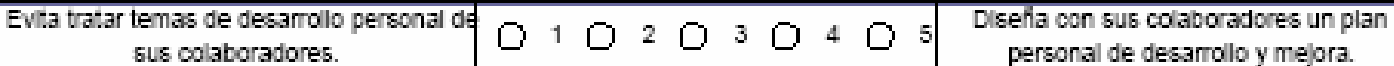

45 Trabajo en equipo: capacidad de fomentar un ambiente de colaboración, comunicación y confianza.

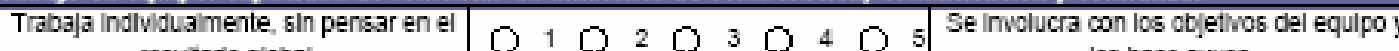
resultado global.

46 Carisma: capacidad de lograr el compromiso de los colaboradores, inspirando su comfianza, dando

sentido a su trabajo y motivindoles a conseguir los objetivos.

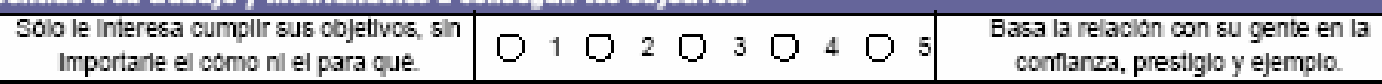

\section{PERSONALES}

\section{PROACTIVIDAD}

Inlclativa: capacldad de mostrar un comportamlento emprendedor, Iniclando e Impulaando los

camblos A14necesarlos con energla y responsabillidad personal.

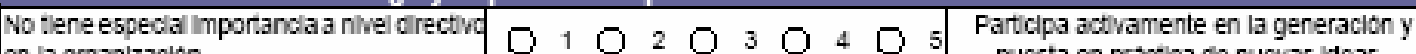
en la organizacion

Optimlemo: capacidad de ver el lado positivo de la realldad, tener fe en las proplas posibillidades y afrontar las dinicultades con entusiasmo.

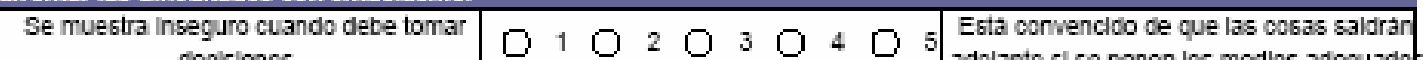
decisiones. adelante sl se ponen 106 medlos adecuado: Ambiclon: capacidad de establecer metes elevadas para sl y para los damis, con determinacion

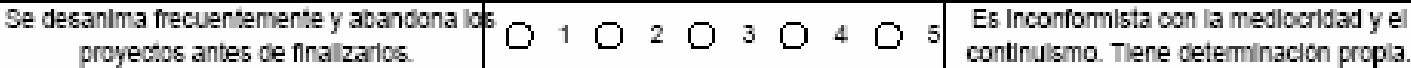

48 GESTION PERBOMAL

Gestion del tiempo: capecidad de prlorlzar los objetivos, programar las actividades de manera

adicuada y ejecutarlas en el plazo prevlato. \begin{tabular}{|c|ccccccccc|c|c|}
\hline $\begin{array}{c}\text { No respeta los plazos, se le amontona el } \\
\text { trabajo, tlene escasa productividad. }\end{array}$ & 0 & 1 & 0 & 2 & 0 & 3 & 0 & 4 & 0 & 5 & $\begin{array}{c}\text { Asigna el tiempo adecuado a cada tarea y } \\
\text { evita internpciones Innecesareas. }\end{array}$ \\
\hline
\end{tabular} evita Internupclones innecesareas. Eastion de la Informacion: capacidad de Identificar y tratar de manera efoctiva la informacion relevante.

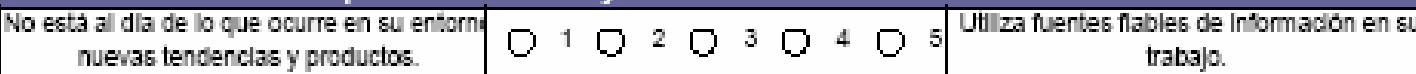
nuevas tendenclas y productos. 


\begin{tabular}{|c|c|c|}
\hline $\begin{array}{l}\text { Conflictos frecuentes entre la5 } \\
\text { responsabilldades familares y laborales. }\end{array}$ & $\square \begin{array}{llllllllll} & 1 & \ddots & 2 & \square & 3 & \square & 4 & \square & 5\end{array}$ & $\begin{array}{c}\text { Sabe detectar los sintomas del estres y } \\
\text { toma medidas para pallario. }\end{array}$ \\
\hline
\end{tabular}

49 MENORA PERSONAL

Autocritica: capacidad de aceptar y asumir las linmitaclones y errores personales.

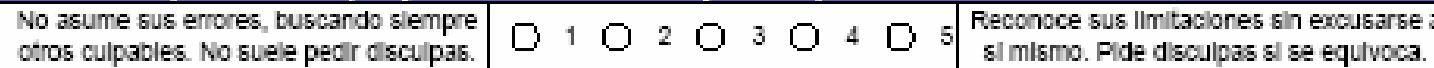

Autoconocimlento: ceapacidad de entender como 69 y como reacelona uno mlemo ante distintas clrcunstanclas tanto en lo personal como en lo protesional. \begin{tabular}{c|ccccccccc|c|c}
$\begin{array}{c}\text { No examina su comportamiento ni plde } \\
\text { feedback a los que le rodean. }\end{array}$ & $\begin{array}{llllllll}\text { Concce sus purtos fuertes y deblles. Plde } \\
\text { feedback a colaboradores y superiores }\end{array}$ \\
\hline
\end{tabular} Aprendlzaje: capacidad de adqulrir nuewos conoclmlentos, modificar habitos y estar ablerto al camblo

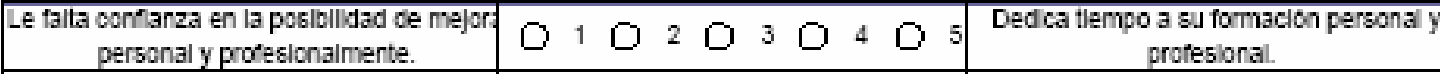

50 AUTOGOBIERMO

Toma da declalones: capacliad de tomar declalones de modo adecuado y en el momento oportuno

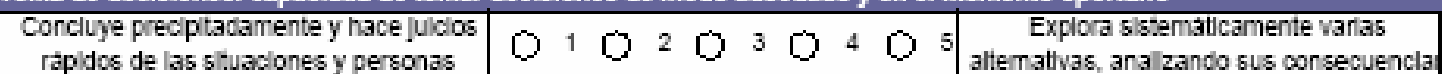
Autocontrol: capseldad de acometer acclones costosas.

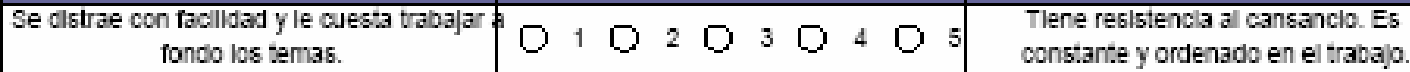

Equilibrio emoctonal: capacidad de rescclonar con las emoclones y los estados de animo apropladios a

cadla situselon. \begin{tabular}{c|ccccccccc|c|c|}
\hline $\begin{array}{c}\text { Reacciona de manera desproporcionada } \\
\text { violenta ante sltuaciones de tension. }\end{array}$ & $\begin{array}{llllllll}\text { Reacclona equilloradamente ante } \\
\text { sltuaclones confictivas. }\end{array}$ \\
\hline
\end{tabular}

51 WTEERIDAD

Integrildad: capecidad de comportarie de manera recta y honrada ante cualquiter situacion.

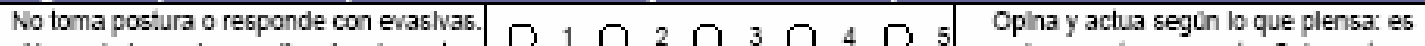

No suele hacer lo que dlce. Inconerente. sincero y transparente. Coherente.

\section{W. VALORACION GLOBAL DELA ORGAMIZACION}

Tenlendo en cuenta ÚNICAMENTE el compartamiento de los Indlviduos, de los grupos y la organizacion valore entre las posiclones 1 (Muy negativa) a 5 (Muy positiva) la tendencla que en los uitimos anos han experimentado los sigulentes resultados:

Resultados no economicos

52 La satisfaccion de los cllentes (quejas y reclamaclones, eic.)

(Comparado con aflos anterlores)

53 El Incremento de los cllentes (Base de clentes)

(Comparado con aflos anteriores)

54 La satisfaccion de los empleados (rotacion, permanencla)

(Comparado con aflos anteriores)

55 El nlvel de caldad (tasa de error, rapldez de servicio, etc.)

(Comparado con aflos anteriores)

56 La reputacion de la organizaclon (Marca, Nombre Comerclal)

(Comparado con aflos anteriores)

Risulitados economicos

57 La rentabilldad sobre fondos propios

(Comparado con aflos anterlores)

58 El crecimlento de la chra de negocio (ventas)

(Comparado con aflos anterlores)

59 El crecimlento del beneficio

(Comparado con aflos anteriores)

60 La productividad del trabajo

(Comparado con aflos anterlores)

61 La mejora en los costes de producción

(Comparado con afios anteriores)

\begin{tabular}{|l|llllllllll|}
\hline & 0 & 1 & $\bigcirc$ & 2 & 0 & 3 & 0 & 4 & 0 & 5 \\
& 0 & 1 & 0 & 2 & 0 & 3 & 0 & 4 & 0 & 5 \\
\hline & 0 & 1 & 0 & 2 & 0 & 3 & 0 & 4 & 0 & 5 \\
\hline & 0 & 1 & 0 & 2 & 0 & 3 & 0 & 4 & 0 & 5 \\
\hline & 0 & 1 & 0 & 2 & 0 & 3 & 0 & 4 & 0 & 5 \\
\hline
\end{tabular}

\section{COMENTARIOS PERSONALES:}




\subsection{CARACTERISTICAS DE LA MUESTRA $Y$ TRABAJO DE CAMPO}

Una vez elaborado el cuestionario definitivo, la siguiente etapa en nuestra investigación es la de obtener datos. Para ello, previamente tenemos que seleccionar el universo objeto de estudio.

Tabla 17: Ficha técnica del estudio empírico (Lara, 2005)

\begin{tabular}{|l|l|}
\hline Universo: & Empresas: +100 empls.; $+6 \mathrm{~m} . €$ facturación \\
\hline Ámbito de la investigación: & Comunidad Valenciana \\
\hline Tipo de entrevista: & Correo, cuestionario estructurado \\
\hline Tamaño muestral: & 512 empresas \\
\hline Margen de error estadístico: & $\pm 5,7 \%$ (95\% confianza, $\mathrm{p}=\mathrm{q}=50 \%)$ \\
\hline Fecha del trabajo de campo: & Febrero- Julio 2005 \\
\hline
\end{tabular}

Una vez tenemos los instrumentos de medida para medir los conceptos teóricos que aparecen en nuestro modelo, el siguiente paso es determinar si efectivamente estas escalas son adecuadas para medir los conceptos teóricos que hemos planteados, y por otra parte contrastar el modelo teórico que hemos elaborado.

Con el fin de recoger los datos necesarios para contrastar las hipótesis formuladas, hemos optado por una encuesta postal como método de recolección de datos. La no disponibilidad de información relativa a las variables que hemos considerado en el estudio, nos obliga a utilizar como fuente de información primaria la encuesta.

Con el fin de corregir los problemas que se le atribuyen a este método de recolección de datos, persiguiendo elevar la tasa de respuesta y la calidad de 
los cuestionarios, se emplearon un conjunto de procedimientos sugeridos para la investigación mediante encuestas, que suponen una versión modificada al "método de diseño total" de Dillman (1978). Estos procedimientos ya fueron utilizados por Conant, Mokwa y Varadarajan (1990).

Se desarrolló una prueba piloto en 10 empresas con el fin de determinar cuestiones relativas al grado de dificultad del cuestionario, la utilización de un lenguaje comprensible por los directivos, la extensión del cuestionario, el grado de conocimiento previo sobre la materia, el índice de respuestas obtenidas, etc.

Una vez depurado el cuestionario a partir de la prueba piloto, se realizó el envío postal a la población de empresas. En el primer envío se incluía: una carta de presentación, explicando los diversos objetivos que se pretenden en la investigación; el cuestionario junto con una lista de instrucciones para rellenarlo adecuadamente; y un sobre franqueado para la devolución del cuestionario.

Transcurridos 20 días del primer envío, se remitió una tarjeta postal de recuerdo insistiendo en la colaboración, junto con una llamada telefónica. Después de cinco semanas, se les volvió a enviar a las empresas que todavía no habían contestado el cuestionario y el sobre franqueado. Adicionalmente, y con el mismo fin, (elevar la tasa de respuesta) se incentivaba al encuestado con el compromiso de facilitarle los resultados del estudio si éste lo solicitaba expresamente.

El cuestionario estaba dirigido a la dirección general de la empresa, ya que es el capital humano con mayor visión global de la empresa y además dispone de la información necesaria para responder al cuestionario que hemos diseñado.

Finalmente, hemos obtenido 52 respuestas, lo cual representa más de una $10 \%$ del total de la muestra. En este sentido podemos afirmar que los resultados serán representativos de la muestra, teniendo en cuenta las limitaciones y restricciones de la misma, y dado que se ha seguido un muestreo simple aleatorio. 


\title{
CAPÍTULO 6:
}

\section{ANÁLISIS ESTADÍSTICO DE RESULTADOS}

\author{
6.1. OBJETO Y CONTENIDO DEL CAPÍTULO \\ 6.2. ANÁLISIS ESTADÍSTICO DE RESULTADOS \\ 6.3. CONTRASTE DE LAS HIPÓTESIS
}




\section{1.- OBJETIVOS Y CONTENIDOS DEL CAPÍTULO}

En este capítulo se expondrán los resultados obtenidos previamente a la realización de los contrastes de hipótesis. En el apartado 6.2., se ha realizado un análisis factorial sobre las escalas relativas a capacidades, características, competencias y resultados, que permitirá sintetizar y simplificar los contrastes realizados en el apartado 6.3.

Se ha completado este apartado 6.2., con un análisis de la validez y fiabilidad de los diferentes constructos, que forman las 3 dimensiones de estudio, recogidos en las variables de escala:

- Dimensión 1 (GESTIÓN DE CONOCIMIENTO): características externas y capacidades internas.

- Dimensión 2 (COMPETENCIAS DIRECTIVAS): competencias estratégicas, intratégicas y personales.

- Dimensión 3 (RESULTADOS ORGANIZATIVOS): tangibles e intangibles. 


\section{2.- ANÁLISIS ESTADÍSTICO DE RESULTADOS}

\subsection{1.- Validez y fiabilidad de las escalas utilizadas}

Se pueden distinguir tres tipos de análisis de la validez (Spanos y Lioukas, 2001): validez de contenido, validez de constructo y validez nomológica. En este apartado vamos a analizar la validez de los constructos planteados. La validez nomológica no tiene aplicación en nuestro caso.

\section{Validez de los constructos}

Para analizar la fiabilidad de las escalas utilizaremos el estadístico alpha propuesto por Cronbach (1951), que determina el grado de consistencia interna de una escala de medición mediante el cálculo de la correlación media de una de sus variables con todas las demás variables de la escala. Su valor varía entre 0 y 1 , de manera que cuanto más cercano esté el valor del $\alpha$ de Cronbach a 1 mayor es la consistencia interna de los ítems que componen el instrumento de medición. En la tabla siguiente se muestran los resultados obtenidos correspondientes al cálculo de los $\alpha$ para cada una de las escalas utilizadas en la encuesta, a saber:

- De 1 (muy poco importante) a 5 (muy importantes)

- De 1 (muy en desacuerdo) a 5 (muy de acuerdo)

- De 1 (muy negativa) a 5 (muy positiva)

- En general, 1 es lo pésimo y 5 lo óptimo 
También hemos recogido para cada escala los ítems que mayor discrepancia muestran con los restantes de la escala a la que pertenecen.

\begin{tabular}{|l|l|r|c|}
\hline \multicolumn{4}{|l|}{ Tabla 18. Fiabilidad de las escalas (Lara, 2005) } \\
\hline Dimensión & Constructo & $\begin{array}{l}\boldsymbol{\alpha} \\
\text { Cronbach }\end{array}$ & Ítems discrepantes \\
\hline \multirow{2}{*}{$\begin{array}{l}\text { GESTIÓN DEL } \\
\text { CONOCIMIENTO }\end{array}$} & CARACTERÍSTICAS EXTERNAS & 0,871 & Ninguno \\
\cline { 2 - 4 } & CAPACIDADES INTERNAS & 0,851 & Ninguno \\
\hline \multirow{2}{*}{$\begin{array}{l}\text { COMPETENCIAS } \\
\text { DIRECTIVAS }\end{array}$} & COMPETENCIAS ESTRATÉGICAS & 0,811 & Ninguno \\
\cline { 2 - 4 } & COMPETENCIAS INTRATÉGICAS & 0,849 & Ninguno \\
\cline { 2 - 4 } & COMPETENCIAS PERSONALES & 0,844 & Ninguno \\
\hline ORGANIZATIVOS & TANGIBLES & 0,744 & Ninguno \\
\cline { 2 - 4 } & INTANGIBLES & 0,776 & \\
\hline
\end{tabular}

Como se puede observar los valores de la $\alpha$ de Cronbach no varían demasiado según los constructos considerados y son muy elevados. Para la Gestión del conocimiento y Competencias Directivas se sitúan por encima de 0,8 , lo que demuestra una alta fiabilidad de los mismos como instrumentos de medida. Igualmente se sitúan por encima de 0,7 , indicando una adecuada fiabilidad para Resultados Organizativos, siendo aceptables con los criterios de Churchill (1979).

\subsection{2.- Reducción de variables: Análisis Factorial}

Con el objetivo de pasar a resumir la información contenida en las variables que definen los constructos, se ha realizado un análisis factorial de componentes principales para reducir el número de variables utilizadas con la menor pérdida de información posible. Este análisis se ha realizado de manera separada para cada bloque de variables que define cada uno de los constructos considerados. Para este análisis el constructo Características externas se ha separado en 4 subconstructos y las Capacidades internas en 2 subconstructos. Éstos son: 


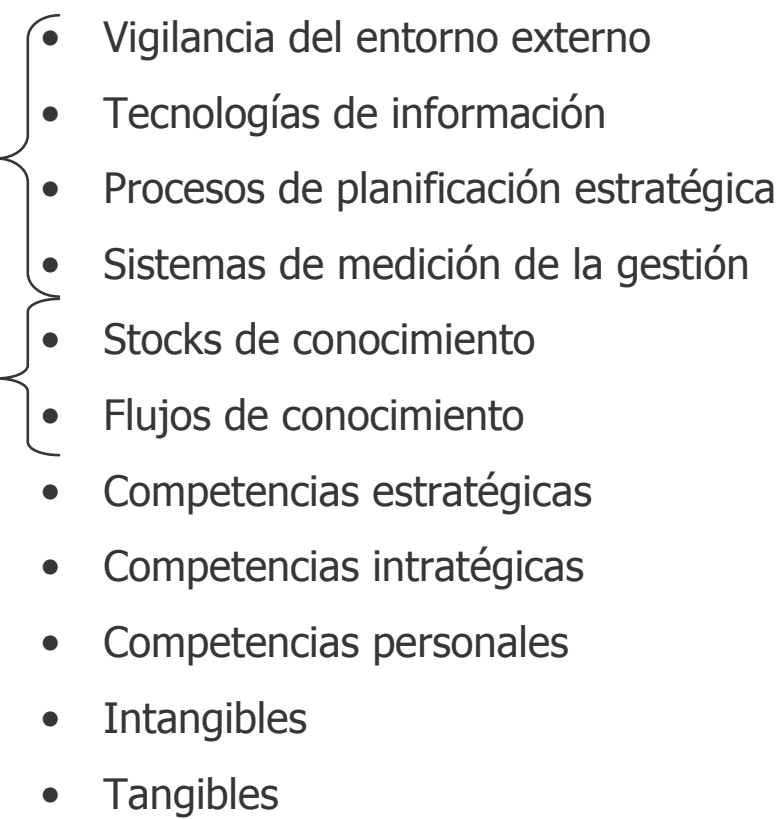

Tras la realización del análisis factorial sobre cada grupo de ítems se han calculado las puntuaciones obtenidas de los mismos y éstas se han utilizado en el posterior análisis de regresión para determinar su importancia a la hora de pronosticar los resultados de la empresa.

Para realizar el análisis factorial se ha utilizado el método de componentes principales y, posteriormente, una rotación varimax de los mismos. Este es un tipo de rotación ortogonal de los factores que trata de minimizar el número de variables con saturaciones altas en un factor. El objetivo de la rotación de los factores originales es obtener una solución más fácilmente interpretable, en el sentido de que las variables fuertemente correlacionadas entre sí presenten saturaciones altas (en valor absoluto) sobre un mismo factor y bajas sobre el resto.

Previamente a la aplicación del análisis de componentes principales sobre cada grupo de variables, para evaluar la validez y la idoneidad de su aplicación se ha recurrido a la prueba de esfericidad de Barlett y a la prueba de KaiserMeyer-Olkin (KMO en adelante). 


\section{1.- Vigilancia del entorno externo}

Para la realización del análisis factorial sobre los ítems relativos a la vigilancia del entorno externo partimos de las variables originales de la 1 a la 5 incluidas en el cuestionario I que se indican a continuación:

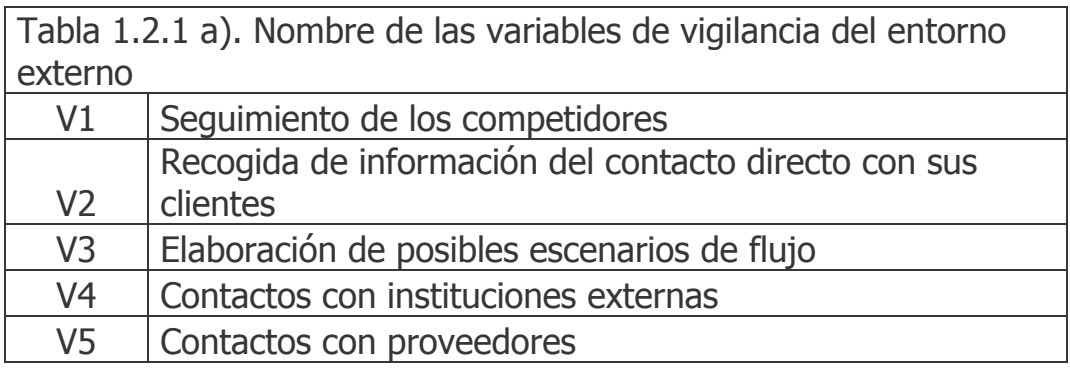

El resultado obtenido de la prueba de Barlett (tabla 1.2.1 b)) alcanza un valor aceptable ya que el nivel de significación es nulo y, por tanto, podemos rechazar la hipótesis de incorrelación de las variables originales. Ésta prueba junto con el resultado de la de $\mathrm{KMO}$, ligeramente superior al umbral generalmente aceptado de de 0,5, justifican la adecuación del análisis factorial.

Los resultados de este análisis aparecen en la matriz de componentes rotados (tabla 1.2.1 b)) en la cual hemos conservado, siguiendo el criterio de Kaiser, los factores con autocovalores superiores (o cercanos) a 1 (Ferrán, 1996). A partir de dichos resultados disponemos de la información necesaria para interpretar y asignar una denominación apropiada a cada uno de los factores que se obtienen. 
Capítulo 6: Análisis Estadísitico de Resultados

\begin{tabular}{|c|c|c|c|c|}
\hline & \multirow[b]{2}{*}{ Alpha sin ítem } & \multicolumn{2}{|c|}{ Factores } & \multirow[b]{2}{*}{ Comunalidades } \\
\hline & & Factor 1 & Factor & \\
\hline CONTACTOS CON INSTITUCIONES EXTERNAS & 0,868 & 0,943 & $-0,007$ & 0,889 \\
\hline $\begin{array}{l}\text { ELABORACIÓN DE POSIBLES ESCENARIOS DE } \\
\text { FLUJO }\end{array}$ & 0,864 & 0,665 & 0,483 & 0,675 \\
\hline CONTACTOS CON PROVEEDORES & 0,869 & 0,572 & 0,231 & 0,381 \\
\hline SEGUIMIENTO DE LOS COMPETIDORES & 0,865 & 0,091 & 0,890 & 0,800 \\
\hline $\begin{array}{l}\text { RECOGIDA DE INFORMACIÓN DEL CONTACTO } \\
\text { DIRECTO CON SUS CLIENTES }\end{array}$ & 0,862 & 0,252 & 0,803 & 0,709 \\
\hline \multicolumn{2}{|l|}{ Autocovalores } & 2,458 & 0,996 & \\
\hline \multicolumn{2}{|l|}{$\%$ Varianza explicada } & $49,15 \%$ & $19,92 \%$ & \\
\hline \multicolumn{5}{|l|}{$\alpha$ de Cronbach de la escala completa: 0,871} \\
\hline \multicolumn{5}{|l|}{$\%$ Total de varianza explicada: : $69,07 \%$} \\
\hline \multicolumn{5}{|l|}{ Prueba de KMO: 0,588} \\
\hline
\end{tabular}

A partir del análisis factorial realizado, se han obtenido dos factores, los cuales explican el $69,07 \%$ de la varianza. Como se puede comprobar todas las variables poseen marcadores superiores a 0,5 en un factor. Por otro lado, excepto para la variable Contacto con proveedores, el factor explica una proporción elevada de las variables, como lo demuestran las elevadas comunalidades. Se puede también observar la consistencia interna de la escala por la escasa variación del coeficiente $\alpha$ al eliminar cada uno de los ítems respecto al $\alpha$ de 0,871 de la escala completa para la vigilancia del entorno externo.

Pasemos a describir los dos factores obtenidos a partir de la saturación con las variables originales en la matriz de componentes rotados.

- Factor 1

Este factor, que explica el $49,15 \%$ de la varianza adquiere saturaciones altas para las variables V3, V4 y V5. Entre ellas, destaca la elevada puntuación del contacto con instituciones externas $(0,943)$. También adquieren saturaciones relevantes las variables elaboración de posibles escenarios de flujo y contactos con proveedores. 
- Factor 2

Este factor, que explica el $19,92 \%$ de la varianza, se asocia a las variables seguimiento de los competidores y recogida de información del contacto directo con sus clientes con puntuaciones de 0,890 y 0,803 respectivamente.

Los resultados del análisis factorial realizado sobre las variables de vigilancia del entorno externo permiten destacar la reducción relevante desde 5 variables originales a sólo 2 factores, manteniendo la varianza explicada del $69,07 \%$.

\section{2.- Tecnologías de información}

Para la realización del análisis factorial sobre los ítems relativos a las tecnologías de información partimos de las variables originales de la 6 a la 10 incluidas en el cuestionario I que se indican a continuación:

\begin{tabular}{|c|c|}
\hline V6 & Tecnologías intranet \\
\hline V7 & Otras tecnologías de colaboración \\
\hline V8 & Herramientas tecnológicas de gestión \\
\hline V9 & Sistemas de gestión documental \\
\hline V10 & Herramientas tecnológicas de búsqueda \\
\hline
\end{tabular}

Tanto el resultado obtenido de la prueba de Barlett (tabla 1.2.2 b)) que alcanza un valor aceptable ya que el nivel de significación es nulo, como el resultado de la de $\mathrm{KMO}$, superior al umbral generalmente aceptado de de 0,5, justifican la adecuación del análisis factorial.

Los resultados de este análisis aparecen en la matriz de componentes rotados (tabla 1.2.2 b)) en la cual -como en el caso previo y en los siguientes- 
hemos conservado los factores con autocovalores superiores (o cercanos) a 1. A partir de dichos resultados disponemos de la información necesaria para interpretar y asignar una denominación apropiada a cada uno de los factores que se obtienen.

\begin{tabular}{|l|c|c|c|c|}
\hline \multicolumn{4}{|l|}{ Tabla 1.2.2 b): Análisis factorial de las tecnologías de la información } \\
\hline & Alpha sin ítem & Factor 1 & Factor 2 & Comunalidades \\
\hline SISTEMAS DE GESTIÓN DOCUMENTAL & 0,863 & $\mathbf{0 , 8 8 0}$ & $-0,046$ & 0,777 \\
\hline HERRAMIENTAS TECNOLÓGICAS DE BÚSQUEDA & 0,870 & $\mathbf{0 , 7 2 4}$ & 0,368 &, 0659 \\
\hline TECNOLOGÍAS INTRANET & 0,865 & $\mathbf{0 , 6 6 5}$ & 0,440 & 0,636 \\
\hline OTRAS TECNOLOGÍAS DE COLABORACIÓN & 0,868 & 0,026 & $\mathbf{0 , 9 0 4}$ & 0,818 \\
\hline HERRAMIENTAS TECNOLÓGICAS DE GESTIÓN & 0,862 & 0,402 & $\mathbf{0 , 6 8 8}$ & 0,635 \\
\hline Autocovalores & & 2,593 & 0,932 & \\
\hline$\%$ Varianza explicada & $51,86 \%$ & $18,65 \%$ & \\
\hline$\alpha$ de Cronbach de la escala completa: 0,871 & & & \\
\hline$\%$ Total de varianza explicada: : $70,51 \%$ & & \\
\hline Prueba de KMO: 0,772 & Prueba de esfericidad de Barlett: Chi ${ }^{2}=50,927$ gl: 10 sig. 0,000 \\
\hline
\end{tabular}

A partir del análisis factorial realizado, se han obtenido dos factores, los cuales explican el $70,51 \%$ de la varianza. Como se puede comprobar todas las variables poseen marcadores superiores a 0,6 en un factor. Por otro lado, el factor explica una proporción elevada de las variables, como lo demuestran las elevadas comunalidades. Se puede también observar la consistencia interna de la escala por la escasa variación del coeficiente $\alpha$ al eliminar cada uno de los ítems respecto al $\alpha$ de 0,871 de la escala completa para tecnologías de la información.

Pasemos a describir los dos factores obtenidos a partir de la saturación con las variables originales en la matriz de componentes rotados. 
- Factor 1

Este factor, que explica el $51,86 \%$ de la varianza adquiere saturaciones altas para las variables V6, V9 y V10. Entre ellas, destaca la elevada puntuación sistemas de gestión documental $(0,880)$.

- Factor 2

Este factor, que explica el $18,65 \%$ de la varianza, se asocia a las variables V7 y V8, con una puntuación de 0,904 en otras tecnologías de colaboración.

Los resultados del análisis factorial realizado sobre las variables de vigilancia del entorno externo permiten destacar la reducción relevante desde 5 variables originales a sólo 2 factores, manteniendo la varianza explicada del $70,51 \%$.

\section{3.- Procesos de planificación estratégica de la organización}

Para la realización del análisis factorial sobre los ítems relativos a los procesos de planificación estratégica de la organización partimos de las variables originales de la 11 a la 15 incluidas en el cuestionario I que se indican a continuación:

\begin{tabular}{|c|l|}
\hline \multicolumn{2}{|l|}{$\begin{array}{l}\text { Tabla } 1.2 .3 \text { a). Nombre de las variables de procesos de planificación estratégica de la } \\
\text { organización }\end{array}$} \\
\hline V11 & $\begin{array}{l}\text { Definición de una misión común conforme a la que establecer un sentido } \\
\text { general de dirección }\end{array}$ \\
\hline V12 & $\begin{array}{l}\text { Desarrollo de procesos de reflexión estratégicos dirigidos a elaborar unos } \\
\text { objetivos concretos }\end{array}$ \\
\hline V13 & $\begin{array}{l}\text { Coherencia estratégica mediante integración y coordinación de objetivos y } \\
\text { políticas }\end{array}$ \\
\hline V14 & Objetivos y políticas son comunicados a los empleados de la organización \\
\hline V15 & $\begin{array}{l}\text { Promoción y estimulación del compromiso de los empleados con los aspectos } \\
\text { estratégicos }\end{array}$ \\
\hline
\end{tabular}


Tanto el resultado obtenido de la prueba de Barlett (tabla 1.2.3 b)) que alcanza un valor aceptable ya que el nivel de significación es nulo, como el resultado de la de KMO, superior al umbral generalmente aceptado de de 0,5, justifican la adecuación del análisis factorial.

Los resultados de este análisis aparecen en la matriz de componentes rotados (tabla 1.2.3 b)). A partir de dichos resultados disponemos de la información necesaria para interpretar y asignar una denominación apropiada a cada uno de los factores que se obtienen.

\begin{tabular}{|c|c|c|c|c|}
\hline & \multirow[b]{2}{*}{ Alpha sin ítem } & \multicolumn{2}{|c|}{ Factores } & \multirow[b]{2}{*}{ Comunalidades } \\
\hline & & Factor 1 & \begin{tabular}{|c|} 
Factor \\
2 \\
\end{tabular} & \\
\hline $\begin{array}{l}\text { PROMOCIÓN Y ESTIMULACIÓN DEL COMPROMISO DE } \\
\text { LOS EMPLEADOS CON LOS ASPECTOS ESTRATÉGICOS }\end{array}$ & 0,865 & 0,919 & 0,174 & 0,875 \\
\hline $\begin{array}{l}\text { OBJETIVOS Y POLÍTICAS SON COMUNICADOS A LOS } \\
\text { EMPLEADOS DE LA ORGANIZACIÓN }\end{array}$ & 0,864 & 0,883 & 0,190 & 0,815 \\
\hline $\begin{array}{llllr}\text { DESARROLLO } & \text { DE } & \text { PROCESOS } & \text { DE } & \text { REFLEXIÓN } \\
\text { ESTRATÉGICOS } & \text { DIRIGIDOS } & \text { A } & \text { ELABORAR } & \text { UNOS } \\
\text { OBJETIVOS CONCRETOS } & & & \\
\end{array}$ & 0,866 & 0,077 & 0,881 & 0,782 \\
\hline $\begin{array}{l}\text { COHERENCIA ESTRATÉGICA MEDIANTE INTEGRACIÓN } \\
\text { Y COORDINACIÓN DE OBJETIVOS Y POLIITICAS }\end{array}$ & 0,865 & 0,238 & 0,844 & 0,768 \\
\hline $\begin{array}{l}\text { DEFINICIÓN DE UNA MISIÓN COMÚN CONFORME A LA } \\
\text { QUE ESTABLECER UN SENTIDO GENERAL DE } \\
\text { DIRECCIÓN } \\
\text { DIR }\end{array}$ & 0,864 & 0,454 & 0,554 & 0,513 \\
\hline Autocovalores & & 2,724 & 1,028 & \\
\hline$\%$ Varianza explicada & & $54,48 \%$ & $20,57 \%$ & \\
\hline \multicolumn{5}{|l|}{$\alpha$ de Cronbach de la escala completa: 0,871} \\
\hline \multicolumn{5}{|l|}{$\%$ Total de varianza explicada: : 75,05\% } \\
\hline Prueba de KMO: 0,631 & & & & \\
\hline
\end{tabular}

A partir del análisis factorial realizado, se han obtenido dos factores, los cuales explican el $75,05 \%$ de la varianza. Como se puede comprobar todas las variables poseen marcadores superiores a 0,5 en un factor. Por otro lado, el factor explica una proporción elevada de las variables, como lo demuestran las elevadas comunalidades. Se puede también observar la consistencia interna de la escala por la escasa variación del coeficiente $\alpha$ al eliminar cada uno de los 
ítems respecto al $\alpha$ de 0,871 de la escala completa para los procesos de planificación estratégica de la organización.

Pasemos a describir los dos factores obtenidos a partir de la saturación con las variables originales en la matriz de componentes rotados.

- Factor 1:

Este factor, que explica el $54,48 \%$ de la varianza adquiere saturaciones altas para las variables V14 y V15. Entre ellas, destaca la elevada puntuación promoción y estimulación del compromiso de los empleados con los aspectos estratégicos $(0,919)$.

- Factor 2:

Este factor, que explica el $20,56 \%$ de la varianza, se asocia a las variables V11, V12 y V13: definición de una misión común conforme a la que establecer un sentido general de dirección, desarrollo de procesos de reflexión estratégicos dirigidos a elaborar unos objetivos concretos y coherencia estratégica mediante integración y coordinación de objetivos y políticas con puntuaciones de $0,554,0,881$ y 0,844 respectivamente.

Los resultados del análisis factorial realizado sobre las variables de vigilancia del entorno externo permiten destacar la reducción relevante desde 5 variables originales a sólo 2 factores, manteniendo la varianza explicada del $75,05 \%$. 


\section{4.- Sistemas de medición de la gestión}

Para la realización del análisis factorial sobre los ítems relativos a los sistemas de medición de la gestión partimos de las variables originales de la 16 a la 20 incluidas en el cuestionario I que se indican a continuación:

\begin{tabular}{|c|c|}
\hline V16 & Sistemas de información contable y de control presupuestario \\
\hline V17 & Sistemas de evaluación del desempeño de los trabajadores \\
\hline V18 & Parámetros técnicos y sistemas de evaluación de la calidad \\
\hline V19 & Sistemas de medición de la satisfacción de los clientes \\
\hline V20 & Otros aspectos no estrictamente financieros de los resultados \\
\hline
\end{tabular}

El resultado obtenido de la prueba de Barlett (tabla 1.2.4 b)) que alcanza un valor aceptable ya que el nivel de significación es prácticamente nulo, justifica la adecuación del análisis factorial, aunque el resultado de la prueba de $\mathrm{KMO}$, inferior al umbral generalmente aceptado de de 0,5 , nos indica que los resultados pueden ser pobres.

Los resultados de este análisis aparecen en la matriz de componentes rotados (tabla 1.2.4 b)). A partir de dichos resultados disponemos de la información necesaria para interpretar y asignar una denominación apropiada a cada uno de los factores que se obtienen.

\begin{tabular}{|c|c|c|c|c|}
\hline & \multirow[b]{2}{*}{ Alpha sin ítem } & \multicolumn{2}{|c|}{ Factores } & \multirow[b]{2}{*}{ Comunalidades } \\
\hline & & \multicolumn{2}{|c|}{\begin{tabular}{l|l} 
Factor 1 & Factor 2 \\
\end{tabular}} & \\
\hline $\begin{array}{l}\text { PARÁMETROS TÉCNICOS Y SISTEMAS DE EVALUACIÓN } \\
\text { DE LA CALIDAD }\end{array}$ & 0,863 & 0,829 & 0,117 & 0,701 \\
\hline $\begin{array}{lclll}\text { SISTEMAS DE } & \text { INFORMACIÓN } & \text { CONTABLE } & \text { Y } & \text { DE } \\
\text { CONTROL PRESUPUESTARIO } & & & \\
\end{array}$ & 0,868 & 0,803 & 0,083 & 0,651 \\
\hline $\begin{array}{l}\text { OTROS ASPECTOS NO ESTRICTAMENTE FINANCIEROS } \\
\text { DE LOS RESULTADOS }\end{array}$ & 0,870 & $-0,154$ & 0,885 & 0,807 \\
\hline $\begin{array}{l}\text { SISTEMAS DE MEDICIÓN DE LA SATISFACCIÓN DE LOS } \\
\text { CLIENTES }\end{array}$ & 0,862 & 0,350 & 0,696 & 0,607 \\
\hline $\begin{array}{l}\text { SISTEMAS DE EVALUACIÓN DEL DESEMPEÑO DE LOS } \\
\text { TRABAJADORES }\end{array}$ & 0,861 & 0,505 & 0,660 & 0,691 \\
\hline \multicolumn{2}{|l|}{ Autocovalores } & 2,333 & 1,124 & \\
\hline \multicolumn{2}{|l|}{$\%$ Varianza explicada } & $46,66 \%$ & $22,48 \%$ & \\
\hline \multicolumn{5}{|l|}{$\alpha$ de Cronbach de la escala completa: 0,871} \\
\hline \multicolumn{5}{|l|}{$\%$ Total de varianza explicada: : 69,14\% } \\
\hline \multicolumn{5}{|l|}{ Prueba de KMO: 0,696 } \\
\hline \multicolumn{5}{|c|}{ Prueba de esfericidad de Barlett: $\mathrm{Chi}^{2}=43,177$ gl: 10 sig. 0,000} \\
\hline
\end{tabular}


A partir del análisis factorial realizado, se han obtenido dos factores, los cuales explican el $69,14 \%$ de la varianza. Como se puede comprobar todas las variables poseen marcadores superiores a 0,6 en un factor. Por otro lado, el factor explica una proporción elevada de la mayoría de las variables, como lo demuestran las elevadas comunalidades. Se puede también observar la consistencia interna de la escala por la escasa variación del coeficiente $\alpha$ al eliminar cada uno de los ítems respecto al $\alpha$ de 0,871 de la escala completa para los sistemas de medición de la gestión.

Pasemos a interpretar los dos factores obtenidos a partir de la saturación con las variables originales en la matriz de componentes rotados.

- Factor 1

Este factor, que explica el 46,66\% de la varianza adquiere saturaciones altas para las variables V16 y V18: Sistemas de información contable y de control presupuestario con 0,803 y Parámetros técnicos y sistemas de evaluación de la calidad con 0,829.

- Factor 2

Este factor, que explica el 22,48\% de la varianza se asocia a las variables V17, V19 y V20. Destaca la elevada puntuación de Otros aspectos no estrictamente financieros de los resultados $(0,885)$.

Los resultados del análisis factorial realizado permiten la reducción relevante desde 5 variables originales a sólo 2 factores, manteniendo la varianza explicada del $69,14 \%$. 


\section{5.- Stocks de conocimiento}

Para la realización del análisis factorial sobre los ítems relativos a los stocks de conocimiento partimos de las variables originales de la 21 a la 29 incluidas en el cuestionario II se indican a continuación:

\begin{tabular}{|c|c|}
\hline V21 & La organización dispone de estrategias claras de posicionamiento para el futuro \\
\hline V22 & $\begin{array}{l}\text { La organización dispone de una estructura organizativa que permite trabajar } \\
\text { eficientemente }\end{array}$ \\
\hline V23 & La cultura organizativa representa unos valores significativos para la organización \\
\hline V24 & $\begin{array}{l}\text { Los grupos de trabajo están capacitados para tomar las decisiones relativas a su } \\
\text { actividad }\end{array}$ \\
\hline V25 & $\begin{array}{l}\text { Los grupos de trabajo demuestran estar capacitados para resolver con eficacia sus } \\
\text { conflictos }\end{array}$ \\
\hline V26 & $\begin{array}{l}\text { Los integrantes de los grupos comparten internamente logros y fracasos de su trabajo } \\
\text { en común }\end{array}$ \\
\hline V27 & Los empleados de la organización poseen la cualificación y conocimientos necesarios \\
\hline V28 & $\begin{array}{l}\text { Los empleados de la organización realizan con competencia las tareas propias de su } \\
\text { trabajo }\end{array}$ \\
\hline V29 & $\begin{array}{l}\text { Los empleados manifiestan en su trabajo un alto sentido del rigor y de la } \\
\text { responsabilidad }\end{array}$ \\
\hline
\end{tabular}

El resultado obtenido de la prueba de Barlett (tabla 1.2.5 b)) alcanza un valor aceptable, ya que el nivel de significación es nulo. Además el resultado de la prueba de KMO supera el umbral generalmente aceptado de 0,5 y, por tanto, justifica la adecuación del análisis factorial.

Los resultados de este análisis aparecen en la matriz de componentes rotados (tabla 1.2.5 b)) en la cual -como en el caso previo y en los siguienteshemos conservado los factores con autocovalores superiores a 1. A partir de dichos resultados disponemos de la información necesaria para interpretar y asignar una denominación apropiada a cada uno de los factores que se obtienen. 


\begin{tabular}{|c|c|c|c|c|}
\hline & \multirow[b]{2}{*}{ Alpha sin ítem } & \multicolumn{2}{|c|}{ Factores } & \multirow[b]{2}{*}{ Comunalidades } \\
\hline & & Factor 1 & Factor 2 & \\
\hline $\begin{array}{l}\text { GRUPOS DE TRABAJO ESTÁN CAPACITADOS PARA TOMAR } \\
\text { DECISIONES RELATIVAS A SU ACTIVIDAD }\end{array}$ & 0,830 & 0,839 & 0,159 & 0,729 \\
\hline $\begin{array}{l}\text { GRUPOS DE TRABAJO ESTÁN CAPACITADOS PARA } \\
\text { RESOLVER CON EFICACIA SUS CONFLICTOS }\end{array}$ & 0,834 & 0,823 & 0,145 & 0,698 \\
\hline $\begin{array}{l}\text { LA CULTURA ORGANIZATIVA REPRESENTA VALORES } \\
\text { SIGNIFICATIVOS PARA LA ORGANIZACIÓN }\end{array}$ & 0,834 & 0,821 & 0,038 & 0,675 \\
\hline $\begin{array}{l}\text { SE DISPONE DE UNA ESTRUCTURA ORGANIZATIVA QUE } \\
\text { PERMITE TRABAJAR EFICIENTEMENTE }\end{array}$ & 0,837 & 0,663 & 0,257 & 0,505 \\
\hline $\begin{array}{l}\text { LOS INTEGRANTES DE LOS GRUPOS COMPARTEN LOGROS } \\
\text { Y FRACASOS DE SU TRABAJO EN COMÚN }\end{array}$ & 0,835 & 0,652 & 0,437 & 0,617 \\
\hline $\begin{array}{l}\text { LA ORGANIZACIÓN DISPONE DE ESTRATEGIAS DE } \\
\text { POSICIONAMIENTO PARA EL FUTURO }\end{array}$ & 0,842 & 0,605 & 0,407 & 0,531 \\
\hline $\begin{array}{l}\text { EMPLEADOS POSEEN CUALIFICACIÓN Y CONOCIMIENTOS } \\
\text { NECESARIOS }\end{array}$ & 0,849 & 0,054 & 0,870 & 0,760 \\
\hline $\begin{array}{l}\text { LOS EMPLEADOS DE LA ORGANIZACIÓN REALIZAN CON } \\
\text { COMPETENCIA SUS TAREAS }\end{array}$ & 0,842 & 0,200 & 0,827 & 0,725 \\
\hline $\begin{array}{l}\text { EMPLEADOS POSEEN EN SU TRABAJO ALTO SENTIDO DEL } \\
\text { RIGOR Y DE LA RESPONSABILIDAD }\end{array}$ & 0,845 & 0,300 & 0,693 & 0,570 \\
\hline \multicolumn{2}{|l|}{ Autocovalores } & 4,402 & 1,408 & \\
\hline \% Varianza explicada & & $48,91 \%$ & $15,65 \%$ & \\
\hline \multicolumn{5}{|l|}{$\alpha$ de Cronbach de la escala completa: 0,851} \\
\hline \multicolumn{5}{|l|}{$\%$ Total de varianza explicada: : $64,56 \%$} \\
\hline \multicolumn{5}{|l|}{ Prueba de KMO: 0,790 } \\
\hline \multicolumn{5}{|l|}{ Prueba de esfericidad de Barlett: $\mathrm{Chi}^{2}=177,774$ gl: 36 sig. 0,000} \\
\hline
\end{tabular}

A partir del análisis factorial realizado, se han obtenido dos factores, los cuales explican el $64,56 \%$ de la varianza. Como se puede comprobar todas las variables poseen marcadores superiores a 0,6 en un factor. Por otro lado, el factor explica una proporción elevada de la mayoría de las variables, como lo demuestran las elevadas comunalidades. Se puede también observar la consistencia interna de la escala por la escasa variación del coeficiente $\alpha$ al eliminar cada uno de los ítems respecto al $\alpha$ de 0,851 de la escala completa para los stocks de conocimiento.

Pasemos a describir los dos factores obtenidos a partir de la saturación con las variables originales en la matriz de componentes rotados.

- Factor 1: Capacidades de la organización y los grupos

Este factor, que explica el $48,91 \%$ de la varianza adquiere saturaciones altas para las variables relacionadas con las capacidades de la organización y los grupos. Destacan las elevadas puntuaciones de la 
cultura organizativa representa valores significativos $(0,821)$, los grupos están capacitados para tomar decisiones relativas a su actividad $(0,839)$ y los grupos están capacitados para resolver sus conflictos $(0,823)$.

- Factor 2: Capacidades de los individuos

Este factor, que explica el $15,65 \%$ de la varianza se asocia a las capacidades de los individuos. Destaca la elevada puntuación de los empleados possen cualificación y conocimientos necesarios $(0,870)$.

Los resultados del análisis factorial realizado permiten la reducción relevante desde 9 variables originales a sólo 2 factores, manteniendo la varianza explicada del $64,56 \%$.

\section{6.- Flujos de conocimiento}

Para la realización del análisis factorial sobre los ítems relativos a los flujos de conocimiento partimos de las variables originales de la 30 a la 35 incluidas en el cuestionario II se indican a continuación:

\begin{tabular}{|c|c|}
\hline Tabla 1.2.6 a). Nombre de las variables de los flujos de conocimiento \\
\hline V30 & $\begin{array}{l}\text { La formación es utilizada para mejorar los conocimientos y habilidades de los } \\
\text { individuos o de los grupos }\end{array}$ \\
\hline V31 & $\begin{array}{l}\text { Prácticas como el outdoor trainning o asignaciones especiales a otros departamentos } \\
\text { son utilizadas para desarrollar una fuerza de trabajo más flexible. }\end{array}$ \\
\hline V32 & $\begin{array}{l}\text { La organización tiene tecnologías y herramientas que permiten y facilitan el } \\
\text { intercambio de conocimiento }\end{array}$ \\
\hline V33 & $\begin{array}{l}\text { Los integrantes de los grupos de trabajo de la organización comparten entre sí sus } \\
\text { experiencias y sus conocimientos individuales }\end{array}$ \\
\hline V34 & $\begin{array}{l}\text { Los empleados de la organización tienen oportunidad de participar en decisiones de la } \\
\text { misma }\end{array}$ \\
\hline V35 & $\begin{array}{l}\text { Existe un sistema de retribución que fomenta compartir el conocimiento a toda la } \\
\text { organización }\end{array}$ \\
\hline
\end{tabular}

El resultado obtenido de la prueba de Barlett (tabla 1.2.6 b)) alcanza un valor aceptable, ya que el nivel de significación es nulo. Además el resultado de 
la prueba de KMO supera el umbral generalmente aceptado de 0,5 y, por tanto, justifica la adecuación del análisis factorial.

Los resultados de este análisis aparecen en la matriz de componentes rotados (tabla 1.2.6 b)) en la cual -como en el caso previo y en los siguienteshemos conservado los factores con autocovalores superiores a 1. A partir de dichos resultados disponemos de la información necesaria para interpretar y asignar una denominación apropiada a cada uno de los factores que se obtienen.

\begin{tabular}{|c|c|c|c|c|}
\hline & & \multicolumn{2}{|c|}{ Factores } & \multirow[b]{2}{*}{ Comunalidades } \\
\hline & Alpha sin ítem & Factor 1 & Factor 2 & \\
\hline $\begin{array}{l}\text { EL OUTDOOR TRAINNING O ASIGNACIONES ESPECIALES } \\
\text { A OTROS DEPARTAMENTOS SON UTILIZADAS PARA } \\
\text { DESARROLLAR UNA FUERZA DE TRABAJO MÁS FLEXIBLE. }\end{array}$ & 0,837 & 0,784 & 0,203 & 0,657 \\
\hline $\begin{array}{l}\text { LOS INTEGRANTES DE LOS GRUPOS DE TRABAJO DE LA } \\
\text { ORGANIZACIÓN COMPARTEN ENTRE SÍ SUS } \\
\text { EXPERIENCIAS Y SUS CONOCIMIENTOS INDIVIDUALES }\end{array}$ & 0,830 & 0,755 & $-0,312$ & 0,668 \\
\hline $\begin{array}{l}\text { LA ORGANIZACIÓN TIENE TECNOLOGÍAS Y } \\
\text { HERRAMIENTAS QUE PERMITEN Y FACILITAN EL } \\
\text { INTERCAMBIO DE CONOCIMIENTO }\end{array}$ & 0,834 & 0,752 & 0,228 & 0,617 \\
\hline $\begin{array}{l}\text { EXISTE UN SISTEMA DE RETRIBUCIÓN QUE FOMENTA } \\
\text { COMPARTIR EL CONOCIMIENTO A TODA LA } \\
\text { ORGANIZACIÓN }\end{array}$ & 0,835 & 0,752 & $-0,164$ & 0,593 \\
\hline $\begin{array}{l}\text { LOS EMPLEADOS DE LA ORGANIZACIÓN TIENEN } \\
\text { OPORTUNIDAD DE PARTICIPAR EN DECISIONES DE LA } \\
\text { MISMA }\end{array}$ & 0,834 & 0,729 & 0,039 & 0,533 \\
\hline $\begin{array}{l}\text { LA FORMACIÓN ES UTILIZADA PARA MEJORAR LOS } \\
\text { CONOCIMIENTOS Y HABILIDADES DE LOS INDIVIDUOS O } \\
\text { DE LOS GRUPOS }\end{array}$ & 0,842 & 0,030 & 0,930 & 0,865 \\
\hline \multicolumn{2}{|l|}{ Autocovalores } & 2,848 & 1,084 & \\
\hline \multicolumn{2}{|l|}{ \% Varianza explicada } & $47,47 \%$ & $18,06 \%$ & \\
\hline \multicolumn{5}{|l|}{$\alpha$ de Cronbach de la escala completa: 0,851} \\
\hline \multicolumn{5}{|l|}{$\%$ Total de varianza explicada: : $65,53 \%$} \\
\hline \multicolumn{5}{|l|}{ Prueba de KMO: 0,777} \\
\hline \multicolumn{5}{|l|}{ Prueba de esfericidad de Barlett: $\mathrm{Chi}^{2}=66,310$ gl: 15 sig. 0,000} \\
\hline
\end{tabular}

A partir del análisis factorial realizado, se han obtenido dos factores, los cuales explican el $65,53 \%$ de la varianza. Como se puede comprobar todas las variables poseen marcadores superiores a 0,7 en un factor. Por otro lado, el factor explica una proporción elevada de la mayoría de las variables, como lo demuestran las elevadas comunalidades. Se puede también observar la consistencia interna de la escala por la escasa variación del coeficiente $\alpha$ al 
eliminar cada uno de los ítems respecto al $\alpha$ de 0,851 de la escala completa para los flujos de conocimiento.

Pasemos a describir los dos factores obtenidos a partir de la saturación con las variables originales en la matriz de componentes rotados.

- Factor 1

Este factor, que explica el $47,47 \%$ de la varianza adquiere saturaciones altas para las variables V31 hasta V35. Las puntuaciones de estas variables varían poco: oscilan entre 0,729 y 0,784.

- Factor 2:

Este factor, que explica el $18,06 \%$ de la varianza se asocia a la formación como herramienta para mejorar conocimientos y habilidades. La puntuación de la única variable implicada es muy alta: 0,930.

Los resultados del análisis factorial realizado permiten la reducción relevante desde 6 variables originales a sólo 2 factores, manteniendo la varianza explicada del $65,53 \%$.

\section{7.- Competencias Estratégicas}

Para la realización del análisis factorial sobre los ítems relativos a competencias estratégicas partimos de las variables originales de la V36 a la V40 incluidas en el cuestionario III se indican a continuación:

\begin{tabular}{|c|l|}
\hline Tabla 1.2.7 a). Nombre de las variables de competencias estratégicas \\
\hline V36 & $\begin{array}{l}\text { Visión de Negocio: capacidad de reconocer los peligros y aprovechar las } \\
\text { oportunidades que repercuten la efectividad del negocio. }\end{array}$ \\
\hline V37 & $\begin{array}{l}\text { Gestión de los recursos: utiliza los recursos del modo más idóneo, rápido, } \\
\text { económico y eficaz }\end{array}$ \\
\hline V38 & $\begin{array}{l}\text { Orientación al cliente: capacidad de satisfacer las necesidades del cliente, } \\
\text { ofreciendo una oferta de valor, cuidando todos los detalles de la relación, y } \\
\text { dando respuesta a sus peticiones y sugerencias. }\end{array}$ \\
\hline V39 & $\begin{array}{l}\text { Networking: capacidad de desarrollar, mantener y utilizar una amplia red de } \\
\text { relaciones con personas clave dentro de la empresa y del sector. }\end{array}$ \\
\hline V40 & $\begin{array}{l}\text { Negociación: capacidad de alcanzar acuerdos satisfactorios para las partes } \\
\text { implicadas, descubriendo o creando elementos que produzcan valor añadido a la } \\
\text { relación. }\end{array}$ \\
\hline
\end{tabular}


Tanto el resultado obtenido de la prueba de Barlett (tabla 1.2.7 b)) que alcanza un valor aceptable ya que el nivel de significación es nulo, como el resultado de la de KMO, superior al umbral generalmente aceptado de de 0,5, justifican la adecuación del análisis factorial.

Los resultados de este análisis aparecen en la matriz de componentes rotados (tabla 1.2.7 b)) en la cual -como en el caso previo y en los siguienteshemos conservado los factores con autocovalores superiores a 1. A partir de dichos resultados disponemos de la información necesaria para interpretar y asignar una denominación apropiada a cada uno de los factores que se obtienen.

\begin{tabular}{|l|c|c|c|}
\hline \multicolumn{3}{|l|}{ Tabla 1.2.7 b): Análisis factorial de las competencias estratégicas } \\
\hline & Alpha sin ítem & Factor 1 & Comunalidades \\
\hline GESTIÓN DE LOS RECURSOS & 0,742 & 0,836 & 0,698 \\
\hline NEGOCIACIÓN & 0,770 & 0,778 & 0,605 \\
\hline VISIÓN DE NEGOCIO & 0,775 & 0,756 & 0,572 \\
\hline ORIENTACIÓN AL CLIENTE & 0,789 & 0,709 & 0,503 \\
\hline NETWORKING & 0,793 & 0,703 & 0,494 \\
\hline Autocovalores & 2,872 & \\
\hline$\%$ Varianza explicada & $57,45 \%$ & \\
\hline$\alpha$ de Cronbach de la escala completa: 0,811 & & \\
\hline$\%$ Total de varianza explicada: : $57,45 \%$ & & \\
\hline Prueba de KMO: 0,828 & & \\
\hline Prueba de esfericidad de Barlett: Chi ${ }^{2}=63,567$ gl: 10 sig. 0,000 \\
\hline
\end{tabular}

A partir del análisis factorial realizado, se ha obtenido un único factor, que explica el $57,45 \%$ de la varianza. Como se puede comprobar todas las variables poseen marcadores superiores a 0,5 en el factor. Por otro lado, el factor explica un proporción no muy elevada de la mayoría de las variables, excepto para gestión de los recursos $(0,698)$. Se puede también observar la consistencia interna de la escala por la escasa variación del coeficiente $\alpha$ al eliminar cada uno de los ítems respecto al $\alpha$ de 0,811 de la escala completa. 
Pasemos a describir el factor obtenido a partir de la saturación con las variables originales en la matriz de componentes.

- Factor 1

Este factor, que explica el $57,45 \%$ de la varianza adquiere saturaciones altas para todas las variables. Entre ellas, destaca la elevada puntuación de la gestión de los recursos $(0,836)$.

Los resultados del análisis factorial realizado sobre las variables de competencias estratégicas permiten destacar la reducción relevante desde 5 variables originales a sólo 1 factor, manteniendo la varianza explicada del $57,45 \%$.

\section{8.- Competencias Intratégicas}

Para la realización del análisis factorial partimos de las variables originales de la V41 a V46 incluidas en el cuestionario III que se indican a continuación:

\begin{tabular}{|c|l|}
\hline \multicolumn{2}{|l|}{$\begin{array}{l}\text { Tabla 1.2.8 a). Nombre de las variables de competencias intratégicas } \\
\text { Financiación }\end{array}$} \\
\hline V41 & $\begin{array}{l}\text { Comunicación: capacidad de escuchar y transmitir ideas de manera efectiva, } \\
\text { empleando el canal adecuado en el momento oportuno, y proporcionando datos } \\
\text { concretos para respaldar sus conclusiones. }\end{array}$ \\
\hline V42 & $\begin{array}{l}\text { Gestión de conflictos: capacidad de diagnosticar, afrontar y resolver conflictos } \\
\text { interpersonales con prontitud y profundidad, sin dañar la relación personal. }\end{array}$ \\
\hline V43 & $\begin{array}{l}\text { Delegación: capacidad de conseguir que los colaboradores del equipo dispongan } \\
\text { de la información y los recursos necesarios para tomar decisiones y lograr sus } \\
\text { objetivos. }\end{array}$ \\
\hline V44 & Coaching: es la capacidad de ayudar a desarrollar el potencial de cada persona. \\
\hline V45 & $\begin{array}{l}\text { Trabajo en equipo: capacidad de fomentar un ambiente de colaboración, } \\
\text { comunicación y confianza. }\end{array}$ \\
\hline V46 & $\begin{array}{l}\text { Carisma: capacidad de lograr el compromiso de los colaboradores, inspirando su } \\
\text { confianza, dando sentido a su trabajo y motivándoles a conseguir los objetivos. }\end{array}$ \\
\hline
\end{tabular}

Tanto el resultado obtenido de la prueba de Barlett (tabla 1.2.8 b)) que alcanza un valor aceptable ya que el nivel de significación es nulo, como el 
resultado de la de KMO, superior al umbral generalmente aceptado de de 0,5, justifican la adecuación del análisis factorial.

Los resultados de este análisis aparecen en la matriz de componentes rotados (tabla 1.2.8 b)) en la cual -como en el caso previo y en los siguienteshemos conservado los factores con autocovalores superiores a 1. A partir de dichos resultados disponemos de la información necesaria para interpretar y asignar una denominación apropiada a cada uno de los factores que se obtienen.

\begin{tabular}{|l|c|c|c|}
\hline \multicolumn{3}{|l|}{ Tabla 1.2 .8 b): Análisis factorial de las competencias intratégicas } \\
\hline TRABAJO EN EQUIPO & Alpha sin ítem & Factor 1 & Comunalidades \\
\hline COMUNICACIÓN & 0,796 & 0,863 & 0,744 \\
\hline GESTIÓN DE CONFLICTOS & 0,811 & 0,811 & 0,658 \\
\hline COACHING & 0,823 & 0,765 & 0,586 \\
\hline DELEGACIÓN & 0,829 & 0,737 & 0,544 \\
\hline CARISMA & 0,836 & 0,702 & 0,492 \\
\hline Autocovalores & 0,845 & 0,640 & 0,409 \\
\hline$\%$ Varianza explicada & 3,433 & \\
\hline$\alpha$ de Cronbach de la escala completa: 0,849 & $57,22 \%$ & \\
\hline$\%$ Total de varianza explicada: : $57,22 \%$ & & \\
\hline Prueba de KMO: 0,824 & & \\
\hline Prueba de esfericidad de Barlett: Chi ${ }^{2}=101,066$ gl: 15 sig. 0,000 \\
\hline
\end{tabular}

A partir del análisis factorial realizado, se ha obtenido un único factor, que explica el $57,22 \%$ de la varianza. Como se puede comprobar todas las variables poseen marcadores superiores a 0,6 en el factor. Por otro lado, el factor explica un proporción elevada de la mayoría de las variables, excepto para delegación $(0,492)$ y carisma $(0,409)$. Se puede también observar la consistencia interna de la escala por la escasa variación del coeficiente $\alpha$ al eliminar cada uno de los ítems respecto al $\alpha$ de 0,824 de la escala completa.

Pasemos a describir el factor obtenido a partir de la saturación con las variables originales en la matriz de componentes. 
- Factor 1

Este factor, que explica el 57,22\% de la varianza adquiere saturaciones altas para todas las variables, en especial para comunicación $(0,811)$ y trabajo en equipo $(0,863)$.

Los resultados del análisis factorial realizado sobre las variables de competencias estratégicas permiten destacar la reducción relevante desde 6 variables originales a sólo 1 factor, manteniendo la varianza explicada del $57,22 \%$.

\section{9.- Competencias Personales}

Para la realización del análisis factorial sobre los ítems relativos a las competencias personales partimos de las variables originales V47 hasta V51 incluidas en el cuestionario III que se indican a continuación:

\begin{tabular}{|c|l|}
\hline \multicolumn{2}{|c|}{ Tabla 1.2 .9 a). Nombre de las variables de competencias personales } \\
\hline V47 & PROACTIVIDAD \\
\hline V48 & GESTIÓN PERSONAL \\
\hline V49 & MEJORA PERSONAL \\
\hline V50 & AUTOGOBIERNO \\
\hline V51 & INTEGRIDAD \\
\hline
\end{tabular}

Tanto el resultado obtenido de la prueba de Barlett (tabla 1.2.9 b)) que alcanza un valor aceptable ya que el nivel de significación es nulo, como el resultado de la de $\mathrm{KMO}$, superior al umbral generalmente aceptado de de 0,5, justifican la adecuación del análisis factorial.

Los resultados de este análisis aparecen en la matriz de componentes rotados (tabla 1.2.9 b)) en la cual -como en el caso previo y en los siguienteshemos conservado los factores con autocovalores superiores a 1. A partir de 
dichos resultados disponemos de la información necesaria para interpretar y asignar una denominación apropiada a cada uno de los factores que se obtienen.

\begin{tabular}{|l|c|c|c|}
\hline Tabla 1.2.9 b): Análisis factorial de las competencias personales \\
\hline & Alpha sin ítem & Factor 1 & Comunalidades \\
\hline AUTOGOBIERNO & 0,798 & 0,827 & 0,684 \\
\hline MEJORA PERSONAL & 0,801 & 0,826 & 0,682 \\
\hline GESTIÓN PERSONAL & 0,815 & 0,777 & 0,604 \\
\hline INTEGRIDAD & 0,818 & 0,772 & 0,595 \\
\hline PROACTIVIDAD & 0,830 & 0,732 & 0,536 \\
\hline Autocovalores & & 3,101 & \\
\hline$\%$ Varianza explicada & $62,03 \%$ & \\
\hline$\alpha$ de Cronbach de la escala completa: 0,844 & & \\
\hline$\%$ Total de varianza explicada: : $62,03 \%$ & & \\
\hline Prueba de KMO: 0,826 & & \\
\hline Prueba de esfericidad de Barlett: $\mathrm{Chi}^{2}=81,474$ gl: 10 sig. 0,000 \\
\hline
\end{tabular}

A partir del análisis factorial realizado, se han obtenido un factor, el cual explica el $62,03 \%$ de la varianza. Como se puede comprobar todas las variables poseen marcadores superiores a 0,7 en el factor. Por otro lado, el factor explica una proporción intermedia de algunas de las variables, como lo demuestran las comunalidades entre 0,5 y 0,7 aproximadamente. Se puede también observar la consistencia interna de la escala por la escasa variación del coeficiente $\alpha$ al eliminar cada uno de los ítems respecto al $\alpha$ de 0,844 de la escala completa para competencias personales.

Pasemos a interpretar el factor obtenido a partir de la saturación con las variables originales en la matriz de componentes rotados.

\section{- Factor 1}

Este factor, que explica el 62,03\% de la varianza adquiere saturaciones altas para todas las variables relacionadas con las competencias personales. Entre ellas, destacan las elevadas puntuaciones de mejora personal $(0,826)$ y autogobierno $(0,827)$. 
Los resultados del análisis factorial realizado sobre las variables de las competencias personales permiten destacar la reducción relevante desde 5 variables originales a sólo 1 factor, manteniendo la varianza explicada del $62,03 \%$.

\section{0.- Resultados Intangibles}

Para la realización del análisis factorial sobre los ítems relativos a los resultados intangibles partimos de las variables originales V52 hasta V56 incluidas en el cuestionario III que se indican a continuación:

\begin{tabular}{|c|l|}
\hline \multicolumn{2}{|c|}{ Tabla 1.2.10 a). Nombre de las variables de resultados intangibles } \\
\hline V52 & La satisfacción de los clientes \\
\hline V53 & El incremento de los clientes \\
\hline V54 & La satisfacción de los empleados \\
\hline V55 & El nivel de calidad \\
\hline V56 & La reputación de la organización \\
\hline
\end{tabular}

Tanto el resultado obtenido de la prueba de Barlett (tabla 1.2.10 b)) que alcanza un valor aceptable ya que el nivel de significación es nulo, como el resultado de la de $\mathrm{KMO}$, superior al umbral generalmente aceptado de de 0,5, justifican la adecuación del análisis factorial.

Los resultados de este análisis aparecen en la matriz de componentes rotados (tabla 1.2.10 b)) en la cual -como en el caso previo y en los siguienteshemos conservado los factores con autocovalores superiores a 1. A partir de dichos resultados disponemos de la información necesaria para interpretar y asignar una denominación apropiada a cada uno de los factores que se obtienen.

\begin{tabular}{|l|c|c|c|}
\hline \multicolumn{4}{|l|}{ Tabla 1.2.10 b): Análisis factorial de los resultados intangibles } \\
\hline LA SATISFACCIÓN DE LOS CLIENTES & Alpha sin ítem & Factor 1 & Comunalidades \\
\hline LA REPUTACIÓN DE LA ORGANIZACIÓN & 0,666 & 0,799 & 0,639 \\
\hline
\end{tabular}




\begin{tabular}{|c|c|c|c|}
\hline EL NIVEL DE CALIDAD & 0,687 & 0,757 & 0,574 \\
\hline LA SATISFACCIÓN DE LOS EMPLEADOS & 0,735 & 0,616 & 0,379 \\
\hline EL INCREMENTO DE LOS CLIENTES & 0,736 & 0,574 & 0,329 \\
\hline \multicolumn{2}{|l|}{ Autocovalores } & 2,555 & \\
\hline \multicolumn{2}{|l|}{$\%$ Varianza explicada } & $51,10 \%$ & \\
\hline \multicolumn{4}{|l|}{$\alpha$ de Cronbach de la escala completa: 0,844} \\
\hline \multicolumn{4}{|l|}{$\%$ Total de varianza explicada: : $51,10 \%$} \\
\hline \multicolumn{4}{|c|}{ Prueba de KMO: 0,767} \\
\hline \multicolumn{4}{|c|}{ Prueba de esfericidad de Barlett: $\mathrm{Chi}^{2}=49,569$ gl: 10 sig. 0,000 } \\
\hline
\end{tabular}

A partir del análisis factorial realizado, se ha obtenido un factor, que explica el $51,10 \%$ de la varianza. Como se puede comprobar todas las variables poseen marcadores superiores a 0,5 en el factor. Por otro lado, los factores explican una proporción elevada de 3 de las variables, como lo demuestran las elevadas comunalidades (salvo para V53 y V54).

Pasemos a describir el factor obtenido a partir de la saturación con las variables originales en la matriz de componentes rotados.

- Factor 1

Este factor, que explica el $51,10 \%$ de la varianza adquiere saturaciones altas excepto para satisfacción de los empleados $(0,616)$ e incremento de los clientes $(0,574)$.

Los resultados del análisis factorial realizado sobre las variables de los resultados intangibles permiten destacar la reducción relevante desde 5 variables originales a sólo 1 factor, manteniendo la varianza explicada del $51,10 \%$. 


\section{1.- Resultados Tangibles}

Para la realización del análisis factorial sobre los ítems relativos a los resultados tangibles partimos de las variables originales de la V57 a la V61 incluidas en el cuestionario III se indican a continuación:

\begin{tabular}{|c|l|}
\hline \multicolumn{2}{|c|}{ Tabla 1.2 .10 a). Nombre de las variables de los resultados tangibles } \\
\hline V57 & La rentabilidad sobre fondos propios \\
\hline V58 & El crecimiento de la cifra de negocio \\
\hline V59 & El crecimiento del beneficio \\
\hline V60 & La productividad del trabajo \\
\hline V61 & La mejora en los costes de producción \\
\hline
\end{tabular}

El resultado obtenido de la prueba de Barlett (tabla 1.2.10 b)) alcanza un valor aceptable, ya que el nivel de significación es nulo. Además el resultado de la prueba de KMO supera el umbral generalmente aceptado de 0,5 y, por tanto, justifica la adecuación del análisis factorial.

Los resultados de este análisis aparecen en la matriz de componentes rotados (tabla 1.2.10 b)) en la cual -como en el caso previo y en los siguienteshemos conservado los factores con autocovalores superiores a 1. A partir de dichos resultados disponemos de la información necesaria para interpretar y asignar una denominación apropiada a cada uno de los factores que se obtienen.

\begin{tabular}{|c|c|c|c|c|}
\hline & & \multicolumn{2}{|c|}{ Factores } & \multirow{2}{*}{ Comunalidades } \\
\hline & Alpha sin ítem & Factor 1 & Factor 2 & \\
\hline EL CRECIMIENTO DE LA CIFRA DE NEGOCIO & 0,701 & 0,852 & 0,249 & 0,788 \\
\hline LA RENTABILIDAD SOBRE FONDOS PROPIOS & 0,727 & 0,851 & 0,115 & 0,738 \\
\hline EL CRECIMIENTO DEL BENEFICIO & 0,747 & 0,804 & 0,109 & 0,658 \\
\hline LA MEJORA EN LOS COSTES DE PRODUCCIÓN & 0,800 & 0,021 & 0,939 & 0,882 \\
\hline LA PRODUCTIVIDAD DEL TRABAJO & 0,697 & 0,397 & 0,825 & 0,838 \\
\hline \multicolumn{2}{|l|}{ Autocovalores } & 2,755 & 1,148 & \\
\hline \multicolumn{2}{|l|}{$\%$ Varianza explicada } & $55,10 \%$ & $22,97 \%$ & \\
\hline \multicolumn{5}{|l|}{$\alpha$ de Cronbach de la escala completa: 0,776} \\
\hline \multicolumn{5}{|l|}{$\%$ Total de varianza explicada: : 78,07\% } \\
\hline \multicolumn{5}{|c|}{ Prueba de KMO: 0,670 } \\
\hline \multicolumn{5}{|c|}{ Prueba de esfericidad de Barlett: $\mathrm{Chi}^{2}=82,772$ gl: 10 sig. 0,000} \\
\hline
\end{tabular}


A partir del análisis factorial realizado, se han obtenido dos factores, los cuales explican el $78,07 \%$ de la varianza. Como se puede comprobar todas las variables poseen marcadores superiores a 0,8 en un factor. Por otro lado, el factor explica una proporción elevada de todas las variables, como lo demuestran las elevadas comunalidades. Se puede también observar la consistencia interna de la escala por la escasa variación del coeficiente $\alpha$ al eliminar cada uno de los ítems respecto al $\alpha$ de 0,776 de la escala completa para los resultados tangibles.

Pasemos a describir los dos factores obtenidos a partir de la saturación con las variables originales en la matriz de componentes rotados.

- Factor 1: Ventas y beneficios

Este factor, que explica el 55,10\% de la varianza adquiere saturaciones altas para las variables asociadas a las ventas y beneficios del negocio. Las puntuaciones de estas variables varían poco: oscilan entre 0,804 y 0,852 .

- Factor 2: Productividad

Este factor, que explica el $22,97 \%$ de la varianza se asocia a la productividad del negocio. Destaca el 0,939 de la variable la mejora en los costes de producción.

Los resultados del análisis factorial realizado permiten la reducción relevante desde 5 variables originales a sólo 2 factores, manteniendo la varianza explicada del $78,07 \%$. 


\subsection{3.- Valoración global y comparativa}

Con el objetivo de realizar una valoración global del análisis factorial realizado así como una comparativa la siguiente tabla resume los resultados obtenidos:

\begin{tabular}{|l|c|c|c|c|c|c|}
\hline Tabla 19: Resumen de los resultados obtenidos del análisis factorial (Lara, 2005) \\
\hline Constructo & $\begin{array}{c}\text { No de } \\
\text { Variables }\end{array}$ & $\begin{array}{c}\text { No }^{0} \text { de } \\
\text { factores }\end{array}$ & KMO & $\begin{array}{c}\text { p- valor de la } \\
\text { prueba de Barlett }\end{array}$ & $\begin{array}{c}\% \text { varianza } \\
\text { explicada }\end{array}$ & $\begin{array}{c}\text { Variables no } \\
\text { incluidas en un } \\
\text { factor }\end{array}$ \\
\hline VEE & 5 & 2 & 0,588 & 0,000 & $69,07 \%$ & Ninguna \\
\hline TDI & 5 & 2 & 0,772 & 0,000 & $70,51 \%$ & Ninguna \\
\hline PPE & 5 & 2 & 0,631 & 0,000 & $75,06 \%$ & Ninguna \\
\hline SMG & 5 & 2 & 0,696 & 0,000 & $69,13 \%$ & Ninguna \\
\hline SDC & 9 & 2 & 0,790 & 0,000 & $64,56 \%$ & Ninguna \\
\hline FDC & 6 & 2 & 0,777 & 0,000 & $65,53 \%$ & Ninguna \\
\hline ESTRATÉGICAS & 5 & 1 & 0,828 & 0,000 & $57,45 \%$ & Ninguna \\
\hline INTRATÉGICAS & 5 & 1 & 0,824 & 0,000 & $57,22 \%$ & Ninguna \\
\hline PERSONALES & 5 & 1 & 0,826 & 0,000 & $62,03 \%$ & Ninguna \\
\hline INTANGIBLES & 5 & 1 & 0,767 & 0,000 & $51,10 \%$ & Ninguna \\
\hline TANGIBLES & 5 & 2 & 0,670 & 0,000 & $78,07 \%$ & Ninguna \\
\hline
\end{tabular}

En general tanto los resultados obtenido de la prueba de Barlett (tabla 1.2.11), que alcanzan un valor aceptable ya que el nivel de significación es nulo en todos los casos, como con los resultados de la de KMO, superior al umbral generalmente aceptado de de 0,5, justifican la adecuación del análisis factorial.

A partir del análisis factorial realizado, se han obtenido un total de 18 factores. En el peor de los casos los factores explican el 51,10\% de la varianza y en el mejor el 78,07\%. En general el porcentaje de varianza explicada es muy bueno. Como se puede comprobar todas las variables poseen marcadores superiores a 0,5 en un factor. Se puede también observar la consistencia interna de la escala por la escasa variación del coeficiente $\alpha$ al eliminar cada uno de los ítems respecto al $\alpha$ de la escala completa.

Así, se ha pasado de 61 variables a 18 factores. 


\subsection{4.- Correlaciones entre factores}

Para ver como se interrelacionan las distintas dimensiones realizaremos las correlaciones de Pearson entre los factores de los distintos constructos ${ }^{1}$. Consideraremos significativas las relaciones con coeficientes mayores que 0,45 y sólo se hará referencia a coeficientes de la parte superior de la tabla, pues es una matriz simétrica:

- GESTIÓN DEL CONOCIMIENTO: Características externas - Capacidades internas

Tabla 20: Correlación entre los factores de la GC (Lara, 2005)

\begin{tabular}{|c|c|c|c|c|c|c|c|c|c|c|c|}
\hline \multicolumn{12}{|l|}{$\underline{\text { Correlaciones }}$} \\
\hline & $\begin{array}{c}\text { FACTOR } 1 \\
\text { VEE }\end{array}$ & $\begin{array}{c}\text { FACTOR } 2 \\
\text { VEE }\end{array}$ & $\begin{array}{c}\text { FACTOR } 1 \\
\text { TDI }\end{array}$ & $\begin{array}{c}\text { FACTOR } 1 \\
\text { TDI }\end{array}$ & $\begin{array}{c}\text { FACTOR } 1 \\
\text { PPE }\end{array}$ & $\begin{array}{c}\text { FACTOR } 2 \\
\text { PPE }\end{array}$ & $\begin{array}{c}\text { FACTOR } 1 \\
\text { SMG }\end{array}$ & $\begin{array}{c}\text { FACTOR } 1 \\
\text { SDC }\end{array}$ & $\begin{array}{c}\text { FACTOR } 2 \\
\text { SDC }\end{array}$ & $\begin{array}{c}\text { FACTOR } 1 \\
\text { FDC }\end{array}$ & $\begin{array}{c}\text { FACTOR } 2 \\
\text { FDC }\end{array}$ \\
\hline FACTOR 1 VEE & 1 & ,000 & 088 &, $415^{*}$ &, 300 & 089 & ,000 & , 193 &,- 269 & , 165 & 163 \\
\hline FACTOR 2 VEE & 000 & 1 & ,038 & ,250 & ,003 & $483^{*}$ &, $399^{* *}$ & ,220 & ,263 & ,117 & 001 \\
\hline FACTOR 1 TDI & ,088 &, 038 & 1 & ,000 &, $396^{* *}$ & ,267 &, $387^{*}$ & ,113 &, 354 &,- 089 & ,318 \\
\hline FACTOR 1 TDI &, $415^{*}$ &, 250 &, 000 & 1 &,- 031 & ,045 &, $325^{*}$ &, $412^{*}$ &,- 319 &,- 053 & ,267 \\
\hline FACTOR 1 PPE & $300^{\circ}$ &, 003 &, $396^{*}$ &,- 031 & 1 & ,000 & , 189 & ,290 & ,067 &, $326^{k}$ & , 158 \\
\hline FACTOR 2 PPE &, 089 & $483^{*}$ &, 267 &, 045 &, 000 & 1 & ,225 & , 140 &, $402^{*}$ & ,025 & ,042 \\
\hline FACTOR 1 SMG &, 000 & $39 \mu^{*}$ & $387^{*}$ & 325 &, 189 &, 225 & 1 & $473^{*}$ & 265 & 005 & 367 \\
\hline FACTOR 1 SDC & , 193 &, 220 &, 113 & $412^{*}$ &, 290 &, 140 & $473^{\star}$ & 1 & ,000 & 349 &, $399^{*}$ \\
\hline FACTOR 2 SDC &,- 269 &, 263 & .354 &,- 319 &, 067 &, $402^{* *}$ &, 265 & 000 & 1 & 054 & , 153 \\
\hline FACTOR 1 FDC &, 165 &, 117 &,- 089 &,- 053 &, 326 &, 025 &, 005 &, 349 &, 054 & 1 & ,000 \\
\hline FACTOR 2 FDC & .163 & .001 &, 318 & 267 & ,158 & .042 &, 367 &, $399^{*}$ &, 153 & .000 & 1 \\
\hline
\end{tabular}

La relación lineal entre los factores de los constructos que forman la dimensión Gestión del conocimiento es muy débil. Dentro de las CARACTERÍSTICAS EXTERNAS los aspectos procesos de planificación estratégica y la vigilancia del entorno externo están ligeramente relacionados, mientras que el constructo CAPACIDADES INTERNAS sólo existe la débil relación entre sistemas de medición de la gestión y stocks de conocimiento.

\footnotetext{
1 Recordemos que por construcción los factores de un mismo constructo son siempre
} incorrelados. 
Por tanto realmente la GESTIÓN DEL CONOCIMIENTO es un constructo que se debe recoger a través de las diferentes dimensiones consideradas, dado que cada una de ellas está midiendo dicho constructo desde perspectivas diferentes.

- COMPETENCIAS DIRECTIVAS: Estratégicas - Intratégicas - Personales

Tabla 21: Correlación entre los factores de las CD (Lara, 2005)

\begin{tabular}{|c|c|c|c|c|}
\hline \multicolumn{5}{|l|}{ Correlaciones } \\
\hline & & $\begin{array}{c}\text { FACTOR } 1 \\
\text { PERSONAL } \\
\text { ES }\end{array}$ & $\begin{array}{l}\text { FACTOR } 1 \\
\text { INTRATEG }\end{array}$ & $\begin{array}{l}\text { FACTOR } 1 \\
\text { ESTRATEG }\end{array}$ \\
\hline FACTOR 1 PERSONALES & Correlación de Pearson & 1 & $618^{1}$ & $455^{* *}$ \\
\hline FACTOR 1 INTRATEG & Correlación de Pearson & $618^{* *}$ & 1 & $528^{* *}$ \\
\hline FACTOR 1 ESTRATEG & Correlación de Pearson & $455^{* *}$ &, $528^{* \star}$ & 1 \\
\hline
\end{tabular}

Los constructos que forman la dimensión COMPETENCIAS DIRECTIVAS están los tres relacionados entre sí, siendo la relación más fuerte la de competencias personales e intratégicas con un coeficiente de 0,618.

Es por tanto claro que estos tres subconstructos están midiendo conceptos muy ligados entre si y avalarían la idea de seleccionar sólo uno de ellos como indicador de las COMPETENCIAS DIRECTIVAS según el criterio que sea pertinente.

- RESULTADOS: Tangibles - Intangibles

Tabla 22: Correlación entre los factores de los RO (Lara, 2005)

\begin{tabular}{|c|c|c|c|c|}
\hline \multicolumn{5}{|l|}{$\underline{\text { Correlaciones }}$} \\
\hline & & $\begin{array}{l}\text { FACTOR } 1 \\
\text { INTANGIBLE }\end{array}$ & $\begin{array}{l}\text { FACTOR } 1 \\
\text { TANGIBLE }\end{array}$ & $\begin{array}{l}\text { FACTOR } 2 \\
\text { TANGIBLE }\end{array}$ \\
\hline FACTOR 1 INTANGIBLE & Correlación de Pearson & 1 & 150 & 239 \\
\hline FACTOR 1 TANGIBLE & Correlación de Pearson & 150 & 1 &, 000 \\
\hline FACTOR 2 TANGIBLE & Correlación de Pearson & 239 &, 000 & 1 \\
\hline
\end{tabular}


No existe relación alguna entre los resultados intangibles y tangibles, puesto que los coeficientes de correlación están por debajo de 0,45. Esto indica que ambos conceptos (intangibles y tangibles) explican de forma complementaria diferentes aspectos de los resultados empresariales.

La siguiente tabla recoge las correlaciones entre los 18 factores resultantes:

Correlaciones

\begin{tabular}{|c|c|c|c|c|c|c|c|c|c|c|c|c|c|c|c|c|c|c|}
\hline & $\begin{array}{c}\text { FACTOR } 1 \\
\text { VEE }\end{array}$ & $\begin{array}{c}\text { FACTOR } 2 \\
\text { VEE }\end{array}$ & $\begin{array}{c}\text { FACTOR } 1 \\
\text { TDI }\end{array}$ & $\begin{array}{c}\text { FACTOR } 2 \\
\text { TDI }\end{array}$ & $\begin{array}{l}\text { FACTOR } 1 \\
\text { PPE }\end{array}$ & $\begin{array}{c}\text { FACTOR } 2 \\
\text { PPE }\end{array}$ & $\begin{array}{l}\text { FACTOR } 1 \\
\text { SMG }\end{array}$ & $\begin{array}{l}\text { FACTOR } 2 \\
\text { SMG }\end{array}$ & $\begin{array}{l}\text { FACTOR } 1 \\
\text { SDC }\end{array}$ & $\begin{array}{c}\text { FACTOR } 2 \\
\text { SDC }\end{array}$ & $\begin{array}{l}\text { FACTOR } 1 \\
\text { FDC }\end{array}$ & $\begin{array}{c}\text { FACTOR } 2 \\
\text { FDC }\end{array}$ & $\begin{array}{l}\text { FACTOR } 1 \\
\text { ESTRATEG }\end{array}$ & $\begin{array}{l}1 \text { FACTOR } 1 \\
\text { G INTRATEG }\end{array}$ & $\begin{array}{c}\text { FACTOR } 1 \\
\text { PERSONAL } \\
\text { ES }\end{array}$ & $\begin{array}{l}\text { FACTOR } 1 \\
\text { TANGIBLES }\end{array}$ & $\begin{array}{c}\text { FACTOR } 1 \\
\text { NTANGIBL } \\
\text { ES }\end{array}$ & $\begin{array}{l}\text { FACTOR } 2 \\
\text { NTANGIBL } \\
\text { ES }\end{array}$ \\
\hline FACTOR 1 VEE & 1 & ,000 & ,088 &, $415^{*}$ &, 300 & ,089 & ,000 & , 183 & , 193 &,- 269 & 165 & 163 & ,159 & 059 & ,013 &,- 049 & ,088 & ,017 \\
\hline FACTOR 2 VEE & ,000 & 1 & ,038 & ,250 & ,003 &, $483^{*}$ & ,39٪* &, $429^{*}$ & ,220 & ,263 & ,117 & ,001 & ,370 & ,159 & ,092 & ,370 & ,005 & ,040 \\
\hline FACTOR 1 TDI & ,088 & ,038 & 1 & ,000 & $396^{*}$ & ,267 & $387^{*}$ & ,221 & 113 & 354 &,- 089 & ,318 & , 027 & 155 &,- 098 & 148 &,- 077 & ,033 \\
\hline FACTOR 2 TDI & $.415^{x}$ & 250 &, 000 & 1 &,- 031 & .045 &, 325 & ,102 &, $412^{\star}$ &,- 319 &,- 053 & ,267 & 382 & ,007 &,- 065 &,- 012 &,- 007 &, 119 \\
\hline FACTOR 1 PPE & .300 & .003 & $396^{*}$ &,- 031 & 1 &, 000 & , 189 & 345 & 290 & ,067 & 326 & ,158 & ,293 & 356 & 063 & ,116 &,- 296 & ,087 \\
\hline FACTOR 2 PPE &, 089 & $483^{*}$ & 267 &., 045 & ,000 & 1 & ,225 & , 195 & ,140 &, $402^{*}$ & ,025 & ,042 & , 130 & 206 & 297 & 286 & 317 &,- 177 \\
\hline FACTOR 1 SMG &, 000 & $.39 \%^{*}$ & $.387^{*}$ &, 325 &, 189 & ,225 & 1 &, 000 &, $473^{\star}$ & ,265 & ,005 &, 367 &, $474^{*}$ &, $414^{\star}$ & , 191 &, $417^{\star}$ &,- 036 & 198 \\
\hline FACTOR 2 SMG &, 183 & $.429^{\circ}$ & .221 & .102 & .345 &., 195 & ,000 & 1 & 106 & ,131 & ,286 & ,083 & .034 & 130 & ,099 & ,218 &,- 073 & 309 \\
\hline FACTOR 1 SDC &, 193 &, 220 &, 113 & $412^{x}$ & 290 &, 140 & $473^{*}$ & , 106 & 1 & 000 & 349 & $399^{*}$ & 610 & $669^{*}$ & ,332 & $407^{\star}$ & ,217 & , 136 \\
\hline FACTOR 2 SDC & -269 & .263 & .354 &., 319 & .067 & $.402^{*}$ & .265 & .131 &, 000 & 1 & ,054 & ,153 &, 137 & 289 & 354 &, 349 & , 183 & ,167 \\
\hline FACTOR 1 FDC & .165 & .117 & .089 & .053 & .326 & .025 & .005 &, 286 & .349 &, 054 & 1 & ,000 & 266 & $35+$ & ,021 & 346 & ,036 & 300 \\
\hline FACTOR 2 FDC &, 163 &, 001 &, 318 & .267 &, 158 & .042 & .367 &, 083 &, $399^{*}$ &, 153 & 000 & 1 &, 057 & 263 & 869 & 115 & ,044 & 325 \\
\hline FACTOR 1 ESTRATE &, 159 & .370 &., 027 &, 382 &, 293 & .130 &, $474^{*}$ &, 034 & $.616^{*}$ &, 137 & ,266 & ,057 & 1 & ",528* & $\overrightarrow{.455^{*}}$ & ,388* & ,086 & 100 \\
\hline FACTOR 1 INTRATE & .059 & .159 & .155 &, 007 & .356 & 206 & $.414^{*}$ & .130 & $.669^{*}$ & 289 & $.35 t$ & .263 &, $528^{*}$ & 1 &, $618^{*}$ &, $585^{*}$ & ,168 & , 027 \\
\hline FACTOR 1 PERSON & .013 & .092 &., 098 & .065 & .063 & 297 & .191 &, 099 & .332 & .354 & .021 & .069 & $455^{\star}$ & $.618^{*}$ & 1 & 399* & $454^{\star}$ &,- 007 \\
\hline FACTOR 1 TANGIBL & -.049 & .370 & .148 & .012 & .116 & .286 & $417^{x}$ & .218 & $.407^{*}$ & .349 & .346 & .115 & $388^{\prime \prime}$ & $.585^{*}$ & $.399^{*}$ & 1 & 150 & 239 \\
\hline FACTOR 1 INTANGII & .088 & .005 & .077 & .007 & -.296 & .317 &., 036 &., 073 & .217 & .183 & .036 & .044 & .086 & .168 & $.454^{x}$ & , 150 & & ,000 \\
\hline FACTOR 2 INTANGII &, 017 &, 040 &, 033 &, 119 & .087 &,- 177 & .198 &, 309 &, 136 & .167 &, 300 &, 325 &, 100 & .027 &., 007 & 239 & 000 & 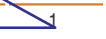 \\
\hline
\end{tabular}

Tabla 23: Correlación entre todos los factores del modelo (Lara, 2005)

Marcados en naranja están los coeficientes mayores que 0,45 pertenecientes al análisis de las 3 dimensiones realizado anteriormente, y en rojo el resto de coeficientes mayores que 0,45 .

El triángulo verde señala las relaciones existentes entre la GESTIÓN DEL CONOCIMIENTO y LAS COMPETENCIAS DIRECTIVAS: como indican los coeficientes más altos, las uniones más fuertes se dan entre stocks de conocimiento y las competencias tanto estratégicas como intratégicas.

El triángulo azul remarca las relaciones entre LAS COMPETENCIAS DIRECTIVAS y LOS RESULTADOS ORGANIZATIVOS: nuevamente, el coeficiente más elevado indica la relación más fuerte, que se da entre las competencias intratégicas y los resultados intangibles. 


\section{3.- CONTRASTES DE HIPÓTESIS}

En este apartado vamos a resolver una serie de contrastes de hipótesis a través de regresiones lineales y correlaciones. Las hipótesis a resolver hacen referencia a la existencia de relación tanto entre constructos como entre dimensiones. Las analizaremos una a una:

- H 11: Las características externas están relacionadas con los resultados organizativos

Para resolver este contraste realizaremos 3 regresiones lineales donde las 3 variables dependientes serán los 3 factores obtenidos de los resultados organizativos (1 para intangibles y 2 para tangibles). Las variables independientes, serán en este caso, los 8 factores resultantes de las características externas.

Resumimos los resultados en la siguiente tabla:

\begin{tabular}{|c|c|c|c|c|c|c|}
\hline & \multicolumn{2}{|c|}{ Factor 1 Intangibles } & \multicolumn{2}{|c|}{ Factor 1 Tangibles } & \multicolumn{2}{|c|}{ Factor 2 Tangibles } \\
\hline & $\beta$ & Sig. & $\beta$ & Sig. & $\beta$ & Sig. \\
\hline Constante & $\begin{array}{c}-1,421 \mathrm{E}- \\
17 \\
\end{array}$ & 1,000 & $\begin{array}{c}-1,082 \mathrm{E}- \\
17\end{array}$ & 1,000 & $3,378 \mathrm{E}-16$ & 1,000 \\
\hline FACTOR 1 VEE & 0,002 & 0,990 & 0,198 & 0,280 & $-0,013$ & 0,941 \\
\hline FACTOR 2 VEE & 0,096 & 0,654 & $-0,233$ & 0,291 & $-0,230$ & 0,296 \\
\hline FACTOR 1 TDI & $-0,115$ & 0,529 & $-0,109$ & 0,561 & $-0,123$ & 0,510 \\
\hline FACTOR 2 TDI & $-0,214$ & 0,241 & $-0,102$ & 0,585 & 0,003 & 0,987 \\
\hline FACTOR 1 PPE & $-0,001$ & 0,993 & $-0,359$ & 0,059 & $-0,116$ & 0,529 \\
\hline FACTOR 2 PPE & 0,137 & 0,437 & 0,409 & 0,030 & $-0,225$ & 0,219 \\
\hline FACTOR 1 SMG & 0,463 & 0,023 & 0,106 & 0,599 & 0,407 & 0,049 \\
\hline FACTOR 2 SMG & 0,197 & 0,295 & 0,070 & 0,718 & 0,521 & 0,010 \\
\hline $\mathrm{R}^{2}$ & \multicolumn{2}{|c|}{0,296} & \multicolumn{2}{|c|}{0,252} & \multicolumn{2}{|c|}{0,258} \\
\hline $\mathrm{R}^{2}$ corregida & \multicolumn{2}{|c|}{0,135} & \multicolumn{2}{|c|}{0,081} & \multicolumn{2}{|c|}{0,089} \\
\hline Durbin - Watson & \multicolumn{2}{|c|}{2,372} & \multicolumn{2}{|c|}{1,494} & \multicolumn{2}{|c|}{2,082} \\
\hline F de Snedecor & \multicolumn{2}{|c|}{1,841} & \multicolumn{2}{|c|}{1,476} & \multicolumn{2}{|c|}{1,524} \\
\hline Significatividad $\mathrm{F}$ & \multicolumn{2}{|c|}{0,102} & \multicolumn{2}{|c|}{0,201} & \multicolumn{2}{|c|}{0,185} \\
\hline
\end{tabular}


- La $\mathrm{R}^{2}$ varía entre 0 y 1 e indica la proporción de varianza explicada por el modelo: valores próximos a 1 señalan modelos óptimos y valores próximos a 0 señalan modelos no adecuados. La $\mathrm{R}^{2}$ corregida valora lo mismo que la $\mathrm{R}^{2}$ pero permite comparar entre modelos ya que 'unifica' las unidades de medida.

- El estadístico de Darwin-Watson también es un indicador de la adecuación del modelo: los valores óptimos oscilan entre 1,5 y 2,5.

- Y por último la $\mathrm{F}$ de Snedecor indica también si el modelo se ajusta o no: si el $p$-valor es menor que 0,05 entonces el modelo será significativo y por tanto adecuado.

Como se observa en la tabla, ninguno de los 3 modelos es adecuado ya que ninguna $F$ de Snedecor es significativa. Además los $R^{2}$ corregidos de los 3 modelos son muy bajos, por tanto los modelos no explican mucho.

A la vista de los coeficientes $\beta$, el único concepto que influye significativamente cuando la variable dependiente es el factor de los resultados intangibles son los sistemas de medida de gestión, siendo ésta una influencia positiva.

Para los resultados tangibles, los procesos de planificación estratégica influyen positivamente para el factor 1 de tangibles (ventas y beneficios) y nuevamente los sistemas de medida de la gestión influyen positivamente en el segundo factor de tangibles (productividad).

- H 12: Las capacidades internas están relacionadas con los resultados organizativos

Para resolver este contraste realizaremos 3 regresiones lineales donde las 3 variables dependientes serán los 3 factores obtenidos de los resultados organizativos (1 para intangibles y 2 para tangibles). Las variables 
independientes, serán en este caso, los 4 factores resultantes de las capacidades internas.

Resumimos los resultados en la siguiente tabla:

Tabla 25: Resumen de regresiones para las capacidades internas (Lara, 2005)

\begin{tabular}{|c|c|c|c|c|c|c|}
\hline & \multicolumn{2}{|c|}{ Factor 1 Intangibles } & \multicolumn{2}{|c|}{ Factor 1 Tangibles } & \multicolumn{2}{|c|}{ Factor 2 Tangibles } \\
\hline & $\beta$ & Sig. & $\beta$ & Sig. & $\beta$ & Sig. \\
\hline Constante & $\begin{array}{c}-4,185 \mathrm{E}- \\
17\end{array}$ & 1,000 & $2,162 \mathrm{E}-16$ & 1,000 & $1,215 \mathrm{E}-16$ & 1,000 \\
\hline FACTOR 1 SDC & 0,373 & 0,021 & 0,283 & 0,126 & $-0,126$ & 0,458 \\
\hline FACTOR 2 SDC & 0,352 & 0,012 & 0,202 & 0,200 & 0,093 & 0,523 \\
\hline FACTOR 1 FDC & 0,196 & 0,174 & $-0,073$ & 0,660 & 0,339 & 0,033 \\
\hline FACTOR 2 FDC & $-0,088$ & 0,553 & $-0,100$ & 0,563 & 0,361 & 0,029 \\
\hline $\mathrm{R}^{2}$ & \multicolumn{2}{|c|}{0,332} & \multicolumn{2}{|c|}{0,092} & \multicolumn{2}{|c|}{0,217} \\
\hline $\mathrm{R}^{2}$ corregida & \multicolumn{2}{|c|}{0,264} & \multicolumn{2}{|c|}{$-0,002$} & \multicolumn{2}{|c|}{0,137} \\
\hline Durbin - Watson & \multicolumn{2}{|c|}{2,110} & \multicolumn{2}{|c|}{1,574} & \multicolumn{2}{|c|}{2,413} \\
\hline F de Snedecor & \multicolumn{2}{|c|}{4,856} & \multicolumn{2}{|c|}{0,983} & \multicolumn{2}{|c|}{2,708} \\
\hline Significatividad $\mathrm{F}$ & \multicolumn{2}{|c|}{0,003} & \multicolumn{2}{|c|}{0,428} & \multicolumn{2}{|c|}{0,044} \\
\hline
\end{tabular}

Como se observa en la tabla, el único modelo no adecuado es el de variable dependiente el primer factor de intangibles cuya $\mathrm{F}$ de Snedecor es no significativa. Los $\mathrm{R}^{2}$ corregidos de los 3 modelos siguen siendo muy bajos, por tanto los modelos no explican mucho.

Según los coeficientes $\beta$, se ve claramente que los stocks del conocimiento influyen positivamente sobre los resultados intangibles y los flujos del conocimiento sobre los resultados tangibles (productividad).

- H 1: La gestión del conocimiento está relacionada con los resultados organizativos

Para resolver este contraste realizaremos 3 regresiones lineales donde las 3 variables dependientes serán los 3 factores obtenidos de los resultados organizativos (1 para intangibles y 2 para tangibles). Las variables 
independientes, serán en este caso, los 12 factores resultantes: 8 de características externas y 4 de capacidades internas.

Resumimos los resultados en la siguiente tabla:

\begin{tabular}{|c|c|c|c|c|c|c|}
\hline & \multicolumn{2}{|c|}{ Factor 1 Intangibles } & \multicolumn{2}{|c|}{ Factor 1 Tangibles } & \multicolumn{2}{|c|}{ Factor 2 Tangibles } \\
\hline & $\beta$ & Sig. & $\beta$ & Sig. & $\beta$ & Sig. \\
\hline Constante & $\begin{array}{c}-3,354 \mathrm{E}- \\
17\end{array}$ & 1,000 & $1,900 \mathrm{E}-17$ & 1,000 & $2,828 \mathrm{E}-16$ & 1,000 \\
\hline FACTOR 1 VEE & 0,014 & 0,934 & 0,256 & 0,157 & $-0,031$ & 0,858 \\
\hline FACTOR 2 VEE & 0,081 & 0,699 & $-0,238$ & 0,269 & $-0,212$ & 0,319 \\
\hline FACTOR 1 TDI & $-0,006$ & 0,973 & $-0,073$ & 0,705 & $-0,154$ & 0,421 \\
\hline FACTOR 2 TDI & $-0,203$ & 0,312 & $-0,159$ & 0,437 & 0,152 & 0,452 \\
\hline FACTOR 1 PPE & $-0,156$ & 0,398 & $-0,480$ & 0,015 & $-0,141$ & 0,447 \\
\hline FACTOR 2 PPE & 0,051 & 0,773 & 0,290 & 0,117 & $-0,278$ & 0,127 \\
\hline FACTOR 1 SMG & 0,317 & 0,128 & $-0,100$ & 0,634 & 0,298 & 0,156 \\
\hline FACTOR 2 SMG & 0,138 & 0,455 & 0,059 & 0,755 & 0,403 & 0,036 \\
\hline FACTOR 1 SDC & 0,300 & 0,129 & 0,471 & 0,023 & $-0,170$ & 0,388 \\
\hline FACTOR 2 SDC & 0,157 & 0,399 & 0,236 & 0,221 & 0,250 & 0,189 \\
\hline FACTOR 1 FDC & 0,218 & 0,201 & $-0,037$ & 0,830 & 0,307 & 0,079 \\
\hline FACTOR 2 FDC & $-0,080$ & 0,630 & $-0,060$ & 0,725 & 0,260 & 0,130 \\
\hline $\mathrm{R}^{2}$ & \multicolumn{2}{|c|}{0,433} & \multicolumn{2}{|c|}{0,403} & \multicolumn{2}{|c|}{0,419} \\
\hline $\mathrm{R}^{2}$ corregida & \multicolumn{2}{|c|}{0,213} & \multicolumn{2}{|c|}{0,172} & \multicolumn{2}{|c|}{0,195} \\
\hline Durbin - Watson & \multicolumn{2}{|c|}{2,135} & \multicolumn{2}{|c|}{1,588} & \multicolumn{2}{|c|}{2,313} \\
\hline F de Snedecor & \multicolumn{2}{|c|}{1,970} & \multicolumn{2}{|c|}{1,744} & \multicolumn{2}{|c|}{1,866} \\
\hline Significatividad $\mathrm{F}$ & \multicolumn{2}{|c|}{0,064} & \multicolumn{2}{|c|}{0,105} & \multicolumn{2}{|c|}{0,080} \\
\hline
\end{tabular}

Como se observa en la tabla, los modelo 1 y 3 son moderadamente adecuados ya que el estadístico $\mathrm{F}$ de Snedecor es significativo para un nivel de confianza del $90 \%$. Los $\mathrm{R}^{2}$ corregidos de los 3 modelos siguen siendo muy bajos, por tanto los modelos no explican mucho.

Según los coeficientes $\beta$, los resultados intangibles no están influidos por la gestión del conocimiento en global. Sin embargo, los resultados tangibles están influenciados positivamente por los sistemas de medición de la gestión y los 
stocks del conocimiento (en concreto las capacidades de la organización y los grupos), y de forma negativa por los procesos de planificación estratégica.

- H 21: Las competencias estratégicas están relacionadas con los resultados organizativos

Para resolver este contraste realizaremos 3 regresiones lineales donde las 3 variables dependientes serán los 3 factores obtenidos de los resultados organizativos (1 para intangibles y 2 para tangibles). La variable independiente, será en este caso, el único factor resultante de las competencias estratégicas.

Resumimos los resultados en la siguiente tabla:

Tabla 27: Resumen de regresiones para las competencias estratégicas (Lara, 2005)

\begin{tabular}{|l|c|c|c|c|c|c|}
\hline & \multicolumn{2}{|c|}{ Factor 1 Intangibles } & \multicolumn{2}{c|}{ Factor 1 Tangibles } & \multicolumn{2}{c|}{ Factor 2 Tangibles } \\
\cline { 2 - 7 } & $\beta$ & Sig. & $\beta$ & Sig. & $\beta$ & Sig. \\
\hline Constante & $\begin{array}{c}-9,377 \mathrm{E}- \\
17\end{array}$ & 1,000 & $1,558 \mathrm{E}-16$ & 1,000 & $2,238 \mathrm{E}-16$ & 1,000 \\
\hline FACTOR 1 ESTRATEG & $\mathbf{0 , 3 8 8}$ & $\mathbf{0 , 0 0 9}$ & 0,086 & 0,581 & 0,100 & 0,520 \\
\hline $\mathrm{R}^{2}$ & \multicolumn{2}{|c|}{0,150} & \multicolumn{2}{c|}{0,007} & 0,010 \\
\hline $\mathrm{R}^{2}$ corregida & \multicolumn{2}{|c|}{0,130} & \multicolumn{2}{c|}{$-0,016$} & $-0,014$ \\
\hline Durbin - Watson & \multicolumn{2}{|c|}{2,352} & \multicolumn{2}{c|}{0,353} & 1,942 \\
\hline F de Snedecor & \multicolumn{2}{|c|}{7,426} & 0,581 & 0,421 \\
\hline Significatividad F & \multicolumn{2}{|c|}{$\mathbf{0 , 0 0 9}$} & 0,520 \\
\hline
\end{tabular}

Como se observa en la tabla, el único modelo adecuado es el de variable dependiente el factor de intangibles cuya $\mathrm{F}$ de Snedecor es significativa. Los $\mathrm{R}^{2}$ corregidos de los 3 modelos siguen siendo muy bajos, aunque si los comparamos se observa que el 0,130 del modelo intangible es muy superior a los otros dos.

Según los coeficientes $\beta$, se ve claramente que las competencias estratégicas influyen positivamente sobre los resultados intangibles. 
- H 22: Las competencias intratégicas están relacionadas con los resultados organizativos

Para resolver este contraste realizaremos 3 regresiones lineales donde las 3 variables dependientes serán los 3 factores obtenidos de los resultados organizativos (1 para intangibles y 2 para tangibles). La variable independiente, será en este caso, el único factor resultante de las competencias intratégicas.

Resumimos los resultados en la siguiente tabla:

Tabla 28: Resumen de regresiones para las competencias intratégicas (Lara, 2005)

\begin{tabular}{|l|c|c|c|c|c|c|}
\hline & \multicolumn{2}{|c|}{ Factor 1 Intangibles } & \multicolumn{2}{c|}{ Factor 1 Tangibles } & \multicolumn{2}{c|}{ Factor 2 Tangibles } \\
\cline { 2 - 7 } & $\beta$ & Sig. & $\beta$ & Sig. & $\beta$ & Sig. \\
\hline Constante & $\begin{array}{c}-8,751 \mathrm{E}- \\
17\end{array}$ & 1,000 & $1,574 \mathrm{E}-16$ & 1,000 & $2,247 \mathrm{E}-16$ & 1,000 \\
\hline FACTOR 1 INTRATEG & $\mathbf{0 , 5 8 5}$ & $\mathbf{0 , 0 0 0}$ & 0,168 & 0,275 & 0,027 & 0,860 \\
\hline $\mathrm{R}^{2}$ & \multicolumn{2}{|c|}{0,342} & \multicolumn{2}{c|}{0,028} & 0,001 \\
\hline $\mathrm{R}^{2}$ corregida & \multicolumn{2}{|c|}{0,327} & \multicolumn{2}{c|}{0,005} & $-0,023$ \\
\hline Durbin - Watson & \multicolumn{2}{|c|}{2,225} & \multicolumn{2}{c|}{1,503} & 1,963 \\
\hline F de Snedecor & \multicolumn{2}{|c|}{21,872} & 0,031 \\
\hline Significatividad F & \multicolumn{2}{|c|}{$\mathbf{0 , 0 0 0}$} & 0,275 & 0,860 \\
\hline
\end{tabular}

Como se observa en la tabla, el único modelo adecuado es el de variable dependiente el factor de intangibles cuya $\mathrm{F}$ de Snedecor es significativa. Los $\mathrm{R}^{2}$ corregidos de los 3 modelos siguen siendo muy bajos, aunque si los comparamos se observa que el 0,342 del modelo intangible es muy superior a los otros dos.

Según los coeficientes $\beta$, se ve claramente que las competencias intratégicas influyen positivamente sobre los resultados intangibles.

- H 23: Las competencias personales están relacionadas con los resultados organizativos 
Para resolver este contraste realizaremos 3 regresiones lineales donde las 3 variables dependientes serán los 3 factores obtenidos de los resultados organizativos (1 para intangibles y 2 para tangibles). La variable independiente, será en este caso, el único factor resultante de las competencias personales.

Resumimos los resultados en la siguiente tabla:

Tabla 29: Resumen de regresiones para las competencias personales (Lara, 2005)

\begin{tabular}{|c|c|c|c|c|c|c|}
\hline & \multicolumn{2}{|c|}{ Factor 1 Intangibles } & \multicolumn{2}{|c|}{ Factor 1 Tangibles } & \multicolumn{2}{|c|}{ Factor 2 Tangibles } \\
\hline & $\beta$ & Sig. & $\beta$ & Sig. & $\beta$ & Sig. \\
\hline Constante & $\begin{array}{c}-1,135 \mathrm{E}- \\
17\end{array}$ & 1,000 & $2,470 \mathrm{E}-16$ & 1,000 & $2,232 \mathrm{E}-16$ & 1,000 \\
\hline FACTOR 1 PERSONALES & 0,399 & 0,007 & 0,454 & 0,002 & $-0,007$ & 0,966 \\
\hline $\mathrm{R}^{2}$ & \multicolumn{2}{|c|}{0,159} & \multicolumn{2}{|c|}{0,206} & \multicolumn{2}{|c|}{0,000} \\
\hline $\mathrm{R}^{2}$ corregida & \multicolumn{2}{|c|}{0,139} & \multicolumn{2}{|c|}{0,187} & \multicolumn{2}{|c|}{$-0,024$} \\
\hline Durbin - Watson & \multicolumn{2}{|c|}{2,463} & \multicolumn{2}{|c|}{1,364} & \multicolumn{2}{|c|}{1,965} \\
\hline F de Snedecor & \multicolumn{2}{|c|}{7,941} & \multicolumn{2}{|c|}{10,922} & \multicolumn{2}{|c|}{0,002} \\
\hline Significatividad $\mathrm{F}$ & \multicolumn{2}{|c|}{0,007} & \multicolumn{2}{|c|}{0,002} & \multicolumn{2}{|c|}{0,996} \\
\hline
\end{tabular}

Como se observa en la tabla, el único modelo que no es adecuado es el de variable dependiente el segundo factor de tangibles cuya F de Snedecor es no significativa. Los $\mathrm{R}^{2}$ corregidos de los 3 modelos siguen siendo muy bajos, aunque si los comparamos se observa que el 0,139 y el 0,187 de los modelos adecuados son muy superiores al otros.

Según los coeficientes $\beta$, se ve claramente que las competencias personales influyen positivamente sobre los resultados intangibles y sobre el primer factor de los resultados tangibles (ventas y beneficios).

- H 2: Las competencias directivas están relacionadas con los resultados organizativos

Para resolver este contraste realizaremos 3 regresiones lineales donde las 3 variables dependientes serán los 3 factores obtenidos de los resultados 
organizativos (1 para intangibles y 2 para tangibles). Las variables independientes, serán en este caso, los tres factores correspondientes a los tres constructos.

Resumimos los resultados en la siguiente tabla:

\begin{tabular}{|c|c|c|c|c|c|c|}
\hline & \multicolumn{2}{|c|}{ Factor 1 Intangibles } & \multicolumn{2}{|c|}{ Factor 1 Tangibles } & \multicolumn{2}{|c|}{ Factor 2 Tangibles } \\
\hline & $\beta$ & Sig. & $\beta$ & Sig. & $\beta$ & Sig. \\
\hline Constante & $\begin{array}{c}-8,095 \mathrm{E}- \\
17\end{array}$ & 1,000 & $2,740 \mathrm{E}-16$ & 1,000 & $2,106 \mathrm{E}-16$ & 1,000 \\
\hline FACTOR 1 ESTRATEG & 0,102 & 0,508 & $-0,110$ & 0,512 & 0,130 & 0,495 \\
\hline FACTOR 1 INTRATEG & 0,507 & 0,006 & $-0,138$ & 0,467 & $-0,001$ & 0,997 \\
\hline FACTOR 1 PERSONALES & 0,039 & 0,814 & 0,590 & 0,002 & $-0,065$ & 0,750 \\
\hline $\mathrm{R}^{2}$ & \multicolumn{2}{|c|}{0,352} & \multicolumn{2}{|c|}{0,235} & \multicolumn{2}{|c|}{0,013} \\
\hline $\mathrm{R}^{2}$ corregida & \multicolumn{2}{|c|}{0,303} & \multicolumn{2}{|c|}{0,178} & \multicolumn{2}{|c|}{$-0,061$} \\
\hline Durbin - Watson & \multicolumn{2}{|c|}{2,345} & \multicolumn{2}{|c|}{1,243} & \multicolumn{2}{|c|}{1,952} \\
\hline F de Snedecor & \multicolumn{2}{|c|}{7,240} & \multicolumn{2}{|c|}{4,101} & \multicolumn{2}{|c|}{0,180} \\
\hline Significatividad $\mathrm{F}$ & \multicolumn{2}{|c|}{0,001} & \multicolumn{2}{|c|}{0,013} & \\
\hline
\end{tabular}

Como se observa en la tabla, el único modelo que no es adecuado es el de variable dependiente el segundo factor de tangibles cuya F de Snedecor es no significativa. Los $\mathrm{R}^{2}$ corregidos de los 3 modelos siguen siendo muy bajos, aunque si los comparamos se observa que el 0,303 y el 0,178 de los modelos adecuados son muy superiores al otros.

Según los coeficientes $\beta$, se ve claramente que las competencias personales influyen positivamente sobre el primer factor de los resultados tangibles (ventas y beneficios) y las competencias intratégicas influyen positivamente sobre los resultados intangibles.

En resumen, excepto el segundo factor de los resultados tangibles, tanto intangibles cómo tangibles se hayan influenciados positivamente por las competencias directivas. 
- H 3: La gestión del conocimiento está relacionado con las competencias directivas

Para comprobar esta hipótesis calcularemos la matriz de correlaciones entre los 15 factores que forman ambas dimensiones.

Tabla 31: Matriz de correlaciones (Lara, 2005)

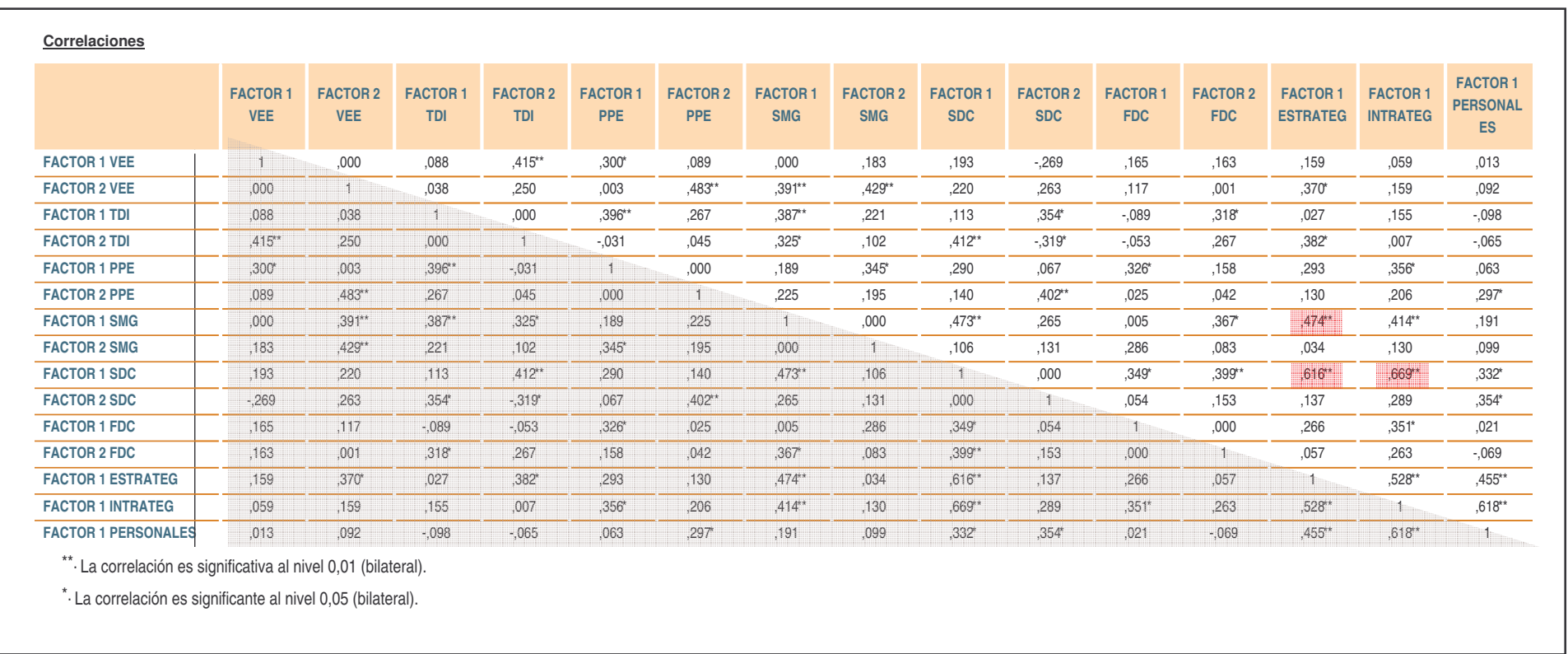

Los recuadros en rojo señalan las relaciones existentes entre la GESTIÓN DEL CONOCIMIENTO y LAS COMPETENCIAS DIRECTIVAS: como indican los coeficientes más altos, las uniones más fuertes se dan entre stocks de conocimiento (en concreto las capacidades de la organización y los grupos) y las competencias tanto estratégicas como intratégicas.

En general no existe una fuerte correlación entre GESTIÓN DEL CONOCIMIENTO y LAS COMPETENCIAS DIRECTIVAS $y$, aunque con matices, se puede considerar que la hipótesis 3 no se da.

- H 4: Los Resultados organizativos se pueden explicar en función de la intermediación de la Gestión del conocimiento y las Competencias directivas 
Para resolver este contraste realizaremos 3 regresiones lineales donde las 3 variables dependientes serán los 3 factores obtenidos de los resultados organizativos (1 para intangibles y 2 para tangibles). Las variables independientes, serán en este caso, todos los factores obtenidos en cada uno de los constructos: un total de 18.

Para realizar esta regresión y debido al alto número de variables hemos utilizado el método 'hacia atrás' que consiste en que en un primer paso están todas las variables, para ir eliminando del modelo en sucesivos pasos aquellas cuyo nivel de significación de su valor de $\mathrm{F}$ es mayor que el valor de salida $(0,10)$.

Resumimos los modelos resultantes después de la serie de pasos en la siguiente tabla:

\begin{tabular}{|c|c|c|c|c|c|c|}
\hline & \multicolumn{2}{|c|}{ Factor 1 Intangibles } & \multicolumn{2}{|c|}{ Factor 1 Tangibles } & \multicolumn{2}{|c|}{ Factor 2 Tangibles } \\
\hline & $\beta$ & Sig. & $B$ & Sig. & $\beta$ & Sig. \\
\hline Constante & $-3,69 \mathrm{E}-17$ & 1,000 & $2,379 \mathrm{E}-16$ & 1,000 & $2,226 \mathrm{E}-16$ & 1,000 \\
\hline FACTOR 2 VEE & 0,284 & 0,023 & & & & \\
\hline FACTOR 1 INTRATEG & 0,540 & 0,000 & & & & \\
\hline FACTOR 1 PPE & & & $-0,326$ & 0,016 & & \\
\hline FACTOR 1 PERSONALES & & & 0,475 & 0,001 & & \\
\hline FACTOR 2 PPE & & & & & $-0,255$ & 0,076 \\
\hline FACTOR 2 SMG & & & & & 0,333 & 0,022 \\
\hline FACTOR 2 FDC & & & & & 0,308 & 0,031 \\
\hline $\mathrm{R}^{2}$ & \multicolumn{2}{|c|}{0,421} & \multicolumn{2}{|c|}{0,312} & \multicolumn{2}{|c|}{0,248} \\
\hline $\mathrm{R}^{2}$ corregida & \multicolumn{2}{|c|}{0,393} & \multicolumn{2}{|c|}{0,279} & \multicolumn{2}{|c|}{0,192} \\
\hline Durbin - Watson & \multicolumn{2}{|c|}{2,342} & \multicolumn{2}{|c|}{1,165} & \multicolumn{2}{|c|}{2,295} \\
\hline F de Snedecor & \multicolumn{2}{|c|}{14,908} & \multicolumn{2}{|c|}{9,302} & \multicolumn{2}{|c|}{4,401} \\
\hline Significatividad $\mathrm{F}$ & \multicolumn{2}{|c|}{0,000} & \multicolumn{2}{|c|}{0,000} & \multicolumn{2}{|c|}{0,009} \\
\hline
\end{tabular}


Como se observa, se ha pasado de un modelo que constaría de 18 variables independientes a otro modelo donde el número máximo de variables independientes es 3.

Para el modelo de resultados intangibles, se observa que éstos están influenciados positivamente por la vigilancia del entrono externo y las competencias intratégicas. Es decir, se precisa tanto un factor de la GESTIÓN DEL CONOCIMIENTO como otro de LAS COMPETENCIAS DIRECTIVAS.

Para el modelo de resultados tangibles 1 , es decir, ventas y beneficios, se observa que éste está influenciado negativamente por los procesos de planificación estratégica (perteneciente a la GESTIÓN DEL CONOCIMIENTO) y positivamente por las competencias personales (del constructo COMPETENCIAS DIRECTIVAS).

Para el modelo de resultados tangibles 2, es decir, la productividad, se observa que ésta está influenciada positivamente por los sistemas de medición de la gestión y los flujos del conocimiento (en concreto por la formación), todas ellas variables del constructo GESTIÓN DEL CONOCIMIENTO.

Resumiendo, podemos explicar cada una de las 3 variables dependientes como combinación de los factores significativos:

- FACTOR 1 INTANGIBLES $=0,284 *$ FACTOR 2 VEE $+0,540 *$ FACTOR 1 INTRATEG

- FACTOR 1 TANGIBLES $=-0,326 *$ FACTOR 1 PPE $+0,475 *$ FACTOR 1 PERSONALES

- FACTOR 2 TANGIBLES $=0,333 *$ FACTOR 2 SMG $+0,308 *$ FACTOR 2 FDC

Si lo expresamos en función de los constructos, tenemos:

- FACTOR 1 INTANGIBLES $=a_{1} *$ CARAC. EXTERNAS $+a_{2} *$ COMP. INTRATÉGICAS

- FACTOR 1 TANGIBLES $=-\beta_{1} *$ CARAC. EXTERNAS $+\beta_{2} *$ COMP. PERSONALES

- $\quad$ FACTOR 2 TANGIBLES $=y_{1} *$ CARAC. EXTERNAS $+\gamma_{2} *$ CAPAC. INTERNAS 
Y si lo expresamos en función de las dimensiones y con el nombre de los factores, tenemos:

- RES. INTANGIBLES $=\mathrm{a}_{1} *$ GESTIÓN CONOCIMIENTO $+\mathrm{a}_{2} *$ COMP. DIRECTIVAS

- VENTAS Y BENEFICIOS $=-\beta_{1} *$ GESTIÓN CONOCIMIENTO $+\beta_{2} *$ COMP. DIRECTIVAS

- $\quad$ PRODUCTIVIDAD $=y *$ GESTIÓN CONOCIMIENTO 


\section{CAPÍTULO 7:}

\section{CONCLUSIONES}

7.1. VALORACIÓN PERSONAL

7.2. FUTURAS LÍNEAS DE INVESTIGACIÓN 


\subsection{VALORACIÓN PERSONAL}

Una vez realizado el análisis estadístico de los resultados, podemos pasar a realizar una valoración personal de los mismos, a la luz de los resultados.

En primer lugar, respecto a la fiabilidad de las escalas, hemos comprobado que los valores de la $\alpha$ de Cronbach no varían demasiado según los constructos considerados y son muy elevados. Para la Gestión del conocimiento y Competencias directivas se sitúan por encima de 0,8 , lo que demuestra una alta fiabilidad de los mismos como instrumentos de medida. Igualmente se sitúan por encima de 0,7, indicando una adecuada fiabilidad para Resultados organizativos, siendo aceptables con los criterios de Churchill (1979).

En segundo lugar, respecto al análisis factorial realizado, en general tanto los resultados obtenido de la prueba de Barlett, que alcanzan un valor aceptable ya que el nivel de significación es nulo en todos los casos, como con los resultados de la de KMO, superior al umbral generalmente aceptado de 0,5, justifican la adecuación del análisis factorial. A partir del análisis factorial realizado, se han obtenido un total de 18 factores. En el peor de los casos los factores explican el $51,10 \%$ de la varianza y en el mejor el $78,07 \%$. En general el porcentaje de varianza explicada es muy bueno.

De esta forma la dimensión CARACTERÍSTICAS EXTERNAS de la organización, pasa de tener 20 factores, a tener solamente 8. 
En este sentido, la dimensión CAPACIDADES INTERNAS de la organización, pasa de tener 15 factores, a tener solamente 4 . En consecuencia, la dimensión superior GESTIÓN DE CONOCIMIENTO, queda sintetizada en 12 factores o componentes principales

La segunda dimensión COMPETENCIAS DIRECTIVAS, pasa de tener 16 factores a sólo 3: "Gestión de los recursos de forma eficiente" $(0,836)$, "Trabajo en equipo y comunicación" $(0,863)$ y "Autogobierno y mejora personal" $(0,827)$.

Esta síntesis, si bien supone una confirmación de la estrecha correlación entre las tres dimensiones de segundo orden (Estratégicas, Intratégicas y Personales), presenta por contraste una gran perdida de información relevante de la diferenciación de las mismas.

La tercera dimensión, RESULTADOS ORGANIZATIVOS, se ha visto sintetizada en 3 factores, uno para los RESULTADOS INTANGIBLES "Satisfacción de los clientes" $(0,799)$ y dos para los RESULTADOS TANGIBLES "Ventas y Beneficios" (0,852) y "Productividad" (0.939).

Como se puede comprobar todas las variables poseen marcadores superiores a 0,5 en un factor. Se puede también observar la consistencia interna de la escala por la escasa variación del coeficiente $\alpha$ al eliminar cada uno de los ítems respecto al $\alpha$ de la escala completa. 
En tercer lugar, respecto a la correlación entre factores, la relación lineal entre los factores de los constructos que forman la dimensión Gestión del conocimiento es muy débil. Dentro de las CARACTERÍSTICAS EXTERNAS los aspectos procesos de planificación estratégica y la vigilancia del entorno externo están ligeramente relacionados, mientras que el constructo CAPACIDADES INTERNAS sólo existe la débil relación entre sistemas de medición de la gestión y stocks de conocimiento.

Por tanto, realmente la GESTIÓN DEL CONOCIMIENTO es un constructo que se debe recoger a través de las diferentes dimensiones consideradas, dado que cada una de ellas está midiendo dicho constructo desde perspectivas diferentes.

Los constructos que forman la dimensión COMPETENCIAS DIRECTIVAS están los tres relacionados entre sí, siendo la relación más fuerte la de competencias personales e intratégicas con un coeficiente de 0,618 . Es por tanto claro que estos tres subconstructos están midiendo conceptos muy ligados entre si y avalarían la idea de seleccionar sólo uno de ellos como indicador de las COMPETENCIAS DIRECTIVAS según el criterio que sea pertinente.

En tercer lugar, no existe relación alguna entre los resultados intangibles y tangibles, puesto que los coeficientes de correlación están por debajo de 
0,45. Esto indica que ambos conceptos (intangibles y tangibles) explican de forma complementaria diferentes aspectos de los RESULTADOS empresariales.

En resumen, por un lado, tenemos que en las relaciones existentes entre la GESTIÓN DEL CONOCIMIENTO y LAS COMPETENCIAS DIRECTIVAS, como indican los coeficientes más altos, las uniones más fuertes se dan entre stocks de conocimiento y las competencias tanto estratégicas como intratégicas. En este sentido, podría ser interesante en futuras investigaciones unificar esos indicadores en uno solo, para obtener una información más significativa. Por otro lado, en las relaciones entre LAS COMPETENCIAS DIRECTIVAS y LOS RESULTADOS ORGANIZATIVOS nuevamente, el coeficiente más elevado indica la relación más fuerte, que se da entre las competencias intratégicas y los resultados intangibles.

Finalmente, respecto al contraste de hipótesis, como se desprende de los resultados del contraste de la primera hipótesis $\mathrm{H} 11$, la relación positiva entre las Características Externas de las organizaciones y los Resultados organizativos no se da con carácter general, si con carácter particular.

En concreto, dicha influencia positiva se circunscribe estrictamente a tres relaciones: en primer lugar, a los Sistemas de Medición de la Gestión (en concreto, el primer factor relativo a los sistemas de evaluación de la calidad e información contable) respecto a los Resultados Intangibles (Satisfacción de los Clientes). Parece lógico pensar que al elevar la eficiencia en los sistemas de 
evaluación y control de la calidad, se consigan mayores índices de satisfacción de los clientes, tanto por los productos físicos como por los servicios; en segundo lugar, a los Procesos de Planificación Estratégica (en concreto, el desarrollo de procesos de reflexión estratégicos dirigidos a elaborar unos objetivos concretos) respecto al primer factor de los Resultados Tangibles (es decir, las Ventas y Beneficios). La concreción de unos objetivos que vayan encaminados al logro de la estrategia de una organización, parece lógico que estén relacionados con la existencia de objetivos concretos en ventas y beneficios; y en tercer lugar, a los Sistemas de Medición de la Gestión (los dos factores) respecto al segundo factor de los Resultados Tangibles (es decir, a la Productividad). Tanto los sistemas de evaluación de la calidad y de la contabilidad, como aquellos que no sean estrictamente financieros influyen en la productividad de una organización, en la medida en que se busca la eficiencia.

Respecto al contraste de la segunda hipótesis $\mathrm{H} 12$, se confirma una influencia positiva entre las Capacidades Internas de las organizaciones y los Resultados organizativos.

De nuevo, cabría matizar dicha afirmación, en la medida en que únicamente queda confirmada dicha influencia respecto de los Stocks de Conocimiento (tanto la capacidad de la organización y los grupos, como la capacidad de los individuos) sobre los Resultados Intangibles (satisfacción de los clientes). En este sentido, parece lógico pensar que la satisfacción de los 
clientes está positivamente relacionada tanto con la capacidad de trabajar en equipo de la organización como de las capacidades individuales de los miembros que la forman, en la medida en que el cliente percibe la unidad y coherencia del grupo a través de los individuos con quienes tiene relación directa. Por otro lado, la influencia de los Flujos del Conocimento (Experiencias compartidas de Outdoor training, así como intercambio de información, y la formación para mejorar los conocimientos y las habilidades) sobre los Resultados Tangibles (y más en concreto, sobre la Productividad). También parece razonable pensar que tanto el intercambio de información como de experiencias personales, así como la formación, especialmente en habilidades, influye positivamente en la productividad, en el sentido que aumenta la satisfacción de los empleados en la organización, y en consecuencia su rendimiento.

Como consecuencia de las hipótesis anteriores, en la hipótesis $\mathrm{H} 1$, se puede decir, con carácter general, que los Resultados Intangibles no están siendo influidos por la Gestión del Conocimiento en global. Sin embargo, los Resultados Tangibles (Productividad), están influenciados positivamente por los Stocks de Conocimiento (Capacidad de la organización y de los grupos), y de forma negativa por los Procesos de Planificación Estratégica (Procesos de reflexión estratégica dirigidos a elaborar objetivos concretos). Además, los Resultados Tangibles (Ventas y Beneficios) también están influenciados positivamente por Sistemas de Medición de la Gestión (No financieros) 
En consecuencia, esto vendría a confirmar una mayor influencia de la Gestión del Conocimiento con los Resutados Tangibles, frente a los Resultados Intangibles, lo cual no suele ser frecuente en la literatura, pues normalmente se vincula su influencia a los Resultados Intangibles.

Por otro lado, respecto a la hipótesis $\mathrm{H} 21$, podemos confirmar que las Competencias Estratégicas influyen positivamente en los Resultados Organizativos. En concreto, el factor de las Competencias Estratégicas (Gestión eficiente de los recursos), influye principalmente en los Resultados Intangibles (Satisfacción de los clientes).

También podemos confirmar la relación positiva planteada en la hipótesis H22, que relaciona las Competencias Intratégicas con los Resultados Organizativos. En concreto, el factor principal de las Competencias Intratégicas (es decir, el Trabajo en equipo y la comunicación) influyen directamente en los Resultados Intangibles (Satisfacción de los clientes).

Y en tercer lugar, también queda confirmada la hipótesis H23 al relacionar positivamente las Competencias Personales con los Resultados Organizativos. Sin embargo, y a diferencia de los dos casos anteriores, en este tercer caso, si que existe una influencia tanto en los resultados tangibles (en concreto, en Ventas y Beneficios) como en los resultados intangibles. En ambos casos, el factor principal de las competencias personales hace referencia al Autogobierno y la Mejora personal. 
Como consecuencia de las tres hipótesis anteriores, planteábamos la hipótesis $\mathrm{H} 2$, en la que tratábamos de relacionar las Competencias Directivas con los Resultados Organizativos. Como ha quedado demostrado podemos afirmar la existencia de una relación positiva entre ambas dimensiones. En concreto, existe una influencia positiva de las Competencias Personales (Autogobierno y Mejora Personal) sobre los Resultados Tangibles (en concreto, sobre las Ventas y Beneficios), y por otro lado, también existe una influencia positiva de las Competencias Intratégicas (Trabajo en equipo y Comunicación) sobre los Resultados Intangibles (Satisfacción de los Clientes).

Una cuestión bastante distinta ocurre con la hipótesis H3. En general, podemos decir que la relación entre la Gestión del Conocimiento y las Competencias Directivas no están relacionadas. Es decir, no existe una fuerte correlación entre ambas dimensiones. No obstante, las uniones más fuertes se dan entre stocks de conocimiento (en concreto las capacidades de la organización y los grupos) y las competencias tanto estratégicas como intratégicas.

En general no existe una fuerte correlación entre GESTIÓN DEL CONOCIMIENTO y LAS COMPETENCIAS DIRECTIVAS y, aunque con matices, se puede considerar que la hipótesis $\mathrm{H} 3$ no se da. 
Esta conclusión vendría a confirmar la separación entre ambas dimensiones: esta idea resulta muy interesante desde el punto de vista práctico, pues permite no confundir ambos constructos tanto en la literatura científica y académica, como en la práctica profesional (por ejemplo, en la consultoría).

Por último, la hipótesis H4, planteaba la posibilidad de que los Resultados Organizativos se puedan expresar en función de la intermediación de la Gestión del Conocimiento y de las Competencias Directivas. Como resultado de la contraste de dicha hipótesis, se ha pasado de un modelo de 18 variables independientes, a un modelo de 3 variables independientes.

Para el modelo de Resultados Intangibles, se observa que éstos están influenciados positivamente por la vigilancia del entorno externo y las competencias intratégicas. Es decir, se precisa tanto un factor de la GESTIÓN DEL CONOCIMIENTO como otro de LAS COMPETENCIAS DIRECTIVAS.

Para el modelo de resultados tangibles 1 , es decir, ventas y beneficios, se observa que éste está influenciado negativamente por los procesos de planificación estratégica (perteneciente a la GESTIÓN DEL CONOCIMIENTO) y positivamente por las competencias personales (del constructo COMPETENCIAS DIRECTIVAS). 
Para el modelo de resultados tangibles 2, es decir, la productividad, se observa que ésta está influenciada positivamente por los sistemas de medición de la gestión y los flujos del conocimiento (en concreto por la formación), todas ellas variables del constructo GESTIÓN DEL CONOCIMIENTO.

En resumen, podemos explicar cada una de las 3 variables dependientes como combinación de los factores significativos:

FACTOR 1 INTANGIBLES $=0,284 *$ FACTOR 2 VEE $+0,540 *$ FACTOR 1 INTRATEG

FACTOR 1 TANGIBLES $=-0,326 *$ FACTOR 1 PPE $+0,475 *$ FACTOR 1 PERSONALES

FACTOR 2 TANGIBLES $=0,333 *$ FACTOR 2 SMG $+0,308 *$ FACTOR 2 FDC

Si lo expresamos en función de los constructos, tenemos:

FACTOR 1 INTANGIBLES $=a 1 *$ CARAC. EXTERNAS + a2* COMP. INTRATÉGICAS

FACTOR 1 TANGIBLES $=-\beta 1 *$ CARAC. EXTERNAS $+\beta 2 *$ COMP. PERSONALES

FACTOR 2 TANGIBLES $=\gamma 1 *$ CARAC. EXTERNAS $+\mathrm{y}^{2} *$ CAPAC. INTERNAS

Y si lo expresamos en función de las dimensiones y con el nombre de los factores, tenemos:

RES. INTANGIBLES $=a 1 *$ GESTIÓN CONOCIMIENTO $+a 2 *$ COMP. DIRECTIVAS

VENTAS Y BENEFICIOS $=-\beta 1 *$ GESTIÓN CONOCIMIENTO $+\beta 2 *$ COMP. DIRECTIVAS PRODUCTIVIDAD $=\mathrm{Y}^{*}$ GESTIÓN CONOCIMIENTO 
Por último, conviene matizar, con relación al capítulo 4, que se ha propuesto un modelo a partir del elaborado por Palacios, D. (2003), pero en vez de partir de la distinción entre principios y prácticas, nos orientamos a una distinción de la Gestión del Conocimiento entre características y capacidades, pues creemos que representan con mayor propiedad el constructo citado.

Por otro lado, respecto al constructo de Competencias Directivas, y en referencia a su efecto mediador entre la Gestión del Conocimiento y los Resultados Organizativos, señalar que a diferencia del modelo propuesto por Palacios, D. (2003), que habla de Competencias Dinámicas de Dirección (CDD), en el modelo que proponemos las consideramos suficientemente importantes en sí mismas como para justificar y constituir un modelo a investigar que centre su atención en dichas competencias.

De hecho los resultados, así nos han confirmado la importancia de las mismas en la mediación con los Resultados Organizativos, y en especial las Competencias Directivas Intratégicas y Personales, alcanzando respectivamente los mayores valores de entre los factores principales $(0,54$ y 0,475$)$. Factores que hacen referencia al trabajo en equipo y a la comunicación, por un lado, y el autogobierno y la mejora personal de otro.

En el capítulo 5, hemos hemos revisado modelos y herramientas de medida que se mueven en distintos ámbitos, como aproximación al modelo de investigación empírica que finalmente hemos adoptado. Por eso, hemos hecho tratado de aproximarnos tanto al plano organizativo como individual, al enfoque 
estático y al dinámico, y a la literatura estratégica, de recursos humanos y de aprendizaje.

Finalmente, hemos optado por un modelo centrado en el plano individual o personal, dinámico y de recursos humanos. No obstante, en la herramienta de medida que hemos utilizado, se podrán apreciar ciertos matices que nos recuerdan los otros planos, enfoques y literaturas, ya que dada la novedad de la materia, todavía sería demasiado atrevido por mi parte dejar de lado.

Las conclusiones que presentamos sean quizás demasiado optimistas, y una redacción más autocrítica en la valoración de las hipótesis, para dar un mayor rigor a los resultados, hubiera sido de desear. Sin duda sería necesaria una reflexión más detenida y detallada de las limitaciones de la investigación.

En este sentido, especial mención requiere la relación negativa resultante entre el factor principal de los procesos de planificación estratégica (la complejidad de los procesos de reflexión estratégica) y el segundo factor principal de los resultados intangibles (en concreto, la productividad). Sin duda, resulta sumamente interesante apreciar como a medida que aumenta la complejidad de los procesos de reflexión estratégica, disminuye la productividad, y en último término la competitividad.

Una conclusión, que aun a pesar de ser paradójica, no deja de resultar sorprendente, es que podríamos afirmar, a sensu contrario, que a medida que disminuyen o se hacen más sencillos los procesos de planificación estratégica, aumentará la productividad, y en último término la competitividad tanto de la organización como de las personas. 


\subsection{FUTURAS LÍNEAS DE INVESTIGACIÓN}

Una vez presentadas las conclusiones y los resultados de nuestra investigación, procede a comentar algunas deficiencias que hemos encontrado en nuestra labor, que esperamos sirvan de experiencia y propuesta de mejora para futuras líneas de investigación.

Por un lado, dado la novedad de esta materia, y a pesar de que últimamente se está publicando e investigando en esta línea, nos hemos encontrado con escasez de referencias bibliográficas específicas de la materia, así como revistas científicas especializadas.

Por otro lado, en la fase de investigación empírica, nos hubiera gustado entrar con mayor profundidad en la utilización de las últimas técnicas de investigación estadística para las ciencias sociales como son los sistemas de ecuaciones estructurales, que tanto renombre están adquiriendo en el ámbito universitario y de investigación. En nuestro caso particular, a pesar del intento inicial de aplicar estas metodologías, no ha sido posible dado el escaso número de individuos que contestaron a nuestra investigación y el elevado número de variables que queríamos abordar. En futuros estudios, esperamos aumentar el índice de respuesta para poder así comparar los resultados. En concreto, después de unas pruebas con los datos presentados en el programa SPSS, obteníamos únicamente como información adicional que las "Competencias Directivas Personales" es el factor que más explica por si mismo con 
independencia de los demás la variable resultado "Resultado Tangibles", con lo que reitera nuestro interés y futuras líneas de investigación en esta orientación.

Consideramos sin duda que la investigación realizada tiene grandes limitaciones. Especialmente, es de destacar la baja respuesta de individuos que obtuvimos para la muestra, 50, lo que nos impidió utilizar otro tipo de metodología estadística como los modelos de ecuaciones estructurales, so pena de obtener unos resultados poco fiables. En este sentido, proponemos como futura línea de investigación profundizar en este estudio a nivel nacional e internacional, para obtener una visión de conjunto y poder comparar los resultados. Por otro lado, considero que sería muy interesante hacer una comparativa de los resultados por los distintos sectores representados en la muestra que dada la diversidad y la baja representación en cada uno no ha permitido hacer una comparativa fiable.

Por último, y a modo de futura línea de investigación, pretendemos publicar este estudio como estado de la situación de la Gestión del Conocimiento, las Competencias Directivas y su relación con los Resultados Organizativos en la Comunidad Valenciana. Si las empresas muestran a su vez interés en este estudio, podriamos incluso sacar un estudio anual actualizado para ver la evolución de las mismas y establecer así un índice comparativo entre ellas, que les permita contrastar como se encuentra su empresa respecto a la competencia de su sector o actividad, o comparase asimismo con otras comunidades autónomas. 
Aaker, D.A. (1989): "Managing assets and skills: the key to sustainable competitive advantage". California Management Review, vol. 31, n 2, pp. 91-106.

AECA (1988) : "El objetivo eficiencia de la empresa". Documento 1 de la Comisión Principios de Organización y Sistemas. AECA, Madrid.

Alvesson, M. (2000): "Social identity and the problem of loyalty in knowledge-intensive companies". Journal of Management Studies, vol. 37, no 8, pp. 1101-1111.

Amit, R. y Schoemaker, P. (1993): "Strategic assets and organizational rent". Strategic Management Journal, vol. 14, pp. 33-46.

Anderson, J.C. y Gerbing, D.W. (1982): "Some methods for respecifying measurement models to obtain unidimensional constructs measures". Journal of Marketing Research, vol. 19, pp. 453-460.

Anderson, J.C. y Gerbing, D.W. (1988): "Structural equation modeling in practice: A review and recommended two-step approach". Psychological Bulletin, vol. 119, pp. 411-423.

Andreu, R. y Ciborra, C. (1996): "Core capabilities and information technology: An organizational learning approach". En Moingeon, B.; Edmondson, A. (ed.): Organizational Learning Competitive Advantage, pp. 121-138. London: Sage Publications.

Andrews, K. R. (1971): The Concept of Corporate Strategy. Dow-Jones-Irwin, Homewood.

Ansoff, H.I. (1965): Corporate Strategy. McGraw-Hill, New York.

Ansoff, H.I. (1979): La dirección y su actitud ante el entorno. Ediciones Deusto, Bilbao.

Ansoff, H.I. (1985): "¿Qué es la estrategia de la empresa?". En Enciclopedia de Dirección y Administración de la Empresa. Volumen V: Dirección general y política de empresa. Ediciones Orbis, Barcelona, pp. 21-40.

Argyris, C. (1976): "Single Loop and Double Loop Models In Research on Decision Making". Administrative Science Quarterly, vol. 21, pp. 363-375.

Argyris, C. (1994): "Good communication that blocks learning". Harvard Business Review, Julio-Agosto, pp. 77-85.

Argyris, C. (1996): "Unrecognized defenses of scholars: Impact on theory and research". Organization Science, vol. 7, no 1, pp. 79-87.

Argyris, C. y Schon, D. (1978): Organizational learning: a theory of action perspective. Reading, Mass. Addison-Wesley.

Argyris, C. y Schon, D. (1996): Organizational learning II: Theory, method and practice. Reading, Mass. Addison-Wesley.

Arora, A. y Gambardella, A. (1994): "The changing technology of technological science". Research Policy, vol. 23, pp. 523-532.

Asebio (2002): Informe Asebio 2001. Editado por la Asociación Española de Bioempresas.

Ashby, W.R. (1968): "Principles of the self organizing system". En Buckley (ed.): Modern systems research for the behavioral scientist. pp. 108-118. Chicago: Aldine. 
Bagozzi, R.P. (1980): A causal model in marketing. John Wiley, New York.

Bagozzi, R.P. (1981): "An examination of the validity of two models of attitude". Multivariate Behavioral Research, vol. 16, pp. 323-359.

Bagozzi, R.P. (1982): "The role of measurement in theory construction and hypothesis testing: Toward a holistic model". En Fornell, C. (Ed.): A second generation of multivariate analysis. Vol. 2. Measurement and Evaluation. Praeger Publishers, New-York, pp. 3-23.

Bagozzi, R.P. (1994): "Structural equation models in marketing research: Basic principles". En Bagozzi, R.P. (Ed.): Principles of Marketing Research, Blackwell Publishers, Oxford, England, pp. 317-385.

Bagozzi, R.P. y Phillips, L.W. (1982): "Representing and testing organizational theories: A holistic construct". Administrative Science Quarterly, vol. 27, pp. 459-489.

Baldwin, C.Y y Clark, K.B. (1991): Capabilities and capital investment: New perspectives on capital budgeting. Harvard Business School, Working Paper no 92-004, Cambridge.

Barney, J.B. (1986): "Strategic factor markets: Expectations, luck and business strategy". Management Science, vol. 32, no 10, pp. 1231-1241.

Barney, J.B. (1989): "Asset stock accumulation and sustained competitive advantage: A comment". Management Science, vol. 35, no 12, pp. 1511-1513.

Barney, J.B. (1991): "Firm resources and sustained competitive advantage". Journal of Management, vol. 17, no 1, pp. 99-120.

Barney, J.B. (1997): Gaining and sustaining competitive advantage. Addison-Wesley Publishing Co.

Barrio, S. y Luque, T. (2000): "Análisis de ecuaciones estructurales". En Luque, T. (coord): Técnicas de análisis de datos en investigación de mercados. Editorial Pirámide, Madrid.

Bartoli, A. y Hermel, P. (1989): Le développement de I'entreprise. Economica, París.

Batista, J.M. y Coenders, G. (2000): Modelos de ecuaciones estructurales. Editorial La Muralla / Hespérides, Madrid.

Bearden, W.O.; Netemeyer, R.G. y Mobley, M.F. (1993): Handbook of marketing scales. Multi-item measures for marketing and consumer behaviour research. SAGE Publications, Inc. Newbury Park, California.

Beckman, T. (1997): "A methodology for knowledge management". Artificial Intelligence and Software Computing Conference. Organizado por AIAI (Grupo de investigación en Inteligencia Artificial de la Universidad de Edinburgo). Banff, Canada.

Bentler, P.M. (1995): EQS: Structural equations program manual. Los Angeles: BDMP Statistical Software.

Bentler, P.M. y Bonett, D.G. (1980): "Significance tests and goodness-of-fit in the analysis of covariance structures". Psychological Bulletin, vol. 88, pp. 588-606. 
Berné, C.; Pedraja, C.M. y Rivera, P. (1994): "Los determinantes de la actitud del consumidor ante la publicidad: un estudio exploratorio". VII Encuentros de profesores de Marketing, San Sebastián, pp. 191-202.

Bisquerra, R. (1989): Introducción conceptual al análisis multivariante. Un enfoque informático con los paquetes SPSS-X, LISREL y SPAD. Promociones y Publicaciones Universitarias, S.A., Barcelona.

Black, J.A. y Boal, K.B. (1994): "Strategic resources: traits, configurations and paths to sustainable competitive advantage". Strategic Management Journal, Summer Special Issue, vol. 15, pp. 131-148.

Blackler, F. (1993): "Knowledge, knowledge work and organizations: An overview and interpretation". Journal of Management Studies, vol. 30, no 6, pp. 863-884.

Blair, M.M. y Wallman, M.H. (2000): Unseen Wealth. Report of the Brookings Task Force on Understanding Intangible Sources of Value. Brookings Institution, Washington.

Bogaert, I.; Martens, R. y Van Cauwenbergh, A. (1994): "Strategy as a situational puzzle: the fit of components". En Hamel and Heene (eds., 1994), pp. 57-74.

Bogner, W.C. y Thomas, H. (1994): "Core competence and competitive advantage: a model and illustrative evidence from the pharmaceutical industry". En Hamel y Heene (eds., 1994), pp. 111-144.

Bollen, K.A. (1989): Structural equations with latent variables. John Wiley \& Sons, New York.

Bommensath, M. (1987): Manager I'intelligence de votre entreprise. Les Éditions d'Organisation, París.

Bontis, N. (1998): "Intellectual capital: an exploratory study that develops measures and models". Management Decision, vol. 36, no 2, pp. 63-76.

Bontis, N. (2000): "Intellectual capital and business performance in Malaysian industries". Journal of Intellectual Capital, vol.1, no 1, pp. 85-100.

Boyatzis, R., (1983): "The Competent Manager", Jossey-Bass, San Francisco, 1983.

Brooking, A. (1996): Intellectual Capital. Core Asset for the Third Millennium Enterprise. International Thomson Business Press, London, $1^{\text {aed. }}$

Brown, J.S. y Duguid, P. (1991): "Organizational learning and communities of practice: Toward a unified view of working, learning and innovation". Organization Science, vol. 2, no 1, pp. 40-57.

Brown, J.S. y Duguid, P. (1998): "Organizating knowledge". California Management Review, vol. 40, no 3, pp. 90-111.

Brown, S.L. y Eisenhardt, K.M. (1998): Competing on the edge, strategy as structured chaos. Massachusetts: Harvard Business School Press. 
Brumagin, A. (1994): "A hierarchy of corporate resources". En Advances in Strategic Management, vol. 10: Shrivastava, Huff A (eds). JAI Press: Greenwich, CT. pp. 81-112.

Bueno, E. (1998): "El capital intangible como clave estratégica en la competencia actual". Boletín de Estudios Económicos, no 164, pp. 207-229.

Burrill, S.G. y Lee, K.B. (1992): Biotech 92: Promise to Reality. Ernst \& Young, San Francisco, CA.

Byrne, B.M. (1989): A primer of LISREL basic applications and programming for confirmatory factor analytic models. SpringerVerlag, New York.

Camelo, C. (1999): "El estudio de la estrategia de diversificación desde la teoría basada en el conocimiento". Revista Europea de Dirección y Economía de la Empresa, vol. 8, no 4, pp. 33-53.

Camisón, C. (1998): Configuraciones organizativas, entorno y desempeño: Un contraste empirico de los modelos teóricos sobre la relación organización-entorno en la empresa industrial española. Trabajo de investigación para el concurso de Cátedra. Universidad de Valencia.

Camisón, C. (1999): "Sobre cómo medir las competencias distintivas: Un examen empírico de la fiabilidad y validez de los modelos multi-ítem para la medición de los activos intangibles". The Iberoamerican Academy of Management, First International Conference, Madrid, Diciembre.

Camisón, C. (2000): "La empresa valenciana ante la sociedad del conocimiento: situación actual y retos de futuro". Revista Valenciana d'Estudis Econòmics, pp. 3-28.

Camisón, C. (2002a): "Una propuesta de conceptualización del patrimonio de competencias distintivas de una organización". Grupo de Investigación en Estrategia, Gestión del Conocimiento y Aprendizaje Organizativo. Documento de Trabajo 3/02, Universitat Jaume I, Castellón.

Camisón, C. (2002b): "Competencias distintivas basadas en activos intangibles". En Nuevas claves para la dirección estratégica, pp. 117-153. Ariel Economía.

Camisón, C. y Palacios, D. (1999): "Un modelo para la medición del capital intelectual en la empresa: el modelo Nova". Documento obtenido en Internet: www.gestiondelconocimiento.com

Cardona, P. y Chinchilla, N. (1999):"Evaluación y desarrollo de las competencias directivas", Harvard-Deusto Business Review, núm. 89, marzo-abril 1999.

Cardona, P. (2001): "Paradigmas del liderazgo: clave de la dirección de personas", MacGrawHill, 2001.

Cardona, P y García-Lombardía, P. (2005): "Cómo desarrollar las competencias de liderazgo", EUNSA, 2005.

Carlile, R. (2002): "A Pragmatic View of Knowledge and Boundaries: Boundary Objects in New Product Development". Organization Science, vol. 13, no 4, pp. 442-455.

Castanias, R.P. y Helfat, C.E. (1991): "Managerial resources and rents". Journal of Management, vol. 17, pp. 155-171.

Cohen, S.G. (1993): New approaches to teams and teamwork. En Galbraith, J.R. y Lawler III

E. (Eds.): Organizing for the future, San Francisco: Jossey-Bass Publishers, pp. 194-226. 
Cohen, W.M. y Levinthal, D.A. (1990): "Absorptive capacity: A new perspective on learning and innovation". Administrative Science Quarterly, vol. 35, pp. 128-152.

Collis, D.J. (1994): "Research Note: How Valuable are Organizational Capabilities? ". Strategic Management Journal, vol. 15, pp. 143-152.

Collis, D.J. y Montgomery, C.A. (1995): "Competing on resources: Strategy in the 1990s". Harvard Business Review, vol. 73, no 4, pp. 118-128.

Conant, J.S.; Mokwa, M.P. y Varadarajan, P.R. (1990): "Strategic types, distinctive marketing competencies and organizational performance: A multiple measures-based study". Strategic Management Journal, vol. 11, no 5, pp. 365-383.

Conner, K.R. (1991): "A historical comparison of resource-based theory and five schools of thought within industrial organization economics: Do we have a new theory of the firm? ". Journal of Management, vol. 17, nº 1, pp. 121-154.

Cook, S. y Brown, J.S. (1999): "Bridging Epistemologies: The Generative Dance Between Organizational Knowledge and Organizational Knowing". Organization Science, vol. 10, no 4, pp. 381-400.

Cook, S. y Yanow, D. (1996): "Culture and organizational learning". En Cohen, M.; Sproull, L. (Eds.): Organizational Learning. California: Sage Publications.

Coyne, K.P. (1986): "Sustainable competitive advantage: what it is and what it isn' $t$ ". Business Horizons, vol. 29, no 1, pp. 54-61.

Cronbach, L. (1951): "Coefficient Alpha and the internal structure of tests". Psychometrica, vol. 16, pp. 297-334.

Crossan, M.M.; Lane, H.W. y White, R.E. (1999): "An organizational learning framework: from intuition to institution". Academy of Management Review, vol. 24, no 3, pp. 522-537.

Chi, T. (1994): "Trading in Strategic Resources: Necessary Conditions, Transactions, Transaction Costs Problems and Choice of Exchange Structure". Strategic Management Journal, vol. 15, pp. 271-290.

Christensen, J.F. (1996): "Analysing the technology base of the firm. A multi-dimensional resource and competence perspective". En N. Foss y C. Knudsen (Eds.), Towards a competence theory of the firm, pp. 111-132. Londres: Routledge.

Churchill, G.A. (1979): "A Paradigm for Developing Better Measures of Marketing Constructs". Journal of Marketing Research, vol.16, no 1, pp. 64-73.

Churchill, G.A. y Peter, J.P. (1984): "Research Design Effects on the Reliability of Rating Scales: A Meta-Analysis". Journal of Marketing Research, vol. 21, n04, pp. 360-375.

Davenport, T. (1996): "Some principles of Knowledge Management". CIO Journal, pp. 12-18.

Davenport, T. (1999): "Knowledge Management and the broader firm: Strategy, advantage, and performance". En Liebowitz, J. Knowledge Management Handbook, pp. 1-11. 
Davenport, T. y Prusak, L. (1998): Working Knowledge: How Organizations Manage What They Know. Boston: Harvard Business School Press.

De Bodinat, H. y Mercier, V. (1979): "L'analyse stratégique moderne". Harvard-L 'Expansion, Winter.

Decarolis, D.M. y Deeds, D.L. (1999): "The impact of stocks and flows of organizational knowledge on firm performance: An empirical investigation of the biotechnology industry". Strategic Management Journal, vol. 20, pp. 953-968.

Deeds, D.L. y Decarolis, D.M. y Coombs J. (1997): "The impact of firm specific capabilities on the amount of capital raised in an initial public offering: An empirical study of new biotechnology firms". Journal of Business Venturing, vol. 12, no 1, pp. 31-46.

Demsetz, H. (1991):: "The Theory of the Firm". Revisited en Williamson, O. y Winter, S. (Eds.) The Nature of the Firm, Oxford University Press, pp.159-178.

DeVellis, R. F. (1991): Scale Development: Theory and Applicationes. Sage Publications, Newbury Park, California.

Diamantopoulos, A. (1994): "Modelling with LISREL: A guide for the uninitiated". Journal of Marketing Management, vol. 10, pp. 105-136.

Dibella, A. y Nevis, E. (1998): How organizations learn: An integrated strategy for building learning capacity. Jossey-Basss.

Dierickx, I. y Cool, K. (1989): "Asset stock accumulation and sustainability of competitive advantage". Management Science, vol. 35, no 12, pp. 1504-1513.

Dillman, D.A. (1978): Mail and telephone surveys: The total design method. John Wiley \& Sons, Nueva York.

Dorothy, L. y Sensiper, S. (1998): "The Role of Tacit Knowledge in Group Innovation". California Management Review, no 40, pp. 112-132.

Dosi, G. (1982): "Technological paradigms and technological trajectories". Research Policy, vol. 11 , pp. 147-162.

Dosi, G.; Freeman, C.; Nelson, R.R.; Silverberg, G. y Soete, L. (1988): Technical change and Economic theory. Printer Publishers, London.

Dosi, G.; Teece, D.J. y Winter, S. (1992): "Towards a theory of corporate coherence: preliminary remarks". En Dosi, G.; Giannetti, R.; Toninelli, P.A. (eds., 1992), pp. 185-211.

Dosi, G.; Nelson, R. y Winter, S. (eds., 2000): The Nature and Dynamics of Organizational Capabilities. Oxford University Press, New York.

Drucker, P. F. (1993). Post-Capitalist Society. Oxford: Butterworth Heinemann.

Duncan, R. y Weiss, A. (1979): "Organizational learning: implications for organizational design". Research in Organizational Behaviour, vol. 1, pp. 75-123.

Dunn, G.; Everitt, B. y Pickles, A. (1993): Modelling covariances and latent variables using EQS. Chapman \& Hall, London. 
Durant, T. (1997): "Strategizing for innovation: Competence Analysis in Assessing Strategic Change". En Heene, A. y Sánchez, R. (Ed.): Competence-Based Strategic Management. John Wiley \& Sons, Chichester, England, pp. 127-150.

Durkheim, E. (1964): The rules of sociological method. Free press, New York.

Edvisson, L. y Malone, M.S. (1997): Intellectual Capital. Realizing your company's true value by finding its hidden brainpower. Harper Collins Publishers, Inc., $1^{\mathrm{a}}$ ed.

Eisenhardt, K.M. y Martin, J.A. (2000): "Dynamic Capabilities: What are they?". Strategic Management Journal, vol. 21, no 10/11, pp. 1105-1121.

Ericksen, G.K. (1996): "Creating value by managing your organization's information and knowledge". Directorship Summer, vol. 22, no 8, pp. 1-3.

Eriksen, B. y Mikkelsen, J. (1996): "Competitive advantage and the concept of core competence". En Foss, N.J. y Knudsen, C. (eds., 1996), pp. 38-53.

Erramilli, M.; Agarwal, S. y Dev, S. (2002): "Choice between Non-Equity entry modes: An Organizational Capability Perspective". Journal of International Business Studies, vol. 33, no 2, pp. 223-242.

Escrig, A. B. (2000): "Efectos de la Dirección de Calidad en los resultados: El papel mediador de las competencias distintivas". Tesis Doctoral. Facultad de Ciencias Jurídicas y Económicas. Departamento de Administración de Empresas y Marketing. Universitat Jaume I de Castellón.

Fernández, Z. (1993): "La organización interna como ventaja competitiva para la empresa". Papeles de Economía Española, no 56, pp. 78-193.

Fernández, E.; Montes, J.M. y Vázquez, C.J. (1997): "La teoría de la ventaja competitiva basada en los recursos: Síntesis y estructura conceptual". Revista Europea de Dirección y Economía de la Empresa, vol. 6, no 3, pp. 11-32.

Fernández, E.; Montes, J.M. y Vázquez, C.J. (1998): "Tipología e implicaciones estratégicas de los recursos intangibles. Un enfoque basado en la Teoría de los recursos". Revista Asturiana de Economía, no 11, pp. 159-183.

Fernández, Z. y Suárez, I. (1996): "La estrategia de la empresa desde una perspectiva basada en los recursos". Revista Europea de Dirección y Economía de la Empresa, vol. 5, no 3, pp. 73-92.

Ferrán, M. (1996). SPSS para Windows. Programación y análisis estadístico. Mc Graw-Hill (ed.)

Fiol, C.M. y Lyles, M.A. (1985): "Organizational learning". Academy of management review, vol. 10, pp. 803-813.

Firestone, J.M. (2001): "Estimating benefits of knowledge management initiatives: Concepts, methodology, and tools". Journal of Knowledge and Innovation, vol. 1, no 3.

Fornell, C. y Larcker, D.F. (1981): "Evaluating structural equations models with unobservable variables and measurement error". Journal of Marketing Research, vol. 18, pp. 39-50. 
Foss, N.J. (1996a): "Introduction: the emerging competence perspective".En Foss, N.J. y Knudsen, C. (Ed.): Towards a Competence Theory of the Firm. Routledge, London and New York, pp. 1-12.

Foss, N.J. (1996b): "Whither the competence perspective?". En Foss, N.J. y Knudsen, C. (Ed.): Towards a Competence Theory of the Firm. Routledge, London and New York, pp.175-200.

Foss, N.J. (1997): "Resources and Strategy: Problems, Open issues and ways ahead". En Foss, N.J. (Ed.): Resources, Firms and Strategies. A reader in the resource-based perspective. Oxford University Press, New York, pp. 345-365.

Foss, N.J.; Knudsen, C. y Montgomery, C.A. (1995): "An exploration of common ground: Integrating evolutionary and strategic theories of the firm". En Montgomery, C.A. (ed., 1995), pp. 1-17.

Fredrickson, J.W. (ed., 1990): Perspectives on strategic management. Harper \& Row, Nueva York.

Galán, J.L y Vecino, J. (1997): "Las fuentes de rentabilidad de las empresas". Revista Europea de Dirección y Economía de la Empresa, vol. 6, no 1, pp. 21-36.

Galbraith, J.R. (1994): Competing with flexible lateral organizations. Second Edition, AddisonWesley Publishing company.

Galunic, D.C. y Rodan, S. (1998): "Resource recombinations in the firms: Knowledge structures and the potential for schumpeterian innovation". Strategic Management Journal, vol. 19, pp. 1193-1201.

García, C. y Enrione, A. (1994): "¿Aprovecha usted sus activos estratégicos?". Documento de trabajo del IESE.

García, F.; Ortiz de Urbina, M. y Vargas, P. (2001): "Conceptualización y clasificación de las capacidades empresariales desde una perspectiva dinámica". XI Congreso Nacional de ACEDE, Zaragoza.

Garvin, D.A. (1994): "Building a learning organization". Business Credit, vol. 96, no 1, pp. 19 28.

Godfrey, P.C. y Hill, C.W. (1995): "The problem of unobservables in strategic management research". Strategic Management Journal, vol. 16, pp. 519-533.

Goh, S. y Richards, G. (1997): "Benchmarking the learning capacity of organizations". European Management Journal, vol. 15, n 5, pp. 575-583.

Gopal, C. y Gagnon, J. (1995): "Knowledge, information, learning and the IS manager". Computerworld (Leadership Series), vol. 1, no 5, pp. 1 - 7.

Grant, R.M. (1991): "The Resource-Based Theory of Competitive Advantages: Implications for Strategy Formulation". California Management Review, vol. 33, nº 3, pp. 114-135. 
Grant, R.M. (1995): Dirección Estratégica. Conceptos, Técnicas y Aplicaciones. Civitas, Madrid. Edición original: Grant, R.M. (1991): Contemporary Strategic Analysis: Concepts, Techniques, Applications. Blackwell Publishers, Cambridge, USA.

Grant, R.M. (1996): "Prospering in Dynamically-Competitive Environments: Organizational Capability as Knowledge Integration". Organizational Science, vol. 7, no 4, pp. 375-388.

Grant, R.M. (1997): "The Knowledge-Based View of the Firm: Implications for Management Practice". Long Range Planning, vol. 30, n 3, pp. 450-454.

Grant, R.M. (1998): "Resources, Capabilities and the Knowledge-based view: Assessment and Prospects". VIII Congreso Nacional de ACEDE, Septiembre, Las Palmas de Gran Canaria, pp. 213.

Grapentine, T. (1994): "Problematic scales: When measuring quality, expectations scales exhibit several drawbacks". Marketing Research, vol. 6, no 4, pp. 8-12.

Gribbons, B.C. y Hocevar, D. (1998): "Levels of aggregation in higher level confirmatory factor analysis: Application for academic self-concept". Structural Equation Modeling, vol. 5, no 4, pp. 377-390.

Hair, H.F.; Anderson R.E.; Tatham, R.L. y Black, W.C. (1999): Análisis Multivariante. Prentice Hall, Madrid.

Hall, R.H. (1992): "The strategic analysis of intangible resources". Strategic Management Journal, vol. $13, n^{\circ} 2$, pp. 135-144.

Hall, R.H. (1993): "A Framework Linking Intangible Resources and Capabilities to Sustainable Competitive Advantage". Strategic Management Journal, vol. 14, no 8, pp. 607-618.

Hamel, G. (1994): "The Concept of Core Competence". En Hamel y Heene (eds., 1994), pp. 11-34.

Hamel, G. y Heene, A. (1994): Competence-Based Competition. The Strategic Management Series, John Wiley \& Sons, England.

Hamel, G. y Prahalad, C.K. (1993): "Strategy as Stretch and Leverage". Harvard Business Review, vol. 69, pp. 75-84.

Hamel, G. y Prahalad, C.K. (1994): Competing for the future. Harvard Business School Press, Boston.

Hansen, M.T. (1999): "The search-transfer problem: The role of weak ties in sharing knowledge across organizational subunits". Administrative Science Quarterly, vol. 44, pp. 82111.

Hansen, G.S. y Wernerfelt, B. (1989): "Determinants of Firm Performance: the Relative Importance of Economic and Organizational Factors". Strategic Management Journal, vol. 10, pp. 399-411.

Hargadon, A. (1998): "Firms as Knowledge Brokers: Lessons in Pursuing Continuous Innovation". California Management Review, no 40, pp. 209-227. 
Hayes, B. (1992): Measuring customer satisfaction: Development and use of questionnaires. The Quality Press, Milwaukee.

Hayes, R.H. y Wheelwright, S.C. (1984): Restoring our competitive edge. John Wiley \& Sons, Nueva York.

Hedlund, G. (1994): "A model of knowledge management and the N-form corporation". Strategic Management Journal, vol. 15, pp. 73-90.

Heene, A. y Sánchez, R. (eds., 1997): Competence-Based Strategic Management. John Wiley \& Sons, The Strategic Management Society Series, Chichester.

Helfat, C.E. y Raubitschek, R.S. (2000): "Product Sequencing: Co-evolution of knowledge, capabilities and products". Strategic Management Journal, vol. 21, pp. 961-979.

Henderson, R. y Cockburn, I. (1994): "Measuring competence? Exploring firm effects in pharmaceutical research". Strategic Managament Journal, vol. 15, pp. 63-84.

Hibbard, J. (1997): Knowing What We Know. Information Week, vol. 20, October.

Hill, C. y Deeds, D.L. (1996): "The importance of industry structure for the determination of firm profitability: A neo-austrian perspective". Journal of Management Studies, vol. 33, pp. 429451.

Hitt, M.A. y Ireland, R.D. (1985): "Corporate Distinctive Competence, Strategy, Industry and Performance". Strategic Management Journal, vol. 6, no 3, pp. 273-293.

Huber, G.P. (1991): "Organizational learning: the contributing processes and the literature". Organization Science, vol. 2, pp. 88-115.

Hudson, W. (1993): Intellectual Capital: How to build it, enhance it, use it. John Wiley, New York.

Itami, H. y Roehl, T.W. (1987): Mobilizing Invisible Assets. Harvard University Press, Cambridge. Ittner, C.D. y Larcker, D.F. (1997): "Quality strategy, strategic control systems, and organizational performance". Accounting, Organizations and Society, vol. 22, no 3/4, pp. 293-314.

Jacobsen, R. (1988): "The persistence of abnormal returns". Strategic Management Journal, vol. 9, pp. 41-58.

Jacobsen, R. (1992): "The Austrian school of strategy". Academy of Management Review, vol. 17 , no 4, pp. 782-807.

Javidan, M. (1998): "Core competence: what does it mean in practice?". Long Range Planning, vol. 31 , no 1 , pp. 60-71.

Jöreskog, K.G. (1969): "An approach to confirmatory maximum likelihood factor analysis". Psychometrica, vol. 34, pp. 183-202.

Jöreskog, K.G. (1971): "Simultaneous factor analysis in several populations". Psychometrica, vol. 57, pp. 409-426.

Jöreskog, K.G. y Sörbom, D. (1989): LISREL 7: User's reference guide. Scientific Software, Inc. Mooresville. 
Kaplan, R. y Norton, D. (1996) "The balanced scorecard: translating strategic into action". Harvard Business School Press.

Katzenberg, J.R., (2003): "Why Pride matters More than money", Crown Business, 2003.

Kinnear, T.C. y Taylor, J.R. (1993): Investigación de Mercados: Un enfoque aplicado. McGrawHill Interamericana.

Knudsen, C. (1996): "The competence perspective: a historical view". En Foss, N.J. y Knudsen, C. (eds., 1996), pp. 13-37.

Kogut, B. y Zander, U. (1992): "Knowledge of the firm, combinative capabilities and the replication of technology". Organization Science, vol. 3, n 3, pp. 383-397.

Kogut, B. y Zander, U. (1996): "What firms do? Coordination, identity, and learning". Organization Science, vol. 7, no 5, pp. 502-518.

Kumar, M.; Stern, L. y Anderson, J.C. (1993): "Conducting interorganizational research using key informants". Academy of Management Journal, vol. 36, no 6, pp. 1633-1651.

Lado, A.A.; Boyd, N.G. y Wright, P. (1992): "A Competency-Based Model of Sustainable Competitive Advantage: Toward a Conceptual Integration". Journal of Management, vol. 18, no 1 , pp. 77-91.

Lado, A.A. y Wilson, M.C. (1994): "Human resource systems and sustained competitive advantage: A competency-based perspective". Academy of Management Review, vol. 19, no 4, pp. 699-727.

Lam, A. (1997): "Embedded firms, embedded knowledge: Problems of collaboration and knowledge transfer in global cooperative ventures". Organization Studies, vol. 18, pp. 973-996.

Landis, R.S.; Bela, D.J. y Tesluk, P.E. (2000): "A comparison of approaches to composite measures in structural equation models". Organization Research Methods, vol. 3, no 2, pp. 186207.

Lave, J. y Wenger, E. (1991): Situated learning: Legitimate peripheral participation. New York: Cambridge University Press.

Law, K.S.; Wonk, C. y Mobley, W.H. (1998): "Towards a taxonomy of multidimensional constructs". Academy of Management Review, vol. 23, no 4, pp. 741-755.

Lawler, E.E. (1994):"From job-based to competency-based organizations", Journal of Organizational Behavior, 1994, vol. 15, issue 1.

Lei, D.; Hitt, M.A. y Bettis, R. (1996): "Dynamic Core Competences through Meta-Learning and Strategic Context". Journal of Management, vol. 22, no 4, pp. 549-569.

Leonard-Barton, D. (1992): "Core capabilities and core rigidities: a paradox in managing new product development". Strategic Management Journal, vol. 13, pp. 111-125.

Levitt, B. y March, J.G. (1988): "Organizational Learning". Annual Review of Sociology, vol. 14 , pp. 319-340. 
Liebeskind, J.P. (1996): "Knowledge, strategy and the theory of the firm". Strategic Management Journal, vol. 17, pp. 93-107.

Liebowitz, J. y Beckman, T. (1998): Knowledge Organizations: What Every Manager Should Know. Boca Raton: St. Luci press.

Lingle, J.H. y Schieman, N.A. (1996): "Medición Estratégica: Compruebe que su esfuerzo hacia el cambio está dando resultados". Harvard-Deusto Business Review, Septiembre-Octubre.

Lippman, S.A. y Rumelt, R.P. (1982): "Uncertain imitability: an analysis of interfirm differences in efficiency under competition". Bell Journal of Economics, vol. 23, pp. 418-438.

Lowendahl, B. y Haanes, K. (1997): "The unit of activity: A new way to understand competence building and leveraging". En Sánchez, R.; Heene, A. (ed.): Strategic Learning and Knowledge Management, pp. 19-38. West Sussex: John Wiley \& Sons Ltd.

Macintosh, A. (1996): Position Paper on Knowledge Asset Management. Artificial Intelligence Applications Institute, University of Edinburgh, Scotland, Mayo.

Madhok, A. (1997): "Cost, value and foreign market entry mode: The transaction and the firm". Strategic Management Journal, vol. 18, pp. 39-61.

Mahoney, J. y Pandian, J.R. (1992): "The resource-based view within the conversation of strategic management". Strategic Management Journal, vol. 13, no 5, pp. 363-380.

Makadok, R. (2001): "Toward a synthesis of the resource-based and dynamic-capability views of rent creation". Strategic Management Journal, vol. 22, pp. 387-401.

March, J. (1991): "Exploration and Exploitation in Organizational Learning". Organization Science, vol. 2, no 1, pp. 71-87.

March, J.G. y Olsen, J.P. (1975): "The Uncertainty of the Past: Organizational Learning under Ambiguity". European Journal of Political Research, no 3, pp. 147-171.

Markides, C.C. y Williamson, P.J. (1994): "Related diversification, core competences and corporate performance". Strategic Management Journal, vol. 15, pp. 149-165.

Markides, C.C. y Williamson, P.J. (1996): "Corporate diversification and organizational structure: a resource-based view". Academy of Management Journal, vol. 39, n० 2, pp. 340367.

Martínez, J.F.; Escribá, M. A.; Lloria, M. B.; Méndez, M. y Moreno M.D. (2001): "Principios genéricos y específicos de la gestión del conocimiento: Análisis comparativo con los principios de la Gestión de la Calidad Total". XI Congreso Nacional de Acede, Zaragoza.

Mauri, A.J. y Michaels, M.P. (1998): "Firm and industry effects within strategic management: An empirical examination". Strategic Management Journal, vol. 19, pp. 211-219.

Mayo, A. y Lank, E. (1994): The power of learning. A guide to gaining competitive advantage. IPD House, Londres. 
McEvily, S. y Chakravarthy, B. (2002): "The persistence of knowledge-based advantage: An empirical test for product performance and technological knowledge". Strategic Management Journal, vol. 23, pp. 285-305.

McGill, M. y Slocum, J.W. (1994): The smarter organization. How to build a business that learns and adapts to marketplace needs. John Wiley \& Sons, New York.

McGraw, K. y Harbison-Briggs, K. (1989): Knowledge Acquisition: Principles and Guidelines. Englewood-Cliffs: Prentice Hall.

Miles, G.; Miles, R.E.; Perrone, V. y Edvinsson, L. (1998). "Some Conceptual and Research Barriers to the Utilization of Knowledge". California Management Review, vol. 40, no 3, pp. 281288.

Miller, D. (2002): "Knowledge Inventories and Managerial Myopia". Strategic Management Journal, vol. 13, pp. 689-706.

y Shamsie, J. (1996): "The resource-based view of the firm in two environments: The Hollywood film studios from 1936 to 1965". Academy of Management Journal, vol.39, no 3, pp. 519-543.

Miner, A. y Mezias, S. (1996): "Ugly duckling no more: Pasts and futures of organizational learning research". Organization Science, vol. 7, n 1, pp. 88-89.

Moilanen, R. (2001): "Diagnostic tools for learning organisations". The Learning Organization, vol. 8, no 1 , pp. 6-20.

Montgomery, C.A. (ed., 1995): Resource-based and evolutionary theories of the firm: toward a synthesis. Kluwer Academic Publishers, Boston.

Mosakowski, E. (1997): "Strategy making under causal ambiguity: Conceptual issues and empirical evidence". Organization Science, vol. 8, no 4, pp. 414-442.

Mosakowski, E. y McKelvey, B. (1997): "Predicting rent generation in competence-based competition". En Heene, A. y Sánchez, R. (eds., 1997), pp. 65-85.

Moss, E. (1995): The grammar of consciousness. St. Martin's Press, Houndmills, UK.

Mueller, R.O. (1996): Basic principles of structural equation modeling. An introduction to LISREL and EQS. Springer Texts in Statistics, New York.

Nelson, R.R. (1991): "Why do firms differ and how does it matter?". Strategic Management Journal, vol. 12, pp. 61-74.

Nelson, R.R. (1995): "Recent evolutionary theorizing about economic change". Journal of Economic Literature, vol. 33, pp. 48-90.

Nelson, R.R. y Winter, S.G. (1982): An Evolutionary Theory of Economic Change. Harvard University Press, Cambridge.

Nonaka, I. (1991): "The knowledge-creating company". Harvard Business Review, vol. 69, no 6, Noviembre-Diciembre, pp. 96-104. 
Nonaka, I. (1994): "A dynamic theory of organizational knowledge creation". Organization Science, vol. 5, pp. 14-37.

Nonaka, I. y Takeuchi, H. (1995): The knowledge-Creating Company: How Japanese Companies Create the Dynamics of Innovation. Oxford University Press, New York.

Nonaka, I. y Konno, N. (1998): "The concept of 'Ba': building a foundation for knowledge creation". California Manegement Review, vol. 40, no 3, pp. 40-54.

Norusis, M.J. (1994): SPSS Professional Statistics ${ }^{\mathrm{TM}}$ 6.1. SPSS Inc. Chicago, IL.

Nunnally, J.C. (1978): Psycometric Theory. McGraw-Hill, New York.

Nybo, G. (2004): "Personnel Development for Dissolving Jobs: Towards a Competency-based Approach", International Journal of Human Resource Management, may 2004, vol. 15, issue 3.

O'Dell, C. (1996): A Current Review of Knowledge Management Best Practice. Conference on Knowledge Management and the Transfer of Best Practices. Business Intelligence, Londres, Diciembre.

O'Dell, C. y Grayson, C.J. (1998). "If Only We Knew What We Know: Identification and trasfer of Internal Best Practices". California Management Review, vol. 40, no 3, pp.154- 173.

Ouchi, W.G. (1980): "Markets, bureaucracies and clans". Administrative Science Quarterly, vol. 25, pp. 129-141.

Palacios, D. (2003) "La Gestión del conocimiento y la medición del capital intangible: un modelo para el sector de las telecomunicaciones y de la biotecnología." Tesis Doctoral. Universidad Jaume I de Castellón.

Pedler, M.; Burgoyne, J. y Boydell, T. (1997): The learning company, a strategy for sustainable development. Ed. McGraw-Hill, Londres.

Pearn, M.; Roderick, C. y Mulrooney, C. (1995): Learning organizations in practice. Ed. McGraw-Hill, Maidenhead.

Penrose, E.T. (1959): The theory of the growth of the firm. Basil Blackwell, Oxford. Las citas corresponden a la edición española: Teoría del crecimiento de la empresa. Aguilar, Madrid, 1962.

Perez Lopez, J.A., (1991): "Fundamentos de la Dirección de Empresas", Editorial Rialp, Madrid, 1991.

Peter, J.P. y Churchill, G.A. (1986): "Relationship among research design choices and psychometric properties of rating scales: A Meta-analysis". Journal of Marketing Research, vol. 23, pp. 1-10.

Peteraf, M.A. (1993): "The Cornerstone of Competitive Advantage: A Resource-Based View". Strategic Management Journal, vol. 14, pp. 179-191.

Peters, T.J. y Waterman, R.H. (1982): In search of excellence: Lessons from America's bestrun companies. Harper \& Row Publishers, Nueva York. 
Petrash, G. (1996): Managing Knowledge Assets for Value. Knowledge-Based Leadership Conference. Linkage, Inc. Boston. Octubre.

Pfeffer, J. (1998):" The Human Equation", Harvard Business Press, Boston, 1998.

Pisano, G. P. (1996): "Learning-before-doing in the development of new process technology". Research Policy, vol. 25, no 7, pp. 1097-1119.

Plaza, C. (2002): Informe anual de las Telecomunicaciones y Tecnologías de la Información 2001. Ediciones Zeta.

Polanyi, M. (1948): Personal Knowledge. The University of Chicago Press, Chicago.

Porter, M.E. (1985): Competitive advantage: creating and sustaining superior performance. The Free Press, Nueva York.

Porter, M.E. (1991): "Towards a Dynamic Theory of Strategy". Strategic Management Journal, vol. 12 (Special Issue), pp. 95-117.

Prahalad, C.K. y Hamel, G. (1990): "The core competence of the corporation". Harvard Business Review, vol. 90, no 3, pp.79-91.

Prahalad, C.K. y Hamel, G. (1994): "Strategy as a field of study: Why search for a new paradigm?". Strategic Management Journal, vol. 15, pp. 5-16.

Provost, L. y Leddick, S. (1993): "Kow to take multiple measures to get a complete picture of organizational performance". National Productivity Review, Fall, pp. 477-490.

Puig, P. (dir., 1996): La competitivitat de l'empresa industrial a Catalunya. Anàlisi de l'entorn econòmic i de les estratègies competitives en un context de modernització del sector públic. ESADE, Barcelona.

Quinn, J.B.; Anderson, P. y Finkelstein, S. (1996): "Making professional intellect: Making the most of the best". Harvard Business Review, Marzo-Abril, pp. 71-80.

Ranft, A. y Lord, M. (2002): "Acquiring New Technologies and Capabilities: A Grounded Model of Acquisition Implementation". Organization Science, vol. 13, no 4, pp. 420-441.

Rastogi, P.N. (2000): "Knowledge management and intellectual capital - the new virtuous reality of competitiveness". Human Systems Management, vol. 19, pp.19-26.

Redding, J.C. y Catalanello, R.F. (1994): Strategic readiness. The Making of the learning organization. Jossey-Bass, San Francisco, CA.

Reed, R. y Defillippi, R.J. (1990): "Causal ambigüity, barriers to imitation, and sustainable competitive advantage". Academy of Management Review, vol. 15, no 1, pp. 88-102.

Revilla, E. (1996): Factores determinantes del aprendizaje organizativo. Un modelo de desarrollo de productos. Club de Gestión de Calidad, Madrid. 
Roos, J.; Roos, G.; Edvinsson, L. y Dragonetti, N. (1997): Intellectual capital: Navigating in the new business landscape. New York: University Press.

Ruggles, R. (1997): Tools for Knowledge Management: An Introduction. Ruggles, R., ed. Knowledge Management Tools. Butterworth-Heinemann.

Rumelt, R.P. (1984): "Toward a strategic theory of the firm". En Lamb, R. (ed., 1984): Competitive strategic management. Prentice-Hall, Englewood Cliffs, pp. 556-570.

Rumelt, R.P. (1991): "How much does industry matter?". Strategic Management Journal, vol. 12, no 3, pp. 167-185.

Rumelt, R.P. (1994): "Foreword". En Hamel, G. y Heene, A. (Ed.): Competence-Based Competition, The Strategic Management Series. John Wiley \& Sons, England.

Rumelt, R.P.; Schendel, D. y Teece, D. (1991): "Strategic management and economics". Strategic Management Journal, vol. 12, pp. 5-29.

Salas, V. (1996): "Economía y gestión de los activos intangibles". Economía Industrial, no 307, pp. 17-24.

Sánchez, R.; Heene, A. y Thomas, H. (1996): "Introduction: Towards the theory and practice of competence-based competition". En Sánchez, R.; Heene, A.; Thomas, H. (eds., 1996), pp. 1-35.

Sánchez, R.; Heene, A. y Thomas, H. (eds., 1996): Dynamics of Competence-Based Competition: Theory and Practice in the New Strategic Management. Elsevier Science Publishers, Oxford.

Sánchez, R. y Heene, A. (1997): "Competence-based strategic management: concepts and issues for theory, research, and practice". En Heene, A. y Sánchez, R. (eds., 1997), pp. 3-42.

Santos, M.V.; García, M.T. y Pérez, M.P. (1998): "Adaptación e imitación en la estrategia empresarial. El caso de la estrategia de mercado de las cajas de ahorro españolas". Cuadernos de Economía y Dirección de la Empresa, vol. 2, pp. 203-230.

Satorra, A. y Bentler, P.M. (1994): "Corrections to test statistics and standard errors in covariance structure analysis. En Von Eye, A. y Clogg, C.C. (Eds.): Latent variables analysis. Applications for Development Research. Sage publications, Thousand Oaks, California, pp. 399419.

Schoemaker, P. y Amit, R.H. (1994): "Investment in Strategic Assets: Industry and FirmLevel Perspectives". En Shirivastava, P.; Huff, A.; Dutton, J. (eds., 1994), pp. 3-33.

Schumpeter, J.A. (1934): The theory of economic development. Harvard University Press, Boston.

Schüppel, J.; Müller-Stewens, G. y Gómez, P. (1998): "The knowledge spiral". En Von Krogh, G.; Roos, J.; Kleine, D. (eds.): Knowing firms. Understanding, managing and measuring knowledge, pp. 223-239. Londres: Sage publications. 
Selznick, P. (1949): TVA and the grass roots. University of California Press, Berkeley, CA.

Selznick, P. (1957): Leadership in Administration: A Social Interpretation. Harper \& Row, Nueva York.

Senge, P.M. (1990): The fifth Discipline: The Age and Practice of the Learning Organization. London: Century Business.

Shan, W.; Walker, G. y Kogut, B. (1994): "Interfirm cooperation and start-up innovation in the biotecnhnology industry". Strategic Management Journal, vol. 15, no 5, pp. 387-394.

Sharma, S. (1996): Applied Multivariate Techniques. John Wiley \& Sons, New York.

Shrivastava, P. (1983): "A typology of organizational learning systems". Journal of Management Studies, vol. 20, pp. 7-28.

Sicard, C. (1987): Practique de la stratégie d'entreprise. Hommes et Techniques, París.

Simon, H.A. (1991): "Bounded rationality and Organizational Learning". Organization Science, vol. 2, no 1, pp. 125-134.

Smelser, N. (1963): Theory of collective behaviour, New York: The free press.

Smith, K.G.; Guthrie, J.P. y Chen, M.J. (1989): "Strategy, size and performance". Organization Studies, vol. 10, no 1, pp. 63-81.

Snow, C.C. y Hrebiniak, L.G. (1980): "Strategy, distinctive competence and performance". Administrative Science Quarterly, vol. 25, pp. 317-336.

Sonnenberg, F. (1994): "La era de los intangibles". Harvard-Deusto Business Review, no 59, pp. 30-35.

Spanos, Yiannis E.; Lioukas, Spyros. (2001) An examination into the causal logic of rent generation: contrasting Porter's competitive strategy framework and the resource-based perspective, Strategic Management Journal 22, 907-934

Spender, J.C. (1994): "Organizational Knowledge, Collective practice and Penrose rents". International Business Review, vol. 3, no 4, pp. 353-367.

Spender, J.C. (1996): "Competitive advantage from tacit knowledge? Unpacking the concept and its strategic implications". En Moingeon, B., Edmondson A. (eds.), Organizational Learning and Competitive Advantage. Sage Publications, Thousand Oaks, CA, pp. 56-73.

Spender, J.C. y Grant, R.M. (1996): "Knowledge and the firm: Overview". Strategic Management Journal, vol. 17, Winter Special Issue, pp. 5-9.

Stalk, G.; Evans, P. y Shulman, L.E. (1992): "Competing on capabilities: The rules of corporate strategy". Harvard Business Review, vol. 70, no 2, pp. 57-69.

Stewart, T. (1997): Intellectual Capital: The new wealth of organizations. New York: Doubleday.

Sullivan, P. (1998): Profiting from Intellectual Capital. Extracting Value from Innovation. Wiley Intellectual Property Series.

Symons, C. (1991): Software sizing and estimating. Mk II FPA, John Wiley and Sons, England. 
Szulanski, G. (1996): "Exploring internal stickiness: Impediments to the transfer of best practice within the firm". Strategic Management Journal, Winter Special Issue, vol. 17, pp. 2744.

Tannenbaum, S. (1997): "Enhancing continuous learning: diagnostic findings from multiple companies". Human Resource Management, vol. 36, no 4, pp. 437-452.

Taylor, W.A. (1996): "Sectoral differences in Total Quality Management implementation: The influence of management mind-set". Total Quality Management, vol. 7, nº 3, pp. 235-248.

Teece, D.J. (1986): "Profiting from technological innovation: Implications for integration, collaboration, licensing and public policy". Research Policy, vol. 15, pp. 285-305.

Teece, D.J. (1990): "Contributions and impediments of economic analysis to the study of strategic management". En Fredrickson (ed., 1990), pp. 38-50.

Teece, D.J. (1998): "Capturing Value from Knowledge Assets: The New Economy, Markets for Know How, and Intangible Assets". California Management Review, vol. 40, no 3, pp. 55-79.

Teece, D.J. y Pisano, G. (1998): "The Dynamic capabilities of the firm: An introduction". En Dosi, G., Teece, D. y Chytry, J. (Ed.): Technology, Organization and Competitiveness. Perspectives on Industrial and Corporate change. Oxford University Press, Oxford, pp. 193-212.

Teece, D.J.; Pisano, G. y Shuen, A. (1990): Firm capabilities, resources and the concept of strategy. University of California, Working Paper.

Teece, D.J.; Pisano, G. y Shuen, A. (1997): "Dynamic capabilities and strategic management". Strategic Management Journal, vol. 18, no 7, pp. 509-533.

Teece, D.J.; Rumelt, R.; Dosi, G. y Winter, S. (1994): "Understanding corporate coherence. Theory and evidence". Journal of Economic Behaviour and Organization, vol. 23, pp. 1-30.

Tejedor, B. y Aguirre, A. (1998): "Proyecto Logos: Investigación relativa a la capacidad de aprender de las empresas españolas". Boletín de Estudios Económicos, vol. 53, n¹64, pp. 231249.

Thornton, C. y Byham, C., (1986): "Assessment Center and Management Performance", Academia Press, New Cork, 1986.

Tirole, J. (1990): La Teoría de la Organización Industrial. Ed. Ariel, Barcelona.

Tissen, R.; Andriessen, D. y Deprez, F.L. (1998): Value-based knowledge managemen. Addison - Wesley, Longman.

Tobin, J. (1969): "A General Equilibrium Approach to Monetary Theory". Journal of Money Credit and Banking, no 1.

Toffler, A. (1990). Powershift: Knowledge, Wealth and Violence at the Edge of the 21st Century. New York: Bantam Books.

Trussler, S. (1998): "The rules of game". Journal of Business Strategy, vol. 19, n 1, pp. 1619. 
Turner, D. y Crawford, M. (1994): "Managing Current and Future Competitive performance: the Role of Competence". En Hamel y Heene (eds., 1994), pp. 241-264.

Van den Bosch, F.A.; Volberka, H.W. y Boer, M. (1999): "Coevaluation of firm absorvative capacity and knowledge environment: Organizational forms and combinative capabilities". Organization Science, vol. 10, no 5, pp. 551-568.

Venkatraman, N. (1989): "Strategic orientation of business enterprises: the construct, dimensionality and measurement". Management Science, vol. 35, pp. 942-962.

Venkatraman, N. y Ramanujam, V. (1986): "Measurement of business economic performance in strategic research: A comparison of approaches". Academy of Management Review, vol. 11, no 4, pp. 801-814.

Ventura, J. (1996): Análisis dinámico de la estrategia empresarial: un ensayo interdisciplinar. Universidad de Oviedo, Servicio de Publicaciones.

Von Hippel, E. (1988): The sources of innovation. MIT Press, Cambridge.

Von Hippel, E. (1994): " 'Sticky information' and the locus of problem solving: Implications for innovation", Management Science, vol. 40, no 4, pp. 429-439.

Von Krogh, G.; Roos, J. y Slocum, K. (1994): "An essay on corporate epistemology". Strategic Management Journal, vol. 15, pp. 53-71.

Vytgotsky, L.S. (1962): Thought and language. Mass: MIT Press.

Weick, K.E. y Roberts, K.H. (1993): "Collective mind in organizations: heeding interrelating on flight decks". Administrative Science Quarterly, vol. 38, pp. 330-358.

Weick, K.E. y Westley, F. (1996): "Organizational learning: affirming an oxymoron", en Clegg, S.R.; Hardy, C.; Nord, W.R. (ed.): Handbook of organizational studies, pp. 440-458, London: Sage.

Wernerfelt, B. (1984): "A resource-based view of the firm". Strategic Management Journal, vol. 5, n० 2, pp. 171-180.

Wernerfelt, B. (1995): "The resource-based view of the firm: ten years later". Strategic Management Journal, vol. 16, no 3, pp. 171-174.

Whitehill, M. (1997): "Knowledge-based strategy to deliver sustained competitive advantage". Long Range Planning, vol. 30, no 4, pp. 621-627.

Wiig, K. M. (1999): "Introducing Knowledge Management into the enterprise". En Liebowitz, J. Knowledge Management Handbook, pp. 1-41.

Williamson, O.E. (1999): "Strategy research: governance and competence perspectives". Strategic Management Journal, vol. 20, no 12, pp. 1087-1108.

Winter, S.G. (1987): "Knowledge and competence as strategic assets". En Teece, D.J. The competitive challenge-strategies for industry, pp. 159-184.

Winter, S.G. (1995): "Four R's of profitability: rents, resources, routines and replication". En Montgomery, C.A. (ed., 1995), pp. 147-178. 
Winterscheid, B.C. (1994): "Building capability from within: the insider's view of core competence". En Hamel, G. y Heene, A. (eds., 1994), pp. 265-292.

Woodrufe, C., (1993): "Assessment Centers: identifying and developing competentes", Institute Personnel Management, Londres, 1993.

Yang, B.; Watkins, K.E. y Marsick, V.J. (1998): Examining construct validity of the dimensions of the learning organization. En R. Torraco (Ed.), Proceedings of the 1997 Annual Academy of Human Resource Development Conference, pp. 543-546, Atlanta, G.A.

Yeung, A.K.; Ultrich D.O.; Nason, S.W. y Von Glinow, M.A. (1999): Las capacidades de aprendizaje en la organización. Editorial Oxford, México.

Zack, M. H. (1994): "Shared Context and Communication Effectiveness in a ComputerSupported Work Group". Information Systems Resarch, vol. 26, no 4, pp. 231-241.

Zander, U. y Kogut, B. (1995): "Knowledge and the speed of the transfer and imitation of organizational capabilities: an empirical test". Organization Science, vol. 6, no 1, pp. 76-92.

Zollo, M. y Winter, S. (2002): "Deliberate Learning and the Evolution of Dynamic Capabilities". Organization Science, vol. 13, no 3, pp. 339-351. 